\title{
The Science of Stories
}

\author{
Human History and the \\ Narrative Philosophy of Science
}

by

Robert Alexander Hurley
A thesis presented to the Victoria University of Wellington in fulfilment of the requirements for the degree of Doctor of Philosophy

Victoria University of Wellington 



\begin{abstract}
There is a pronounced tendency within contemporary philosophy of history to think of historical knowledge as something apart from the kind of knowledge generated in the sciences. This has given rise to a myriad of epistemological issues. For if historical knowledge is not related to the scientific, then what is it? By what logic does it proceed? How are historical conclusions justified? Although almost the entirety of contemporary philosophy of history has been dedicated to such questions, there has been little real and agreed upon progress. Rather than fire yet another salvo in this rhetorical war, however, this thesis wishes instead to examine what lies beneath the basic presumption of separatism which animates it. Part One examines several paradigmatic examples of twentieth century philosophy of history in order to identify the grounds by which their authors considered history fundamentally different in kind from the sciences. It is concluded that, in each case, the case for separatism flows from the pervasive assumption that any body of knowledge which might rightly be called a science can be recognised by its search for general laws of nature. As history does not seem to share this aim, it is therefore considered to be knowledge of a fundamentally different kind. This thesis terms this the "nomothetic assumption." Part Two argues that such nomothetic assumptions are not an accurate representation of either scientific theory or practice and therefore that any assumption of separatism based upon them is unsound. To do this, examples of acknowledged scientific problems from the biological and geological sciences which do not involve the use of general laws are examined, with the aim of discovering how these historical disciplines are able to do the work of explanation in their absence. They do so, it is concluded, through a mechanism of epistemic (as opposed to literary) narrative. Having thus identified how historical sciences proceed without making direct use of laws, Part Two then generalises this model of scientific narrative and shows how it can be used to model existing practices in human history. This conclusion has far-reaching consequences, for it brings a single definition, method, and logic of confirmation to all studies of the past - whether traditionally acknowledged as scientific or historical. Thus all historical enquiries proceed by a common logic and by a common method. This effectively and definitively places human history among the sciences, without the need for the kind of radical transformation past attempts to do this have required. (409 words)
\end{abstract}




\section{Acknowledgements}

First and foremost, I am most grateful for the assistance of my supervisor Professor Miles Fairburn, whose unwavering assistance and positivity over these long years is greatly appreciated. To say nothing of the fact that some of the most challenging intellectual exchanges of my life so far have begun with Professor Fairburn placing a pen and blank piece of paper in front of me and asking, "could you please explain to me how..." I would also like to thank my second supervisor, Doctor Alexander Maxwell. The fear of Alexander's Disapproving Grammar Finger sometimes kept me awake late into the night. I dreaded the seas of red ink my drafts would invariably come back covered in. "He's not mad," I would tell myself, "only disappointed." Not being a natural writer by any stretch of the imagination, this thesis almost certainly contains much prose that is somewhat less than optimal. Without the input of Doctor Maxwell, however, it would have been so much worse. I am also grateful for the assistance of Doctor Benjamin Jeffares, who assisted me throughout his post-doctoral tenure at Victoria University. When I first met Doctor Jeffares, I knew what I wanted historical explanation to be, but was unsure of how I might get there. It was Ben who pointed me towards the work of David Hull, and thus was responsible for the almost audible click that could be heard as the jumble of ideas and plans in my head snapped into place. Ben also deserves praise for allowing me to borrow half of his personal library, and for waiting so patiently for it to be returned. His input is especially valuable in that it was entirely in an unofficial capacity, and was given freely without hope of reward. I would also like to thank Professor Donald MacRaild who, during his brief time at Victoria University, picked me up off the fainting couch after an exhausting Honours year, and patiently (and repeatedly) set about convincing me I might maybe have something worthwhile to say about history and theory at the graduate level. Thanks are also due to Professor Melanie Nolan, who absolutely always took the time to aggressively fight my corner whenever she was asked. Melanie was my staunchest ally back in 2008 when I was upgrading from an MA to a $\mathrm{PhD}$, and did more than anyone to make that transition happen. Professor Nolan was also kind enough to give me Research Assistant work at a time when I was having serious trouble keeping the lights on. Thank you, Melanie!

On a more personal note, I would also like to acknowledge those others without whom this would have been impossible. Most importantly, Anna Young, who was always exactly what the situation demanded. Supportive when I was despondent, argumentative when I was in need of a foil, and always far more intelligent than I'll ever be. Also, my mother, Gail Hurley, whose unrelenting belief in the ability of her son was quite simply an irresistible and almost tangibly solid force. Whenever I put the phone down from calling home, I felt not merely heartened, but invincible. I would also like to thank my friends and fellow graduate students Rebecca Lenihan and Megan Simpson. You both proved it could be done. Your tales of a life after graduate school were tantalising hints of a whole other world, and welcome reminders that I wouldn't be working on this thing forever. Additional thanks to Megan for buying me dinner all those times. I would also like to thank the medical professionals who kept me on my feet and functioning during my time at Victoria. Given my persistent ill health, this was often not a trivial matter. Thank you to Doctor Kathryn Leslie, Marion Kirker, and Doctor Susie Poon. Particular thanks to Doctor Leslie. Before I met you, I really had almost given up. I would also like to thank my dear friend Martinetta Woodfield-Fijn. Not for anything in particular (although you did buy me that Piaget book when I was flat broke, thank you!) but for being a source of great support, and for turning up on those random Wednesday afternoons to force me to take a break and drive somewhere new and interesting. Thanks also to Simon Gigg, for bravely and selflessly volunteering to endlessly play video games on my desktop computer, thus preventing me from doing the same and forcing me to get on with my work. How did you ever find the courage? And lastly, my cat Dax - whose pathological need for human company combined with an actively violent resistance to being removed from my lap kept me at my computer and working when I would rather have been doing something - anything - else.

In memory of my beloved cat Marjorie, who passed away on the $31^{\text {st }}$ of August 2006, shortly after I began work on this thesis. 


\section{Table of Contents}

Abstract

Acknowledgements

Introduction - “Loomings"

Part One - The Nomothetic Assumption $\quad 10$

$\begin{array}{ll}\text { The Structure of Part One } & 17\end{array}$

$\begin{array}{ll}\text { Part Two - Taking Narrative Seriously } & 20\end{array}$

The Structure of Part Two 33

\section{Part One - "Ask Any Scientician" \\ The Nomothetic Assumption in Twentieth \\ Century Philosophy of History}

Chapter One - "Introducing the Nomothetic Assumption"

The Nomothetic Assumption in Action, or: The Misunderstanding of J. B. Bury 42

Idealism and Historical Autonomy

The Influence of Benedetto Croce

$\begin{array}{ll}\text { Charles A. Beard } & 60\end{array}$

Carl L. Becker $\quad 64$

The Covering Law Thesis, or: Laws of History versus Laws in History 67

Problems with the Covering Law Thesis $\quad 76$

The Impact of the Nomothetic Assumption, or: Universality is the Problem 81

Chapter Two - "The Death of Empathy" 84

The Importance of Empathy for the Covering Law Program 85

Patrick Gardiner and the Assault on Idealism 86

Making History Look Nomothetic 96

W. H. Walsh and the Idea of Colligation 103

$\begin{array}{ll}\text { Colligation and the Beginnings of Narrative } & 108\end{array}$

Walsh and the Nomothetic Assumption 111

$\begin{array}{ll}\text { Colligation versus Classification } & 114\end{array}$

Chapter Three - "The Rise of Narrative" 121

William Dray's Model of Historical Explanation $\quad 123$

Dray and the Nomothetic Assumption $\quad 129$

W. B. Gallie and the Literary Interpretation of Narrative 135

The Role of Explanation in Gallie's Model of Narrative $\quad 142$

Gallie and Narrative Determinism 145

$\begin{array}{ll}\text { Arthur Danto and the Logic of Narration } & 148\end{array}$

'Significance' as the Basis for Danto's Narrative $\quad 151$

Danto and the Explanatory Power of Narrative 154

Danto's Narratives Considered as Theories and their Relationship to the Scientific 157

Thomas Kuhn's Revision of the Nature of Science 161

Louis Mink, Hayden White, and the Flight from Epistemology 166

\section{Part Two - "Taking Narrative Seriously" Epistemic Narrative and the Philosophy of Science}

Chapter Four - "The Nomothetic Model and the Historical Sciences" 179

Some Brief Remarks on Contemporary Epistemic Philosophy of History 180

The Failure of the Nomothetic Model to Adequately Capture Scientific Practice 187

The Nomothetic Model and the Early Earth Sciences 189

The Nomothetic Model and the Earth Sciences in the Nineteenth Century 193

The Nomothetic Model and the Biological Sciences in the Nineteenth Century 198

Contemporary Nomothetic Objections to Darwinian Biology 203 
Chapter Five - “The Science of Stories” 213

An Account of Narrative Explanation in Evolutionary Biology 215

Narrative as a 'Special Case' of the Nomothetic Model $\quad 219$

Problems with the Confirmation of Narrative 226

$\begin{array}{ll}\text { Confirmation by Consequences } & 232\end{array}$

$\begin{array}{ll}\text { Narratives as Scientific Theories } & 237\end{array}$

Chapter Six - "The Philosophy of the Science of Stories" 246

Peter Kosso and the Problem of Observation Poverty 247

The Nature of Kosso's Accounting Claims $\quad 258$

David Hull and Nomothetic Compatibilism 260

Hull's Concept of the Central Subject 263

Central Subjects as Necessarily Historical Entities $\quad 266$

What is Narration? $\quad 272$

The Problem of Process versus Particular in Human History 278

Carol Cleland, the Asymmetry of Causation, and Confirmation by Consequences $\quad 284$

Conclusion - "The Future of Human History as a Science" 297

$\begin{array}{ll}\text { The Requirement for Transformation } & 299\end{array}$

Evolution and Human History 304

$\begin{array}{lr}\text { Final Words } & 310\end{array}$

$\begin{array}{ll}\text { Bibliography } & 313\end{array}$ 


\section{Introduction \\ "Loomings"}

This is, speaking in the broadest sense, a thesis dedicated to a re-examination of one of the oldest questions in the philosophy of history - is history a science? The reader might be forgiven for rolling their eyes at this. The question of whether history is or is not a science is, after all, also one of the most thoroughly discussed questions in the philosophy of history. And yet despite - or perhaps because of - this long history of discussion, it seems a common conclusion among contemporary historians and philosophers of history that this question has long been settled in the negative and that there is very little that is new that might be said about it. Indeed, to talk of a scientific history now in the age of the linguistic turn and the postmodern seems almost gauche. There are still those, of course, who claim that history should reorient itself along scientific lines. But the insistence of such authors on the changes that would need to be made to historical practice in order for this to be achieved implies a tacit acceptance of the premise that, as it presently stands, history is not conducted or conceptualised in a way consistent with the sciences. As the ecologist, mathematician, and aspiring philosopher of history Peter Turchin has succinctly phrased it:

We must collect quantitative data, construct general explanations and test them empirically on all the data, rather than on instances carefully selected to prove our pet narratives. To truly learn from history, we must transform it into a science. ${ }^{1}$

Case closed, it would seem. Whatever history is, it seems generally agreed - even self evident - that it isn't science. It is the intention of this thesis, however, to argue that there remains a great deal which might yet be said on the subject, and that this most basic of questions remains far from settled. To this end, this thesis will not only offer a defence of the now somewhat unpopular view that history can be a science, but will further argue that it essentially already is. More specifically, it will be argued that the basic form underlying historical explanations as they are currently accepted and understood is entirely compatible with our most nuanced current understandings of science, and that no separate epistemology (or methodological concession to existing epistemology) is required in order to claim this. No deep structural revisions of current historical practice are necessary.

Certainly these are, or least appear to be, bold claims. To establish claims of such

1 Peter Turchin, 'Arise “Cliodynamics",' Nature. Vol. 454 (3 July 2008). p.35. 
magnitude, which potentially call into question much of what counts as received wisdom and argument in the contemporary philosophy of history, it will come as no surprise to learn that a deep dive into the foundations of that philosophy must be undertaken. For the accusation that so many philosophers and historians have been so mistaken about a question of such magnitude (or have been correct, but for the wrong reasons) suggests that whatever it is that has made such an error possible, it cannot be trivial, nor can it be limited in scope. Therefore, the first of the two major claims made by this thesis will be that just such a systemic error can be reliably identified throughout twentieth century philosophy of history, and that this error takes the form of a persistent assumption regarding the nature of science that has informed almost every aspect of the philosophy of history to the present day. We will call this the "nomothetic assumption." 2 This term will function here as shorthand for the identification of the entire theory and practice of science with the production and deployment of timeless and universal "laws of nature." That is, a nomothetic assumption is effectively a consideration of physics as the exemplar of all science and therefore results in the attempt to apply the practices of that field to all other branches of science. Or, for those outside of the sciences, it is the tendency to argue that if a discipline does not clearly produce or utilise general laws, then that discipline cannot be considered scientific. In the first part of this thesis, we will not only identify a persistent nomothetic assumption throughout twentieth century philosophy of history, we shall also argue that the presence of this assumption whether explicitly or tacitly held - has had a profound impact on the development of

2 As this term will appear frequently throughout this thesis, let us be clear about its meaning from the very outset. "Nomothetic" is a Greek term that has become a commonly used technical term in philosophy. The term was originally introduced into philosophy in the late nineteenth century by the German neo-Kantian philosopher Wilhelm Windelband. Windelband, building on Kant, used the terms "nomothetic" and "idiographic" to describe what he saw as two very different approaches to explanation - the former peculiar to the sciences, the latter to the humanities. "Nomothetic" - literally Greek for "proposition of the law" - was taken by Windelband to describe the efforts of natural science to generalise the objective phenomena of the world into universal laws. This is contrasted with the term "idiographic," which Windelband defines as the tendency as exhibited by the humanities - to deal with particularities, contingencies, and accidents. (See: Wilhelm Windelband, 'Rectorial Address, Strasbourg 1894,' History and Theory. Vol. 19, No. 2 (February 1980). pp.169-185.). Essentially then, this is a more technical way of saying that science aspires to the general, and the humanities to the particular. The term "nomothetic" is to be preferred to merely "generalising" however, as the etymology of the former makes clear that the ideal of generalisation is the universal law. By using this term wherever we wish to imply an ideal of general laws, we are freed to use the terms "general" and "particular" in a more relativistic sense. That is, the aim of a generalising (as opposed to nomothetic) discipline need not be a law in the strictest sense - but merely a conclusion at a higher level of enquiry than the instances used to derive it. As Mark Day has phrased it: "'Parisian merchant' is a more general property than 'Parisian grain trader,' and 'French merchant' is a more general property than both." (See: Mark Day, The Philosophy of History. Continuum: London \& New York, 2008. p.55.) We might therefore, in a sense, generalise about French merchants, without claiming to have uncovered some truly general law. We may not, however, assume the same for a nomothetic discipline - a nomothetic discipline aims for nothing less than laws. 
the philosophy of history. For it is this nomothetic assumption which lies at the root of the widespread perception among historians and philosophers of history that historical knowledge and scientific knowledge are fundamentally different in kind. This is because a thoroughgoing nomothetic assumption regarding science has led to the concomitant assumption that any other kind of explanatory model that history might be shown to use is, by definition, not scientific. And this assumption, it will be argued, is quite fundamental. That is, while there have been many seemingly disparate classes of argument which have attempted to establish the autonomy and epistemic uniqueness of history, we shall see that all such arguments either rest upon some form of the nomothetic assumption or are otherwise unable to achieve their purpose of distinguishing between history (as traditionally understood) and the sciences. $^{3}$

Having identified this persistent nomothetic assumption in the philosophy of history, this thesis will then proceed to argue that it is a deeply flawed and myopic vision of science, and that by merely acknowledging this fact we can clear away many objections to considering the basic kind of explanations that history can and does offer scientific in principle. That this can be done without requiring any truly radical revision of current historical practice is possible because the alternative explanatory form that much contemporary philosophy of history has converged upon in order to describe its own operation - the concept of narrative - is a concept that can and must be grounded in science. This claim that there is such a thing as a scientifically legitimate "technical sense" of the term narrative, and that history's existing methods and explanatory strategies broadly conform to such a sense, represents the second major claim of this thesis. This is a key departure from much contemporary philosophy of history, which has argued that history either attempts to explain through the construction of narratives - which are seen as a uniquely literary rather than epistemic mechanism ${ }^{4}$ - or that history must be grounded in some other

3 To be clear, this thesis is primarily concerned with the class of arguments which have used the nomothetic assumption to argue for history's autonomy from the sciences. Certainly, other arguments by which philosophers have attempted to establish this conclusion - such as those arguments which claim that "the past is gone" and thus beyond the reach of any empirical enquiry, or those which claim that there is simply too much interpretive bias in history - will make an appearance in these pages. But it should be remembered that they are not the primary focus of this work. Therefore, in dealing with them, we will content ourselves with showing that, if they are problematic, they are problematic for both history and the sciences in equal measure.

4 Examples of this literary-narrativist position which are to be examined by this thesis include: $\mathrm{W}$. B. Gallie, Philosophy and the Historical Understanding. $2^{\text {nd }}$ Edition. Schocken Books: New York, 1968. Louis O. Mink, 'The Autonomy of Historical Understanding,' History and Theory. Vol. 5, No. 1 (1966). pp.24-47. Louis O. Mink, 'History and Fiction as Modes of Comprehension,' New Literary History. Vol. 1, No. 3 (Spring 1970). pp.541-558. Hayden White, Metahistory: The Historical 
(presumably more scientifically respectable) explanatory mechanism. ${ }^{5}$ In neither case is the concept of narration taken seriously as an epistemic mechanism. In this respect, by dissolving the nomothetic assumption which has held all narrativism - regardless of its epistemic merits - as separate from science, this thesis attempts to offer a genuine way out of the apparent dilemma which has forced generations of philosophers of history into choosing between science and the status quo. Reflecting these twin requirements, this thesis will be broken into two parts.

\section{Part One - The Nomothetic Assumption}

The first half of this thesis will demonstrate the presence of an underlying nomothetic assumption throughout much of the most influential work in the twentieth century philosophy of history. This assumption, it will be argued, has led philosophers of history to one of two broad conclusions. Either history must be utterly remade in order to conform to this nomothetic-deductive practice in order to produce knowledge worth the name, or history must not have any more than a tangential connection to science. However, the most important argument to be made in Part One regarding the nomothetic assumption is not merely that such assumptions have existed, but that they were/are effectively bipartisan. That is, a nomothetic assumption was not merely an article of faith held by only one side of a broader debate. Were that the case, the assumption itself would rise or fall with the success of that faction, and thus be of little more than marginal interest. Instead, it is the intention of this thesis to argue that a nomothetic assumption regarding science is better understood as having been a basic part of the axiomatic fabric from which all twentieth and early twenty-first century philosophers of history have reasoned. That is, it has guided the reasoning of all participants in the debate over the status of historical knowledge, although not always in the same way. Thus while we can clearly and unambiguously see the nomothetic assumption as underlying the wellknown arguments of the covering law theorists of the mid-twentieth century (as well

\footnotetext{
Imagination in Nineteenth-Century Europe. Johns Hopkins University Press: Baltimore, 1973.

5 Examples of such positions which will be encountered here include attempts to cast history in terms of evolutionary biology. See: Jared Diamond, Guns, Germs and Steel: A Short History of Everybody for the Last 13,000 Years. Vintage Press: London, 2005. William H. McNeill, 'Passing Strange: The Convergence of Evolutionary Science with Scientific History,' History and Theory. Vol. 40, No. 1 (February 2001). pp.1-15. The reduction of history to mathematics and statistics. See: Peter Turchin, 'Arise "Cliodynamics",' Nature. Vol. 454 (3 July 2008). pp.34-35. Contemporary versions of the covering law model. See: Clayton Roberts, The Logic of Historical Explanation. Pennsylvania State University Press: University Park, Pennsylvania, 1996. And the Bayesian statistical model. See: Aviezer Tucker, Our Knowledge of the Past: A Philosophy of Historiography. Cambridge University Press: Cambridge, 2004.
} 
as more subtly informing the more generalist predilections of their modern successors), we can also identify an acceptance of the same nomothetic assumption as a key component in the reasoning of their opponents. For there is also, as Part One will aim to show, ample evidence available that both the early twentieth century idealists and their mid-century narrativist successors have taken - whether explicitly or merely tacitly - a nomothetic assumption regarding the nature of science as axiomatic. Thus the nomothetic assumption does not merely represent the strategy of a single team, but is a part of the field upon which all have agreed to play.

Following the identification of this startlingly pervasive assumption, this thesis will argue that the seemingly stark differences between the modern literary-narrative approach to history and the contemporary evolutionarily-inspired offspring of the covering law approach have their intellectual roots in what is essentially a difference of response to this fundamental assumption. Where the covering lawyers believed that the truth of the nomothetic-deductive model required the theory and practice of history be remade in the likeness of physics, the idealists and their narrativist successors chose the other horn of the dilemma - arguing that history's nomothetic failures were evidence of historical knowledge's epistemological separation from the sciences. The latter conclusion, however, begged the question: if historical knowledge wasn't scientific, what was it? What unique structures of argument and explanation made it knowledge at all? This assertion of a fundamental separation between history and science, while having the advantage of freeing philosophers of history from having to answer the most awkward questions posed by nomothetic philosophers of both science and history, thus brought with it a requirement for the construction of a separate epistemological system of explanation and verification specifically for history. There have been many attempts to formulate such systems - the two most notable being empathy (history as the re-enactment of the thoughts of historical actors), and, in the latter half of the twentieth century, narrativism (historical explanation as the contextualisation of an event/object in terms of the interactions of multiple causes over time). Building either of these concepts into a complete, yet separate, epistemology, however, has proved just as tall an order as the covering law requirement for the remodelling of history into the likeness of nomothetic physics. Perhaps even taller, given that the nomothetic scientific epistemology to be opposed had attained its status through accretion over centuries rather than emerging fully formed in mere decades from the pens of a comparatively few authors. 
The empathic approach to historical epistemology, while widespread during the nineteenth and early twentieth centuries, was largely discredited by the midtwentieth century. This was due to both the failure of empathic conclusions to properly submit to any kind of empirical test and the rather narrow subset of historical situations in which empathic methods might have been useful (i.e., questions of human intent and motivation). The narrativist school which succeeded the empathic instead used the concept of narrative - as opposed to nomothetic laws or human thought - as the primary explanatory mechanism for historical knowledge. History, they argued, did not produce or consume laws, but narratives - sequences of events which attempt to explain a particular event or object in terms of the causal sequence of events that produced it. However, while many narrativist accounts of historical practice are compelling and describe actual historical practice well making them by far the most promising candidate for a genuine historical epistemology - they have often lacked the most basic philosophical and epistemic grounding which might have better legitimised them. That is, no vision of narrative has been convincingly shown to fit into either of the categories permitted by the above dilemma: either being consistent with - and thus assimilable into - nomothetic science, or being a fully-fledged - yet fundamentally separate - epistemology. This has led, in turn, to a broad lack of coherence in contemporary philosophy of history as a whole. There have been, in other words, about as many narrative approaches to the philosophy of history as there have been narrativist philosophers of history. The result is a situation in which theoretical commitments, models and methods of justification, proposed logic of explanation, and even definitions of their most fundamental terms (including "narrative" itself) have been largely idiosyncratic to each author. This lack of basic agreement is, of course, true to a certain extent of any field of philosophy. But the sheer depth of flux evident among philosophers of history represents evidence of the basic failure of philosophers of history to adequately attend to the task of creating a rival epistemology to the nomothetic-deductive model associated with the sciences. Indeed, the only philosophical movement with any broad base of agreement and coherence in contemporary philosophy of history is that affiliated with postmodernism. This movement has achieved much of this cohesion, however, through a basic claim that the lack of agreement upon the philosophical foundations of historical knowledge constitutes evidence that the establishment of such foundations is impossible. The only consistent feature of philosophy of history, 
in other words, is its inconsistency. And this, they argue, should tell us something. As Keith Jenkins has memorably written:

... would you like to follow Hegel or Marx or Dilthey or Weber or Popper or Hempel or Aron or Collingwood or Dray or Oakeshott or Danto or Gallie or Walsh or Atkinson or Leff or Hexter? Would you care to go along with the modern empiricists, feminists, the Annales School, neo-Marxists, new-stylists, econometricians, structuralists or post-structuralists... And this is a short list! The point is that even if you could make a choice, what would be the criteria? How could one know which method would lead to the 'truer' past? ${ }^{6}$

Despite this apparent commitment to pluralism, however, the substance of almost all postmodern philosophy of history is largely derived from the narrative philosophy that preceded it - with one important difference. Disillusioned with previous attempts to render history a separate epistemology, postmodern philosophers of history have chosen to interpret narrativism in terms which dispense with epistemological concerns altogether. More specifically, they have abandoned any epistemic sense of the term "narrative," focusing instead on the purely literary connotations of the term. ${ }^{7}$ This blurs the line between history and fiction to a degree that has made many practising historians and philosophers of history extremely uncomfortable. The philosophers of history who have sought to explicitly resist this conclusion, however, have done so at no small disadvantage. For the fragmentation and lack of coherence that makes the postmodern approach possible has also made any kind of principled and systematic rebuttal of that position extremely difficult. Not only has there not been any truly unified response, such responses as there have been have been extremely philosophically weak. Unable to cite any deep epistemological justification for why history has the form it does or how that form is related to empirical claims about the world, such replies have tended to rely heavily on somewhat glib "common sense" reasoning. ${ }^{8}$

6 Keith Jenkins, Re-Thinking History. Routledge: London \& New York, 1991. p.15.

7 This is not, of course, the position of all those critics of history who might consider themselves postmodern. Many are far more concerned with issues of objectivity and bias, and think that much theory collected under the postmodern banner (Foucault, for instance) is well placed to illuminate such issues. Those postmodernists - or philosophers who have been championed by them - who have engaged with more substantive issues of what history is and what historical claims represent in terms of knowledge, however, have almost all been literary narrativists. Such authors include Louis Mink, Hayden White, and Frank Ankersmit. It is with reference to these philosophers and their arguments about historical epistemology (or lack thereof) that this thesis will henceforth mean by the use of the shorthand term "postmodern." Even this term, however, is worryingly free of informative content. Thus, where issues of narrative philosophy are discussed in any detail in the thesis that follows, the more descriptively apt term "literary-narrativist" will be used.

8 We will encounter this position towards the end of Chapter Three. Examples of these epistemologically weak polemics include: Richard J. Evans, In Defence of History. Granta Books: London, 1997. Arthur Marwick, The New Nature of History: Knowledge, Evidence, Language. Palgrave: Hampshire, 2001. Keith Windschuttle, The Killing of History: How a Discipline is Being Murdered by 
It is not the intention of this thesis to rehearse again the clash between postmodernism and historical traditionalists, however. There is much literature already dedicated to this. Instead, this thesis will focus on the deeper issues of foundational philosophical weakness hinted at by the scattered and idiosyncratic responses to the postmodern approach. Whatever the merits of the postmodern approach, the concern here is with the deep structural flaws in history's self-image that the philosophically naïve responses to their more extreme claims reveal. For our purposes, the nature of the attacker matters much less than the inability of the historical discipline to adequately defend itself. So why is it the case that the historical discipline has such poorly developed and defined epistemic foundations? So poorly developed, in fact, that assertions that no such foundations are even possible have become routine and now represent a significant fraction of contemporary published work in historical theory? And yet the remaining fraction remains as internally incommensurable as has ever been the case. ${ }^{9}$ Moreover, why is it that the perceived self-evidence of this epistemological separateness of history from the sciences has been so thoroughgoing as to now be effectively received wisdom? How did history become so utterly convinced of its position beyond the reach of any serious application of scientific epistemology? This thesis will argue that light can be cast upon all of these questions by examining the nomothetic assumption persistent in almost all twentieth century philosophy of history, and which has proved stubbornly persistent to the present day. Moreover, it will be shown that this assumption, when uncritically adopted, has been at the root of history's separatist impulse, as well as acting to deny philosophers of history access to the very best available arguments regarding the nature of history.

Literary Critics and Social Theorists. Revised and Expanded International Edition. Macleay Press: Paddington, 1996. Perez Zagorin, 'History, the Referent, and Narrative: Reflections on Postmodernism Now,' History and Theory. Vol. 38, No. 1 (February 1999). pp.1-24. This is not to say that their conclusions are invalid, but merely to suggest that they do not provide support for their positions beyond appeals to tradition and circular claims which imply the nature of historical method to be self-evident.

9 That there is excellent epistemological work being done in the philosophy of history is beyond doubt. Examples include: Leon Goldstein, The What and The Why of History: Philosophical Essays. E. J. Brill: New York, 1996. Aviezer Tucker, Our Knowledge of the Past: A Philosophy of Historiography. Cambridge University Press: Cambridge, 2004. Mark Day, The Philosophy of History. Continuum: London \& New York, 2008. Clayton Roberts, The Logic of Historical Explanation. Pennsylvania State University Press: University Park, Pennsylvania, 1996. C. Behan McCullagh, The Truth of History. Routledge: London \& New York, 1998. These works, however, exhibit surprisingly little agreement with each other on anything other than the broadest of terms. All agree that history is a knowledgegenerating discipline - i.e., that it possesses a basic commitment to realism - but offer different methods for conceptualising, attaining, and verifying historical knowledge. 
More specifically, it is the intention of this thesis to argue that the pressure the nomothetic assumption placed upon philosophers of history to establish a separate historical epistemology ultimately led post-covering law philosophers of history such as W. H. Walsh, Arthur Danto, and William Dray - to place far more epistemic weight upon the concept of narrative than it could shoulder without a firm epistemic grounding. That is, while the concepts of narrative offered by these authors were descriptively sound to greater or lesser degrees, they exhibited no deeper structure. For unlike the concept of scientific laws, these ideas of narrative were not anchored to some fundamental fact of the world. That classes of events/objects have commonalities that might be abstracted and formalised is epistemologically uncontroversial - not to mention extremely successful at producing descriptions of certain aspects of reality. Narrative, on the other hand, did not seem to speak to any such fundamental concern - especially when philosophers insisted on conflating the term with the word "story." Thus, not only was the development of the concept weakly constrained, and thereby open to a great deal of interpretive flux, it was also open to accusations that it represented a post hoc rationalisation. The reason the concept of narrative seemed to fit the practice of history so well, in other words, was because it had been developed in order to exhibit such a fit. In addition to this, the connotations of the term with respect to notions of fiction and story-telling implied an ineradicable human subjectivity wherever the term was used. Given such objections, it therefore became possible to argue that the idea of narrative as the explanatory vehicle for history was nothing more than a mere convenience philosophers of history had granted themselves in order to provide a veneer of legitimacy while proceeding with business as usual. The literary-narrativist Hayden White neatly summarises this viewpoint as follows:

... it is precisely because the narrative mode of representation is so natural to human consciousness, so much an aspect of everyday speech and ordinary discourse, that its use in any field of study aspiring to the status of science must be suspect... Viewing modern sciences from this perspective, we can trace their development in terms of their progressive demotion of the narrative mode of representation in their descriptions of the phenomena that their specific objects of study comprise. And this in part explains why the humble subject of narrative should be so widely debated by historical theorists in our time. To many of those who would transform historical studies into a science, the continued use by historians of a narrative mode of representation is an index of failure at once methodological and theoretical. A discipline that produces narrative accounts of its subject matter as an end in itself seems theoretically unsound; one that investigates its data in the interest of telling a story about them appears 
methodologically deficient. ${ }^{10}$

Thus we return to the dilemma hinted at above. History must either be remade in the likeness of a nomothetic discipline such as physics, or it must be established as a somehow separate sphere of knowledge altogether, with only tangential connections to the academic world outside. And although this stems from debates stretching back at least as far as the nineteenth century, we can still see contemporary examples of just such positions. The modern descendants of the covering lawyers, while having abandoned their doctrinaire insistence on the articulation of explicit laws, insist that history as currently practised is riddled with subjectivity and sophistry, and that a truly scientific treatment is only possible when we begin seeking general conclusions and/or large-scale patterns about the past. And this, they say, is only possible through the use of very large scales of time and place, over which the effect of particularity and genuine contingency might be ignored. The direct emphasis on laws might be gone, but the insistence that generality is the most essential quality of science - and that particularity and contingency are intrusions to be expunged if possible and statistically negated if not - represents what might be called a vestigial nomothetic assumption. For while such assertions are true in a more relativistic sense, that is rarely the sense in which they are used. Rather, it seems as though many such advocates of a scientific history use such terms to fight a rearguard action - claiming to have abandoned the old nomothetic certainties while smuggling them in through the back door in disguise. At any rate, it is certainly the case that those modern advocates of a scientific treatment of history have retained the emphasis of their forebears on the requirement for history to be radically transformed if it is to be scientific. On the other hand, we have the postmodern philosophers of the linguistic turn - themselves the descendants of the twentieth century narrativists - who have argued that there is quite simply no firm epistemic basis for history at all. And then there are those in the frequently bewildered middle who rightly retain a belief in the power of the historical discipline to make true statements about the past and to investigate the constellations of causes behind certain events, yet have proved either unable to provide satisfactory philosophical arguments as to why this should be so the aforementioned "common sense" thesis - or have persisted in using the same well-worn classes of arguments that can be found in late nineteenth/early twentieth century books on historical method. ${ }^{11}$ Such is the current state of the philosophy of

10 Hayden White, The Content of the Form: Narrative Discourse and Historical Representation. Johns Hopkins University Press: London and Baltimore, 1990. p.26.

11 There is, of course, no reason why philosophical arguments should be suspect merely because they 
history. It is the intention of the first part of this thesis to show that this particular pattern of intellectual positions within the contemporary philosophy of history have flowed, albeit in different ways and from different directions, from an historic acceptance of the nomothetic assumption.

\section{The Structure of Part One}

Part One of this thesis consists of three chapters. These chapters are separated thematically, but - taken together - progress chronologically through the arguments of some of the most influential philosophers of the twentieth century philosophy of history. Chapter One aims to provide some background regarding the philosophy of history in the first part of the twentieth century, emphasising both its idealistic character and its explicitly stated nomothetic assumptions regarding science. To this end, close readings of the writings of J. B. Bury, Benedetto Croce, Carl Becker, Charles Beard, and R. G. Collingwood will be used to show how the relationship between history and science was discussed - and thus how historical epistemology was conceptualised - in the first few decades of the twentieth century. This will function as context for the introduction of what would become the most widely discussed idea in twentieth century philosophy of history - the "covering law" arguments of Carl Hempel and Karl Popper - which we will encounter near the end of the chapter, and which invoke a far more explicit nomothetic assumption of their own. The primary aim of Chapter One, therefore, is to establish the reality of the nomothetic assumption as a persistent force in the philosophy of history even before the covering law debate began in earnest, and to outline something of the explanatory mechanisms for history proposed by those who argued for history's autonomy.

Chapter Two examines the impact of the covering law debate in more detail, with

are old. The problem is that the kinds of naïve empiricist arguments in question have been largely derived from the idealist tradition. That is, for example, from the von Rankean "let the evidence speak for itself" perspective, or from the Collingwoodian idea of empathy. The idealistic/empathic basis upon which such arguments were built - and their concomitant assumptions about science are now thoroughly philosophically discredited. This is why they are to be considered suspect. Some examples of the "common sense" position have already been given. Examples of the more archaic style of argument can be found in classic works such as: G. R. Elton, The Practice of History. Blackwell: Oxford, 2001. Arthur Marwick, The New Nature of History: Knowledge, Evidence, Language. Palgrave: Hampshire, 2001. E. H. Carr, What is History? Palgrave: Basingstoke, 2001. The continued reprinting and popularity of these books - all originally published in the 1960s and 70s - is itself suggestive of the barren nature of much well-known contemporary philosophy of history. While the work of more recent authors such as Aviezer Tucker, C. Behan McCullagh, and Mark Day is a good deal more sophisticated, nuanced, and aware of subsequent developments in philosophy than these texts, these authors seem unlikely to attain similar levels of fame and republication. 
particular emphasis on the transformative effect it had upon the philosophy of history. This was not the desired transformation of history into a scientifically precise likeness of physics, however, but the systematic discrediting of the then-widespread empathic understanding of how historical explanation functioned and was separate from the sciences. This part of the Popper/Hempel program at least, was responsible for a thorough re-examination of the justifications for historical knowledge. For not only did the covering law program make explicit what were formerly merely implicit nomothetic assumptions, it also forced those philosophers of history who would resist Popper and Hempel's conclusions into attempting to formulate a means by which the kind of work historians already produced could still be called knowledge. This chapter will seek to document this intellectual transformation by examining in detail the writings of two highly influential mid-century figures who attempted just such post-Hempelian reconstructions of the philosophy of history - albeit from different directions. First, Patrick Gardiner, who was sympathetic to covering law arguments, and saw some conceptual integration with the sciences as necessary if history were to remain credible as a knowledge-generating field. And second, W. $\mathrm{H}$. Walsh, who was among the first to concede the naivety of then-existing empathic ideas about historical epistemology in the wake of the covering law attack and attempted to develop the twin concepts of colligation and narrative as an alternative epistemology which could simultaneously claim both legitimacy and autonomy from the sciences. The primary aim of this chapter is to show that despite the radical conceptual revisions the philosophy of history underwent as a result of Popper and Hempel's challenge, the perception of a deep detachment between history and the sciences that had been the key feature of previous debates was merely reinforced, and that this reinforcement is attributable to the nomothetic assumption.

Chapter Three examines the long-term consequences of this perceived epistemic gulf between history and the sciences. For, as the previous chapter argues, one of the primary reasons for the existence of the emerging class of narrative arguments regarding the nature of historical explanations in the mid-to-late twentieth century was the fact that they promised an alternative to the scientific pretensions of the covering lawyers. The very idea of narrative itself thus represented a philosophical commitment, as well as an assumption about the nature of science. And this, as Chapter Three will argue, is perhaps the only common thread we can find among philosophers of history who have favoured the term. Indeed, it almost appears as if 
the decision to use the term was made before any serious thought as to how it was to be defined. This chapter examines several of the most influential twentieth century attempts to define what a narrative philosophy of history would look like, and how it would conceive of its central idea - those of William Dray, W. B. Gallie, Arthur Danto, Louis Mink, and Hayden White. Each of these authors is examined with specific reference to their oppositional definition of the term "narrative," and their corresponding conceptions of the relationship - or lack thereof - between science and history. The primary aim of this chapter, therefore, is not only to show that narrativism arose out of a desire to avoid the covering law vision for history, but also to demonstrate that its development has been almost entirely predicated on an opposition to science arising from the nomothetic assumption. To try to define narrative largely by what it is not, however, has not proved good enough. Thus, the primary aim of this chapter is to show that this lack of any deep philosophical foundation for the term ultimately led to its conflation with its colloquial meaning of "story." In this sense, it might be argued that even the contemporary conclusions of the postmodern literary-narrativists are ultimately based upon a foundation predicated upon the nomothetic assumption.

Taken together then, these three chapters seek to demonstrate two key points. First, that there has been a persistent nomothetic assumption throughout modern philosophy of history - explicit enough to be clearly detectable in the writings of historians and philosophers even today, yet sufficiently sublimated as to survive even major conceptual upheavals in the discipline. And second, that this nomothetic assumption has exercised considerable influence with respect to how the philosophy of history has been conducted, and how the historical discipline as a whole sees itself. But even if these conclusions are accepted, it might subsequently be asked: why does it matter? It matters because, as a part of the rhetorical framework by which arguments regarding the status of historical knowledge have been prosecuted, the nomothetic assumption has contributed - consciously or not - to the modern image of history as an autonomous and epistemologically distinct branch of knowledge. History is not a part of science, it is usually assumed, because it clearly fails to conform to even the most liberalised conceptions of the scientific ideal. That is, history does not seem to have any close connection to the production and/or deployment of laws, nor does it exclusively seek generalisation. Nor has any attempt at the remaking of history into such a nomothetic - or even merely generalising - 
discipline ever succeeded beyond the most limited of scopes. What is history, then? History, the reply seems to be, is... well... history. As Chapter Three argues, it might be claimed that history constructs narratives, but this means little if the most widely agreed upon characteristic of a narrative is simply that it isn't a law. Put simply, the nomothetic assumption has been a powerful force in the definition of history - no matter which side of the debate one sympathises with. And the influence of this argument persists to this day. So, again, why does this matter? It matters because, as a description of the theory and practice of science, the nomothetic assumption is deeply flawed. If we can successfully demonstrate this, it follows that a good deal of the legitimacy and contemporary relevance of these intellectual positions within the philosophy of history would be called into question. With this in mind, Part Two of this thesis will concern itself with offering just such a refutation, as well as an assessment of just what a dissolution of the nomothetic assumption might portend for the relationship between history and the sciences.

\section{Part Two - Taking Narrative Seriously}

To point out that the nomothetic assumption has made the notion of a scientific treatment of narrative - and thus a potential scientific basis for historical explanation - almost unthinkable is, of course, not the same as actually claiming that such a scientific vision of narrative is possible and that such a vision can be applied to the study of historical explanations. Having argued for the former in Part One, Part Two will take up the latter. In doing so, we will seek to demonstrate not only that there is such a scientific vision of narrative, but also that it is able to be driven into epistemic bedrock at least as secure as that of the traditional nomothetic model, and that it can be meaningfully applied to the kinds of questions those who study human history ask and the explanations they are inclined to offer. In order to accomplish this, three main claims will have to be established. First, it will have to be demonstrated that the nomothetic assumption regarding science is false. That is, while the nomotheticdeductive model is highly successful in certain areas of science, it does not fully encompass all explanations legitimately offered under the aegis of the sciences. Scientists, after all, often require answers to historical questions too. Therefore, as a model it needs to be extended or otherwise augmented in some way. Part Two will demonstrate that the best way to do this - and the solution offered by many practising scientists and philosophers of science themselves - is to introduce the 
concept of narrative into science. Second, we will also have to demonstrate that the concept of scientific narrative we would wish to defend is not vulnerable to accusations of being a post hoc rationalisation or merely a promissory note for a real explanation to follow at some later date. For if this is not done, we have merely exchanged the shallow concept of narrative already evident in the philosophy of history for another that is superficially scientific, but ultimately equally shallow. As we shall see, this problem can be solved by splitting the difference between the two approaches seen in Part One. By defining narrative in terms of existing scientific epistemology, we avoid the error of earlier philosophers who believed it necessary to make narrative (and thus history) stand utterly apart from the sciences, while simultaneously providing the tools for their integration. In other words, the concept of narrative will be shown to make sense in the terms of already existing (i.e., nomothetic) philosophy of science, and thus able to be tied to the deepest and most successful epistemological insights available to philosophy. And third, we must show that this model of scientific narrative is able to be applied to the study of human history - thus providing a principled scientific basis for its most basic explanatory form, and putting an end to its rather bizarre claims of epistemological uniqueness.

In order to support these claims, Part Two will examine those historically focused areas of science that have not been able to simply pull up the metaphorical drawbridge and proclaim themselves guardians of a separate epistemology. Indeed, the study of examples drawn from such areas will prove instructive for precisely this reason. Part One of this thesis will argue that the philosophers of history who tried to develop narrative into an epistemology for history were able to evade the most difficult questions about the necessity and verifiability of narratives by claiming that they represented a different kind of knowledge in which such questions were somehow churlish. In this sense, the claim of separatism became little more than the licence historians granted themselves to adhere to lower standards. Part Two, by contrast, will point out that disciplines such as evolutionary biology, paleontology, and geology could afford no such luxury. Whatever concepts of narrative philosophers of such disciplines developed, they could not use claims of epistemic uniqueness in order to explain away the more difficult questions asked of them by philosophers of science. Because of this, the concept of narrative has been far more fully and rigorously developed in the philosophy of science than by any critical theorist or literary-narrativist philosopher of history. This thesis therefore intends to 
examine the concept of narrative explanation offered by the historical sciences - our main example will be drawn from paleontology and evolutionary biology - in order to ascertain whether or not it might be successfully generalised and subsequently applied to human history.

To accomplish their own explanatory goals, it should be noted, narrative philosophers of science were required to be clear about how they understood the term "narrative." And, if we are to make use of their work in this thesis, we must do the same. First and foremost, we need to divest ourselves of the glib conflation of narrative with "fiction" and/or "story." As Haskell Fain rather condescendingly wrote in a 1970 paper:

Important facts of the titmouse life cycle can be arranged as a tale of Tilly the Titmouse. Though naturalists may make up such instructional stories for children, no serious student of natural history could take them seriously. Perhaps the time has come for serious students of human history to put away childish things. ${ }^{12}$

In order to avoid our vision of narrative being so blithely (and wrongly) dismissed, we must give the term "narrative" a more precise meaning which avoids such associations. This is not done in order to close off other potential meanings of the term or to evade responsibility, but instead to provide a more precise sense of the term for certain purposes. This is not unlike the defining of a metric "cup" as 250 millilitres. By doing this, we allow for a degree of transpersonal disambiguation when attempting precise work. We do not, however, immediately insist that the term "cup" be subsequently denied to any vessel of any other size - we merely acknowledge that, when the stakes are low, a certain looseness of language can be permitted without harm. Similarly, we require our sense of narrative to not only be distinct from that of literary-narrativists like Hayden White, but also to be resistant to dismissal as "childish." To this end, this thesis suggests the term "epistemicnarrative" as a foil for the already-introduced term "literary-narrative." This term, while admittedly somewhat unwieldy, is nevertheless useful as it wears openly an emphasis on the key difference between the two positions. Where literary-narrativists such as Louis Mink and Hayden White have chosen to marginalise or outright deny the possibility of narratives functioning as actual knowledge claims and focused on the folk meaning of the term, the epistemic-narrativist position attempts to define and examine narratives as representations of actual past and present states of the

12 Haskell Fain, 'History as Science,' History and Theory. Vol. 9, No. 2 (1970). p.154. 
world. As per the arguments of Part One then, we might argue that the philosophy of history has produced a good deal of literary-narrativists, but almost no epistemicnarrativists. The historical sciences, on the other hand, have produced only epistemicnarrativists (when they have produced narrativists at all). The task of this thesis then, is to examine how these epistemic-narrativist philosophers of science have conceptualised narrative, and then attempt to adapt that concept to the peculiar difficulties involved in the study of human history.

Perhaps the most important and striking aspect of epistemic-narrative philosophy of science is the impressive scope with which narrative is defined. Shorn of its narrow literary connotations, the term is instead defined in purely temporal terms. For example, David Hull - perhaps the philosopher of science who has done the most to develop a scientific sense of narrative - defines historical narratives simply as "descriptions of historical entities as they persist through time,"13 and subsequently dedicated much of his work on narrative to trying to formalise the nature of those entities so narrated, ultimately concluding that such entities could be almost anything at all - some examples Hull uses include individual human beings, Big Ben, Protestantism, the United States of America, and the evolution of "sharks and bony fishes"14 - provided a single criteria was met: they must be individuals (in the technical philosophical sense of the term). That is, they must be somehow unique. But even this stricture is flexible. For the entity in question, in Hull's view, need only be an individual at the level of enquiry in which the questioner is interested in it. That is, despite the fact that many facts about human physiology are able to be generalised, those facts will be of little interest to an historian seeking to write the biography of a single human being. ${ }^{15}$ Such an open-ended definition of narrative hints at the possibility that we might give a narrative account/explanation of almost anything in the physical universe. More recently, the philosopher of science Benjamin Jeffares has built on Hull's definition of narrative in order to introduce the possibility of causal interactions at multiple levels and from multiple branches of knowledge:

Narratives thus have the following character. They document the changes in state in a central historical subject. Those changes in states will be the result of the

13 David L. Hull, 'Central Subjects and Historical Narratives,' History and Theory. Vol. 14, No. 3 (October 1975). p.254.

14 Ibid., pp.253-274.

15 For instance, all human beings have white blood cells - yet knowing this general fact is not likely to be of much use in explaining the actions of Mikhail Gorbachev in pursuing his "Sinatra Doctrine." Whether or not the subject of a narrative is an individual depends, in other words, on the questions we wish to ask. 
operation of particular processes. We may well speculate that processes are operating in tandem rather than sequentially. These processes might work at different levels and invoke causes from quite different domains. Volcanism and erosion are two rather different processes, and in a narrative recounting the formation of a volcanic island, we may well invoke both processes. Each process may well be linked to the final state of the island in its own way. ${ }^{16}$

In terms of actually formulating and expressing knowledge claims about historical entities and their persistence over time, the philosopher of history Arthur Danto has given us a similarly wide-ranging definition with what he calls the "narrative sentence." These sentences are devices for expressing a temporal relationship between multiple events/objects such as to bind them into a single claim. Such sentences, Danto wrote, "refer to at least two time-separated events though they only describe (are only about) the earliest event to which they refer." ${ }^{17}$ We will meet this concept again in Chapter Three, but for now it will suffice merely to point out that, once again, we might construct one of Danto's narrative sentences about almost any single event/object conceivable. Exactly this kind of open definition of narrative lies at the heart of the epistemic-narrative approach to science. The question then remains - given the flexibility of the term - why shouldn't this definition be applied to the events / objects of human history as well?

Surprisingly, the question of whether or not such a broad temporal view of narrative can be applied to human history often does not get any answer at all, let alone a detailed one. Indeed, due to the nomothetic assumption biasing a generation of philosophers of history against the possibility of a non-nomothetic science, it is frequently ignored almost entirely. The philosopher Mark Day, in his otherwise excellent 2008 book The Philosophy of History - itself designed as a handbook for students studying the subject - makes this particular disconnect clear. In a chapter devoted to narrative in history, Day argues that there are two ways in which to understand narrative in history - the "thin" sense, and the "thicker." The former understanding, Day writes, "is that a narrative is any report of two or more events with some temporal ordering between them." According to this view:

... narratives are found in physics (concerning the development of the universe over the first minute), biology, geology, as well as in a variety of reports about human activity and behaviour... Narrative is unavoidable in any subject that

16 Benjamin Jeffares, Testing Times: Confirmation in the Historical Sciences. PhD Thesis, Australian National University, 2008. pp.30-31.

17 Arthur C. Danto, Narration and Knowledge (including the Integral Text of Analytical Philosophy of History). Columbia University Press: New York, 2007. p.143. (emphasis in original) 
studies different events at different times. ${ }^{18}$

However, Day then categorically dismisses this "thin" approach, writing that "nothing of substance, either critical or positive, follows from that observation." And because of this, he writes, a "consequent demand that narrative be moved to the philosophical margins... is prominent in recent comments by philosophers of the analytic tradition." Within a single paragraph, Day has effectively opened and then closed discussion of any possible scientific sense of the term narrative. Day immediately goes on to argue - citing, among others, W. B. Gallie, Louis Mink, and Hayden White - that there is another "thicker" understanding of narrative, which is built upon a more literary understanding of the term. This literary-narrativist sense of narrative is apparently legitimate in a way the "thin" sense is not, however, as Day goes on to discuss it for a further sixteen pages! ${ }^{19}$ Nor is he alone. One can find similar dismissals of any possibility of bringing a scientific view of narrative to history in much contemporary philosophy of history. In the case of the literarynarrativists, this is unsurprising. What is more surprising is that the same tendency is also evident in the work of contemporary philosophers of history who seek to resist the literary-narrativist arguments regarding history's proximity to fiction and reconcile the seeming contradiction between an autonomous history and scientific epistemology. This is what is meant by the nomothetic assumption cutting such philosophers of history off from precisely those arguments which would best accomplish their purpose.

For example, Aviezer Tucker (whom Day cites as one of those philosophers calling for narrative to be marginalised if the philosophy of history is to be meaningfully connected to the sciences), argues for a re-conceptualisation of explanation in the philosophy of history in terms of Bayesian statistical analysis. ${ }^{20}$ This, he argues, is necessary in order to give historical explanation legitimacy. Indeed, one of the key advantages of his general approach, Tucker claims, is that it "renders the debate about narrative superfluous." ${ }^{21}$ Why then are those philosophers of history who seek an epistemic legitimacy for history that philosophers like White have long abandoned so keen to expunge the idea of narrative from their work? This thesis will

18 Mark Day, The Philosophy of History. Continuum: London \& New York, 2008. p.168.

19 Ibid., pp.168-184.

20 See the entire third chapter of: Aviezer Tucker, Our Knowledge of the Past: A Philosophy of Historiography. Cambridge University Press: Cambridge, 2004. pp.92-140.

21 Aviezer Tucker, 'The Future of the Philosophy of Historiography,' History and Theory. Vol. 40, No. 1 (February 2001). p.51. 
suggest that there is simply no principled reason to do so, and that all such attempts must ultimately stem from the stubborn persistence of the nomothetic assumption. For, as Part One will show, the perception of narrative as somehow oppositional to science has been the primary attraction of the concept for a great many philosophers of history keen to distinguish history from the sciences. Conversely, it appears that the beliefs regarding narrative of those who would seek a modern rehabilitation of the concept of scientific history are effectively a mirror image of the same prejudice. Either way, the perception that narrative is, and must remain, an inherently unscientific concept represents an effectively unchallenged axiomatic assumption in almost all contemporary philosophy of history. This assumption must be refuted and the realisation that narrative is a fully scientific concept which can be directly applied to historical explanation established in its place. It is the contention of this thesis that the best way to accomplish this is to replace the ill-defined literary sense of narrative pervasive in history with the kind of broad scientific sense of the term hinted at above - using the broad applicability of the term as the means by which we will integrate history with the sciences. We will thus directly and squarely challenge Day's glib assertion that "nothing of substance, either critical or positive" follows from the conception of narrative as "any report of two or more events with some temporal ordering between them."

How then do we use this this exclusively temporal "thin" sense of the term narrative in order to give substance to the three claims stated earlier - that the nomothetic assumption is false; that narrative is a necessary feature of science and not merely a placeholder for future (i.e., better) explanations; and that such a model of narrative is applicable to explanations in human history? We must first begin with an acknowledgement of the semantic difficulties inherent in crossing the perceived boundary between history and science. It is something of a cliché to point out that some languages other than English - syntactically at least - count history as among the sciences. ${ }^{22}$ This assertion accomplishes nothing, however, as it offers no further account of how the epistemological disconnect between the substantive claims of the philosophy of history and the philosophy of almost everything else can be bridged. It is effectively the equivalent of claiming that two different objects might be made identical simply by giving them the same name. Something similar might also be

22 For example, the German term Wissenschaft, which is often used to describe any field which uses systematic methods of research and thus makes no hard and fast distinction between human history and any other science. 
said, however, about the sciences. For the question "what is science" - as opposed to the question we are concerned with, "how does science explain?" - is a difficult one, and lies largely outside the scope of this thesis. We will have to content ourselves with merely establishing a clear correspondence between disciplines that are uncontroversially considered scientific and human history. In this thesis, the successful establishment of such a correspondence will be taken as evidence that human history is at least as scientific as the discipline it is being compared with. ${ }^{23}$ We will be using, in other words, an argument by analogy. Paleontology, for example, is considered scientific. If there are explanations in paleontology which use a model of epistemic-narrative to do their explanatory work, and it can be shown that the same model of epistemic-narrative can perform similar explanatory work in human history, then human history must therefore be at least as scientific as paleontology.

With this in mind, this thesis will justify the claim that the nomothetic assumption is false by demonstrating that there are branches of science that have long found the nomothetic model of explanation insufficient for their purposes. Indeed, from even a cursory examination of this literature, we can see a clear narrative emphasis emerging almost immediately - as well as comparisons with human history. From the mere existence of this debate we can reasonably conclude that the nomothetic model alone was simply not enough to meet the needs of certain branches of science, and that this fact - despite the condescension of philosophers of science - has not proved sufficient to have these disciplines ruled unscientific. Thus we might reasonably conclude that the nomothetic model does not exhaust all possibilities of scientific explanation. If we wish to move from mere resemblance to a demonstration that history really is scientific, however, we must examine how historical sciences have tackled the problem of explanation. While the kinds of solutions historical sciences have offered have often tended toward the parochial, we can nonetheless see a more detailed scientific conception of narrative emerge with enough areas of broad coherence to suggest the possibility of a generalisable model. From this it can be argued that narrative is a concept worth taking seriously in a scientific sense and can function as a viable complement to nomothetic explanation.

The circumscribed intent of such intra-disciplinary models of narrative explanation,

23 This does not, of course, counter those who would argue that not only is human history not science, neither are geology, paleontology, evolutionary biology, etc. But those who would make such an argument are in very deep waters indeed, having gone well beyond questions of explanation and into questions of definition which are far outside the scope of this thesis. 
however, potentially opens the way for charges that scientific models of narrative are - like their counterparts in the philosophy of history - effectively post hoc conveniences, designed to descriptively legitimise certain practices, but not to actually explain anything. Such charges could not go as far in the sciences as they have in history - where they have ended with the accusation that history is essentially fiction - as the sciences in question cannot and do not begin with the presupposition that narrative is a purely literary device. But this is a difference of degree rather than kind. Thus, for the general model of narrative explanation advanced in this thesis to stand, the post hoc rationalisation class of arguments must be refuted. To this end, we must examine not only whether parochial models of narrative explanation can be meaningfully generalised, but whether the resulting general model can be given a deep scientific structure which would show it to be at least as necessary a mode of explanation as the nomothetic model. If this can be done, then we will have finally arrived at a juncture where we might legitimately ask: if this definition covers such deeply varied subject matter as the birth of the universe, the formation of geologic features, and the evolution of organisms, why should it not be applied to human history as well?

Fortunately, contemporary philosophy of science has begun work on the problem of producing a generalised model of epistemic-narrative. While it is still early days, there are signs of a new seriousness emerging regarding narrative in the philosophy of science. Philosophers from disciplines such as archaeology, biology, geology, and pure philosophy have largely converged on a common language regarding narrative, and have built on each other's work. A unified narrative philosophy of science is taking shape, with much of the more recent work focusing on precisely the kind of firm epistemic grounding needed in order to secure narrative as something more than mere convenience. The legacy of the nomothetic assumption has, however, acted to effectively prevent philosophers of history - to say nothing of philosophical historians - from taking an active and co-equal role in this discussion. In fact, most historians and students of history in the early twenty-first century remain largely unaware that such genuinely new work is even being done in historical/narrative theory - let alone its potential relevance for their discipline. As showing this perceived barrier between history and science to be illusory is the primary aim of this thesis, we will therefore examine several key lines of argument from the philosophy of science which have attempted to place narrative explanation in the historical 
sciences on a much firmer footing, while demonstrating for each of these arguments that the insights they generate are as applicable to human history as they are to the sciences. Moreover, it will also be shown that these arguments, taken together, constitute an essentially complete model of scientific narrative explanation providing not only a way to provide a principled link between narrative and nomothetic explanation, but also arguing that a narrative dimension to explanation is a necessary feature of the universe as we understand it. The ultimate conclusion of this thesis then, can only be that if explanations as currently understood in human history obey a model of explanation that can be shown to be both valid in other accepted branches of science, and conceptually integrated into our very best understanding of the the philosophy of science, then human history is, for all intents and purposes, a science.

The first task a general model of narrative explanation must attend to is to offer some rebuttal to the objection that historical studies of any kind are dramatically, and perhaps fatally handicapped - at least scientifically speaking - by a lack of direct access to the events/objects they seek to study. Therefore, even if narrative were to be a fully-fledged explanatory model, the kinds of studies which would disproportionately make use of it still could not be considered of equal standing with the nomothetic sciences. We will refer to this as the argument from "observation poverty." ${ }^{24}$ On the surface, this objection does not seem relevant to human history in particular - as one might merely point out that in this respect the historian with her documents is in a far better position than the paleontologist attempting to infer the properties of now-extinct organisms from a handful of fossilised remains. To properly eliminate this objection in a general model of narrative, however, such a glib search for counterexamples will not be sufficient. Fortunately, it can be convincingly argued from a purely philosophical viewpoint that observation poverty is not any more weighted against historical disciplines than any other. For whatever disadvantage the historian suffers with respect to temporal distance from the objects of their interest is mirrored in the difference in scale between, for example, particle physicists and the objects of their interest. One can easily imagine, for instance, situations in which the temporal separation faced by the historian is less obfuscatory than the spatial distance faced by the particle physicist. That is, an archaeologist

24 One might also use the term "Experimental Poverty." "Observation Poverty" will be preferred in this thesis for the simple reason that - as experimental results must be observed in order to be of any use - framing in terms of observation effectively covers both observation and experiment with a single expression. 
inferring the existence of an ancient city seems on much firmer epistemic ground than a physicist attempting to "observe" subatomic particles. In light of such arguments, the claim that history is particularly disadvantaged by observation poverty begins to seem like special pleading. The more appropriate way to talk about observation of any kind then, is in terms of the interactions and interchanges required in order to carry information from the source to the observer. ${ }^{25}$ This is not only a much more consistent and informative way to conceptualise observation as a concept, but has the advantage of being completely agnostic when it comes to historical/ narrative versus non-historical/ nomothetic enquiry.

Secondly, a principled model of narrative that hopes to be considered scientific must be able to claim some non-arbitrary connection to the core philosophy of science. Otherwise, we are effectively permitting separate, incommensurable bodies of knowledge to call themselves scientific, while having no principled way for explanations in any one area to be used - or even conceptualised - in any other. In other words, we permit precisely that fracturing of knowledge we are trying to avoid. For without bringing narrative into some sort of harmony with existing philosophy of science, we potentially allow, for example, evolutionary biology to be called a science, yet be - philosophically speaking - totally epistemically unconnected to any other area, even those other areas of biology which are more amenable to traditional nomothetic understanding. We would, in other words, be replacing one disconnect with many. This is obviously counterproductive. The way to avoid this then, is to define a narrative - in the broad epistemic sense discussed above - in basic terms compatible with the existing nomothetic-deductive model. We will refer to this argument in this thesis as the "nomothetic compatibility requirement" or simply "nomothetic compatibilism." This will provide the necessary connection to philosophy of science, while simultaneously preventing a repeat of the mistake many philosophers of history have made in trying to make narrative stand utterly and totally alone. In doing this, however, we cannot go too far in the other direction and attempt to reduce narrative to a special case of the nomothetic - or it would have no reason to exist at all. Instead, we must define it in a way that is complementary and coequal.

Philosophically speaking, this thesis will argue that this can be accomplished simply

25 Peter Kosso, Knowing the Past: Philosophical Issues of History and Archaeology. Humanity Books: New York, 2001. pp.43-45. 
by inverting the direction of reasoning of the traditional nomothetic-deductive model. That is, instead of taking those things that a population of events/objects have in common and extrapolating from them a unifying law or principle shared by all members of that population, we proceed in the opposite direction and apply all relevant laws and principles to a single event/object. This, it will be shown, produces a definition of narrative that retains the wide applicability and flexibility hinted at above, neatly accommodates the definitions of narrative offered by Hull and Jeffares, and - most importantly - maintains a principled connection with existing philosophy of science. Moreover, this definitional move not only distinguishes the narrative from the nomothetic in terms of the direction of reasoning, it provides a clear delineation as to when each is appropriate. For a necessary consequence of this view is that a narrative can only be about an individual of some kind. Therefore, if the event/object we are interested in is unique (in the sense in which we are interested in it) then it follows that narrative will be the appropriate method for its explanation. And that explanation will take the basic form of an account of how multiple causal factors have interacted upon that single event/object over time. From this, it becomes possible to show that explanations in human history obey precisely this basic form at least as closely as any other historical science, provided we account for the disproportionate propensity of human history to cite other events/objects - rather than laws and theories - as causal factors in their explanations. This is not an insurmountable obstacle however, and we shall argue that it can be dealt with if we accept that our chains of narrative reasoning will almost never - even in the most ideal cases - be only one level deep.

A more pressing problem is that of confirmation. For if we invert the direction of reasoning of the nomothetic model we are immediately presented with a problem of verifiability. That is, if we reason from effects back to causes, and that cause was either inherently or functionally unique, then how can we be sure we are even close to correct in our inference of it? Especially given that the uniqueness required by the narrative model prevents the use of experimental duplication? In the traditional vision of science, this is often where the prediction of future instances is invoked yet this option is of limited use to the historical sciences, as the event/object in which we are interested has already taken place or otherwise already exists. We might, of course, speculate as to future transformations - or even the disappearance - of our central subject, and in this sense we are making prospective predictions, but this is a 
comparatively rare way for historians to work. Certainly, there are classes of predictions that focus entirely upon past events. Evolution by natural selection, for example, cannot predict the exact body plans of future organisms. Yet it can be said that a key prediction of evolution is that, for example, no fossilised remains of organisms exhibiting a high degree of organisational complexity ought to be found in extremely old Cambrian-era rocks. This is a kind of prediction that works in a timeagnostic manner - as predicting that no such fossils exist is functionally equivalent to predicting that they will never be found - and is far friendlier to historical enterprises. This style of prediction has been called "negative prediction." ${ }^{26}$ In this sense, "prediction poverty" - like observation poverty - is not the fatal objection to a science of history that many of its advocates have imagined it to be. Nevertheless, we must still offer a principled reason why prediction appears to function quite differently in the narrative domain than in the nomothetic - otherwise we once again become vulnerable to charges of engineering a post hoc rationalisation to hide a basic failure of historical study. Therefore, any general model of narrative explanation that hopes to be called scientific must not only be able to provide a non-arbitrary logic for confirmation and disconfirmation of narrative claims, but also be able to account for this basic discrepancy. For if we have no reliable mechanism for telling a true claim from a false one then any general theory of narrative, no matter how conceptually sound, is useless. ${ }^{27}$ This is of particular importance for history, where the charge that narratives are entirely arbitrary constructions of the historian/author which can never be checked against reality (this failure usually being attributed to observation poverty) has become a central feature of its contemporary philosophy. To this end, it will be shown that a viable solution to this problem flows elegantly from one fundamental observation about the operation of causation: its asymmetry.

Simply put, "asymmetry of causation" is a term by which we might express a single and seemingly deep feature of causality: a single cause will almost always have multiple effects, yet the reverse is hardly ever true. That is, the single cause that is the striking of a match will have multiple effects - smoke, flame, heat, and so on - but multiple causes do not often exhibit a single effect. While seemingly a trite observation, from this asymmetry a logic of confirmation can be derived for unique,

26 T. A. Goudge, 'Causal Explanations in Natural History.' The British Journal for the Philosophy of Science. Vol. 9, No. 35 (November 1958). pp.201-202.

27 Note that having a reliable mechanism for counting evidence for or against a narrative claim is not the same as actually having evidence for or against that claim. There are, for instance, some formally valid narrative claims for which there is simply insufficient evidence. This is a distinctly different problem from possessing evidence and not having a consistent logic for using it. 
past causes by noting that we need not observe/ recover every single effect in order to be able to infer their cause. That is, we do not need to capture every particle of smoke and ash in order to know that a match was struck. As we shall see, this can not only provide a principled justification for making inferences from incomplete evidence one the hallmarks of any historical science - it also provides a mechanism for discriminating between competing narrative explanations. This is because the asymmetry of causation entitles us to expect that there will almost always be more effects than causes, and thus virtually assures us of a wealth of evidential material with which to work. ${ }^{28}$ Therefore we simply need to search for an effect among this constellation consistent with a subset (or even only one) of the available hypotheses regarding the event/object of the past in which we are interested. If it is found, then we have generated a reason to accept only those hypotheses that involve the presence of that effect. This mechanism we will refer to in this thesis as "confirmation by consequences." This confirmation logic will not only be shown to have the advantage of accurately describing the kind of reasoning historical scientists undertake, it will also be demonstrated that it effectively ties the differences between the narrative and the nomothetic to a fundamental feature of causation. And this is exactly what is required if we are to plausibly claim that the narrative method is a necessary mode of explanation, rather than merely a convenient one. This thesis will also argue, moreover, that this logic - like the "accounting claim" rejoinder to the argument from observation poverty - has the additional advantage of being completely agnostic regarding any perceived boundary between human history and the sciences. That is, it applies equally well whether we are reasoning about the possibility of a meteor causing the extinction of the dinosaurs, or the role of economic factors in the fall of the Roman Republic. Thus we will again be driven to conclude that there is nothing here which excludes human history from being considered one of the historical sciences.

\section{The Structure of Part Two}

Part Two of this thesis consists of three chapters. These chapters are separated thematically, but - considered together - move roughly chronologically through the emergence and development of an epistemic narrativism by both philosophers of science and practising scientists. The primary aim of Chapter Four is to give

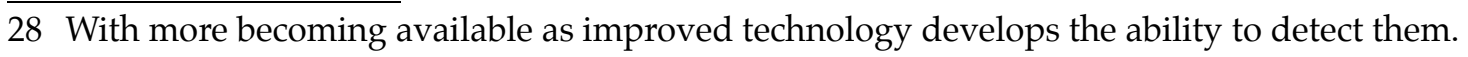


substance to our first claim of Part Two: that the nomothetic model of explanation alone is inadequate to describe the operation of disciplines such as biology, geology, and paleontology - despite their relatively uncontroversial acceptance as scientific. To this end, Chapter Four will examine some of the historical tensions between the theory and practice of both the biological and the earth sciences and nomothetic orthodoxy in the philosophy of science. The earliest geologists and earth scientists, for example, finding little or no guidance in the philosophy of science, often turned to history to help give theoretical shape to their work. This was not considered problematic for the philosophy of science, however, especially in the wake of Newton and other nomothetic triumphs of the seventeenth and eighteenth centuries. The troubled relationship between such historical sciences and nomothetic orthodoxy only became impossible to ignore with the nineteenth century publication of both Charles Lyell's Principles of Geology, ${ }^{29}$ and Charles Darwin's On the Origin Of Species by Means of Natural Selection. ${ }^{30}$ These works were problematic for the nomothetic model given that they were both enormously successful in terms of explanatory power, yet neither seemed to have discovered or deployed any firm nomothetic laws. Because of this, both men drew a good deal of criticism from philosophers of science, much of it rooted in the nomothetic assumption. This philosophical condescension was not limited to the nineteenth century, however, as hostility to these kinds of sciences particularly biology - can still be found among contemporary philosophers of science. To this end, Chapter Four will go on to examine some of the most influential modern criticisms of the scientific status of biology - specifically those offered by Karl Popper and Mario Bunge - as well as the defences offered by such philosophers of biology as Michael Ruse and David Hull. All of this, Chapter Four will argue, represents compelling evidence that the insistence on a single nomothetic model for all scientific explanation could not capture the kind of science disciplines such as geology and biology were pursuing. For although one could certainly see a clear role for laws in such disciplines, laws alone were not enough to fully conceptualise the kind of work being done in these fields. Chapter Four then, will show the inadequacy of a strict nomothetic formalism even within the sciences themselves.

Chapter Five's primary aim will be to give substance to the second of our earlier

29 Lyell's work was published in three volumes between 1830 and 1833. See: Charles Lyell, Principles of Geology: Being an Attempt to Explain the Former Changes of the Earth's Surface, by Reference to Causes Now in Operation. John Murray: London, 1830-1833.

30 Charles Darwin, On The Origin of Species by Means of Natural Selection, or the Preservation of Favoured Races in the Struggle for Life. John Murray: London, 1859. 
claims: that those scientific disciplines the explanations of which do not conform to the nomothetic model have often found narrative useful as an explanatory concept and that such scientific conceptions of narrative have therefore already become a part of mainstream scientific explanation, despite a widespread lack of recognition from philosophers of science. In order to establish this claim, this chapter will examine in some detail one of the first serious attempts to offer a narrative solution to the bind in which the nomothetic-deductive model had placed the historical sciences. This model was offered as an attempt to capture the form of explanation in evolutionary biology, and was the work of one T. A. Goudge. Goudge's example will be instructive here because, unlike history, historical scientists could not simply opt out of scientific epistemology by fiat. Thus it was essential that any model of narrative used in the historical sciences be somehow scientifically defensible. To test the success of Goudge's model at maintaining this testability while also claiming to proceed by narrative rather than general law, Chapter Five will undertake an extended examination of the applied example offered by Goudge - the evolution of the first genuinely limbed creatures (tetrapods) during the Devonian era. ${ }^{31}$ This case study will be examined with particular reference to both the narrative form of the various potential explanations and their ability to be confirmed or disconfirmed by empirical means. This will be accomplished by seeing how these mid-twentieth century explanations of tetrapod evolution have actually fared in light of the new evidence that has become available in subsequent years. From this it will be argued that the concept of narrative can indeed perform useful explanatory work in the historical sciences and is able to be made answerable to evidence. However, narrative - even in the comparatively advanced form in which Goudge offered it - remained vulnerable to charges of being a post hoc rationalisation, or some kind of placeholder for an actual explanation. Chapter Five then, will demonstrate that, despite narrative being a useful practical concept in the historically focused sciences, mid-twentieth century narrative theorists such as Goudge could not make narrative respectable by showing it to be a necessary mode of explanation linked to some fundamental property of the world.

Chapter Six will seek to provide the philosophical foundations missing from the work of Goudge, and thus give substance to the third claim of Part Two - that narrative is a necessary and fundamental mode of explanation, able to be linked to

31 The Devonian period is a division of the Paleozoic era, which spans approximately 57 million years, from $\sim 416$ million years ago to $\sim 359$ million years ago. 
both existing nomothetic models and to our deepest insights regarding the nature of causation. To establish this, this chapter will examine in detail how the philosophy of science has acted to address each of the potential hindrances hinted at above observation poverty, the nomothetic compatibility requirement, and a principled logic of confirmation by consequences. As it so happens, some of the most recent work done in the philosophy of the non-nomothetic historical sciences has focused on removing just such barriers and thus generalising narrative as a form of explanation. In this sense at least, Chapter Six will not be required to reinvent the wheel. Therefore, in addition to detailing the arguments which establish narrative as a fully co-equal mode of explanation Chapter Six will also examine whether the requirements that these philosophical arguments introduce can be met in the practice of human history. With respect to observation poverty, we will examine the work of the philosopher of science Peter Kosso, whose reorientation of the terms of the observation poverty argument from a crude "observable"/ "unobservable" dichotomy to a more nuanced system of "observation, all things considered" through what he calls "accounting claims" effectively refutes this class of arguments. With respect to the requirement for "nomothetic compatibilism" referred to earlier, we will examine the work of the philosopher of biology David Hull. Hull's argument that the narrative form is essentially the nomothetic-deductive model inverted - creating a "particular-circumstance" model - provides a way to connect the broad, inclusive definition of narrative seen earlier to the existing structures of science. This inversion introduces the idea of a narrative as a "central subject" which is explained by detailing all of the relevant law-governed processes which have interacted over time to produce/transform/destroy that subject. Such a definition is, however, difficult to reconcile with the practice of history simply because explanations in history do not always explain their central subjects in terms of laws and processes, instead offering singular events/objects in explanation of other singular events/objects. In order to justify our claim that Hull's model can be applied to human history, therefore, Chapter Six will argue that narrative explanations can be nested. That is, we can use narrative explanations as components of other narrative explanations. With respect to the final requirement for narratives to be made to submit to empirical confirmation or disconfirmation, this chapter will examine the work of the philosopher Carol Cleland. Cleland has convincingly argued (building on the work of David Lewis) that there is a basic asymmetry in the operation of causation which forces very different - albeit complementary and reconcilable - methods and forms upon 
empirical knowledge-generating disciplines depending on which side of this asymmetry they are working on. This, it will be shown, provides a justification for the lack of future prediction in the historical sciences, as well as providing a way in which to discriminate objectively between narrative theories. Ultimately then, Chapter Six will argue that if a narrative account satisfies inspection in these three areas, it can legitimately be called scientific. Moreover, it can be called such without apology, for the narrative form in which it is cast is not merely arbitrary or a result of incomplete information but a necessary form, imposed upon historical studies by the nature of science and the operation of causation.

The overarching theme of this thesis, considered as a whole, is that there is not only one fundamental model of scientific explanation, but two - the narrative and the nomothetic. The two are co-equal, and the form of each is dictated by whichever side of the asymmetry of causation a desired subject lies. All branches of science can potentially make use of both modes of explanation, but - depending on their chosen subject matter - will usually favour one explanatory mode over the other. From this it can be concluded that history is - along with archaeology, paleontology, geology, and any number of others - simply one of those branches whose subject matter heavily favours the narrative mode. Ultimately then, the solution to the problem of how historical knowledge is related to that of the sciences can be solved not by attempting to expunge narrative from all historical work, but by finally taking it seriously as an epistemic concept. More importantly, adopting such a view of history will effectively dissolve many of those vexing dilemmas which have dominated discussion in the philosophy of history for more than a century. For the failure of historical knowledge to conform to a nomothetic model of explanation could no longer be considered credible evidence of the unscientific nature of that knowledge. Nor could it be taken as evidence of a methodological failure that might only be remedied by a radical transformation of historical practice. And so we might finally rid ourselves of the need to maintain the polite fiction of separate epistemic realms. Similarly, it could no longer be argued that narrative itself is a post hoc rationalisation, designed as an attempt to legitimise the historical status quo. For a deep understanding of narrative and how it flows from our best understanding of the operation of the universe must show instead that narrative explanation is a necessary reflection of the nature of causation. And all that is required to make possible such a rapprochement between history and the sciences is the abandonment of the thoroughgoing and persistent 
nomothetic assumption which has tainted the philosophy of history since the nineteenth century. This seems, to put it mildly, a small price to pay. The nomothetic assumption has contributed little more than an inferiority complex and identity crisis to the philosophy of history for quite some time now. Historians and the discipline of history in general, as this thesis intends to demonstrate, would be far better off without it. 


\title{
Part One
}

\author{
"Ask Any Scientician": \\ The Nomothetic Assumption in Twentieth \\ Century Philosophy of History
}





\section{Chapter One \\ "Introducing the Nomothetic Assumption"}

While generalisations regarding entire academic fields are notoriously difficult to make, and therefore rightly regarded with suspicion, the fact is that this thesis proceeds on the basis of just such a generalisation. That is, the success or failure of the arguments presented here will depend upon our basic assertion that there has been - among historians and philosophers of history at least - a systemic and persistent identification of the entirety of science with the law-seeking deductive methods used by some of its sub-disciplines (i.e., physics). This is the meaning of the shorthand term "nomothetic assumption," as coined in the Introduction. Given the foundational nature of this claim, it is imperative that it be adequately justified. To this end, Part One will primarily concern itself with an examination of the work of some of the most influential twentieth century philosophers of history in an attempt to ascertain the extent to which they were promulgators (consciously or otherwise) of the nomothetic assumption. Chapter One begins to tackle this overarching task by examining the work of J. B. Bury, G. M. Trevelyan, R. G. Collingwood, Benedetto Croce, Charles Beard, and Carl Becker - all of whom were active from the turn of the twentieth century up until the transformative arrival of the covering law theories of Karl Popper and Carl Hempel. ${ }^{32}$ More than merely a chronology, however, Chapter One will seek to use these examples in service of two key arguments. First, we will demonstrate the reality of the nomothetic assumption among these prominent and influential philosophers of history even before the arrival of Popper and Hempel. This will be achieved through an examination of their relevant writings on the nature of history and its relationship to the sciences. This approach will have the additional benefit of allowing us to simultaneously examine the effect the nomothetic assumption has had on these philosophers with respect to their ultimate assessments of the relationship between history and the sciences. The second aim of this chapter, however, is more subtle. For if these philosophers were convinced that history could not be scientific as it did not proceed in accordance with nomothetic-deductive

32 This debate, of course, has a history extending much further back than the twentieth century. In fact, the question of both the proper form of scientific knowledge and the status of historical knowledge relative to that form extend well back into the nineteenth century and even beyond. Nevertheless, this thesis - given that it is primarily concerned with the narrativist response to the covering law thesis in the mid-twentieth century - has chosen to limit its scope to the twentieth century. While ultimately 1900 is an arbitrary division, of course, it has been chosen in order to allow a period long enough to demonstrate both the existence of a pervasive nomothetic assumption before Popper and Hempel, and the idealist character of historical thought that Popper and Hempel were primarily concerned with eliminating (and thus provide the proper context for their covering law theories) - yet short enough to be covered within the available space. 
methods, the question remains: having said what history wasn't, did they also have anything to say about what history was? Chapter One, therefore, will also seek to outline something of the perceived character of historical knowledge - often gathered under the term "idealism" - among philosophers of history prior to the arrival of covering law theory. But this idealism, too, it will be shown, is deeply influenced by the nomothetic assumption. For the presumption of a stark difference in kind between history and science, underwritten by the nomothetic assumption, was one of the underpinnings of the idealist approach, which emphasised both the total epistemic autonomy of history and the primacy of "re-thinking" human thought as a method for gaining historical knowledge. Thus, as such idealistic views seemingly represented a majority view among elite philosophers of history at that time, Chapter One will seek to demonstrate a link between the idealistic vision of historical knowledge and the nomothetic assumption.

\section{The Nomothetic Assumption in Action, or: The Misunderstanding of J. B. Bury}

During his inaugural address as Regius Professor of Modern History at Cambridge University in $1903{ }^{33}$ the historian J. B. Bury made his now famous claim that, "though she may supply material for literary art or philosophical speculation, she [history] is herself simply a science, no less and no more." ${ }^{34}$ One of the most enduring sound-bites in the twentieth century philosophy of history, mention of this statement is likely to be found somewhere in any text - introductory or otherwise - published on historical theory since. And while the relevance of this statement today has been rendered somewhat obscure by age and inattention, at the time it was published it became the pithy, quotable centre of a renewed debate concerning the status of historical knowledge relative to the natural sciences which would occupy much of the attention of philosophers of history for almost the entire first half of the century, until its enfant terrible status relative to idealist orthodoxy was usurped by the publication of Carl Hempel's 1942 paper 'The Function of General Laws in History. ${ }^{135}$ And yet, while oft-quoted, Bury's statement is only rarely given adequate context. Indeed, modern historical handbooks and philosophy of history texts often refer to Bury only briefly, and usually as a springboard to the discussion of others who spoke

33 J. B. Bury, 'The Science of History,' in Harold Temperley (ed), Selected Essays of J. B. Bury. Cambridge University Press: Cambridge, 1930. pp.3-22.

34 Ibid., p.22.

35 Carl G. Hempel, 'The Function of General Laws in History,' The Journal of Philosophy. Vol. 39, No. 2 (15 January 1942). pp.35-48. 
against him, ${ }^{36}$ or as an example of obvious and egregious error. ${ }^{37}$ In the interest of fairness then, let us examine J. B. Bury's famous statement and the reaction to it among the historical community at the time with a little more depth than is customary. What did Bury mean by it, and can it be so easily dismissed?

Speaking in the context of this thesis as a whole, we shall see that such an examination will prove instructive if only because it reveals Bury himself to be something of a prophet who - despite his status as a perennial footnote in philosophy of history textbooks and a frequent target of condescension by their authors - effectively anticipated the conceptual basis of a modern scientific approach to history. Indeed, Bury himself was seemingly one of the very few philosophers of history in the twentieth (or indeed any other) century who was able to conceive of science in anything other than strict nomothetic terms. In this sense, despite Bury's failure to provide any comprehensive philosophical framework for his statement, his intellectual vision for history - that if history were to talk in terms of cause and effect, then it must ultimately be answerable to the scientific - proved ultimately to be broadly correct. And, as this thesis progresses, we shall see how just such a vision of a scientific history can be constructed. While it might seem perverse to lead off a chapter designed to demonstrate the reality of a pervasive nomothetic assumption by citing what is effectively a counter-example, Bury's case is included here not only to provide a certain metaphorical symmetry to this thesis, but also as it allows us to open this chapter with an excellent example not only of the existence of the nomothetic assumption, but also of its insidious ability to twist and distort any debate regarding the relationship between history and the sciences. The nomothetic assumptions at issue, however, are not Bury's, but those of his detractors. For, as we shall see, the reactions to Bury's statement among prominent philosophers of history seemed to be based less on what Bury himself thought and said, but on the associations his accusers read into the word "science." Bury's own arguments, even as thin as they were, were barely considered.

Perhaps the most revealing single point of Bury's address was his assertion that

36 For example: Richard J. Evans, In Defence of History. Granta Books: London, 1997. p.23. Bury's speech is mentioned here in only a single paragraph, and then primarily only in order to provide a force for Trevelyan to push against in subsequent pages.

37 For example: Arthur Marwick, The New Nature of History: Knowledge, Evidence, Language. Palgrave: Hampshire, 2001. p.82. Here Marwick writes of Bury's famed pronouncement: "This kind of naïve rhetoric is as dated as that of Burckhardt, and my strong warning to all readers is to distrust any work on historical epistemology written in this vein." 
history had already been "enthroned and ensphered among the sciences," but that the "particular nature of her influence, her time-honoured association with literature, and other circumstances, have acted as a sort of vague cloud, half concealing from men's eyes her new position in the heavens." More significant, at least for the purposes of this thesis, is the perceived engine of this transformation - which, for Bury, was strictly methodological. Arguing that, "the proposition that before the beginning of the last century the study of history was not scientific may be sustained in spite of a few exceptions," Bury asserts that despite the erudition and industry of pre-nineteenth century historians, "the systematised method which distinguishes a science" was beyond their vision, and that - thanks to German scholars such as Barthold Niebuhr and Leopold von Ranke - mere "erudition has been supplemented by scientific method." 38 So, for Bury then, a science was defined by exactitude of method, and thus history could be called a science, due to the widespread adoption of "systematic and minute" techniques of source analysis - a "microscopic criticism, now recognised as indispensable." 39 And with this improvement in method, Bury argued, came the more stringent standards of evidence appropriate to a science:

All truths (to modify a saying of Plato) require the most exact methods; and closely connected with the introduction of a new method was the elevation of the standard of truth. The idea of a scrupulously exact conformity to facts was fixed, refined, and canonised; and the critical method was one of the means to secure it. ${ }^{40}$

This then, is what Bury meant by "science" in his 1903 address. Although there is evidence of far more sophisticated thinking on the subject by the time of his 1909 paper entitled 'Darwinism and History, ${ }^{41}$ there is no evidence in his inaugural address of any use of the term "science" beyond this simple methodological statement emphasising rigour in the handling of sources and their interpretation. ${ }^{42}$ Moreover, in arguing that this was the sense in which history might be thought of as scientific, it should also be noted that Bury made specific reference to nineteenth century German

38 Bury, 'The Science of History,' p.5.

39 Ibid., p.6.

40 Ibid.

41 J. B. Bury, 'Darwinism and History,' in Harold Temperley (ed), Selected Essays of J. B. Bury. Cambridge University Press: Cambridge, 1930. pp.23-42.

42 Such a definition was not uncommon at this time. Other contemporary scholars talked of the science of history in this sense. See, for example: Charles-Victor Langlois and Charles Seignobos, Introduction aux Etudes Historiques (Introduction to the Study of History). Duckworth \& Co.: London, 1898. pp.63-65. A similar use of the term "science" is to be found in the work of Leopold von Ranke. See: Leopold von Ranke, The Theory and Practice of History. Georg G. Iggers \& Konrad von Moltke (editors and trans). Bobs-Merrill Company: Indianapolis \& New York, 1973. Of particular interest in this volume is: Leopold von Ranke, 'On the Character of Historical Science (A Manuscript of the 1830s),' in Leopold von Ranke, The Theory and Practice of History. Georg G. Iggers \& Konrad von Moltke (editors and trans). Bobs-Merrill Company: Indianapolis \& New York, 1973. p.33. 
scholars such as Barthold Niebuhr and Leopold von Ranke. Indeed, Bury directly attributed the methodological advance to the "scientific movement" in historiography with which these scholars were associated. "We owe the change to Germany," he claimed. ${ }^{43}$ Thus, he was - in 1903 at least - aligning himself with the nineteenth century historicist movement which, while it had co-opted the term "science" as a synonym for "rigorous" or "accurate," could not lay any more serious claim to the term.

The reaction to Bury's address was immediate and still shapes perceptions of Bury even today. ${ }^{44}$ The most notable and enduring contemporary reaction was that of G. M. Trevelyan, whose article attempting to refute Bury, "The Latest View of History," was published in the Independent Review in 1903, and was later reworked and appeared as the titular essay in a collection entitled Clio, a Muse. ${ }^{45}$ In this essay, Trevelyan lamented the transformation of history from being "a part of our [English] national literature, written by persons moving at large in the world of letters or politics," to being "proclaimed a 'science' for specialists, not 'literature' for the common reader of books." 46 In short, Trevelyan believed that blame for the drift away from more popular history that had accompanied the professionalisation of the discipline was to be laid at the feet of those who would declare history a science particularly Bury, whom Trevelyan believed had been seduced by the Germanic "scientific" school, which sought to reduce history to the lifeless collection of facts:

And who is the mother country to Anglo-Saxon historians? Some reply "Germany," but others of us prefer to answer "England." The methods and limitations of German learning presumably suit the Germans, but are certain to prove a strait-waistcoat to English limbs and faculties. ${ }^{47}$

On this much, Trevelyan was on firm enough ground, for it is clear that (in 1903 at least) Bury greatly admired the nineteenth century German school of so-called "scientific" historiography, and had - on the surface of it - claimed that history was, in fact, a science. Trevelyan however, went much further than objecting to "scientific" history for being merely inaccessible. He instead sought to base the substance of his

43 Bury, 'The Science of History,' p.5.

44 Doris S. Goldstein, 'J. B. Bury's Philosophy of History: A Reappraisal,' The American Historical Review. Vol. 82, No. 4. (October 1977). pp.896-919.

45 G. M. Trevelyan, 'Clio, A Muse,' in G. M. Trevelyan, Clio, A Muse and Other Essays. Longman's Green \& Co.: London, 1968. pp.140-176. It is to this version that this text will refer, although it should be noted that Trevelyan removed all direct references to Bury in this version. The substance of his arguments however, were unchanged.

46 Ibid., p.140.

47 Ibid., p.142. 
attack on a definitional issue - arguing that the very use of the term "science" itself was inappropriate in the context of history. And it is here that Trevelyan's nomothetic assumptions begin to emerge:

The idea that the facts of history are of value as part of an exact science confined to specialists is due to a misapplication of the analogy of physical science... The functions of physical science are mainly two: direct utility in practical fields; and in more intellectual fields the deduction of laws of "cause and effect." Now history can perform neither of these functions. ${ }^{48}$

This then, is what "science" meant to Trevelyan, and appears - by extension - to be the view that he tacitly assumes Bury (and others like him) share. With respect to this notion of laws, Trevelyan had more to say:

... history cannot, like physical science, deduce causal laws of general application. All attempts have failed to discover laws of "cause and effect" which are certain to repeat themselves in the institutions and affairs of men. The law of gravitation may be scientifically proved because it is universal and simple. But the historical law that starvation brings on revolt is not proved; indeed the opposite statement, that starvation leads to abject submission, is equally true in the light of past events. You cannot so completely isolate any historical event from its circumstances as to be able to deduce from it a law of general application. ${ }^{49}$

What Trevelyan is arguing then, is that the subject matter of history is too rich and complex to be able to be interpreted through the scientific lens, which - due to the nomothetic assumption - Trevelyan believed consisted entirely of isolating the fundamental and universal laws which underwrote its operation. And because history directed toward such a task had singularly failed to convincingly identify any such laws - despite numerous attempts during the nineteenth century ${ }^{50}$ - Trevelyan took this as evidence that the subject matter of history was inherently hostile to scientific treatment. Whatever history was, in other words, it simply couldn't be science. The proper philosophical project, therefore, was to work out a way to conceptualise history apart from the sciences. While Trevelyan's line of argument is

48 Ibid., p.143.

49 Ibid., p.144.

50 Perhaps the most notable of these attempts was that of Henry Thomas Buckle, whose A History of Civilization in England, was a multi-volume work intended to identify the general laws which governed the course of nations. The first volume was published in 1857 and functioned as an introduction to Buckle's methods and the laws he believed he had identified. See: Henry Thomas Buckle, Introduction to the History of Civilization in England. London: Routledge, 1904. Another famed attempt to apply the nomothetic model to human history was that of Auguste Comte, whose six volume Cours de Philosophie Positive (Course in Positive Philosophy) was published between 1830 and 1842. Volumes Four and Five of this work in particular emphasised the application of the methods of physics and astronomy to the social sciences, including history. See: Auguste Comte, The Positive Philosophy of Auguste Comte. $3^{\text {rd }}$ Edition. Harriet Martineau (trans). Kegan Paul: London, 1893. 
logically compelling, it should be noted that it relies upon the nomothetic assumption in order to maintain coherence. For if the nomothetic-deductive form were discovered not to be the only possible shape for science, then the failure of history to adequately mimic it would no longer function as a conclusive argument for history's non-scientific nature. It worth emphasising again that, as mentioned earlier, Bury himself said nothing at all about seeking laws of history. Nor, for that matter, did the German "scientific" historicists such as Leopold von Ranke or Barthold Neibuhr whom Bury had claimed to admire.

Nor was Trevelyan alone in reasoning this way. Perhaps the most significant later example of the distorting power of the nomothetic assumption is that offered by the English historian R. G. Collingwood. In his 1946 book, The Idea of History, Collingwood argued that Bury was "a positivist in historical theory," although "a perplexed and inconsistent one." ${ }^{51}$ Collingwood attempted to substantiate this claim by examining a supposed shift in Bury's reasoning between 1900 and 1903. In 1900, Collingwood argues, one finds Bury adhering to the "strict formulae of positivism." To this end, he cites a 1900 paper by Bury - 'Causes of the Survival of the Roman Empire in the East, ${ }^{152}$ in which, he argues, "the survival of the Eastern Empire is regarded as an event of a certain general kind, and the problem is to find causes of certain general kinds to account for it." ${ }^{53}$ This, for Collingwood is pure nomothetic positivism: "the treatment of an event not as unique but as an instance of a certain type, and the explanation of it by discovering a cause applicable not to it alone but to every event of the same general kind." 54 Thus, as for Trevelyan, we see a clear statement of science as a purely generalising enterprise modelled after natural sciences such as physics and astronomy - the nomothetic assumption. Collingwood further cements this association with science by explicitly defining positivism in The Idea of History as "philosophy acting in the service of natural science, as in the Middle Ages philosophy acted in the service of theology." 55 And nineteenth century positivists, maintained Collingwood, had formed their own "superficial" notion of what natural science meant:

51 R. G. Collingwood, The Idea of History. Revised Edition. Oxford University Press: Oxford, 1994. p.147.

52 J. B. Bury, 'Causes of the Survival of the Roman Empire in the East,' in Harold Temperley (ed), Selected Essays of J. B. Bury. Cambridge University Press: Cambridge, 1930. pp.231-242.

53 R. G. Collingwood, 'Review of Harold Temperley (ed), Selected Essays of J. B. Bury,' English Historical Review, No. 46, No. 183 (July 1931). p.462.

54 Collingwood, The Idea of History. p.148.

55 Ibid., p.126. 
They thought it consisted of two things: first, ascertaining facts; secondly, framing laws. The facts were immediately ascertained by sensuous perception. The laws were framed through generalising from these facts by induction. Under this influence a new kind of historiography arose, which may be called positivistic historiography. ${ }^{56}$

From this it would seem that, in branding such a view "superficial," Collingwood himself was aware, as Trevelyan apparently was not, of the limitations of a narrowly nomothetic view of science. Unfortunately, his subsequent argument, by claiming that just such a view was widespread among nineteenth century historians, essentially reproduces Trevelyan's error. In addition to this, the assumption of ideological uniformity also allowed Collingwood to gather under the banner of nomothetic positivism all of those historians who adhered to the ostensibly strict empiricism toward sources that became popular in the wake of aforementioned German scholars such as Niebuhr and Ranke and which was often (glibly) called "scientific history." For while Collingwood states that, "throwing themselves with enthusiasm into the first part of the positivist programme, historians set to work to ascertain all the facts they could," he also asserts that the motivation for said enthusiasm was "obedience to the spirit of positivism according to which the ascertaining of facts was only the first stage of a process whose second stage was the discovery of laws." ${ }^{57}$ Thus, according to Collingwood, all those historians who had aligned themselves with the increased focus on historical evidence and the critical analysis thereof, were engaged - whether they knew it or not - in some greater nomothetic endeavour to provide raw material for the discovery of the "laws" of history. This rather tortured logic provided Collingwood with a rationale by which he might still claim a nomothetic motivation for an author, even if their texts offered no direct evidence for such. In this way, Collingwood tried to justify his argument for a "general tendency" toward positivism in the nineteenth century. ${ }^{58}$ This is the distorting power of the nomothetic assumption in full flight, effectively distorting new perspectives (such as Bury's) so as to fit within a pre-conceived dichotomy.

Having thus accused the J. B. Bury of 1900 of being a doctrinaire nomothetic positivist seeking to transform history into the likeness of physics, Collingwood then interpreted Bury's lack of advocacy for any such program in his 1903 address despite declaring history to be "a science, no less and no more" - as evidence for his

56 Ibid., pp.126-127.

57 Ibid., p.127.

58 Ibid., p.126. 
being "perplexed and inconsistent." For by the time of the 1903 inaugural address, Collingwood writes, Bury had "begun to revolt" against the positivist requirement that history must have general laws extracted from it in order to be scientific despite this being a position he had supposedly espoused in 1900:

In that [1903] lecture he proclaimed that historical thought as we now understand it is a new thing in the world, barely a century old: not at all the same thing as natural science, but having a special character of its own, offering to mankind a new view of the world and a new armoury of intellectual weapons... Here the uniqueness of historical thought is clearly seen and impressively stated; but when Bury goes on to ask what this new thing is, he replies: 'History is simply a science, no less and no more.' The lecture exhibits a mind torn between two conceptions: one, obscure but powerful, of the difference between history and science, the other, clear and paralysing, of their indistinguishable identity. Bury has made a violent effort to free himself from this latter conception, and failed. ${ }^{59}$

Placed in context then, we can begin to see that whatever the actual state of Bury's thought might have been at the time of his inaugural address was largely irrelevant. What is significant is Collingwood's implied claim that an acknowledgement of the "special character" of historical knowledge and an assertion that history is "simply a science" must be mutually exclusive. Indeed, as has been shown above, Collingwood seemed to take for granted that the mere assertion that history is a science necessarily implied an acceptance of positivist philosophy and the generalising nomothetic approach it required. A similar binary, as has also been seen, can be read from G. M. Trevelyan's reaction to Bury's address. All of which, of course, raises the question: were Trevelyan and Collingwood correct? Was J. B. Bury an advocate of a purely nomothetic view of science, and was his assertion that history is a science an expression of this theoretical alignment? The answer is: almost certainly not. Trevelyan offers no real evidence for his tacit insinuation that Bury was a positivist. And Collingwood cites only the aforementioned 1900 article 'Causes of the Survival of the Roman Empire in the East' as positive evidence for his claim. Yet an examination of this article reveals that Bury was not attempting to draw generally applicable law-like conclusions from the example of the Roman Empire. Rather, the Eastern and Western Roman Empires are compared and contrasted in order to use the Western Empire as evidence to illustrate and support his specific argument regarding the Eastern. At no point are any nomothetic-style extrapolations being made regarding "empires" in any general sense. ${ }^{60}$ And without any firmly established positivist background, it can no longer be argued that Bury's 1903

59 Ibid., p.148.

60 Bury, 'Causes of the Survival of the Roman Empire in the East,' pp.231-242. 
inaugural was the mental watershed Collingwood claimed it to be. For if he had never been a nomothetic positivist, how could he "revolt" against it?

How then, did Bury mean for the term "science" to be understood? Or, put another way, what has been lost by using the nomothetic assumption in order to issue his dismissal? We can begin to answer this by remembering that, in sympathy with the German historicist scholars he so admired, his use of the term appeared to be methodological rather than nomothetic. Such a use of the term "science" has its own deficiencies, however, and is frequently highly misleading. For many nineteenth century historians and philosophers of history who glibly used the term to describe their view of historical practice also retained many religious and metaphysical convictions that were incompatible with any sense of science. As noted in the Introduction, using the name is not enough. Even allowing for this, however, Bury remains a noteworthy example. This is because Bury's alignment with this nineteenth century trend toward calling historiography "scientific" was tangential at best. His own conception of the relationship between history and science was a good deal more substantial. In a later article, entitled 'Darwinism and History,' published in 1909, Bury offered a more detailed account of his understanding of what it meant for a discipline to be scientific:

The conception of the history of man as a causal development meant the elevation of historical inquiry to the dignity of a science. Just as the study of bees cannot become scientific so long as the student's interest in them is only to procure honey or to derive moral lessons from the labours of "the little busy bee," so the history of human societies cannot become the object of pure scientific investigation so long as man estimates its value in pragmatical scales. Nor can it become a science until it is conceived as lying entirely within a sphere in which the law of cause and effect has unreserved and unrestricted dominion. ${ }^{61}$

While such an appeal to the sovereignty of a "law" of cause and effect might seem an endorsement of a nomothetic viewpoint, it was not. Bury was merely arguing that a prerequisite for the scientific study of history must be a commitment to natural - as opposed to supernatural or otherwise metaphysical - explanations. While one might still argue for a supernatural "ultimate" cause if one so wished, historical explanation - if it wished to be scientific - had to proceed on the basis of more proximate causation. While a similar argument underpinned the work of nineteenth century positivists like Henry Thomas Buckle and Auguste Comte, such an argument alone does not speak to the central nomothetic positivist concern - does the study of a 61 Bury, 'Darwinism and History,' pp.26-27. 
history so conceived reveal higher level regularities or causal "laws"? Bury concluded, without ambiguity, that it did not. More importantly, he made it clear that the discovery of such laws was not strictly necessary for science either:

The truth is that Darwinism itself offers the best illustration of the insufficiency of general laws to account for historical development. The part played by coincidence, and the part played by individuals - limited by, and related to, general social conditions - render it impossible to deduce the course of the past history of man or to predict the future. But it is the same with organic development. Darwin (or any other zoologist) could not deduce the actual course of evolution from general principles. Given an organism and its environment, he could not show that it must evolve into a more complex organism of a definite, predetermined type; knowing what it has evolved into, he could attempt to discover and assign the determining causes. General principles do not account for a particular sequence; they embody necessary conditions; but there is a chapter of accidents too. It is the same in the case of history. ${ }^{62}$

In other words, the contingency of historical explanations (i.e., their lack of any generality or law-like quality) could not be correlated to any scientific status they might claim. Bury's subsequent work on contingency - particularly his famous 1916 essay 'Cleopatra's Nose' - took this line of argument as axiomatic. ${ }^{63}$ In these writings, Bury argued that history was too complex for a nomothetic approach - too many interacting chains of causation were interacting at any given moment to allow high level general truths to be isolated. This complexity of interaction, as well as the operation of what is called chance, were not the "intrusion of a lawless element" however, but the "collision of two or more independent chains of causes." 64 Thus, Bury argued, it was possible to talk of history as explicable - even if only in principle - in terms of cause and effect, while being simultaneously beyond the reach of generalisation in the form of uniformities and laws. Contingency then, was rationally explicable. As Doris S. Goldstein has argued of Bury:

His initial premise was that all historical phenomena - those which are defined as "accidental" as well as those which are the result of human purpose - are subject to the law of causation. That is, all occurrences have antecedents. It follows that the causal sequence determining a chance event is as open to discovery and explication as an event stemming from human choice and action. ${ }^{65}$

Thus it can be seen that what was on offer in the work of J. B. Bury was a relatively sophisticated (in comparison to the reception it received) and nuanced view of

62 Ibid., pp.38-39.

63 J. B. Bury, 'Cleopatra's Nose,' in Harold Temperley (ed), Selected Essays of J. B. Bury. Cambridge University Press: Cambridge, 1930. pp.60-69.

64 Ibid., p.61.

65 Goldstein, 'J. B. Bury's Philosophy of History: A Reappraisal,' p.900. 
science, history, and the nature of causation. His use of the term "science," was not only a statement of methodological intent, but a declaration that, at least in principle, historical knowledge was not of a fundamentally different kind from the scientific. Further to this, he appears to have understood science well enough to see that there could be such a thing as a non-nomothetic scientific practice. Indeed, as Part Two of this thesis will show, his account of contingency and causation effectively presages the work of later philosophers of science such as David Hull. And yet, Collingwood and Trevelyan - among others - explicitly attacked him as an advocate of a positivism oriented specifically toward the identification of laws of history. On the basis of this, it seems reasonable to conclude that the reaction of both Trevelyan and Collingwood to Bury's inaugural address can have had little to do with its content, or the content of any of Bury's other writings. One is left, therefore, to conclude that the explicit conflation of the term "science" with the nomothetic-deductive method took place primarily in the minds of Trevelyan and Collingwood themselves. This is the nomothetic assumption in action.

\section{Idealism and Historical Autonomy}

Of course Collingwood and Trevelyan were far from the only examples of this kind of thinking. Indeed, it might reasonably be said that the positions held by Trevelyan and Collingwood were effectively a majority view among philosophers of history during the early twentieth century. And this entire school of historical thought known as idealism - has come to be known for two key arguments. First, that the unique non-repeatable nature of any historical event precluded analysis using scientific techniques. And second, that the focus of history on the realm of the human required an intuitive re-imagining of the thoughts of historical actors by the historian. ${ }^{66}$ These were widespread views among philosophers of history in the first half of the twentieth century, and even retain some adherents to this day. ${ }^{67}$ For the purposes of this chapter, however, it will be enough to note that the second of these arguments - the necessity of a mental "re-enactment" of the thoughts of past men and women - was an attempted solution to the problem introduced by the first. Or, put another way, it is our intention to demonstrate that much of the idealist movement was predicated on an opposition to science engendered by the nomothetic

66 For a similar summary, see: John Tosh, The Pursuit of History: Aims, Methods and New Directions in the Study of History. $3^{\text {rd }}$ Edition. Longman: Harlow, 2002. p.167.

67 For a recent example, see: Raymond Martin, 'The Essential Difference Between History and Science,' History and Theory. Vol. 36, No. 1 (February 1997). pp.1-14. 
assumption. For if the nomothetic-deductive method was perceived to be the only possible form for scientific knowledge, then one might either: attempt to treat history in a nomothetic manner (and by so doing radically transform it), or, declare it to be entirely independent from science and the explanatory requirements it imposed. The idealists believed they were compelled by the failure of previous nomothetic approaches to history to choose the latter. Their corresponding emphasis on mental "re-enactment" can therefore be understood as an attempt to provide a separate epistemology for the autonomous history which was the result. Historical autonomy, in other words, was a proposition for which a plausible epistemic justification had to be manufactured, rather than an epistemic system which had historical autonomy as a necessary consequence.

Once again, it was Collingwood who would come to be most closely associated with this position, coining in The Idea of History the now-classic distinction between the "inside" and the "outside" of an event. Events in the natural world, according to Collingwood, have only an "outside." That is, they are purely the result of blind, physical causes. Hurricanes, for instance, can have physical causes but no intentions or motivations. The actions of human beings, however, not only have an "outside" dimension, in that they involve physical events that materially impact the world, but they also possess an "inside" - the intentions, motivations, thoughts, and feelings that led the actor to choose to become the cause of said events. For Collingwood, it was this "inside" dimension of events which was the proper focus for history:

The historian, investigating any event in the past, makes a distinction between what may be called the outside and the inside of an event. By the outside of the event I mean everything belonging to it which can be described in terms of bodies and movements: the passage of Caesar... across a river called the Rubicon at one date, or the spilling of his blood on the floor of the senate-house at another. By the inside of the event, I mean that in it which can only be described in terms of thought: Caesar's defiance of Republican law, or the clash of constitutional policy between himself and his assassins... [The historian's] work may begin by discovering the outside of the event, but it can never end there... ${ }^{68}$

This, Collingwood argued, combined with the uniqueness of any historical event and the vanished nature of the past (i.e., observation poverty), conspired to place the subject matter of history completely beyond the reach of scientific methods. So much so, in fact, that it should be concluded that historical knowledge was of a

68 Collingwood, The Idea of History. p.213. 
fundamentally different kind from that of the sciences. ${ }^{69}$ It was through these kinds of arguments that the idealist movement came to be associated with a staunch advocacy of historical autonomy. For if one accepted this reasoning, it seemed safe to conclude that history was not only unable to be understood scientifically, it was not answerable at all to issues of scientific explanation. Scientific methods were quite simply the wrong tools for the job at hand. Past failures to treat history scientifically such as those of Buckle and Comte - could be considered evidence of this. How then were historians to probe the "inside" mental dimension of historical events if the tools of science were inadequate? Collingwood answered this question as follows:

If then the historian has no direct or empirical knowledge of his facts, and no transmitted or testimonial knowledge of them, what kind of knowledge has he: in other words, what must the historian do in order that he may know them? My historical review of the idea of history has resulted in the emergence of an answer to this question: namely, that the historian must re-enact the past in his own mind. ${ }^{70}$

The method Collingwood proposed for carrying out this re-enactment was for the historian to "always remember that the event was an action, and that his main task is to think himself into this action, to discern the thought of its agent." ${ }^{71}$ And it is this process that has been called "empathy" or "re-enactment."72 Often hazily defined, even by its advocates, empathy was seen as an intuitive, quasi-mystical process without any clear methodological principles. Despite this, it was frequently considered to be the basic epistemology of idealism. ${ }^{73}$ And, as we shall see in Chapter Two, it was primarily this ill-defined concept that was the target of the covering law theorists - particularly Carl Hempel and Patrick Gardiner - who saw it as empirically unsound and potentially able to justify almost any historical interpretation at all. For the purposes of the current chapter, however, we will content ourselves with pointing out that idealism was first and foremost a movement dedicated to opposing

69 Ibid., pp.216-217

70 Ibid., p.282.

71 Ibid., p.213.

72 Collingwood himself seemed to prefer the latter term. See: Collingwood, The Idea of History. p.215. The term "empathy" has however, also been applied to him and to the similar concerns of other idealists. For a discussion of these terms and their relationship: Mark Day, The Philosophy of History. Continuum: London \& New York, 2008. pp.118-129.

73 And not merely by Collingwood. This quality of "re-imagining" the thoughts of historical actors was also offered in the nineteenth century by the German philosopher Wilhelm Dilthey, who called it Verstehen. See: James Reid, 'Dilthey's Epistemology of the Geisteswissenschaften: Between Lebensphilosophie and Wissenschaftstheorie,' Journal of the History of Philosophy. Vol. 39, No. 3 (2001). p.413. Similarly, the Italian philosopher Benedetto Croce advocated a similar imaginative method. Indeed, there is evidence that Collingwood himself was greatly influenced by Croce in formulating his own views. Certainly, he cites Croce very favourably in The Idea of History. See: Collingwood, The Idea of History. pp.190-204. 
the application of scientific epistemology to history, and only secondarily involved any positive assertions regarding historical epistemology. As evidence for this, we will show that the arguments of some of those associated with the idealist position almost always began with an attempt to argue that scientific epistemology could not adequately address historical questions. This, it was claimed, demonstrated the necessity of some alternative epistemology. The exact nature of that alternative was a separate issue. Some, like Collingwood and his forerunner Benedetto Croce, favoured the intuitive, empathic approach. Others, like Charles Beard and Carl Becker, were less forthright, arguing for the role of the historian's imagination in the writing of history but falling short of openly advocating empathy. Later still, W. H. Walsh would abandon empathy entirely, while still claiming that his work on narrative and the concept of "colligation" was "an attempt to find a plausible version of the Idealist theory of history." 74 If we are to look for coherence among those who have been called Idealists in the pre-covering law philosophical landscape, therefore, it is in their arguments with respect to historical autonomy that we are most likely to be successful.

With respect to Collingwood himself, this link has largely been demonstrated already. We have already encountered his nomothetic assumptions, and the distortions they introduced into his assessment of J. B. Bury. Similarly, the broad flavour of Collingwood's idealism is shown in the "inside" versus "outside" distinction cited above. The only question remaining then, is to what degree his nomothetic assumption influenced his assertions of historical autonomy. And here it is significant that, as Collingwood develops his argument regarding the necessity of empathy as a historical method, his very first rhetorical move is to stress the utter hostility of human history to scientific methods. History, he argues, cannot have anything to do with the sciences without ceasing to be history. Moreover, any attempt to treat history with the methods of science had failed. ${ }^{75}$ This was the problem to which historical autonomy and a separate epistemology were the solution. But the methods he ascribes to science are, of course, totally nomothetic:

... the historian need not and cannot (without ceasing to be an historian) emulate the scientist in searching for the causes or laws of events. For science, the event is discovered by perceiving it, and the further search for its cause is conducted by assigning it to its class and determining the relation between that class and others.

74 W. H. Walsh, 'Colligatory Concepts in History,' in Patrick Gardiner (ed), The Philosophy of History. Oxford University Press: Oxford, 1974. p.134.

75 Collingwood, The Idea of History. pp.205-209. 
For history, the object to be discovered is not the mere event, but the thought expressed in it. ${ }^{76}$

This is to assume that scientific knowledge must be, in some sense, generalised knowledge in order to be given the name "science." And it is the impossibility of doing this in history that Collingwood cites as evidence for history's uniqueness. "If," he writes, "by historical thinking, we already understand how and why Napoleon established his ascendancy in revolutionary France, nothing is added to our understanding of that process by the statement (however true) that similar things have happened elsewhere."77 To this end, Collingwood attempted to devise an epistemology for history which would investigate historical actors as unique particulars. Collingwood still allowed historians to talk about causes, of course. But the causes he held as historically valid were not only mental, but particularistic, and thus (following from the nomothetic assumption) definitionally something other than science. ${ }^{78}$ This was the basis on which Collingwood based his historical epistemology, and the problem to which his "re-enactment" was an attempted solution. With this in mind then, let us turn to other examples of the nomothetic assumption driving the idealist tenet of complete historical autonomy.

\section{The Influence of Benedetto Croce}

With respect to issues of historical autonomy and empathic methods, one of the most influential figures in twentieth century idealism was the Italian philosopher and historian Benedetto Croce. As a philosopher, Croce was instrumental in attempting to provide philosophical justifications for the assertion of historical autonomy. Indeed, Collingwood was greatly influenced by Croce, at one point writing: "Croce has... vindicated the autonomy of history, its right to conduct its own business in its own way, both against philosophy and against science." ${ }^{79}$ This seems a fair assessment, as even a cursory analysis of Croce's philosophy of history reveals an almost maniacal hostility toward the sciences:

Those who undertake the task of creating a new history always succeed in setting up philological history against poetical history, or contemporary history against both of them, and so on. Unless, indeed, as is the case with Buckle and the many tiresome sociologists and positivists of the last ten years, they lament with great

\footnotetext{
76 Ibid., p.214.

77 Ibid., p.223.

78 Ibid., pp.214-215.

79 Ibid., p.201.
} 
pomposity and no less lack of intelligence as to what history is that it lacks the capacity of observation and of experiment... boasting that they 'reduce history to natural science' - that is to say, by the employment of a circle, as vicious as it is grotesque, to a mental form which is its pale derivative. ${ }^{80}$

Croce went much further than merely advocating for the autonomy of history, however. He also believed historical knowledge to be the most fundamental form of all knowledge, to which even the sciences should be subordinate. For Croce, philosophy was the history of philosophy - to truly understand something was to understand its history. ${ }^{81}$ This led Croce to his rather pointed hostility toward the sciences and the respect they were accorded in epistemic matters. Indeed, in his 1917 critical appraisal of the state of historiography, History: Its Theory and Practice, Croce wrote that science was "useless for true knowledge," 82 and that it was history properly understood - that was better suited to truth, as well as being of potentially greater practical use:

... once the indissoluble link between life and thought in history has been effected, the doubts that have been expressed as to the certainty and the utility of history disappear altogether in a moment. How could that which is a present producing of our spirit ever be uncertain? How could that knowledge be useless which solves a problem that has come forth from the bosom of life ${ }^{83}$

Further to this, Croce argued, history in any such grand sense must necessarily be something more than a mere appeal to documentary evidence. Central to Croce's philosophy then, is a division between the raw chronicle - the events of the past as established via documents, and the narrative which gathers them into an explanatory historical account. Such accounts, Croce argued, required something more than mere evidence to create. The additional ingredient, he claimed, was the imagination of the historian. History, for Croce, was "principally an act of thought," whereas mere chronicle was "an act of will." ${ }^{84}$ And this "act of thought" was recognisably empathic in nature:

How could there be a history of philosophy without the works or at least fragments of the works of the philosophers? How could there be a history of a sentiment or of a custom, for example that of Christian humility or of knightly chivalry, without the capacity for living again, or rather without an actual living again of these particular states of the human soul? ${ }^{85}$

80 Benedetto Croce, History: Its Theory and Practice. Douglas Ainslie (trans). Russell \& Russell: New York, 1960. p.46.

81 Ibid., pp.61-63.

82 Ibid., p.311.

83 Ibid., p.15. (emphasis in original)

84 Ibid., p.19.

85 Ibid., pp.14-15. 
Indeed, the very "condition of [history's] existence," Croce claimed, "is that the deed of which the history is told must vibrate in the soul of the historian." ${ }^{86}$ Of the exact nature of this vibration or "living again," however, Croce was somewhat vague. Nor did he offer any practical guidance as to how the historian keen to follow him might cultivate such vibrations.

And so we encounter in Croce these two central tenets of idealism - the necessity of empathy (in the sense of mental/spiritual re-enactment), and a hostility toward the sciences. And while neither was originated by Croce, it was Croce that offered them up to the twentieth century, in a form severely critical of their nineteenth century implementations ${ }^{87}$ Both of these ideas, however, carried within them a perception of scientific antithesis tainted by the nomothetic assumption. While Croce's engagement with the actual arguments of those who espoused "scientific" history was scattershot and vague, only rarely rising above mere condescension, Croce did clearly perceive an oft-overlooked relationship between speculative histories (whether theological or metaphysical), and the naturalistic/positivist strain that succeeded them, and grouped them together under the single epithet of "universal" history:

Universal history really tries to form a picture of all the things that have happened to the human race, from its origins upon the earth to the present moment. Indeed, it claims to do this from the origin of things, or the creation, to the end of the world, since it would not otherwise be truly universal. Hence its tendency to fill the abysses of prehistory with theological or naturalistic fictions and to trace somehow the future, either with revelations and prophecies, as in Christian universal history... or with previsions, as in the universal histories of positivism, democratism, and socialism. ${ }^{88}$

This is an extremely useful insight, and yet, because of it, Croce's treatment of the relationship between "universal history" and his own conceptions of historical knowledge did not specifically address the claims of those who argued for a scientific history (at least in the positivistic sense of causal laws). Instead, he merely emphasised their connection with the grand philosophical structures of thinkers like

86 Ibid., p.12.

87 It might be noted here that the empathic methods of Croce and Collingwood were anticipated somewhat by Dilthey's concept of Verstehen. Unlike Croce and Collingwood, however, Dilthey ultimately wished to somehow fully integrate this concept into the sciences, rather than holding it completely separate. He wrote: "Action everywhere presupposes the understanding of other persons; much of our happiness as human beings derives from being able to feel the states of mind of others; the entire science of philology and of history is based on the presupposition that such reunderstanding of what is singular can be raised to objectivity." See: Wilhelm Dilthey, "The Rise of Hermeneutics (1900), ' in Wilhelm Dilthey, Selected Works, Volume Four: Hermeneutics and the Study of History. Rudolf A. Makkreel and Frithjof Rodi (eds). Princeton University Press: Princeton, 1996. p.235.

88 Croce, History: Its Theory and Practice. p.56. 
Hegel, and summarily dismissed their claims of universality as essentially theological, with naturalism - rather than any particular God or philosophical / metaphysical precept - as the organising principle:

Whoever pays attention to all these and other resemblances which we could enumerate must conclude that positivism is to romanticism as was the enlightenment to the Renaissance - that is to say, it is not so much its antithesis as it is the logical prosecution and the exaggeration of its presuppositions. Even its final conversion into theology corresponds to that of romanticism. This is for the rest an obvious matter, for transcendency is always transcendency, whether it be thought of as that of a God or of reason, of nature or of matter. ${ }^{89}$

This was the extent of Croce's substantive engagement with the arguments of the positivists. Viewing the school of thought as a historically conditioned corruption of the similar systematising impulses of more Romantically aligned thinkers, such as Vico and Hegel, he dismissed it. And yet the manner of this dismissal is instructive. For, as Croce observed, a truly "universal" history must try to "form a picture of all the things that have happened to the human race, from its origins... to the present moment." But if such a history were truly universal, then that understanding ought to be able to transferred into the future, allowing it to be predicted. Thus no truly universal history could be concerned only with the past. ${ }^{90}$ As no attempt to treat history nomothetically had been able to actually accomplish such a goal, it could be concluded that there had either not yet been any truly universal histories, or that such a thing was impossible. Regardless of which of these might have been the case, Croce argued that the form of such a history was starkly at odds with the kinds of questions that historians tend to be concerned with, and that an emphasis on pursuing the study of history in such a manner would likely destroy history as a discipline. Moreover, Croce's specific identification of universality - and more importantly prediction - with positivism strongly suggests that his understanding of science was underwritten by the nomothetic assumption.

There is evidence in the Theory and Practice however, that, regardless of what he himself thought of it, Croce considered this particular nomothetic delusion widespread among historians, opining that "the echo of the noise they made in the world has not yet ceased, and that "everywhere traces of their influence" could be seen. ${ }^{91}$ This conviction that positivism in history was, or had recently been,

89 Ibid., p.305

90 Ibid., p.56.

91 Ibid., p.297. 
widespread was a sentiment that was still being echoed, as we have already seen, by Collingwood in $1946 .^{92}$ Regardless of the validity of this tacit claim that positivism was an all-consuming juggernaut, Croce's fierce advocacy of the autonomy and dignity of history proved highly influential among other early twentieth century historians concerned at the perceived encroachment of science into their discipline. What Croce's work did not do however, was engage with the substance of the scientific reasoning behind the positivist position. Nor did it say much of the methods by which history ought to be practised beyond vague exhortations regarding intuition and imagination. Thus, those influenced by him were free to substitute their own (usually inadequate) understandings of a scientific position that Croce had told them they were diametrically opposed to. For example, the scholar Charles A. Beard, despite being more relativistically inclined pragmatist than Romantic idealist, was nevertheless convinced by much of Croce's rhetoric. ${ }^{93}$

\section{Charles A. Beard}

Beard, along with Carl L. Becker, represented the vanguard of a reaction by the American historical community against the "scientific" conceit of total objectivity they perceived as obsolete, yet still largely dominant, within the practice of history. Both men were - following Croce - exponents of a more relativistic approach that, instead of supposedly "letting facts speak for themselves," emphasised the constructed element of historical facts, and the role of the historian (as well as the time and/or culture in which they operated) in that construction. As Becker, in his paper 'What Are Historical Facts?,'94 argued:

What is it that leads one historian to make, out of all the possible true affirmations about the given event, certain affirmations and not others? Why, the purpose he has in his mind will determine the precise meaning which he derives from the event. The event itself, the facts, do not say anything, do not impose any meaning. It is the historian who speaks, who imposes a meaning. ${ }^{95}$

Beard, for his part in this argument, used no less visible a medium than his 1933

92 While the influence of actual positivists has been more realistically assessed by more modern scholars. See: Christopher Parker, 'English Historians and the Opposition to Positivism,' History and Theory. Vol. 22, No. 2 (May 1983). pp.120-145.

93 For more on the direct influence Croce had on Beard, see: Ellen Nore, 'Charles A. Beard's Act of Faith: Context and Content,' The Journal of American History. Vol. 66, No. 4 (March, 1980). p.852,856.

94 This paper was delivered in 1926, but not published until 1955. See: Carl L. Becker, 'What Are Historical Facts?,' The Western Political Quartlerly, Vol. 8, No. 3 (September 1955). pp.327-340.

95 Becker, 'What Are Historical Facts?,' p.335. 
presidential address to the American Historical Association ${ }^{96}$ to question the definitions and operating assumptions of the discipline:

What is this manifestation of omniscience called history? It is, as Croce says, contemporary thought about the past. History as past actuality includes, to be sure, all that has been done, said, felt, and thought by human beings on this planet since humanity began its long career. History as record embraces the monuments, documents, and symbols which provide such knowledge as we have or can find respecting past actuality. But it is history as thought, not as actuality, record, or specific knowledge, that is really meant when the term history is used in its widest and most general significance. It is thought about past actuality, instructed and delimited by history as record and knowledge - record and knowledge authenticated by criticism and ordered with the help of the scientific method. ${ }^{97}$

While this is certainly a Crocean perspective - placing primacy as it does on human cognition and the role of the historian's imagination in the recovery of the past - it can also be seen that Beard was not as sceptical as Croce regarding the utilisation of what he terms "the scientific method." Yet, later in the same address, Beard alleges that the "intellectual formulas borrowed from natural science" had "cramped and distorted the operations of history as thought." 98

This apparent tension between endorsement and condemnation of science, seems incongruous, and indeed it is. This has been remarked upon before. Hans Meyerhoff, for instance, in his introduction to a reproduction of Beard's address, argues that this "curious wavering between a criticism of scientific conceptions in history, on the one hand, and the final endorsement of the scientific method, on the other" is the "most significant contribution" of the article, and that Beard, "never reached a satisfactory middle ground between his polemics against the pretensions of the scientific method in history and his awareness that some standards of truth and objectivity are necessary in order to be a responsible historian." ${ }^{99}$ Peter Novick, in his classic That Noble Dream: The "Objectivity Question" and the American Historical Profession, also notices this tension - albeit in passing - arguing that Beard, "clung to a distinction between the allegedly direct and immediate observations of the natural scientist, and what the historian saw through a glass darkly, privileging the former." ${ }^{100}$ Neither

96 Charles A. Beard, 'Written History as an Act of Faith,' The American Historical Review. Vol. 39, No. 2 (January 1934). pp.219-231.

97 Ibid., p.219.

98 Ibid., p.222.

99 Hans Meyerhoff, 'Introduction to Charles A. Beard's 'Written History as an Act of Faith," in Hans Meyerhoff (ed), The Philosophy of History in Our Time: An Anthology. Doubleday / Anchor: New York, 1957. p.138.

100 Peter Novick, That Noble Dream: The "Objectivity Question" and the American Historical Profession. Cambridge University Press: Cambridge, 1988. p.278. 
author, however, offers any explanation for this tension other than tacitly ascribing it to Beard's own confusions, whatever form they might have taken. We, on the other hand, are in a position to do somewhat better. For it would be more accurate to say that Beard's confusion was the result of a nomothetic assumption about the nature of science, and that the failure of Meyerhoff and Novick to realise this is due to their blindness to the existence of that assumption. Indeed, hints to this effect are abundant throughout Beard's presidential address. Immediately after his assertion that the desire to ape science had "cramped and distorted the operations of history," for instance, Beard argues that this desire had taken two distinct forms - that of physics, and that of biology:

The first of these [the physical] rests upon what may be called, for convenience, the assumption of causation: everything that happens in the world of human affairs is determined by antecedent occurrences, and events of history are the illustrations or data of laws to be discovered, laws such as are found in hydraulics. ${ }^{101}$

Of this physical conceit, Beard argued that while "no historian has ever been able to array the fullness of history as actuality in any such deterministic order," the mere assumption that it was even possible had acted to mislead the Western historical community. Further to this, those historians who had concerned themselves with this task had failed to comprehend the conceptual flaws within it, attributing "any shortcomings in result to the inadequacy of their known data, not to the falsity of the assumption on which they have been operating." ${ }^{102} \mathrm{He}$ continued:

Undiscouraged by their inability to bring all history within a single law, such as the law of gravitation, they have gone on working in the belief that the Newtonian trick will be turned some time, if the scientific method is applied long and rigorously enough and facts are heaped up high enough... ${ }^{103}$

This then is the nomothetic assumption once again espoused - the definition of science as the identification of the "laws" which governed the operation of the universe, and the accompanying implicit assumption that such laws represent total explanation of the phenomena that are consequences of them. Beard's statement then, offers some insight into how he thought about science, although it alone does not amount to an explicit endorsement of the nomothetic view. All Beard is really saying here is that the physics model had been shown to be inappropriate for history. This view of the relationship between science and history is qualified somewhat by Beards 101 Beard, 'Written History as an Act of Faith,' p.223.

102 Ibid.

103 Ibid. 
assessment of the second form by which he alleged history had attempted to imitate the natural sciences - the biological:

Growing rightly suspicious of this procedure in physico-historiography, a number of historians, still bent on servitude to natural science, turned from physics to biology. The difficulties and failures involved in all efforts to arrange the occurrences of history in a neat system of historical mechanics were evident to them. But on the other side, the achievements of the Darwinians were impressive. If the totality of history could not be brought into a deterministic system without doing violence to historical knowledge; perhaps the biological analogy of the organism could be applied... So under the biological analogy, history was conceived as a succession of cultural organisms rising, growing, competing, and declining. ${ }^{104}$

This view has the advantage of acknowledging the impact of Darwin on the philosophy of science and tacitly recognises the resulting movement away - if only in practice rather than theory - from a strictly mechanistic, law-bound view of science. This is an acknowledgement not seen in Croce or Collingwood, and, to that extent, represents a better awareness (if not understanding) of the state of then-current scientific thought on Beard's part. Yet this picture, while recognising the change Darwin (among others) had wrought in scientific practice, fails to adequately recognise what was truly important about that change. For Beard goes on to implicate this biological approach as sharing the same flaws by which he dismissed the "physical," and thus claims to have achieved a reduction of the "Darwinian" view to the same crude determinism. "The organismic theory of history," he claimed, "is really the old determinism of physics covered with murky words." Thus both approaches are essentially the same, and turn "finally upon the applicability of the deterministic sequence." ${ }^{105}$ And it was exactly this that Beard considered the very definition of science when he came, later in his address, to address that issue directly:

Natural science in a strict sense, as distinguished from mere knowledge of facts, can discover system and law only when occurrences are in reality arranged objectively in deterministic sequences. It can describe these sequences and draw from them laws, so-called. From a given number of the occurrences in any such sequence, science can predict what will happen when the remainder appear. ${ }^{106}$

This then, is as clear and unambiguous an illustration of Beard's nomothetic assumption regarding science as one might find in any of his writings. In this view, whether one follows the physical or the biological model is of no consequence, as the

104 Ibid.

105 Ibid., p.224.

106 Ibid. 
essential nature/problem of each is the same. Both resolve into a deterministic assumption of cause and effect that (in a conflation similar to that seen with Trevelyan and Collingwood's reading of Bury) Beard translated into a nomothetic assumption of the necessity of law, making a leap that presumably seemed selfevident. So, while Beard endorsed a "scientific method" in history which (although he did not explicitly define it) he claimed as the "only method that can be employed in obtaining accurate knowledge of historical facts, personalities, situations, and movements," his identification of a nomothetic model with science as a whole caused him to reject the possibility of a scientific history. ${ }^{107}$ If a science of history in this sense were possible, he argued:

... it would, like the science of celestial mechanics, make possible the calculable prediction of the future in history. It would bring the totality of historical occurrences within a single field and reveal the unfolding future to its last end, including all the apparent choices made and to be made. It would be omniscience. The creator of it would possess the attributes ascribed by the theologians to God. ${ }^{108}$

To state such a case, Beard argued, "is to dispose of it." 109 If history could not predict the future - like "celestial mechanics" - from a handful of universal, unchanging laws, then it was not truly a science. All that was left of the scientific position worth defending then, was an ill-defined "scientific method" which was, in Beard's hands, largely a shorthand for the standards of evidence and source criticism held over from the Rankean practice of the American historical community. ${ }^{110}$ From this it seems reasonable to conclude that this was the source of the confusion remarked upon by both Meyerhoff and Novick. Because Beard defined even post-Darwinian science in this exclusively nomothetic sense, he therefore considered science and historically fundamentally incompatible - at least in terms of their aims, if not their methods.

\section{Carl L. Becker}

Carl Becker, by contrast, did not treat as extensively of science as Beard did, and so his thinking on the subject cannot be inferred in anything like the above level of detail. It has been shown, however, that Becker was - like Beard - influenced in his historical relativism by Benedetto Croce. ${ }^{111}$ In addition to this, there are hints

107 Ibid., p.226.

108 Ibid., p.224.

109 Ibid.

110 Novick, That Noble Dream. pp.26-40.

111 While Becker, like Beard, also exhibited some of the influences of American pragmatism, there is strong evidence that the basis of his historical thinking was Crocean. Indeed, Becker himself said as 
regarding his attitude toward scientific history scattered throughout his works. For example, in his own presidential address to the American Historical Association in 1931, entitled 'Everyman His Own Historian,'112 Becker expressed considerable concern at the possibility of the true nature of history being "camouflaged by the disfiguring jargon of science."113 This famed speech, however, was primarily an endorsement of historical relativism concerned with the reduction of history to "its lowest terms," as one would reduce a mathematical fraction. This reduction Becker claimed to have achieved in his definition of history as "the memory of things said and done."114 Focusing on the term "memory" in this definition, Becker devoted the bulk of his address to articulating the methods by which human cognition "creates" history and to the role of the present in shaping interpretations of the past. While these are classic Crocean idealist concerns carried over into the American pragmatist/relativist traditions, Becker had less to say in 'Everyman' about his own views on the relationship between history and science, other than to hint at his dissatisfaction with the "scientific history" of the previous century:

To establish the facts is always in order, and is indeed the first duty of the historian; but to suppose that the facts, once established in all their fullness, will 'speak for themselves' is an illusion. It was perhaps peculiarly the illusion of those historians of the last century who found some special magic in the word 'scientific.' The scientific historian, it seems, was one who set forth the facts without injecting any extraneous meaning into them. ${ }^{115}$

So Becker's understanding of science (at least as it applied to history) appears to have been less concerned with the generalising impulse than Beard's, hinging instead on claims of objectivity - a specific conceit he ascribes to the "scientific historians" of the nineteenth century. Indeed, musings on the twin questions of objectivity in history and the nature of historical "facts" make up the bulk of Becker's reflective writings on the subject. Thus, while Becker often sought to contrast the pretensions of

much, in response to an invitation to name European and American works that had influenced his thinking, stating "Croce's History and the Writing of History helped to shape my ideas about History, which I set forth in the address 'Every Man His Own Historian."' It should also be noted that, in addition to this, 'Every Man' explicitly deployed Croce's idea of "living history" in service of its argument. See: Chester McArthur Destler, 'The Crocean Origin of Becker's Historical Relativism,' History and Theory. Vol. 9, No. 3 (1970). pp.335-336.

112 Carl L. Becker, 'Everyman His Own Historian: Annual Address of the President of the American Historical Association, delivered at Minneapolis, December 29, 1931,' American Historical Review. Vol. 37, No. 2 (January 1932). pp.221-236. It should be noted here that some sources spell this as "Everyman" rather than "Every Man." Becker appears (if those who have transcribed/reprinted him are to be trusted) to have used both spellings at various points in his own correspondence. The spellings offered here will therefore simply reproduce those in the particular source being cited.

113 Ibid., p.231.

114 Ibid., pp.221-222.

115 Ibid., p.232. 
objectivity in history with that of the natural sciences, he does not dwell at length upon the nature of the latter. In his early (1910) paper 'Detachment and the Writing of History, "116 however, in a discussion of the "synthesis" of the facts of history into a coherent historical account, Becker offers a hint as to his thinking on the subject:

The problem of synthesis is, indeed, not to record exactly what happened, but by simplification to convey an intelligible meaning of what happened.... This necessary simplification may be achieved, I suppose, in one of two ways: by classification in terms of common qualities, or by grouping in terms of concrete relations. Comparing what is related of all kings... the historian may find that all kings have been crowned. This quality common to all kings is then reduced to a single statement, "all kings are crowned." This is the method of the natural sciences, and of sociology as well. Certainly, it is a method well worth while; but, as we are all are agreed that history is not sociology, it cannot be the method of the historian. ${ }^{117}$

This then would appear to be a tacit statement of the scientific "method" as directed toward the articulation of generalisations and laws. Becker goes on to place such a vision of science in direct opposition to history:

The sociologist has simplified by combining particular facts in a generalization, from which any one can deduce again the particular fact, and no other. The historian has simplified by selecting, from a number of particular facts, certain facts which he considers most important to be known. ${ }^{118}$

"It seems, then," Becker concludes, "that the great point in historical synthesis is selection." 119 This was the epistemological gap between history and the sciences into which Becker sought to drive his relativist wedge. For, if the historical method relies on selection, then that selection must be made by the historian, involving them (and their personal and cultural biases) in the process of history. This opens up the conceptual space required for the relativist critique. To be fair, Becker does not completely absolve the sciences of this same relativism, but it seems to be Becker's perception that the generalising method hinted at above insulates them from its full force, if only because of a lesser ambiguity in their subject matter. ${ }^{120}$ Thus, Becker's entire argument regarding the peculiar nature of history can be understood as being predicated upon this assumed fundamental difference between history and science a difference made possible by the nomothetic assumption.

116 Carl L. Becker, 'Detachment and the Writing of History,' in Phil L. Synder (ed), Detachment and the Writing of History: Essays and Letters of Carl L. Becker. Cornell University Press: Ithaca, New York, 1967. pp.3-28.

117 Ibid., p.16.

118 Ibid., pp.17-18.

119 Ibid., p.18.

120 Becker, 'What Are Historical Facts?,' pp.335-336. 
One thing that must be remembered, given the overall objectives of this thesis, is that the objections raised by these idealist authors against history being treated as a science were entirely accurate - if one accepted the definition of science used to derive them. Their error, as has been seen in the examples offered so far, was in equating science in the narrow nomothetic sense (a model derived from the Newtonian, mechanistic worldview) with science as a whole. In Part Two, we will show that this view is dangerously myopic, and that its dissolution goes a long way to allowing the age-old history/science problem to finally be resolved. Yet, knowing of this error does not diminish the weight of their arguments against the narrow target at which they were aimed - the study of history as oriented toward a search for the "laws of history." The fact remained that all attempts to search for and isolate laws of history which might serve as the historical analogue of laws in physics had been failures. This, combined with the belief that laws were the only permissible form of scientific knowledge, had instilled in the idealists a firm belief in the autonomy of history whatever epistemic mechanism they subsequently advocated. In the wake of the idealist critique then, those who would defend the essential premise of natural laws as being the most fundamental form that knowledge in any field could take, would have to either counter these idealist arguments directly, or modify their underlying thesis in order to accommodate them. It was the desire to do both that gave rise to perhaps the most controversial idea in the history of the philosophy of history - the "covering law" model offered by the philosophers of science Karl Popper and Carl Hempel.

\section{The Covering Law Thesis, or: Laws of History versus Laws in History}

At its simplest, the primary aim of the covering law model was to defend the notion that there was only one legitimate mode of explanation - the scientific. And that scientific mode of explanation could likewise take only one legitimate form deduction from nomothetic laws. Thus Popper and Hempel were not prepared to allow a plurality of knowledge-producing disciplines. For them, all knowledge - or all real knowledge - had to be somehow derivable from laws. This led both men to argue vehemently against not only historical autonomy, but the autonomy of any discipline which purported to generate real knowledge by means of some nonnomothetic epistemology. Because of this, they were also motivated to attack the 
empirically questionable epistemology of empathy which underwrote much of the idealist vision of historical knowledge. The covering law thesis thus represented the first major collision of the philosophy of science and the philosophy of history. For Popper and Hempel (and some subsequent philosophers such as Patrick Gardiner) believed that the central arguments of idealism - that the past is unrepeatable, too complex, or too concerned with human thought processes to be treated scientifically - had to be decisively rejected if history hoped to represent any kind of respectable knowledge. With "respectable" in this context being intended as a synonym for "scientific," and "scientific" being a synonym for the discovery and deployment of general laws. And this, they argued, was really only possible in the light of a radical re-orientation of historical theory and practice. It is thus interesting to note that both the early idealists and the covering lawyers shared the fundamental nomothetic assumption that laws were the incontestable basis of science. However, where the idealists saw this - when coupled with history's failure to either explicitly produce and/or consume laws - as proof of history's autonomy, the covering lawyers saw it as a mark of an immature discipline. Likewise, all subsequent arguments from complexity, unrepeatability, and human mental causation were seen as little more than post facto rationalisations advanced to avoid that conclusion. For the purposes of this thesis, the preceding sketch of some of the key positions of idealism and the nomothetic assumptions which have underwritten them should be understood as providing necessary context for the arrival of covering law theory. For the discussion surrounding this influential theory almost immediately came to utterly dominate mid-twentieth century philosophy of history.

But this is to momentarily get ahead of ourselves. For the covering law model was, at least initially, an attempt to move away from the by-then indefensible idea that one could - through a radical re-imagining of historical method - identify the "laws" of which all of observed (and future) history were merely the consequences. Popper and Hempel instead attempted to focus on the linkage of historical explanations as they were traditionally understood to other general laws of nature. This is the subtle but crucial distinction between laws of history and laws in history. Thus, mid-twentieth century covering law theory was, in a sense, designed to save the idea of laws from an idealist point of view that had drawn considerable intellectual justification from the disappointments of law-seeking positivist authors like Henry Thomas Buckle and Auguste Comte. This idea of sublimating laws in order to enable the wider 
application of a nomothetic model seems to have first surfaced as part of a general theory of explanation in the German text of what was later to become Karl Popper's The Logic of Scientific Discovery, published as Logik der Forschung in 1934. ${ }^{121}$ Later, in The Open Society and its Enemies, ${ }^{122}$ he briefly offered an explanation of the idea as it might relate to disciplines such as history:

To give a causal explanation of a certain event means to derive deductively a statement (it will be called a prognosis) which describes that event, using as premises of the deduction some universal laws together with certain singular or specific sentences which we may call initial conditions.... The initial conditions (or more precisely, the situation described by them) are usually spoken of as the cause of the event in question, and the prognosis (or rather, the event described by the prognosis) as the effect... ${ }^{123}$

Note the compatibility of this statement with the pure Newtonian view of science the predominant source of (and argument for) the nomothetic-deductive model. In that view, for instance, the future position of any planet relative to the Earth could be calculated (or "explained," in Popper's terminology) from two pieces of information: its present position, and the laws that describe its motion. Thus, by Popper's above argument, its position on Christmas Day one hundred years from now is "explained" by the twin facts that it was in one particular position on the day of the calculation and that it, as an object, obeys certain laws. This same explanation however, is also a prediction, given that the event it seeks to explain lies in the future. Since it was - as Popper himself later argued at length in The Poverty of Historicism ${ }^{124}$ - emphatically not the purpose of history to attempt to predict the future, Popper's case for applying this model to history therefore hinged on his assertion of the essential logical unity of prediction, confirmation, and explanation. In other words, Popper argued, "the use of a theory for the purpose of predicting some specific event is just another aspect of its use for the purpose of explaining such an event."125 That is to say - usage matters. "Whether we use a theory for the purpose of explanation, or prediction, or of testing," Popper wrote, "depends on our interest, and on what propositions we take as given or assumed." 126

Assuming the truth of this premise led Popper to draw a three-fold theoretical

121 Karl Popper, The Logic of Scientific Discovery. Hutchinson \& Co.: London, 1959.

122 Karl Popper, The Open Society and Its Enemies, Volume II: The High Tide of Prophecy - Hegel, Marx and the Aftermath. Revised ${ }^{\text {rd }}$ Edition. Routledge \& Kegan Paul: London, 1952.

$123 \mathrm{Ibid} .$, p.262. (emphasis in original)

124 Karl Popper, The Poverty of Historicism. $2^{\text {nd }}$ Edition. Routledge \& Kegan Paul: London, 1960.

125 Popper, The Open Society and Its Enemies, Volume II. pp.262-263.

126 Ibid., p.263. 
distinction between scientific disciplines, based on what "aspect" of explanation was required. His primary distinction was between what he termed "historical sciences" and "generalising sciences." The "generalising sciences," he further subdivided into "pure" and "applied." Pure generalising sciences, like physics, sought to use specific cases in order to establish universal laws. These laws could then be extended to cover cases yet unexamined. By contrast, applied generalising sciences, such as engineering, did not seek to discover new laws, but to use existing laws for prediction and the control of nature. The third category - which conceivably included history were the "historical sciences," which were interested in the explanation of specific events. Since historical sciences were not interested in prediction, Popper reasoned, and because the use of historical data to formulate laws was largely unreliable, this category of sciences must operate under a different relationship to general laws. ${ }^{127}$ To this end, Popper argued, rather than formulate or test laws the historical sciences must "take them for granted." ${ }^{128}$ In other words, while the form of explanation in the historical sciences still depends upon general laws that can link the general to the specific, these are not required to be stated explicitly. Instead, the laws lie implicit behind the statements, functioning as unseen epistemological guarantors of the claims being made. This can be allowed, Popper argued, because the historical sciences are typically limited to the explanation of single specific events. Without any intent to link multiple specific events together through generalisation, there is simply no need for the underlying laws to be brought into the foreground. This addresses the idealist argument that history could not be made scientific because history is the study of the unique particular, and science the general. That might be so, argues Popper, but that alone does not represent evidence that history is somehow inherently unscientific or otherwise beyond the reach of "laws of nature." 129

From this we can see that while Popper retained his positivist conviction that explanation in terms of general laws of nature are the only properly legitimate form of knowledge, he conceded the point that the reduction of knowledge in all areas of enquiry to a handful of laws specific to that discipline was not always possible. Yet, Popper argues, universal laws of some kind are still involved at some point. Thus, key idealist criticisms regarding previous failures of the nomothetic method are answered, and the assumption of a purely nomothetic science preserved. Overall,

128 Ibid., p.262. See also p.264. of the same work: “... as a rule, if we are interested in specific events and their explanation, we take for granted all the many universal laws which we need."

129 Ibid., pp.264-265. 
this is an analysis that is very difficult to fault. Certainly, it avoids the undesirable requirement for the separation of knowledge-generating disciplines into incommensurable epistemic domains. It is not clear, however, that Popper's concession actually solves any real problems of historical explanation. To know that, at some level, we must encounter laws of nature which can underwrite and legitimise our historical explanations is likely to be of little help in many practical questions of historical explanation. For that level might be a great distance (theoretically speaking) from our area of interest, thus making it very difficult to leverage. We might be absolutely certain that the laws of quantum mechanics lie at the root of the attempted coup d'etat in the Soviet Union in the August of 1991 and so could legitimately be called its cause. But merely stating this (i.e., taking the laws involved for granted) does not explain the event.

Carl Hempel's formulation of the covering law theory, however, was a good deal less forgiving. The same basic ideas we encounter in Popper are present in Hempel's work, but are much more fully developed. More importantly, they are formulated with specific reference to human history (as opposed to Popper's much more general "historical sciences"). From the opening lines of his influential 1942 paper "The Function of General Laws in History, ${ }^{130}$ Hempel made quite clear his viewpoint on both science and the claim of idealistic history to exist outside of it:

It is a rather widely held opinion that history, in contradistinction to the so-called physical sciences, is concerned with the description of particular events of the past rather than with the search for general laws which might govern those events. As a characterization of the type of problem in which some historians are mainly interested, this view probably cannot be denied; as a statement of the theoretical function of general laws in scientific historical research, it is certainly unacceptable. ${ }^{131}$

Immediately obvious in Hempel's paper then, are concerns similar to those seen in Popper's work. Both authors, for example, appear to be less concerned with directly countering the argument for the particularity of history than with countering those who would deploy that particularity as an argument against the positivist doctrinal assertion of the logical unity of explanation under a single (nomothetic) model. As William Dray has argued in his own considerations of covering law theory: "it is generally part of the purpose of advocates of the [nomothetic] model to vindicate the

130 Carl G. Hempel, 'The Function of General Laws in History,' The Journal of Philosophy. Vol. 39, No. 2 (15 January 1942). pp.35-48. 131 Ibid., p.35. 
'scientific' character of history - or, perhaps more accurately, to forestall the conclusion that history may operate successfully with procedures and criteria of its own." 132 This is also made clear by Hempel's subsequent assertion that general laws have "analogous functions" in both history and natural science, as well as constituting "the common basis of various procedures which are often considered as characteristic of the social in contradistinction to the natural sciences." ${ }^{133}$ Indeed, later in the same article, he states:

We have tried to show that in history no less than in any other branch of empirical inquiry, scientific explanation can be achieved only by means of suitable general hypotheses, or by theories, which are bodies of systematically related hypotheses. This thesis is clearly in contrast with the familiar view that genuine explanation in history is obtained by a method which characteristically distinguishes the social from the natural sciences, namely, the method of empathetic understanding... ${ }^{134}$

Contained within this claim, however, is the assertion that explanation in any field had to reduce to laws in some way in order to be called scientific - or even an explanation. Clearly Hempel was, like Popper, deeply committed not only to the scientific character of all explanation (and therefore knowledge), but also to an assumption of the purely nomothetic character of that knowledge. As Hempel remarked in a later defence of his ideas:

... the nature of understanding, in the sense in which explanation is meant to give us an understanding of empirical phenomena, is basically the same in all areas of scientific inquiry... the deductive and probabilistic model of nomological explanation accommodate vastly more than just the explanatory arguments of, say, classical mechanics: in particular, they accord well also with the character of explanations that deal with the influence of rational deliberation, of conscious and subconscious motives, and of ideas and ideals on the shaping of historical events. In so doing, our schemata exhibit, I think, one important aspect of the methodological unity of all empirical science. ${ }^{135}$

In this light, the ideological commitments of both authors seem clear. Both Hempel and Popper were defending the argument that all disciplines permitting of any sort of empirical treatment should be reducible to scientific explanation. This is the "methodological unity" Hempel speaks of. All other forms of explanation - whether empathic, theological, intuitionist, or derived from any other epistemological system - were mere sophistry. More importantly, both authors very explicitly defined the

132 William Dray, Laws and Explanation in History. Oxford University Press: Oxford, 1957. p.4.

133 Hempel, 'The Function of General Laws in History,' p.35.

$134 \mathrm{Ibid}$. , p.44. (emphasis in original)

135 Carl G. Hempel, 'Explanation in Science and in History,' in Ronald H. Nash (ed), Ideas in History, Volume II: The Critical Philosophy of History. E. P. Dutton \& Co.: New York, 1969. p.106. 
character of that scientific discourse in exclusively nomothetic terms. Indeed, their nomothetic assumptions were less the tacit expression of received wisdom (as seen in the authors already examined) than consciously adopted and staunchly defended positions. From this it follows that, in order to uphold this "methodological unity" argument, both authors were required to find a way to logically tie universal laws to history, or else their positions would become untenable. ${ }^{136}$ Therefore, it is not surprising that the bulk of both Popper and Hempel's work on the subject of historical explanation was directed towards the searching out and justifying of examples in which such explanations could be seen as flowing from general laws. With this in mind, Hempel argued for the role of general law in explanation as follows:

The main function of general laws in the natural sciences is to connect events in patterns which are usually referred to as explanation and prediction.... The explanation of the occurrence of an event of some specific kind $E$ at a certain place and time consists, as it is usually expressed, in indicating the causes or determining factors of $E$. Now the assertion that a set of events - say, of the kinds $C_{1}, C_{2}, \ldots, C_{n}$ - have caused the event to be explained, amounts to the statement that, according to general laws, a set of events of the kinds mentioned is regularly accompanied by an event of kind E. Thus, the scientific explanation of the event in question consists of

(1) a set of statements asserting the occurrence of certain events $C_{1}, \ldots C_{n}$ at certain times and places,

(2) a set of universal hypotheses, such that

(a) the statements of both groups are reasonably well confirmed by empirical evidence,

(b) from the two groups of statements the sentence asserting the occurrence of event $E$ can be logically deduced.

In a physical explanation, group (1) would describe the initial and boundary conditions for the occurrence of the final event; generally, we shall say that group (1) states the determining conditions for the event to be explained, while group (2) contains the general laws on which the explanation is based... ${ }^{137}$

This is a vision of explanation in which explicit logical links to "universal hypotheses" are required in order to consider anything explained at all. Hempel, in other words, was considerably less willing than Popper to let laws be simply taken

136 Note however, that this did not mean a commitment to finding specifically historical laws. This is the difference between laws of history and laws in history. Indeed, Hempel explicitly declared agnosticism with respect to this notion: "The considerations developed in this paper are entirely neutral with respect to the problem of "specifically historical laws": they do not presuppose a particular way of distinguishing historical from sociological and other laws, nor do they imply or deny the assumption that empirical laws can be found which are historical in some specific sense, and which are well confirmed by empirical evidence." See: Hempel, "The Function of General Laws in History,' p.47. (emphasis in original). Popper also made this point: "This view of history makes it clear why so many students of history and its method insist that it is the particular event that interests them, and not any so-called universal historical laws. For from our point of view, there can be no historical laws." See: Popper, The Open Society and Its Enemies, Volume II. p.264.

137 Hempel, 'The Function of General Laws in History,' pp.35-36. (emphasis in original) 
for granted. Consider Hempel's example of the fracturing of a car radiator in cold weather. In order to "explain" this (in the technical sense of the term), Hempel argued, one needed to state the initial and boundary conditions (group 1) - the car was left exposed overnight, the radiator was made of iron, the ranges of temperature fluctuation for the time period concerned, and so on. To these conditions, the relevant general laws must be added - water freezes when temperatures drop below zero degrees (at sea level), water expands when it freezes, etc. The evaluation of the initial "group (1)" conditions against the general laws of "group (2)" then allows the deduction of the logical necessity of a fractured radiator. This is Hempel's generalised form of scientific explanation. ${ }^{138}$

While both Popper and Hempel offered their law-based models of explanation in a way they believed was sufficiently generalised to consistently cover history as well as science, there was no doubt that it set the bar of what constituted a legitimate explanation extremely high. Certainly, disciplines like physics and chemistry might recognise themselves in covering law theory - but could such a model adequately cover actual historical explanations? Moreover, if such a model of science could really count history as among its own (without compromising its nomothetic commitments), then why had historical explanation not already taken such a form by the twentieth century? This was especially perplexing given the power the nomothetic method had already displayed in other disciplines. Hempel believed the answer to this question lay in the sheer complexity of interactions historical explanations would be required to account for:

What is sometimes called the complete description of an individual event (such as the earthquake of San Francisco in 1906 or the assassination of Julius Caesar) would require a statement of all the properties exhibited by the spatial region or the individual object involved, for the period of time occupied by the event in question. Such a task can never be completely accomplished.... A fortiori, it is impossible to give a complete explanation of an individual event in the sense of accounting for all its characteristics by means of universal hypotheses, although the explanation of what happened at a specified place and time may gradually be made more and more specific and comprehensive.... But there is no difference, in this respect, between history and the natural sciences: both can give an account of their subject-matter only in terms of general concepts, and history can "grasp the unique individuality" of its objects of study no more and no less than can physics or chemistry. ${ }^{139}$

But even in the face of this complexity and the obvious difficulties of practical

138 Ibid., p.36.

139 Ibid., p.37. (emphasis in original) 
application, Hempel remained unwilling to allow laws to be taken "for granted," as Popper had. For Hempel, any explanations which did not adhere to the strict terms of his nomothetic-deductive model were to be considered "explanation sketches," which consisted of "a more or less vague indication of the laws and initial conditions considered as relevant," which "needs 'filling out' in order to turn into a full-fledged explanation." 140 That is, no explanation could be given - or even merely sketched without some sense being given of how the linkage between general law and specific case might be accomplished. With respect to the practical difficulties of applying such a thoroughly nomothetic model to history, Popper was also forced to concede a similar point:

And our view explains why, in history, we are confronted, much more than in the generalizing sciences, with the problem of its 'infinite subject matter.' For the theories or universal laws of generalizing science introduce unity as well as a 'point of view'; they create, for every generalizing science, its problems, and its centres of interest as well as of research, of logical construction, and of presentation. But in history we have no such unifying theories; or, rather, the host of trivial universal laws we use are taken for granted; they are practically without interest, and totally unable to bring order to the subject matter. ${ }^{141}$

In other words, a greater deal of precision becomes possible as the constraints of time and space are narrowed. Since history frequently deals in such large swathes of both, however, it is necessarily less precise than, say, physics. But the underlying form of knowledge with which both history and science must work is identical. This is a positivistic view of the relationship between history and science in stark contrast with the understanding of, for instance, Beard, who believed that if a scientific treatment of history were possible, it would allow "the calculable prediction of the future in history" and thus amount to "omniscience." 142 Both Popper and Hempel were saying that this was clearly not the case. But while there may not be any universal laws of history, they cautioned, there were certainly laws in history. The linkage between those laws and the events of history in which historians were interested might be long and difficult, but it was there. And for Popper and Hempel, that was enough.

The essential Popper/Hempel thesis was an important advance over the naïve nomothetic positivism so reviled by Collingwood and other idealists in two main ways. First, because it removed the requirement for historians who wished to be 140 Ibid., p.42.

141 Popper, The Open Society and Its Enemies, Volume II. p.264.

142 Beard, 'Written History as an Act of Faith,' p.224. 
"scientific" to generate specifically historical laws. And second, because it allowed history the freedom to investigate and attempt to explain the specific and the particular, which had been denied to it under the nineteenth century vision of positivism advocated by historical law-seekers like Comte and Buckle. Under their view of "scientific history," the particular was only of interest as evidence in support of the historical laws which were the actual aim of the enterprise. All attempts to actually pursue history in such a manner had, however, failed. Popper and Hempel's major achievement was to provide a plausible reason for this failure while preserving not only the nomothetic model of explanation itself, but also its purported universality. Despite such advantages, however, this updated covering law thesis still suffered from serious flaws which prevented it from finding widespread acceptance.

\section{Problems With The Covering Law Thesis}

Notwithstanding the fact that the covering law thesis appears to beg the question by assuming the methodological unity of science in order to prove it, perhaps the most substantial objection to the theory (at least as it applies to history) is the profound disconnect between its explanatory requirements and actual historical explanation. As Alan Donagan has argued:

The most striking fact about the Popper-Hempel theory is that few of the innumerable historical explanations found in the writings of historians even appear to accord with it. The reason why they do not is that few of them are put forward as resting on covering laws, whether explicit or implicit... In short, if the covering law thesis be true, then no historian has yet succeeded in providing a genuine historical explanation. ${ }^{143}$

Of course it is entirely possible that all attempts at historical explanation up until Hempel's time really could have been worthless - if only for not having yet had covering law theory to show them the error of their ways. ${ }^{144}$ But the objection goes further than this. For even if one accepts covering law theory, the kinds of events/objects that the historian wants to explain (and the available sources from which they attempt to do so) would seem to actively resist analysis in terms of covering laws. That is to say, when one is concerned with the explanation of high-

143 Alan Donagan, 'Historical Explanation: The Popper-Hempel Theory Reconsidered,' History and Theory. Vol. 4. No. 1 (1964). p.14.

144 Indeed, dismissing the covering law theory purely on these grounds would seem somewhat akin to dismissing chemistry because accepting it would mean accepting that no alchemist has yet succeeded in providing a genuine chemical explanation. A similar point is made in: Donagan, 'Historical Explanation: The Popper-Hempel Theory Reconsidered,' p.17. 
level phenomena (as history typically is) the formulation of truly general laws and/or universal hypotheses would appear to be prohibitively difficult, if not impossible. For instance, Hempel himself offered one example of an account that explicitly laid out the universal hypotheses on which it proceeded - that of Economic Behaviour, by Donald W. McConnell, et. al. These "laws," were:

People who have jobs do not like to lose them; those who are habituated to certain skills do not welcome change; those who have become accustomed to a certain kind of power do not like to relinquish their control - if anything, they want to develop greater power and correspondingly greater prestige... ${ }^{145}$

But, as Donagan has noted, none of these laws/hypotheses are truly universal. One might welcome the loss of a job one hates, for instance, or embrace change in the form of technology that makes a tedious task less so, and so on. It is not difficult to imagine any number of caveats to these statements, any and all of which might call into question their claim to universality. And all attempts to explicitly formulate "laws" as the basis of a historical explanation, Donagan argued, were vulnerable in the same way. ${ }^{146}$ To suggest that statements like those above are sufficiently robust to act as covering laws is to radically overstate their ability to act as the kind of epistemological guarantees that Popper and Hempel were seeking. For, if such statements are not universally true at all places and times, then the event being explained is no longer an inescapable logical consequence of the initial conditions. This introduces an element of probability, undermining the claim of the resolving statement to be called a "law." Let us illustrate this with a brief thought experiment.

If we allow probabilistic explanations to pass as "laws" in a covering law model of explanation, then the relevant "law" which explains why one is vastly more likely to draw a white marble than black from a barrel containing 999 white marbles and only a single black one can no longer conclusively rule out either possibility. While it would certainly be reasonable to assume that any random marble drawn will be white, ultimately the colour of the marble that will be drawn cannot be unambiguously deduced from the combination of the initial conditions and the relevant principles of statistics. The outcome, despite taking place in a very well-defined system with almost no conceptual ambiguity, cannot be predicted in advance. And thus, by Popper and Hempel's own insistence on symmetry, neither can it be explained. While

145 D. W. McConnell, et. al., Economic Behaviour. Houghton Mifflin Company: New York, 1939. pp.89495. 146 Donagan, 'Historical Explanation: The Popper-Hempel Theory Reconsidered,' pp.14-15. 
this might appear to be an objection motivated purely by pedantry given the overwhelming likelihood of choosing a white marble, it should be noted that the difficulty of determination becomes more pronounced as the proportion of black marbles (relative to white) increases. ${ }^{147}$ This represents a significant erosion of the claim that a strictly nomothetic model of science can function as an epistemological model for all areas of knowledge. This is because it is the showing of an outcome to be necessary that enables laws to be the arbiters of explanation in the first place. If a single probabilistic (or otherwise circumscribed) law can potentially explain both outcomes of a binary, then that power of necessity is lost. And with it is lost the reason for insisting on universal general laws in the first place. We are left with only tendencies and likelihoods. There is nothing wrong with this, of course. Much useful work can be done with such tools. But it is the demonstration of necessity that a truly universal law allows which gives covering laws their power.

Hempel was certainly aware of this objection and the problem it presented to his reasoning. Indeed, he recognised as much in 'The Function of General Laws in History,' stating that, "if Tommy comes down with the measles two weeks after his brother, and if he has not been in the company of other persons having the measles, we accept the explanation that he caught the disease from his brother." ${ }^{148}$ This example, like so many in science and history alike, affords little opportunity for explanation using general laws, as - like the marble example - the conclusion cannot be made inescapable from the initial conditions using only such laws. Despite being guided by a great deal of reliable knowledge of the measles virus and its propagation, the problem as stated is still probabilistic. While it really is highly likely that Tommy caught the virus from his brother, it is at least possible that he could have contracted a different strain blown in from the street. It was the ease with which counter-examples like this could be formulated which later drove Hempel to attempt to formally accommodate probabilistic reasoning into his schema. He attempted this by weakening his assertion that all explanations must satisfy the deductive and nomothetic demands of pure covering law theory. He postulated instead a weaker inductive/probabilistic mode of explanation, which softened the definition of "law" to allow conclusions reached on the balance of probabilities. ${ }^{149}$ This modification,

147 Ibid., pp.6-7.

148 Hempel, 'The Function of General Laws in History,' p.41.

149 Carl G. Hempel, 'Deductive-Nomological vs. Statistical Explanation,' in H. Feigl \& G. Maxwell (eds), Scientific Explanation, Space, and Time. Minnesota Studies in the Philosophy of Science Vol. 3. University of Minnesota Press: Minneapolis, 1962. pp.98-169. 
however, did not satisfy the technical demands of the deductive model. Thus, Hempel effectively renounced his vision of a single mode of scientific explanation, applicable in all areas of knowledge, and in its place offered a binary model: the strong deductive/nomological model, and the weaker inductive/probabilistic. All scientific explanations, however, were still thought to fall into one of these two classes. ${ }^{150}$

Such objections flow from the attempt to pass non-universal assumptions as universal laws. But what of the historical accounts that do not (or cannot) explicitly state their "laws"? What of the surely greater number of works that, as Popper phrased it, take for granted the "host of trivial universal laws" upon which their explanations depend ${ }^{151}$ The temptation, if one could not hope to explicitly formulate the laws upon which an explanation depended, would be to argue that the more fundamental laws of other sciences were doing the heavy lifting here. This is the form of argument Hempel employed in his example of the frozen car radiator. In that example, basic laws of physics and chemistry were what underwrote his (historical) explanation of why a car radiator had frozen. Karl Popper offered another example:

... these laws may be so trivial, so much part of our common knowledge, that we need not mention them and rarely notice them. If we say that the cause of the death of Giordano Bruno was being burnt at the stake, we do not need to mention the universal laws that all living things die when exposed to intense heat. But such a law was tacitly assumed in our causal explanation. ${ }^{152}$

While Hempel's insistence on hard linkages between known laws and explanation seems a good deal stronger than the tacit assumption of Popper's model, it too fails to address the basic issue. For while it is technically true, the deployment of laws and truisms like this do little to actually shape historical explanations. While one would certainly not trust a historical account that got basic facts wrong regarding the operation of the universe, it is of no real aid to the kinds of explanation historians tend to seek to note that, for instance, the Great Fire of London required oxygen in order to burn. Historians tend to be looking for explanation on a different level from this, and while these kinds of laws certainly are, just as Popper and Hempel have said, tacitly involved in any given description of the world (whether historical or not) one does not arrive at an explanation of the cause, or the effects, of the Great Fire by

150 Carl G. Hempel, 'Explanation and Prediction,' in Bernard Baumrin (ed), Philosophy of Science: The Delaware Seminar. Vol. 1. (1962-63) Interscience: New York, 1963. pp.113-116.

151 Popper, The Open Society and Its Enemies, Volume II. p.264.

152 Popper, The Poverty of Historicism. p.145. 
stacking only statements like this to the rafters. As Donagan has said of Popper's above example: "you cannot in such a way explain why Giordano Bruno was sent to the stake, or why he defied his persecutors." 153 Indeed, many very different explanations of such questions could be formulated on the same set of underlying laws. Legitimate historians and Holocaust deniers alike are unlikely to disagree on the kinds of details that Popper and Hempel are talking about, yet their respective accounts could hardly be more different. Doubtless a complete understanding of human beings as a fully deterministic system might allow one to use fundamental general laws to fully describe the kinds of objects and events with which historians are concerned. Yet, even if one possessed such knowledge, the path of explanation from underlying laws of physics to the actions of Napoleon is a long and difficult one - in both conceptual and logistical terms - and one that there is little reason for historians to take. Chemistry might be completely explained by the interaction of matter according to the laws of physics, but this does not mean that chemists are required to be physicists too, or that the principles of chemistry are not a valid shorthand for describing chemical systems at a higher level than their underlying physics. After all, one need not be cognisant of every atom in a solution in order to say something about it as a chemist. And so it is with history. Thus we can add Hempel's version of covering law theory to our earlier assessment of Popper's likely true, but ultimately useless.

Certainly, Popper and Hempel were aware of the problems involved in postulating a system of explanation that relied so heavily on the universality of the statement which linked initial conditions with explanation. Hempel himself acknowledged this, conceding in 'The Function of General Laws in History' that it would "often be very difficult to formulate the underlying assumptions explicitly with sufficient precision and at the same time in such a way that they are in agreement with all the relevant empirical evidence available." ${ }^{154}$ Yet, despite this, the covering law theory as Popper and Hempel advanced it remained strictly predicated on the universality of the covering laws. Hempel stated it thus: "in no other way than by reference to empirical laws [i.e., strictly universal statements] can the assertion of a causal connection

153 Donagan, 'Historical Explanation: The Popper-Hempel Theory Reconsidered,' p.15.

154 Hempel, 'The Function of General Laws in History,' p.40. Of this statement, Alan Donagan has said: "I should add only: it is always difficult, and it has never been done." See: Donagan, 'Historical Explanation: The Popper-Hempel Theory Reconsidered,' p.14. (emphasis in original). Despite this acknowledgement, Hempel did not seem to consider this objection fatal to his theory, retaining the idea of covering laws even in his much later (circa 1962) responses to criticism. See: Hempel, 'Explanation in Science and in History,' pp.79-106. 
between certain events be scientifically substantiated." ${ }^{155}$ Popper's argument differed slightly from Hempel's, factoring in his celebrated notion of "falsifiability" as well as allowing for probabilistic explanation, ${ }^{156}$ but was ultimately of the same form.

\section{The Impact of the Nomothetic Assumption, or: Universality is the Problem}

If it is the case that explicitly defined covering laws can almost never be formulated in such a way as to exclude all exceptions - and thus cannot lay claim to being universal laws at all. And if it is also true that implicit laws of the kind which can be meaningfully said to be universal can only partially determine the kinds of explanatory outcomes historians are interested in, then it would seem that the central problem for covering law theory in either case lies in its insistence on its own universality. And that universality, as deployed by Popper and Hempel, was inseparable from the idea of laws. From this it follows that the real source of weakness in covering law theory is not to be found in its argument for the methodological unity of explanation, but in the fact that that unity was predicated on a nomothetically conceived science. For not only do all of the objections detailed so far evaporate if one drops the insistence that scientific explanations must be reducible to universal general laws, but the central argument that Popper and Hempel conceived their models as a defence of (that of the unity of all knowledge under a scientific aegis) is unaffected. In fact, dropping the emphasis on laws - the supposed primacy of which, it should be noted, both authors considered self-evident and thus never bothered to fully justify - means that even the probabilistic accommodation Hempel made to the strong version of his theory could no longer be seen as an admission of its weakness, but rather an acknowledgement of an ability to also define science as a model-making discipline capable of proceeding at multiple levels of enquiry. This removes the need to slavishly pursue justification in either self-specified "general laws" (which are riddled with caveats and thus subject to dispute), or by recourse to the more fundamental laws of other disciplines (which are broad enough to satisfy the requirement for universality, but can only ever partially justify the kind of explanations being sought). It might reasonably be concluded, therefore, that the root of the problem is the covering law insistence on defining science in a nomothetic manner, rather than history.

155 Hempel, 'The Function of General Laws in History,' p.37. (emphasis added) 156 Popper, The Logic of Scientific Discovery. p.374. 
It must be remembered that Popper and Hempel were philosophers of science rather than history (although they themselves would perhaps not have accepted the distinction), and were therefore on the "other side" of the debate. Thus, their error was the error of Trevelyan, Collingwood, Croce, Beard, and Becker but in reverse. Where those idealist philosophers of history built their positions around a hostility to a science the nomothetic assumption had caused them to misunderstand, Popper and Hempel based their covering law theory (at least as far as it applied to history) on a misunderstanding of the kinds of explanation that historians actually seek. Because of this, both men seriously overstated the ability of nomothetic science to speak to such explanations. Regardless of this, the authors examined in this chapter all have in common that they rigidly define science in terms of laws. This nomothetic outlook conditions their conclusions, and is the source of the supposed incompatibility between history and the sciences. It therefore seems reasonable to conclude that the nomothetic assumption was not merely widespread, but an essentially unquestioned axiomatic premise upon which both idealists and covering lawyers based their respective arguments. We have also seen, in the example of J. B. Bury, just how powerful a distorting effect the nomothetic assumption could have on discussions regarding the relationship between history and science. In that case, it will be recalled, the nomothetic assumptions of Trevelyan and Collingwood so thoroughly coloured their reading of Bury that they ascribed positivistic motives to him for which there was little evidence. With such an assumption being exceedingly widespread throughout early twentieth century philosophy of history, it is therefore not difficult to see how any genuinely new thought on the subject could be similarly distorted - forced into the Procrustean beds of "nomothetic positivist" or "empathic idealist." In such a way the positivist/idealist distinction became essentially selffulfilling. And lastly, we have seen something of the idealist position - particularly its strong commitment to historical autonomy and its emphasis on mental "reenactment" and "empathy" as epistemological methods.

This introduction to the idealist position, apart from having functioned as important context for the arrival of covering law theory, will become more important in the following chapter. For while this chapter has focused on idealist arguments for historical autonomy and their predication upon nomothetic assumptions regarding science, the other key argument associated with idealism - the empathic process by which they imagined history could underwrite its knowledge claims - has been 
introduced to seemingly little purpose. The following chapter will take up this argument in order to show that, however unconvincing the primary arguments of the covering lawyers proved to be, they were at least successful in holding this quasimystical attempt at epistemology to account. This is perhaps the single most notable outcome of the covering law debate, for it motivated those philosophers of history who would dispute Popper and Hempel's assertions (and thus attempt to retain historical autonomy) to renounce naïve idealism and instead offer more formal and empirically defensible models of historical explanation. And it was as a result of this pressure to replace naïve empathic idealism that the idea of narrative first began to emerge. ${ }^{157}$ We will examine this intellectual transformation in more detail in the following chapter.

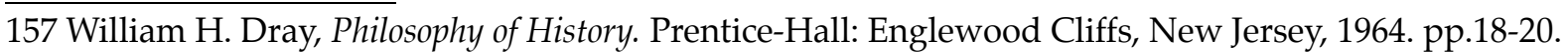




\section{Chapter Two \\ "The Death of Empathy"}

Having now provided some sense of the basic positions at issue in early to midtwentieth century philosophy of history, we are now in a position to begin to examine the debate in more detail. To this end, Chapter Two will examine some of the details of the collision between covering law theory and empathic idealism. This will be done by means of a close reading of two paradigmatic examples, one from each side of this divide. First, Patrick Gardiner, a mid-twentieth century philosopher of history who was somewhat sympathetic to the covering law position. Gardiner has been chosen for inclusion here as his critique of the idealist epistemology of empathic mental re-enactment was among the most thorough ever offered in the context of covering law theory. In contrast to this, his attempt to actually replace idealist empathy with a modification of covering law theory is instructive for its unconvincing and rather contrived character. Secondly, we will examine the work of W. H. Walsh, who rejected any attempt to bring science to history, seeking instead to reform idealism by rejecting the mental re-enactment with which it had been associated and substituting his own concept of colligation in its place. Walsh believed this concept not only better captured the actual form of historical explanations, but was empirically defensible in a way empathy was not. Thus Walsh, like Gardiner, was attempting to replace the flawed idealist notion of empathy. But because the replacement Walsh had in mind was decidedly non-nomothetic, Walsh was able to see himself as formulating "a plausible version of the Idealist theory of history." 158 For this reason, Walsh saw himself as retaining and strengthening the idealist commitment to historical autonomy from the sciences. This is in stark contrast with Gardiner, who saw himself as exporting a single consistent mode of explanation from science into history. Walsh has been chosen for inclusion here because of the clarity of the connection between his own conclusions and the naïve idealism they sought to replace. Walsh's example is also instructive in that it lays valuable rhetorical groundwork for the emerging narrative school of historical philosophy that will be the subject of Chapter Three.

Speaking more broadly, this chapter will argue that the covering law attack as a whole met with, at best, mixed success. Certainly, it was manifestly unsuccessful in

158 W. H. Walsh, 'Colligatory Concepts in History,' in Patrick Gardiner (ed), The Philosophy of History. Oxford University Press: Oxford, 1974. p.134. 
its attempts to reinvent history as an applied nomothetic science. This is hardly a controversial claim, however, as one need only note that while historical theory is very different today, both historical practice and the kinds of questions which interest historians have changed very little since Popper and Hempel's critiques. Our examination of Gardiner will reinforce this point by showing that the tensions between the kinds of explanations historians want and any variant of the nomotheticdeductive model were simply too great to adequately reconcile. Covering law theory was more successful, however, in forcing a re-evaluation of how history saw itself. That is, while a majority of historians and philosophers of history still resisted being integrated into or otherwise made subject to the sciences, the scientifically inspired assessment of how idealist notions of empathy might do epistemological work (or, more precisely, not do such work) forced from them greater efforts at constructing separate systems to formalise historical knowledge. This was the catalyst for the development of narrativism, beginning with Walsh's first halting use of the term as an adjunct to his concept of colligation. Chapter Two will also further the project of Part One as a whole by demonstrating that, despite their position on opposite sides of a theoretical gulf, both Gardiner and Walsh held strong nomothetic assumptions which deeply influenced their respective arguments about the nature of history. These assumptions, it will be shown, not only enforced a perceived need for some way (however contrived) to divide history and the sciences, but were also instrumental in the rhetorical closing off of potentially fruitful avenues of argument. The end result was, despite the discrediting of naïve idealism and the widespread recognition that the historical and scientific worlds were not incommensurable, a strong sense that history and science remained deeply and fundamentally divided. This tendency would go on to infect almost all subsequent twentieth century philosophy of history, and remains common to this day.

\section{The Importance of Empathy for the Covering Law Program}

As hinted at in the previous chapter, one of the key dissatisfactions of the covering law theorists with historical theory was its reliance on concepts of empathy. This was, for instance, one of Carl Hempel's major concerns:

Accounts of this type are based on metaphors rather than laws; they convey pictorial and emotional appeals instead of insight into factual connections; they substitute vague analogies and intuitive "plausibility" for deduction from testable 
statements and are therefore unacceptable as scientific explanations. ${ }^{159}$

Therefore, for Hempel at least, the inadequacy of existing historical epistemology as a whole was deeply linked to his case for history's failure as an explanatory discipline. More importantly, due to the bipartisan nature of the nomothetic assumption, those who sought to resist Hempel's conclusions had nevertheless accepted that laws were the only legitimate form of scientific explanation. Also convinced that history could not proceed nomothetically, they were thus effectively forced to defend historical autonomy from science. To do this, however, they would have to come up with something better than the "metaphors," "emotional appeals," "vague analogies," and other "intuitive" methods which had previously been used to justify historians continuing to offer the kinds of explanations which seemed appropriate to them. And that something would be required, if it were to adequately model existing historical practice, to eschew any direct reference to nomothetic laws, and thus - via the nomothetic assumption - stand completely apart from the sciences. Whatever the merits of the positive arguments of the covering lawyers regarding applying nomothetic forms to the study of history, therefore, the criticism of their negative arguments regarding the inadequacy of existing historical epistemology absolutely had to be met in order to preserve historical autonomy.

\section{Patrick Gardiner and the Assault on Idealism}

What were these arguments against the empathic dimension of idealism exactly? Popper and Hempel themselves had comparatively little to say on the matter. The task of mounting a more comprehensive critique would therefore be taken up by sympathetic philosophers of history rather than science. To this end, let us not only examine Patrick Gardiner's arguments against empathic idealism, but also his proposed solution to the problem it represented. As we shall see, Gardiner was devastating with respect to the former, but less so with respect to the latter. And this failure, it will be demonstrated, is almost entirely attributable to the nomothetic assumption. It is important to note at the outset, however, that Gardiner's criticisms of idealism were almost exclusively based on the kinds of purely empirical arguments (i.e., purged of metaphysics) favoured by the covering lawyers. Gardiner, for instance, had the following to say about Collingwood's idea of empathy as the

159 Carl G. Hempel, 'The Function of General Laws in History,' The Journal of Philosophy. Vol. 39, No. 2 (15 January 1942). p.38. 
"revival" of the thoughts of past historical actors in the mind of the historian:

... even if it were legitimate to regard thoughts and intentions in this way... how, on such an hypothesis, does the historian know that the "revived" thought is the thought the agent in fact had when he performed his action? How does he know that what he calls a "revival" is really a revival? Suppose that two historians both claim to have revived the thoughts and plans of Napoleon on the eve of Austerlitz, and suppose that their accounts diverge. What criteria exist for deciding which is correct? ${ }^{160}$

The point Gardiner is making here is that a certain slipperiness is introduced into historical explanations when one attempts to justify them in this manner. More importantly, such slipperiness was almost entirely a function of the empathic form rather than the quality of the actual account. For however one might wish to resolve such a question of competing mental re-enactments, Gardiner argued, any broadly acceptable decision would likely be the result of an examination of other, mindexternal, evidence relevant to the question. Yet, the problem persists. How can the idealist be sure that the past events/objects which are the cause of the evidence in question produced those particular thoughts within Napoleon's mind? What procedure could be used to check any particular "revival" against such evidence? If such an empathic process really is the epistemic mechanism by which history is to be properly understood (as Croce or Collingwood might have it) then the only way to check such a revivalist account would be with another such account. But here we encounter an infinite regress which renders both the mechanism absurd, and a strong connection with evidence impossible. But if empathy is the epistemology of history, such revivals are absolutely necessary, because without them the result is definitionally not history. Yet it would seem that such revivals are forever beyond the reach of meaningful empirical confirmation. The two realms cannot be meaningfully connected. This approach to the philosophy of history would thus seem to demand the attainment of the unattainable. ${ }^{161}$

Moreover, since such idealist philosophies had been predicated on the "mental" or "imaginative" dimension of history (a characteristic that science supposedly did not possess and that laws could not capture), the empathic argument itself became the primary support for the argument that history was a distinct epistemology apart from the sciences. If empathy were discredited, therefore, then that epistemic

160 Patrick Gardiner, 'The "Objects" of Historical Knowledge,' Philosophy, Vol. 27, No. 102 (July 1952). p.214.

161 Ibid., pp.218-220. 
separation would be called into question. This provided the means by which Gardiner and others sympathetic to covering law theory could claim that a single (nomothetic) model of explanation applied everywhere:

... Collingwood's method of representing historical inquiry as a passage from external behaviour to internal thoughts was unsatisfactory because it led him to the conclusion that historical knowledge consists in the historian's becoming acquainted with entities or agencies subsisting behind, or "inside" the activities of others; and I have given reasons for believing that this conclusion is mistaken. And with its rejection we can dismiss the idea that such knowledge must be sharply differentiated from that involved in other branches of enquiry on the grounds that it is "non-inductive" in character and peculiar in its "objects" or "material."162

Gardiner continued to maintain, however, that a meaningful distinction between "branches of enquiry" could still be made. Indeed, he footnoted the final sentence of the above quote with; "I do not want to suggest that no line can be drawn but only that the line has been drawn in the wrong place and in the wrong way." 163 Gardiner's own arguments regarding where and how such a line should be drawn were outlined in his 1952 book The Nature of Historical Explanation, to which we must now turn. ${ }^{164}$

The Nature of Historical Explanation was, at least in part, an attempt at building a bridge between the covering lawyers and those that Maurice Mandelbaum has called the "reactionists." 165 In it, Gardiner attempted to preserve the best of both worlds. He attempted to import something of the nomothetic model (and the legitimacy it carried with it) into historical explanation, while also preserving the autonomy of history, thus shielding history from the more awkward questions asked by philosophers of science. In this sense, Gardiner, while not a staunch Hempelian, was a good deal more sympathetic to the covering law position than many of his contemporaries. While his success at attempting to remake history was sharply limited by his own acceptance of a nomothetic form as being the only legitimate form of explanation, The Nature of Historical Explanation nevertheless represented one of the first serious attempts to assess the relationship between history and science from outside of the received wisdom of either the old idealism or the new covering law positivism. And his primary concession to the covering law position was in his

162 Ibid., p.219.

$163 \mathrm{Ibid}$. (emphasis in original)

164 Patrick Gardiner, The Nature of Historical Explanation. Oxford University Press: London, 1952.

165 This group consisted of those philosophers of history who, in defence of historical autonomy, offered alternative models of explanation in response to the covering law attack. See: Maurice Mandelbaum, 'Historical Explanation: The Problem of "Covering Laws", History and Theory. Vol. 1, No. 3 (1961). p.229. 
complete rejection of empathy as an epistemological device. As we have already seen, Gardiner's primary problem with idealism was its insistence on a mental dimension to historical explanation that, in his view, could not be satisfactorily connected with evidence. Further to this, Gardiner also argued that this key idealist assertion was inextricably linked to the other pillar of idealism identified in the previous chapter - the strict separation of history and the sciences. These two ideas, Gardiner argued, could not be so easily separated:

The foundation of these views lies in the theory that the subject-matter of history is different in kind from the subject-matter of those studies loosely called the 'natural sciences.' History is a different 'mode of experience,' and the historian must in consequence approach it with methods entirely different from the methods of the natural scientist... To understand history and the writing of it the scientific conception of knowledge must be discarded, and a distinct type of knowledge must be recognised: this type of knowledge has been variously named - it is termed sometimes 'insight,' sometimes 'intuition' or 'empathy,' and sometimes 'recreating past experience'... ${ }^{166}$

In order to demonstrate this, Gardiner makes an interesting philosophical move. As hinted at in Chapter One, the early twentieth century idealists had traditionally begun their chains of reasoning from history's seeming hostility to scientific methods (which were, of course, assumed to be exclusively nomothetic). From this, they had attempted to try to identify something that was supposedly unique to history usually human thought - and build a unique epistemology around it. In other words, empathic re-enactment was seen not as the explicit basis on which the separation of history and the sciences was being advanced, but as a solution to the problem which historical autonomy represented. Gardiner, however, set out to argue that this was largely illusory. All of the major idealist supporting arguments for historical autonomy, he claimed, were utterly untenable without some kind of prior commitment to an empathic model of historical explanation. By arguing in this fashion, Gardiner sought to demonstrate that it was empathy which was the single most fundamental error of idealist epistemology. And so it was empathy which would need to be purged in order to allow a better model of historical explanation to be developed, whether covering law based or otherwise. This then, is where he directed his attack. He writes:

The four propositions often put forward in support of the theory that history is an autonomous branch of study, irreducible in principle to any other, are the following:

166 Gardiner, The Nature of Historical Explanation. pp.28-29. 
A. Historical events are past events and hence cannot be known in the manner in which present events are known.

B. Historical events are unique and unclassifiable.

C. History describes the actions, statements, and thoughts of human beings, not the behaviour of 'dead matter' with which science is concerned.

D. Historical events have an irreducible richness and complexity. ${ }^{167}$

Of the first point - that historical events are removed from direct assessment and thus cannot be "known" in the same fashion as the truths of science - Gardiner argues that this only holds if one considers "true knowledge" to be "knowledge by acquaintance." 168 Yet this would seem to be a very strictly limited sense of the term "knowledge," and far too stringent a predicate for a single theory of explanation. For if what is known can only be based on direct acquaintance, then inference about anything past could be called into question. In other words, this is not an objection unique to the discipline of human history. If the historian cannot be said to have justified an account of a past event without being able to make reference to their own direct experience of that event, then neither can the geologist justify, for example, an account of tectonic upheaval in the distant past. ${ }^{169}$ Both events belong to the unreachable past, all of the relevant "experience" of which has already taken place and passed away. Yet geological inference is not considered problematic in this same fashion. And, to add insult to injury, geology is hardly conducive to an empathic approach. How then is geology to proceed, let alone history?

For the historical example - presumably involving human thoughts and intentions this would appear to be exactly the kind of problem that re-enactment can solve, because it claims to reassemble the past in the mind of the historian here in the present. This theoretically places historical knowledge within the realm of actual experience, thus giving it empirical validity. Yet, as we have already seen Gardiner argue, such an account cannot be meaningfully correlated with mind-independent evidence. Therefore, the problem is only apparently solved by the use of empathy. Moreover, even if empathy could solve the problem of historical inference in the study of human history, it is not a method open to those sciences which study the distant past. And yet there are scientific claims about the past which we feel comfortable calling "knowledge." How are they justified? Gardiner's ultimate point, however, is not merely that knowledge about the past can be established adequately

167 Ibid., p.34.

168 Ibid., p.35.

169 Ibid., pp.39-40. 
in other fields where there is no possibility of re-enactment, but that without any way to connect re-enacted historical accounts with evidence, historians must ultimately appeal to mind-independent evidence in a similar manner to those other fields. ${ }^{170}$ Which, in turn, renders re-enactment utterly superfluous. For instance, Gardiner offers a thought experiment whereby he attempts to convince a hypothetical interrogator of the reality of a trip to "the pillar-box this morning to post a letter.":

I may say that I have a distinct memory of having done so; I may point to the fact that the letter is no longer in my room; I may even produce a witness who affirms that he saw me drop the letter into the pillar-box. By such methods I can produce credentials to substantiate my claim to knowledge of a particular portion of my biography. And a point will come when my questioner will be forced to admit that I have succeeded in establishing my claim. What he will not do is to demand the logically impossible, namely, ask me to point to some event in the past with which I am acquainted when I say that I know that I posted the letter this morning. Thus, to say that we know that such-and-such an event occurred in the past is, in a way, to stake a claim, the claim that, if asked to produce conclusive reasons to justify our statement, we shall be able to do so. ${ }^{171}$

In this way, Gardiner argues that idealist empathy does not offer a solution to the problem of the unreachable nature of the past. Reasoning about the past is, in practice, instead conducted by appeals to evidence. The real work of the philosophy of history then, is to conceptualise how to move from causes in the past to the evidence available in the present. To this, we might only add that the acknowledged historical sciences - including evolutionary biology, paleontology and geology pursue justification for their claims in exactly the same way, and that demonstrating this will be the work of Part Two. Therefore, an appeal to the unreachable nature of the past alone is not sufficient to decisively separate history and science. The difference only appears stark when the given examples are stark - such as the thoughts and intentions of an historical actor contrasted with problems of physical bodies in motion. Thus, for Gardiner, it is an appeal to "bogus mysticism" about the past that is being tacitly invoked to justify the separation, rather than being a necessary consequence of it. ${ }^{172}$

Gardiner summarises the second position - that historical events are unique and unclassifiable - as follows:

History is about what happened on particular occasions. It is not about what 
usually happens or what always happens under certain circumstances; for this we go to science... The historian concentrates upon the event in its unique individuality, regarding it, not as an instance of a type, not as a member of a class, but as something which is to be viewed for and in itself. ${ }^{173}$

This, he continues, is "broadly correct," yet had been used to yield conclusions that were "less defensible."174 First, Gardiner points out that such particularism - if applied naïvely - would preclude any generalisation regarding the past. Yet this is clearly not the case in historical practice, as historians routinely talk of quite general concepts such as nations and revolutions. Clearly then, we cannot simply issue a blanket ban on generalisation and still hope to have much of history left intact. This point will become important in our later discussion of Walsh. The more serious problem, Gardiner argues, is that such a particularism tacitly supposes that "uniqueness" is a quality certain events/objects possess but which the methods and concepts of science cannot apprehend. It is supposed, however, that idealist historians do have access to a method by which that uniqueness can be captured and expressed. And so we are returned to the world of empathy and intuition. By way of example, Gardiner argued the following of Croce:

Croce... in emphasising the unique element in historical judgement, seems to mean more than just this when he speaks of history as 'the narration of individual reality' and contrasts it with the natural sciences. And it is made clearer, I think, what this 'more' is, when we find him saying that history is concerned with 'representations' which are 'individual,' and, again, that the intuitive faculty essential to historical research is bound up with... 'living again' past events. ${ }^{175}$

In other words, the term 'unique' is being reserved specifically for that which can be intuited. Thus, the supposedly special epistemological status of history is not being forced upon it by the special requirements of its unique subject matter, but the other way around. ${ }^{176}$ It should be noted, however, that Gardiner is not entirely unconvinced by the uniqueness argument in general, but only by the specific assertion that uniqueness is the criterion which eliminates the possibility of science from history and thus (by default) establishes the idealist view of history:

... the point at issue is whether our recognizing that the historian's job is to describe and explain what happened upon specified occasions also involves our believing that historical events possess some absolute uniqueness which necessitates their being known and explained in an especial way. ${ }^{177}$

173 Ibid. (emphasis in original)

174 Ibid., p.41.

175 Ibid., p.42.

176 Ibid., pp.43-44.

177 Ibid., p.42. 
Of the third point - that history is fundamentally concerned with the "actions, statements, and thoughts of human beings, not the 'dead matter' with which science is concerned - Gardiner invokes Collingwood's familiar "inside-outside" division. ${ }^{178}$ And, once again, Gardiner argues that this distinction is set up by Collingwood in order to validate his idealist ideas of empathy, rather than to show empathy to be a necessary consequence of it. Gardiner is not unsympathetic to the basic idea of Collingwood's division, however, stating that, "we must agree that the distinction formulated in the above terms between history and science holds good in so far as we do not explain the movement of a 'piece of matter' by referring to its intention, whereas we may explain a human action by making such a reference." ${ }^{179}$ Yet, he is not convinced that this argument necessitates the further step of adopting the empathic model of historical explanation:

... the introduction of a spatial metaphor gives the impression that what are called the 'insides' of events are queer objects, invisible engines that make the wheels go round. And it is only too easy to move from this to the supposition that, in order to 'know' the insides of historical events (where 'knowing' is knowing by acquaintance) some peculiar technique for looking at these is required... ${ }^{180}$

With respect to these three classical arguments for historical autonomy, Gardiner argued that none of them successfully demonstrated the necessity of the idealist/intuitionist viewpoint, and thus were not reliable evidence for that viewpoint. This is not to say they do not have their merits. Indeed, as we have seen, Gardiner was somewhat sympathetic to all three of these arguments for autonomy, but believed they needed to be justified independently of their idealist contexts. His intent was to show that the boundaries of history and science as they had previously been drawn tacitly invoked empathy, and were (to that extent) illegitimate. Yet, throughout The Nature of Historical Explanation, Gardiner was also careful to repeatedly point out that he considered some division of history and science legitimate. Which raises the question: given Gardiner's potent criticisms of the divisions established by the idealists, on what basis could this be done? The answer, for Gardiner, lay in the nature of science itself.

This commitment to separating history and science must be borne in mind, as we turn to the last of Gardiner's pillars of the idealist argument for historical autonomy -

178 R. G. Collingwood, The Idea of History. Revised Edition. Oxford University Press: Oxford, 1994. p.213.

179 Gardiner, The Nature of Historical Explanation. p.47.

180 Ibid., pp.47-48. 
the contention that historical events have an irreducible richness and complexity. Gardiner's approach to this issue differs from that of the previous three arguments, however, for it is here that he makes explicit his own arguments for the placement of a boundary between history and science. History, he concedes, does often present philosophers with "huge chunks of fact that obstinately refuse to fit into the tidy compartments of a scientific system." In fact, he continues, the potential subject matter from which history might be fashioned "spills over, and swamps us in its variety and its richness; confuses us with its queer habit of being highly general and minutely particular at one and the same time." 181 Gardiner's issue with this argument, therefore, is not strictly empirical or definitional - as was the case with the previous three. Instead, Gardiner rejects this argument because it suggests that there is "something 'wrong' with history" for having this quality. ${ }^{182}$ That is to say, Gardiner objects to the assertion that the inability to generalise about history in a manner recognisably scientific represents a problem in need of correction. Instead, he argues, the problem is one of purpose:

If 'wrong' is persuasively defined to mean 'lacking the structure of a developed science' then we must agree that there is something wrong with it. But why should history possess such a structure? We have seen already that the historian is not interested in formulating general hypotheses or in making predictions; he is interested principally in finding out what happened and in describing what happened in all its detail... ${ }^{183}$

In other words, Gardiner is defending history from the charge that it is a second-class epistemological citizen, by instead claiming that history has different intentions which it makes sense to realise by different means. This represents a softening of the rigid idealist separation between disciplines, but not its dissolution. Which is fine, except that Gardiner's defence has the unfortunate consequence of implying that "finding out what happened" and "describing what happened in all its detail" are purposes that scientists cannot have. Thus, by expanding the freedom of movement for historians, Gardiner has inadvertently contracted it for scientists (if one insists on considering them fundamentally separate fields). Moreover, it seems abundantly clear that the "tidy compartments" of scientific systematisation Gardiner has in mind are strictly nomothetic. For example, in the opening pages of the The Nature of Historical Explanation, he clearly states:

181 Ibid., p.51.

182 Ibid., p.52.

183 Ibid., p.54. (emphasis in original) 
The progress of science has been a constant movement in the direction of subsuming known laws under laws of higher generality and of a consequently wider application. Thus explanation, both in science and common life, implies the formulation of laws or generalizations. ${ }^{184}$

A statement such as this would appear to make very clear the meaning of Gardiner's somewhat more modestly worded subsequent assertions. For instance, he later states that the "crux of the distinction between the historian and the scientist" is that "the scientist frames hypotheses of precision and wide generality by a continual refining away of irrelevant factors." But this is merely the nomothetic model in somewhat softer words. The historian's aim, on the other hand, is "to talk about what happened on particular occasions in all its variety, all its richness." ${ }^{185}$ Similarly vague invocations of a supposedly self-evident difference between "general" and "particular" would subsequently come to be a feature of almost all twentieth century philosophy of history which had among its aims the preservation of historical autonomy. The vacuity of this dichotomy thus became the verbal swamp in which a lack of rigour could hide (which was arguably precisely the service terms like "intuition" and "empathy" had provided for idealists like Croce and Collingwood). But this difference in approach is only apparent, for if we engage in close readings of philosophers who invoked this kind of separation, we can find reliable evidence of nomothetic commitments underlying their vague uses of the term "general." Indeed, this is precisely what is meant by the term "vestigial" nomothetic assumption. Ultimately then, "general" would come to stand in for "nomothetic." This was done in order to preserve a world philosophers of history understood - one in which they had as little to do with the sciences as possible. We will encounter this development at greater length in Chapter Three.

Therefore, while Gardiner was an extremely important figure in engineering a break with idealism and in outlining the desiderata of a post-idealist model of historical explanation, his insight could only carry him so far. The primary achievement of The Nature of Historical Explanation was to recast historical autonomy as a consequence of explanatory purpose rather than as a necessary consequence of history's subject matter. This in itself was no mean feat! Gardiner had essentially succeeded in unifying the worlds of history and science - making clear that it was only the way in which they were discussed that separated them, and not some metaphysical and

184 Ibid., pp.4-5.

185 Ibid., p.60. 
epistemic chasm. Gardiner's emphasis on a purely nomothetic model of science, however, still sanctioned a de facto separation:

To conclude, we may, if we choose, say that the subject-matter of history is different from that of science. But we must be careful. We must not take this to mean that the historian is dealing with queer entities, lying about the world or salvaged from the deep-sea forests of the past. The world is one: the ways we use to talk about it, various. And the fact that in some cases we decide to describe it in one way rather than another is contingent upon our purposes. ${ }^{186}$

And so, we can see in Gardiner a clear example of exactly how the entire argumentative structure of the philosophy of history was shifting in the midtwentieth century in response to covering law theory. And yet we can also see in Gardiner a clear example of how the nomothetic assumption survived this shift and continued to exercise a profound impact on how history's relationship to the outside world of knowledge was conceptualised. Where Gardiner might have helped to make history more epistemologically respectable by at least bringing the content of history and the content of science into the same world (an improvement over the largely 'non-overlapping magisteria'187 of Collingwood and Croce, at least), he had also reaffirmed the autonomy of history on the basis of its incompatibility with the nomothetic assumption. This is the reason we have examined Gardiner at such length here. His work represents a paradigm case of how the grammar, but not necessarily the conclusions, of the philosophy of history were changing in the midtwentieth century. All of the subsequent philosophy of history with which we shall subsequently deal, regardless of the conclusions reached, has prosecuted the debate on those terms Gardiner had laid out. These terms were: the primacy of empirical means of confirmation (rather than confirmation by imaginative means), and the banishment of any claim that historical knowledge was rooted in some wholly other realm of mind and thought. In short, the old idealist arguments had been decisively marginalised and the way for narrativism paved, yet some form of separation between history and science was still effectively received wisdom.

\section{Making History Look Nomothetic}

Before closing the book on Gardiner, however, it will prove instructive to examine his own attempt at a model of historical explanation. For when one considers Gardiner's

186 Ibid., p.61.

187 This is a phrase borrowed from Stephen Jay Gould. See: Stephen Jay Gould, 'Nonoverlapping Magisteria,' Natural History. 106 (March 1997). pp.16-22. 
positive contribution to the problem of historical explanation (which he himself had helped to frame through his dissolution of idealist empathy), the nomothetically inspired character of his separation between history and science becomes even more apparent. For, as we have already seen, Gardiner accepted the legitimacy of the most basic thesis of the covering lawyers - that general laws must lie at the root of all claims that might meaningfully be called "knowledge." This, coupled with his assertions that the old idealist arguments that sought to keep science out of history were inexcusably weak, meant that he was required to explain (or explain away) the seeming inability of history to work profitably with the language of laws. Moreover, whatever replacement for empathy he might devise should ideally retain at least something of the nomothetic form. Gardiner sought to harmonise these goals by arguing that while historical method "as a whole is intelligible on the above [covering law/regularity] interpretation," it was necessary that "important differentiating characteristics" of historical explanation be kept in mind. ${ }^{188}$ The primary differentiating characteristic Gardiner had in mind, however, was history's frequent concern with assessing the motivations and intentions of historical actors precisely the problem empathy had purported to be a solution to. Gardiner's solution was to postulate a second mode of explanation which would exist alongside covering law orthodoxy, but still reproduce its basic form. This mode was to be concerned exclusively with this problem of "mental causation," thus replacing implicit appeals to empathy with a recognisably nomothetic structure. Gardiner argued for this as follows:

Historians do not... confine themselves to giving explanations of human actions which refer to various types of what might be called 'physical' or 'publicly observable' events, such as, for example, the actions of other human beings, earthquakes, cold winters, the publication of proclamations, and so forth. When they do give explanations of this kind we have argued that their procedure presupposes the assumption of causal laws... But in history, as well as in ordinary life, explanations are also given that seem to be different: we come across statements of the form ' $x$ did $y$ in order to achieve $z$ ', ' $x$ intended to achieve $z$, therefore he did $y^{\prime}$, ' $x$ did $y$ because he desired $z$ '... Historians, in fact, in many of their explanations of human conduct make reference to the intentions, desires, thoughts, plans, and policies of the people in whom they are interested. ${ }^{189}$

The mechanism Gardiner offered in an attempt to solve this problem of "intentions, desires, thoughts, plans, and policies" was designed to harmonise all of his beliefs regarding historical explanation. To do this, he sought to exploit the seemingly very

188 Gardiner, The Nature of Historical Explanation. p.65.

189 Ibid., p.114. (emphasis in original) 
different ways in which scientists and historians used the term "cause." For rather than maintaining that "words like 'intentions' or 'aims' function as names of causal processes or events," in the same sense as the covering lawyer might speak of a stone causing a window to shatter and then seeking to explain that process with reference to general laws of motion, Gardiner argued instead for an interpretation of mental causation which used the term "cause" in a very different sense. "I want to suggest," he writes, "that to say that man's actions are guided by such-and-such an intention is to make a statement of varying degrees of complexity about him (not about him plus the intentions or aims which influence, affect, or 'act upon' him)." This has the effect of making the character of the agent in question do the explanatory work in cases of mental causation that laws are required to do in cases of natural causation. It sets the actions of an agent within "a pattern, the pattern of his normal behaviour."190 Superficially, this makes a good deal of sense. It neatly preserves the idealist notion of history as a realm comprised of human thought and action by sidestepping the primary consequence of the universality of covering law theory: the requirement to explain the actions of a human being in terms of general laws somehow external to them.

In Gardiner's model, instead of explaining human behaviour with reference to the laws of physics (or specially formulated laws of history), we explain it by reference to other examples of human behaviour. The actions of, for example, Sir Walter Raleigh in supposedly throwing his coat over a puddle so that Queen Elizabeth might cross without getting her feet wet might be explained with reference to examples of his other actions - perhaps his sense of patriotism, or his attitude towards women, or both. This would allow us to get a sense of his character. Raleigh acted the way he did, we might claim, because he was that sort of person. Such explanations have two important advantages for Gardiner. First, they can be settled with mind-external evidence rather than requiring recourse to empathy. That is, we can point to evidence of Raleigh's other actions/behaviour throughout his life, and reason that the best explanation for these groups of evidence is the possession of a certain disposition. And second, they allow for a much closer agreement between covering law theory and historical practice. For historians are clearly far more likely to want to talk of an historical actor in dispositional terms than in terms of psychological generalities or neuron firings. ${ }^{191}$ Gardiner was therefore of the opinion that his dispositional mode of 
explanation could bring something of the structure of laws to human history, as the singular actions and decisions of individuals were still being explained (that is, deduced) from more general statements regarding that individual's overall life and behaviour. This was, in other words, the nomothetic-deductive method at the scale of the individual, carefully slotted into the space empathy had left behind and disturbing the existing theory, practice and - most importantly - boundaries of history as little as possible.

However, while dispositional explanations seen in this way might seem to have a certain "law-like" quality, claiming as they do to explain actions based on patterns of "normal behaviour," there can be no evading the fact that they represent a modification to a theory which claimed that no modifications from it were possible. Gardiner might argue for mental causation as a necessary exception to that universality, but this, as William Dray has countered, “invites the question: 'If one, why not many such logical differences, provided that recognition of them is forced upon us by a consideration of the way historians' explanations go?"' 192 In other words, the covering law approach was predicated on the universality of a single, nomothetic, form for all knowledge and explanation. Modifications of it, therefore, could only constitute evidence for its overall weakness. In addition to this, the use of personal disposition as a substitute for general laws of nature is not only theoretically dubious, but empirically unconvincing. For the kinds of historical problems it can solve are comparatively few when compared to those that remain. While it makes sense when applied to the personal actions of historical actors, it offers no help to the historian pursuing problems and explanations that can only be made sense of at higher levels. For example, there are no known laws which can be used to explain the behaviour of corporations, or social/economic classes of people, or nations as a whole. Yet Gardiner's dispositional analysis does not offer an alternative means to talk about such entities. Certainly, one might speak of the "desires" of the working classes, or the "intentions" of the Dutch East India Company, but it is far from selfevident that these kinds of dispositions actually exist in any sense other than a kind of crude shorthand. If such entities could be said to have dispositions at all, they would likely have to be defined (if one insisted on dispositional traits as being fundamental to historical knowledge) as some kind of aggregate of the individuals which make up that entity.

Press: London, 1957. pp.18-19. 192 Ibid., p.16. 
Which, to be fair, did seem to be Gardiner's intent. His work is replete with examples of political history centred around the actions of individuals, often using classic examples such as Napoleon, ${ }^{193}$ Cardinal Richelieu, ${ }^{194}$ and Julius Caesar ${ }^{195}$ to illustrate key points. And, when confined to such circumscribed examples, it must be said that his dispositional explanation makes some sense. But there is little explanatory help in The Nature of Historical Explanation for the social historian, or the economic historian, or indeed any branch of historical enquiry sufficiently distant from both covering laws and the motives of historical individuals. Gardiner readily concedes the difficulty of high level history, stating that "historical explanation is often an extremely complicated affair." 196 But he offers no solution other than to restate his conviction that regularities must underlie any model of explanation:

There is thus a 'slide' from explanation as it occurs in science to explanation as it occurs in history. We can, if we wish, say that the difference is only one of degree, but we must be careful. We can say this if what we mean to emphasize is the fact that historical explanation presupposes regularity, that it involves a knowledge of how things and people in general behave which can be, and at times is, made more explicit... ${ }^{197}$

Which leads us to the most basic problem with Gardiner's analysis of mental causation - its attempt to bend the nomothetic form of covering law theory to fit historical practice. While it would be implausible to claim that Gardiner was a covering law theorist on the level of Popper and Hempel themselves, it seems reasonable to conclude that his arguments were predicated on the assumption that the basic form and claim to universal applicability of the covering law model were legitimate. As Dray has observed, his "modifications of the model, like those allowed by Popper and Hempel, are all designed to show that, even in the most unlikely cases, the real force or point of the explanations which historians offer is only to be brought out by emphasizing their resemblance to the covering law ideal." ${ }^{198}$ In other words, it wasn't enough for Gardiner to point out that meaningful analysis of human actions could, in appropriate circumstances, be conducted with reference to the disposition of those involved. His own nomothetic assumptions required him to make the form of such an analysis appear "law-like," because it was only through the

193 Gardiner, The Nature of Historical Explanation. pp.121-122.

194 Ibid., pp.122-123.

195 Ibid., p.135.

196 Ibid., p.98.

197 Ibid., p.99.

198 Dray, Laws and Explanations in History. pp.17-18. (emphasis added) 
engineering of such a similarity that they could be made legitimate as explanations. Gardiner himself makes this abundantly clear, writing at one point that the statements which make up historical explanations must "be seen to satisfy the antecedent of a general hypothetical," for if they do not do this, "the force of the 'because'" cannot then be accounted for, and nothing is explained. ${ }^{199}$ Yet, he also claims that:

A postulated historical explanation is not, as a rule, justified (or challenged) by demonstrating that a given law implied by it does (or does not) hold; far less by showing such a law to follow (or not to follow) from an accepted theory or hypothesis, or to be confirmed (or falsified) by experiment; nor, again, by pointing out that the case under consideration does (or does not) satisfy in the required respects the conditions exactly specified in the formulation of the law. ${ }^{200}$

So how then are historical claims justified? Gardiner asserts on the one hand that they must be backed by general truths, and with the other hand rules out all major known ways of doing this. And in their place stands only the comparatively flimsy edifice of mental causation by disposition. Certainly disposition is a reasonable enough explanatory mechanism, but one should ask: does an analysis of the disposition of an historical actor really carry an epistemic force analogous to, for example, the ability of Newton's second law of motion to justify a claim about the path of a projectile? This seems to be more than merely a difference of degree. Consider the case of the exception, for example. In Gardiner's model how can the "out of character" action be explained? We might explain it by the intrusion of an external event/object - perhaps the effect of madness or disease - but this fits neither the pure covering law theory nor its softened dispositional form. Diseases might be well understood biologically and able to be connected to laws, but it is unlikely that our understanding of those laws will be good enough to account for its transmission to that person at that time. Similarly, how can we account for motives that were apparently sublimated in a particular group or a particular era? As W. H. Walsh has argued (although not in specific reply to Gardiner), intention is a slippery concept indeed:

Thus the idea of Great Britain's having an imperial mission, though explicitly advocated by only a small minority of persons in the country at the time, came towards the end of the Victorian era to exercise a most important influence on the conduct of British foreign policy, and no account of that policy could afford to leave it unmentioned. There was, in fact, a recognisable imperialist phase in British

199 Gardiner, The Nature of Historical Explanation. pp.97-98.

200 Ibid., p.96. 
political history, even though the policy of imperialism was not consciously accepted or deliberately pursued by the majority of those in power at the time. ${ }^{201}$

If such statements are reasonable to make in Gardiner's model, then they must, in some way, be the "antecedent of a general hypothetical." Yet neither covering law theory nor Gardiner's dispositional modification of it can adequately cover this kind of example. If one is committed to justifying knowledge only in recognisably nomothetic ways, how are statements like Walsh's to be justified? Are we now obliged to postulate another "logical difference" between classes of covering law explanations in order to account for this new class of explanations? At this point, the difficulty of maintaining even a superficial resemblance to covering laws for all possible historical knowledge claims becomes plainly apparent. ${ }^{202}$ And while this discussion could easily be continued at far greater length, for the purposes of this thesis it will suffice to note that all of these epistemic contortions become trivial if one merely relinquishes covering law theory as the definitive model of all explanation. As William Dray noted of Gardiner in this respect:

The Humean assumption that nothing but 'regularity' can justify a 'because' is thus made from the beginning, and it is too strong to be shaken by information about the way historical arguments actually go. Gardiner does introduce the notion of 'judgement'; but he cannot bring himself entirely to abandon the view that judgement of a particular case is disreputable without the logical support of covering empirical laws... If the historian does not use a precise 'rule', then a vague one must be found; if no universal law is available, then a qualified one must have been assumed. The alternative which is too much to accept is that, in any ordinary sense of the word, the historian may use no law at all. ${ }^{203}$

In other words, if this was the best defence of the relevance of covering laws for history that could be mounted, then it is perhaps unsurprising that the idea that "the historian may use no law at all," went on to become a major theme in the postHempelian philosophy of history. For it was clear that even Gardiner's spirited attempt to modify covering law theory to take account of historical practice was still far too restrictive to be a workable method of historical explanation. And yet, Gardiner had been instrumental in thoroughly dissecting and dismantling the old idealist intuitionist arguments that had been deployed against nomothetic positivism since the nineteenth century. Those ideas too, could no longer stand. In cognisance of this, attempts at providing models of historical explanation began to surface which

201 W. H. Walsh, An Introduction to the Philosophy of History. Revised $3^{\text {rd }}$ Edition. Hutchinson \& Co.: London, 1967. p.61.

202 Ibid., pp.59-60.

203 Dray, Laws and Explanations in History. p.57. (emphasis in original) 
attempted to find a way between these extremes. The explanatory device these attempts would ultimately converge upon was that of narrative. Using this idea, philosophers of history sought to offer modes of historical explanation which avoided the pitfalls of naïve empathic idealism and focused instead on purely empirical means for justifying historical explanations, yet also eschewed any connection with the sciences because of the explicit commitment to laws such a connection was assumed to require. There were, they asserted, at least two modes of explanation - the nomothetic and the narrative. But only one of them was scientific. And, unfortunately, it was the other which was appropriate for history. Thus, in the process of developing narrative as an epistemological device, the baby was thrown out with the bathwater. For, in accepting what now seemed obvious - that covering law theory was functionally inadequate for justifying historical explanations - these narrativists came (via the nomothetic assumption) to the conclusion that history was not, and could never be, scientific in any meaningful sense.

\section{W. H. Walsh and the Idea of Colligation}

One of the first post-Hempelian philosophers of history to offer a model of historical explanation which was consciously formulated as a model unique to history (and thus quite apart from scientific explanation) was W. H. Walsh. Walsh's model - which he called "colligation under appropriate conceptions" - first surfaced in print in a 1942 paper entitled 'Intelligibility in History.' ${ }^{204}$ In developing this model, Walsh had borrowed the term "colligation" from the nineteenth century logician and philosopher of science, William Whewell, who had described the concept in the second volume of his Philosophy of the Inductive Sciences, Founded Upon Their History, first published in 1840. ${ }^{205}$ But where Whewell had defined colligation as the "mental operation" by which a number of empirical "facts" were brought together by "superinducing" upon them an overarching concept which unites them and allows them to be captured by a general law, ${ }^{206}$ Walsh deployed the idea in a manner he saw as specifically applicable to history. In Walsh's view, historical colligation was completely independent of the nomothetic sense of the term emphasised by Whewell and was thus (in a leap of reason consistent with the nomothetic assumption) also completely independent of the sciences.

204 W. H. Walsh, 'Intelligibility in History,' Philosophy. Vol. 17, No. 66 (April 1942). pp.128-143.

205 William Whewell, Philosophy of the Inductive Sciences, Founded Upon Their History - Volume Two. $2^{\text {nd }}$ Edition. John W. Parker: London, 1847.

206 Ibid., pp.46-48. 
Talking about Walsh's idea of colligation is made difficult by the fact that Walsh revisited the idea several times over the course of his career. From its first inchoate appearance in 1942, to what is perhaps its most detailed and thoughtful exposition in the 1967 paper 'Colligatory Concepts in History,'207 the concept underwent significant development - usually through the refinement of boundary conditions. Because of this, it is generally best to consider the 1967 paper as the definitive exposition. As an introduction to the general idea, however, the description offered in his 1951 book, An Introduction to the Philosophy of History, offers a concise summation. ${ }^{208}$ Generally, Walsh argues, when historians are asked to explain an event or period - the example he uses is the British general strike of 1926 - they will:

... begin by tracing connections between that event and others with which it stands in inner relationship (in the case in question, certain previous events in the history of industrial relations in Great Britain). The underlying assumption here is that different historical events can be regarded as going together to constitute a single process, a whole of which they are all parts and in which they belong together in a specially intimate way. And the first aim of the historian, when he is asked to explain some event or other, is to see it as part of such a process, to locate it in its context by mentioning other events with which it is bound up. ${ }^{209}$

Such a process can be used in explaining historical periods as well as events. For Walsh, such descriptors as "the rise of the gentry," "the Romantic movement," "the age of reform," "the evolution of Parliament," "the Enlightenment," and "the Industrial Revolution" were all examples of colligatory concepts. ${ }^{210}$ Each of these terms, in other words, acts as a master concept chosen for its ability to unify - and thus more easily manipulate - large collections of historical events that have some relevant thematic relationship. So, where Whewell might have been seeking a general law that could gather together a variety of natural phenomena under a common cause, Walsh was instead seeking for just this kind of general, but singular, concept.

The first thing to note about such an approach is its increased emphasis on context rather than reduction. While colligation is not a purely contextualist theory of history, Walsh does seek to explain smaller events by gathering them up within greater

207 W. H. Walsh, 'Colligatory Concepts in History,' in Patrick Gardiner (ed), The Philosophy of History. Oxford University Press: Oxford, 1974. pp.127-144.

208 W. H. Walsh, An Introduction to the Philosophy of History. Revised $3^{\text {rd }}$ Edition. Hutchinson \& Co.: London, 1967.

209 Ibid., pp.24-25.

210 This compilation of Walsh's examples taken from: William H. Dray, 'Colligation Under Appropriate Conceptions,' in William H. Dray, On History and Philosophers of History. E. J. Brill: Leiden, The Netherlands, 1989. p.38. 
events and/or periods, thus building up larger historical entities which could constitute an (at least partial) explanation of their component events. And these entities/concepts are necessarily defined as much by what they are not as by what they are. Concepts like "the Industrial Revolution," for instance, can mean little without being understood as a revolution against something. In this way the legacy of medieval feudalism, for example, might become part of an explanation for the rise of Victorian capitalism. This is in stark contrast to the reductionist tendencies of covering lawyers such as Hempel and Gardiner, who sought to show historical events as the expression of general laws - a narrow approach which made the explanation of anything other than the most circumscribed of historical events/objects infeasible. The key difference that enabled Walsh to claim this approach for history was also the single major point of difference between his colligation and Gardiner's covering law theory - it simply was not part of Walsh's project, as it was Gardiner's, to bring out the supposed common form of all knowledge. Walsh had no philosophical axe to grind, and was perfectly happy to describe an explanatory method for history alone. Indeed, for Walsh, colligation was a methodological process rather than any fundamental property of knowledge, historical or otherwise. Where Gardiner's attempt to define historical explanation was normative and reductive, Walsh's was descriptive and contextual - trying to tackle what historians actually do, rather than what they should do. The colligatory process, he argued, "is one which historians do use," and therefore "any account of historical explanation should find a place for it." 211

Interestingly, this difference of approach can be seen more clearly when one considers the similarities between Walsh's colligation and Gardiner's dispositional analysis. Consider the extended example Walsh makes of Hitler's actions in 1936:

If an historian is asked to explain a particular historical event I think he is often inclined to begin his explanation by saying that the event in question is to be seen as part of a general movement which was going on at the time. Thus Hitler's reoccupation of the Rhineland in 1936 might be elucidated by reference to the general policy of German self-assertion and expansion which Hitler pursued from the time of his accession to power. Mention of this policy, and specification of earlier and later steps in carrying it out, such as the repudiation of unilateral disarmament, the German withdrawal from the League of Nations, the absorption of Austria and the incorporation of the Sudetenland, do in fact serve to render the isolated action more intelligible. And they do it by enabling us to locate that action

211 Walsh, An Introduction to the Philosophy of History. p.62. Walsh also argues that: "we cannot help being struck" by historians' use of a method of enquiry which "fits the idealist better than the positivist theory." See: Walsh, An Introduction to the Philosophy of History. p.59. 
in its context... ${ }^{212}$

Note that the events ostensibly being explained in this example are seen as flowing from Hitler's "general policy of German self-assertion and expansion." The "reoccupation of the Rhineland in 1936" is being explained, at least in part, with reference to the conscious intentions of an historical actor, whose motives we might hope to come to some understanding of. Indeed, Walsh went even further than this, arguing - as Gardiner might - that mental causation was the most important factor within his model of historical explanation because "actions are, broadly speaking, the realisation of purposes, and because a single purpose or policy can find expression in a whole series of actions, whether carried out by one person or by several, we can say in an intelligible sense that some historical events are intrinsically related." ${ }^{213}$ This then, despite the difference of its approach, remains a view of history driven by conscious human purpose. One would expect, therefore, Walsh's model to be unable (much like Gardiner's model) to account for mental causation which was not explicitly intentional. And indeed, in the above form, it is. But this problem, which had effectively ruined Gardiner's attempt to account for historical explanation by making a small concession within the form of covering law theory, presents Walsh with consequences far less dire. Where Gardiner had placed himself in a position where a single exception could potentially demolish his entire thesis, Walsh tackles the problem descriptively:

Certainly historians speak of general movements which characterise particular ages: the Enlightenment, the Romantic movements, the age of reform in nineteenth-century England, the rise of monopoly capitalism. But can it be held with any plausibility that these movements are in every case deliberate attempts to give expression to a coherent policy? Of many of them at least any such claim would be palpably untrue. No doubt there are some movements in history - that for legal reform in Great Britain in the early years of the last century would be an example... but they seem to be the exception rather than the rule in history. ${ }^{214}$

But this can be "admitted without sacrificing the main point of our theory," argues Walsh, for while "it is absurd to look on history as a series of deliberate movements," it is also absurd to "ignore the truth that men do sometimes pursue coherent policies." If one were to colligate events relevant to the concept "World War Two," for example, one would certainly be required to take account of the conscious and deliberate plans of the Nazis to conquer Europe. Therefore, applications for a 
relatively straightforward dispositional model do exist. ${ }^{215}$ It is a good deal more difficult, on the other hand, to argue for a colligation such as "the Industrial Revolution" being the result of deliberate, individual action. Of this criticism, Walsh argued:

A historical process, like a man's career, is the product of chance and opposition as well as of purpose and intention; the various stages of which it consists have accordingly only a relatively loose unity. But this is not to say that it cannot be properly treated as a single development. Nor is it to admit that such unity as it possesses is like that possessed by, say, a spell of bad weather, the later part of which grows mechanically out of the earlier. ${ }^{216}$

In other words, the essential logic of the colligatory process was the same in both cases. Thus the difficulty that plagued Gardiner was robbed of much of its lethal force. Rather than claiming that dispositional analysis must be used in a nomothetic fashion to justify knowledge claims in human history, Walsh is instead offering us a more general way of thinking about the construction of large-scale historical concepts from smaller events/objects. The exact nature of the connections used in such a construction was of much less interest to him - they might be conscious, unconscious, or utterly mechanical. Where Gardiner had attempted to precisely define the form such connections must take - either covering laws derived from the nomothetic sciences or the dispositional analysis of his own design - Walsh's emphasis was instead on the overall process by which the multiple connections and influences were brought to bear upon their colligatory target. ${ }^{217}$ This is a very promising line of argument, and we will encounter something recognisably similar, developed into a model which can cover all historical science, in Chapter Six.

Walsh, like Gardiner, was attempting to fashion a middle way between the nomothetic and empathic models, having formulated his idea of colligation, as William Dray has observed, "in response to an apparent need to choose between positivist and idealist theories of historical understanding." ${ }^{218}$ In practice, however, Walsh was a far greater friend to the idealists than the positivists, stating in his 1967 reflection on the history of colligation that its initial formulation was intended as "an attempt to find a plausible version of the Idealist theory of history." ${ }^{219}$ And that plausibility, it seems, was to be obtained through a rejection of the view that empathy

215 Ibid., pp.60-61.

216 Walsh, 'Colligatory Concepts in History,' p.135.

217 Ibid., p.128.

218 Dray, 'Colligation Under Appropriate Conceptions,' p.38.

219 Walsh, 'Colligatory Concepts in History,' p.134. 
was the proper basis for historical knowledge. To state that historians "must penetrate behind the phenomena they study is one thing," Walsh writes, but "to hold that such penetration is achieved by an intuitive act is something very different." 220 On this much at least, Walsh and Gardiner were in agreement. Walsh's colligation is therefore best understood as an attempt to replace that ailing epistemology with something more empirically defensible while still preserving existing historical practice and historical autonomy. But where Gardiner was struggling to preserve historical autonomy while simultaneously uniting historical and scientific explanation, Walsh ceded the latter goal entirely. Historical explanation could not be adequately captured with a nomothetic system, Walsh argued, no matter how much it might be modified. Therefore, the system Walsh chose to offer in place of empathy not only claimed no ties with the sciences, but desired none.

\section{Colligation and the Beginnings of Narrative}

While colligation is an interesting conceptual device for collecting historical events together under a common descriptor, it seems quite clear that this process alone cannot constitute the entirety of historical explanation. For example, we might claim that (speaking in terms of colligation) "World War Two" is a term which collects together and expresses the thematic unity of a large number of otherwise disconnected battles and political divisions. But this operation alone will not tell us all we might wish to know about the myriad causes and effects of those battles and divisions. We cannot give a satisfactory explanation of the Battle of the Bulge, for instance, by simply stating that it was a part of World War Two. There is clearly much more which might be said of it. This is a serious problem which emerges when one tries to make colligation alone shoulder the burden of an entire historical epistemology. Walsh himself was aware of this, conceding that some additional explanatory mechanism was needed in order to establish his claim to have devised an epistemic alternative to both covering law theory and empathic idealism. Colligation, he argued, "needs to be supplemented by further processes if historical explanation is to be complete." 221 The mechanism Walsh chose for this supplementary role was narrative. And so it is at this point that Walsh's credentials as being among the first of the post-Hempelian narrativist philosophers of history begins to emerge. Although Walsh (like many who followed him) never properly defined the term, it is

220 Walsh, An Introduction to the Philosophy of History. p.57.

221 Ibid., pp.62-63. 
clear from his usage that he intended narrative to be an explanatory mechanism which focused on historical evidence, rather than presuming to "re-experience" the "inner" thoughts and subjective experiences of historical actors. The historian's desire to fashion a "coherent whole" from their particular area of study, Walsh argued, was instead accomplished by looking, "for certain dominant concepts or leading ideas by which to illuminate his facts, to trace connections between those ideas themselves, and then to show how the detailed facts become intelligible in the light of them by constructing a 'significant' narrative." 222

Walsh contrasted this idea of "significant" narrative with that of a "plain" narrative. A "plain" narrative, he argued, was an "exact description of what happened," whereas the "significant" narrative "goes beyond" description and "aims not merely at saying what happened but also at (in some sense) explaining it." ${ }^{223}$ Yet, despite the obvious importance of these comparative terms for Walsh, he does not define what narrative itself is. In the chapter of An Introduction to the Philosophy of History devoted to historical explanation, for example, he spends several pages decisively rejecting both the empathic idealism of Collingwood and the doctrinaire nature of the covering law theory advanced as its replacement. Yet he does not develop narrative as part of his solution. Instead, he merely restates his idea of colligation as an alternative to both, albeit an alternative drawn from the actual practice of historians rather than from abstract principles of philosophy. Even as he does this, however, he again concedes that colligation "while of great importance, could not constitute the whole nature of historical explanation." But then neither, he continues, could the covering law model. "Our general result," he concludes, "can be summarised by saying that history is... a form of knowledge with features peculiar to itself..." 224

Narrative is clearly extremely important to Walsh's vision of history. Not only does it complement colligation, it also appears to be the distinguishing feature of historical explanation - one of the "features peculiar" that is not empathy, but is not scientific either. Yet we are left in the dark as to precisely what he means by the term, at least in the Introduction to the Philosophy of History. Fortunately, he comes much closer to defining his vision of narrative in a 1958 reply to criticism from the philosopher Arthur Danto. In this short paper he writes:

222 Ibid., p.61.

223 Ibid., p.32. (emphasis added) See also: W. H. Walsh, "Plain' and 'Significant' Narrative in History,' The Journal of Philosophy. Vol. 55, No. 11 (May 1958). pp.479-484. 224 Walsh, An Introduction to the Philosophy of History. p.70. 
If the word "cause" is taken in a broad sense, as by Aristotle, who used it in reference to dispositional and teleological explanations as well as explanations in terms of efficient causes, we may say that historical narrative is essentially characterized by the presence of causal words and phrases; from the point of view of the logician, this is just what makes it intriguing. ${ }^{225}$

What Walsh appears to be saying here is that narratives (presumably those "significant" narratives which contain explanatory content) invoke causal phrases, but that we cannot be sure ahead of time what the relevant causes might be in any given historical explanation. We must, therefore, be somewhat liberal with respect to the kinds of events and processes we will grant the title of "cause." In this view, a "significant" narrative is simply a "plain" narrative (i.e., a mere description of events) with the missing causal links between events filled in. And, by linking events causally, it might be reasonably said that they are explained. It is precisely this form of explanation, Walsh appears to be arguing, which underlies the practice of history, including his own notion of colligation.

But there is another problem here. Given this liberal definition of the word "cause," we could argue - as Popper, Hempel, or Gardiner might - that each of these causal links should ideally be directly deducible from general laws. If this were the case, the result would be an almost textbook example of the covering law thesis, with each step of the particular narrative at issue being shown to be the necessary product of general laws. Indeed, Walsh skirts precisely such a "laws in history" argument in Introduction to the Philosophy of History, but ultimately withdraws from it for the familiar reason that it is simply too difficult to make the necessary deductions in actual historical practice. Nor is it clear that such deductions, even if they were possible, would help explain the kinds of events/objects in which historians are interested. And regardless of whether or not it is possible, Walsh argues, historians simply do not do this:

... we have rejected the main contention of the idealists about historical explanation and argued that it involves some sort of reference to general truths. This may seem to commit us without further ado to some form of the positivist thesis... But before accepting that conclusion we ought perhaps to take a closer look at the actual practice of historians. If we do that we cannot help being struck by their use of a procedure which fits the idealist better than the positivist theory, the procedure of explaining an event by tracing its intrinsic relations to other events and locating it in its historical context. ${ }^{226}$

225 Walsh, "Plain' and 'Significant' Narrative in History,' pp.482-483.

226 Walsh, An Introduction to the Philosophy of History. p.59. 
What Walsh is doing here is making, in a roundabout way, the point that causal events / objects in history are usually not directly deducible from any known general laws, and that even if they were, it is their proximately unique (as opposed to the purely general) aspects which are doing the explaining. For example, the fact that it rained heavily before the Battle of Waterloo is sometimes thought to have been a significant causal factor in that battle's outcome, having turned the battlefield to mud. Regardless of whether or not this was the case, if one wished to invoke heavy rain as a causal factor, it would be of little help to follow the nomothetic "laws in history" approach and make reference to, for example, atmospheric physics and the chemistry of water absorption in soil. Certainly these would be admirably general processes which we might expect to be able to identify wherever and whenever it rains. But it is not these processes themselves which are doing the explaining in this case. What is explanatory is that it rained in that particular place and at that particular time. We have no reason, of course, to think that the place and time of the rain are not also somehow determined by natural laws. But to demonstrate this link is difficult (likely impossible), and successfully doing so would add little or nothing to our explanation that could not be made equally clear by simply stating "it rained before the Battle of Waterloo, turning the battlefield to mud" and producing the evidence by which we make such a claim. And it is this latter kind of particularistic causation in which historians are interested and which forms the basic causal connections of Walsh's "significant" narratives. In this sense, Walsh really is offering colligation and narrative as alternatives to "some sort of reference to general truths." This makes possible an alternative model of explanation, yet does not require Walsh to recapitulate the idealist assertion that history and the sciences inhabit incommensurable worlds - one mental and one material.

\section{Walsh and the Nomothetic Assumption}

As we have just seen, Walsh's treatment of colligation and his inchoate idea of narrative leave us with an unmistakable impression that Walsh was actively attempting to avoid direct reference to "general truths" in historical explanation. The question that faces us now is why? The answer can be found, once again, in the nomothetic assumption, and what the admission of "general truths" into historical explanation would mean for Walsh's model. Having absorbed so much of the idealist program, Walsh was convinced that history was purely a study of unique particulars. 
"The central preoccupation of the historian," he wrote in the Introduction, "is not with generalities, but with the precise course of individual events: it is this which he hopes to recount and render intelligible." 227 Walsh takes this general/particular division a good deal further, however, by arguing that the epistemology of such a vision of history must also avoid any direct connection to general truths. By doing this, Walsh is attempting to hold history completely apart from the sciences, thus allowing it to formulate its own rules. This is necessary because, if it were not done, history might become philosophically answerable to science. For Walsh, in the grip of a nomothetic assumption and much closer to the heat and light of the covering law debate, this would be functionally equivalent to admitting that Popper and Hempel were right, and that history must be transformed into a deductive enterprise in the likeness of physics. Walsh was understandably anxious to avoid such an outcome, and attempted to forestall it by postulating his ideas of colligation and narrative as purely particularistic modes of explanation. These epistemic devices, he claimed, did not proceed from "general truths" and thus represented knowledge of an entirely different kind, not beholden to the kinds of methods Popper and Hempel advocated. History was, as we have already seen him claim, "a form of knowledge with features peculiar to itself..." 228

But this claim to historical autonomy, of course, only makes sense if one accepts the premiss that science is only the study of the general through nomothetic laws. The corollary to this is that, if history cannot work with general laws, then it can only be the study of the particular. This is clearly an assumption which exercises considerable influence over Walsh. And yet there is nothing in Walsh's stated ideas regarding colligation and narrative which necessitates or adequately justifies such a separation between history and the sciences. It had to be presupposed. This is, once again, the nomothetic assumption in action. If science could intrude into the particular, or be shown to utilise concepts such as historical colligation and/or narrative, this would negate Walsh's premiss and his entire argument would collapse. There would be no difference left to defend between the two (at least if we accept Walsh's other arguments). Nor would there be any need to even argue for such a difference in the first place, as the consequences of admitting a role for "general truths" would no longer be quite so dire. Thus, once again, the nomothetic assumption is implicated in the formulation of history's own self-image and in the separatist impulse it exhibits. 
In order to more precisely ascertain the depth of the nomothetic assumption in Walsh's thinking, it will be necessary to briefly examine his vision of science.

To his credit, Walsh's view of science avoids several of the most common idealist misconceptions. Of the view that historical knowledge - being concerned with events/objects in the unreachable past - is thus a substantively different kind of knowledge from the sciences, Walsh replies, "it is not true that the scientist is concerned with the present to the exclusion of the past," citing geology and paleontology as examples of backwards-looking sciences. ${ }^{229}$ Moreover, he also is careful to rule out the inverse conclusion (that geology and paleontology should be declared history rather than science) by arguing that it cannot be held that "history is, without qualification, a study of the past" as a whole, for "there are large portions of the past of which history... takes no cognisance whatever." Thus, the mere act of examining past events cannot be sufficient to establish history's autonomy, for this would gather disciplines we would still wish to call sciences into history's net. History then, for Walsh, is just "the past of human beings." ${ }^{230}$ This, of course, is a fairly typical conclusion among philosophers of history, and is a largely reasonable one. Certainly it admits of fewer errors of categorisation.

More important, however, is the view of science with which Walsh compares this recognisably idealist definition of history. He initially argues that to call an area of study a science is to assert that it is "a body of knowledge acquired as the result of an attempt to study a certain subject-matter in a methodical way, following a determinate set of principles." Yet, seemingly aware of the shortcomings of such a definition, which would allow a "railway timetable or a telephone directory," to be counted as scientific, Walsh moves quickly to qualify it. These examples are to be refused scientific status because "we tend to employ the word 'scientific' only where we have to do with a body of general propositions." ${ }^{231}$ Rather than attempt any form of "ultimate" explanation, he writes, scientists:

... are content with the far more modest task of building up a system of observed uniformities in terms of which they hope to elucidate any situation which falls to be examined. Given any such situation, their procedure is to show that it exemplifies one or more general laws, which can themselves be seen to follow from, or connect with, other laws of a wider character. The main features of this 
process are, first, that it consists in the resolution of particular events into cases of general laws, and secondly that it involves nothing more than an external view of the phenomena under considerations (since the scientist is not professing to reveal the purpose behind them). ${ }^{232}$

This quote is particularly salient with respect to Walsh's understanding of the "procedure" of doing science. This is, in essence, a nod to Whewell's idea of scientific colligation. For Whewell, the procedure of colligation in science was based around the idea of laws. For Walsh, while the procedure in history was still that of colligation, the explanatory structure toward which that process was oriented was something very different: a significant narrative expressing a colligatory concept. When considered in tandem with Walsh's desire to reject empathic notions of a separate dimension of mind (thus effectively claiming that history and science inhabit the same epistemic world), the only remaining substantive difference between the colligation of Whewell and that of Walsh - and thus between science and history - was the degree to which laws and/or bodies of "general propositions" were involved in their construction. We say "degree" here because, as we have already hinted, it was extremely difficult for Walsh to argue that general propositions are never involved in historical narrative or colligation. They clearly are, even if they could not carry the explanatory load the covering lawyers might have wished for them. Walsh clearly acknowledged this. History, he wrote, "differs from the natural sciences in that it is not the aim of the historian to formulate a system of general laws; but this does not mean that no such laws are presupposed in historical thinking." Thus, while the historian must ultimately "appeal to general propositions in the course of his study," he "does not make these explicit in the same way as the scientist does." ${ }^{233}$ Thus, in formulating his model of historical explanation by colligation and 'significant' narrative, Walsh chose to eschew any direct reference to laws and attempted to focus historical explanation solely on the particular. In this way, Walsh claimed to have cultivated a different and wholly unique relationship between historical knowledge and the "general propositions" of the sciences.

\section{Colligation versus Classification}

Despite his admission that the historian must sometimes "make appeal to general propositions," Walsh's colligation (and presumably his idea of narrative, had he 
developed it sufficiently) relied heavily on the idea that historical explanation must use a particularistic colligation. This was a point he strongly insisted upon throughout his career. "It seems clear," he argued in his 1967 paper, "that the subjects of discourse which are designated by colligating phrases are one and all complex particulars: each of them has a temporal and also a spatial spread ('the rise of the bourgeoisie in western Europe')" Whatever complications the subject matter might present, Walsh argues, generally the historian finds "a set of events which can be intelligibly treated as the vicissitudes of a single subject." ${ }^{234}$ This would seem to be another way of saying that colligatory concepts must be of the form "the American Revolution," rather than merely "a revolution." The former is a colligation, the latter a classification. But classification, when seen from the general/particular mindset nurtured by the nomothetic assumption, must necessarily be more appropriate to the sciences, as it is consistent with their attempts to subsume phenomena under "general truths." And so Walsh becomes a prisoner of his own division of historical from scientific knowledge. He must insist on the pure particularity of colligation in order to satisfy his own pronouncements regarding the nature of science and its differences from history. This would be excusable if such a particularistic emphasis could adequately capture the "actual practices" of historians from which Walsh claims to have drawn his model. Sadly, there are reasons to believe it cannot. To this end, let us examine just one example in which even the historical practice which Walsh was so keen to protect - to say nothing at all of theory - must make reference to the general in order to be intelligible. This is the difference highlighted by the philosopher $\mathrm{C}$. Behan McCullagh between colligation and classification.

McCullagh's paper on this subject, entitled 'Colligation and Classification in History, ${ }^{235}$ was primarily an examination not only of Walsh's concept of colligation, but also of its reception by subsequent authors. Throughout the paper, however, McCullagh returns several times to the question of how the concept of colligation balances notions of the particular and the general. Because of this, Walsh's strong insistence on the particularistic nature of his colligation is of great interest to McCullagh. Of the long history and multiple revisions Walsh made to the concept, McCullagh writes:

What Walsh has insisted upon throughout is that the processes of historical 234 Walsh, 'Colligatory Concepts in History,' pp.142-143.

235 C. Behan McCullagh, 'Colligation and Classification in History,' History and Theory. Vol. 17, No. 3 (October 1978). pp.267-284. 
change, by means of which historical events are colligated, are unique. Such processes as the British Industrial Revolution or the Romantic movement are what Walsh has called "complex particulars" and "concrete universals." The events which make up these processes or movements give concrete expression to ideas shared universally by the people who initiated them. The processes are unique, Walsh has maintained, because the ideas underlying them are unique. The terms referring to or naming these processes, therefore, are always singular, not general. ${ }^{236}$

But this, McCullagh argued, was far too restrictive. For it rejected the possibility of any general process ever playing a role in a colligatory concept. He continues:

If Walsh is right and all the processes by which historical events are colligated are unique, then to colligate events by reference to those processes cannot be to classify the group of events involved. One can classify a group of events only by means of a general concept, that is, by showing that the features of the group are common to those of other groups to which the same concept applies. For colligation to be an instance of classification, the process by means of which events are colligated must be to some extent common, not unique, and the term referring to that process general, not singular. ${ }^{237}$

While McCullagh has much to say about the philosophical merits of Walsh's insistence that colligation must be a purely particularistic process, he has comparatively little to say about why Walsh resisted "admitting that colligatory concepts can be general." McCullagh largely attributes Walsh's reluctance to his "belief that the unity of the historical processes to which colligatory terms refer is achieved in only one way, by means of unique sets of ideas which direct them." 238 That is, McCullagh believed that it was Walsh's focus on the content of the ideas which motivated colligations like "the Industrial Revolution" that led to his emphasis on particularity. But to limit the allowable content of a colligatory concept, McCullagh argues, is to cripple colligation as an explanatory mechanism. For there are potentially many other ways to skin the colligatory cat, many of which involve the use of general concepts.

McCullagh had two key objections to Walsh's assertion that historical colligation could only be so-called in particular situations where the colligatory concept being deployed expresses the ideas which animated the event/object to be explained. The first, according to McCullagh, was that while "some of the processes to which colligatory concepts refer are unified by a common set of ideas, others are unified simply by the form of the change in a subject which they constitute." That is, one 236 McCullagh, 'Colligation and Classification in History,' p.268. 
could reasonably colligate a collection of historical events, objects, and processes as "a revolution," without having any knowledge at all of the specific ideas which drove it. ${ }^{239}$ Such a colligation would be a description of the form of a change only, rather than the underlying idea it expressed. From our point of view, this is a relatively minor point. The second of McCullagh's objections, however, was more serious. Although "some colligatory concepts which refer to processes unified by a common set of ideas are singular," McCullagh writes, "others are general, since such processes sometimes do occur more than once in history." ${ }^{240}$ In other words, a concept like "renaissance," even if defined in a relatively strict sense - McCullagh offers "a "revived interest in and influence by the cultural of classical Rome" - is still a far more general concept than its typical deployment ("the Renaissance") would suggest, for "there have been several periods of renaissance." 241

For McCullagh, terms like "revolution" are "formal colligatory concepts" in that they indicate the form but not the content of a historical process. Because of this, they are often deployed with "another word indicating the subject of change, as in 'social revolution,' 'scientific revolution,' and 'revolution in government."' While this usage pattern helps give a general term like "revolution" a more particularistic focus, such formal terms still say "nothing about the ideas behind instances of changes to which they could refer." Thus, McCullagh argues, even a term like "scientific revolution," which seems quite uncontroversial in terms of its subject, leaves open the question of the ideas which animated it. Nor is this an isolated example. To this list could be added such terms as : "evolution," "growth," "decay," "polarization" and "conflict." Thus, despite Walsh's particularistic commitments, his concept of colligation is not specific enough. An unwanted generality also intrudes, McCullagh continues, with colligatory concepts that, while they are not mute with respect to their animating ideas, can nevertheless apply to multiple unrelated processes. His primary example is the concept of "renaissance," but he also points out that there are arguments which might be made for multiple periods of "enlightenment" in Europe. And, like the above examples of formal colligatory concepts, this list too is potentially endless. "Feudalism," he argues, "has been discovered, not only in Europe, but also in Japan. And there have been many instances of mercantilism and imperialism, capitalism

239 Moreover, McCullagh argued, this was not merely a theoretical objection, but a practical one: "Quite often." he argues, "historians know the form of a change but are uncertain about the reasons for it." See: McCullagh, 'Colligation and Classification in History,' p.272.

240 Ibid., p.271.

241 Ibid., p.272. 
and socialism, nationalism and fascism." ${ }^{242}$

As this brief summary makes clear, McCullagh makes some extremely valuable points, all of which suggest that it was a good deal more difficult to maintain the notion of history as being purely a study of the particularistic than Walsh had supposed. McCullagh's case for admitting at least something of the general into history is compelling, and this thesis has no wish to add to his substantive arguments. We are, however, in a position to augment McCullagh's account of why Walsh chose to insist on the particularistic nature of colligation. We might offer, for instance, our own observation that Walsh's very definition of colligation demanded an emphasis on particularism. This was necessary in order to secure history's autonomy from scientific explanation, and thus avoid the difficulties of accounting for historical explanation in terms of "general truths" that the lack of such autonomy was thought to require. We are also in a position to see a plausible reason for something else which puzzled McCullagh. With reference to Walsh's paper 'Colligatory Concepts in History,' McCullagh observes that, despite his particularistic emphasis, Walsh "repeatedly referred to colligation as a process of generalization," using such terms as "summative generalization" and "large-scale generalizing history." Walsh even went so far, McCullagh notes, as to devote "a section of the essay to the problems of generalization associated with colligation, the dangers of over-simplification and consequent distortion of the past." ${ }^{243}$ What McCullagh saw as confusion and contradiction on Walsh's part, however, is neatly explained by the very difference we established earlier between Walsh's colligation and Whewell's - the role of laws. For Walsh, colligations are generalisations. But they are generalisations of their own separate and unique kind, built up out of pure particulars through a mechanism of narratives. That is, they aren't generalities built from, or seeking to establish, "general truths." That is the aim of scientific explanation, which Walsh considers something entirely separate. Understanding Walsh's desire to keep historical explanation and scientific explanation separate therefore allows us to make sense of what otherwise appears to be a schizophrenic use of the term "generalization." 244

242 Ibid., pp.272-273.

243 Ibid., p.271.

244 This same distinction, we might also note, can also make sense of McCullagh's claim that "Walsh must have been aware that scientists also interpret natural facts by means of colligation, since he acknowledged a debt to Whewell's account of the function of colligation in science." See: McCullagh, 'Colligation and Classification in History,' p.267. As we have seen, Walsh certainly was aware that colligation was possible in the sciences. But Whewell's vision of colligation, as we have argued, was rooted in general laws. Walsh saw his own version of colligation as rooted in narratives. Thus we can reasonably conclude that, for Walsh, the admission that colligatory 
So, while McCullagh's purpose was not to pursue the consequences of these arguments, it should be apparent (in light of our own discussion of Walsh) that they broadly support our conclusion that there is no compelling philosophical justification for Walsh's insistence on particularism as necessary for every stage of historical explanation and the point of its separation from the sciences. Yet, for Walsh, having conceded that the subject matter of history was not fundamentally different to that of the sciences, such a separation was essentially the only difference left between history and the sciences. It can reasonably be concluded, therefore, that Walsh's attachment to idealism, when coupled with his nomothetic assumptions regarding science, goes a long way toward explaining his insistence upon particularism as a fundamental property of historical explanation. And this, while certainly a serious flaw in Walsh's philosophy of history, has even greater consequences than might initially be supposed. For Walsh (like many other early narrativists) never offered a strong definition of narrative, despite it being a cornerstone of his reconstruction of idealism. But because Walsh also believed that the epistemic tools of the sciences were denied him because history could not be meaningfully nomothetic, his notions of narrative and colligation were required to be much more than merely methods and interpretive concepts. They were required to provide the epistemic basis for what was widely perceived as an autonomous discipline completely apart from the sciences - to stand in the place of the absent laws. This they were simply unable to do. This was not necessarily because they were conceptually weak, but because they were simply being asked to do too much.

In closing then, it should be remembered that the extended examples of Gardiner and Walsh have been used here to illustrate the profound change in the terms upon which the philosophy of history was conducted in the aftermath of the covering law attack. The boundaries between the old positivist and idealist camps were beginning to soften. Empathy and re-enactment were discredited as methods, as was the tacit claim that the only interesting aspects of history lay in the minds of long dead historical actors. Narrative was beginning to emerge as an alternative to both idealism and positivism. On the other side of the aisle, the covering law debate had moved from a nineteenth century "laws of history" mode to the "laws in history"

concepts need not be particular was functionally equivalent to admitting that colligation could be classification. And this would destroy precisely the distinction between scientific and historical colligation he was trying to establish. 
mode of Popper and Hempel. And yet, while Maurice Mandelbaum, in dubbing those authors constituting the narrativist backlash against covering law theory "reactionists," was careful to distinguish them from old idealists like Collingwood and Croce, ${ }^{245}$ it seems that their attempts to move beyond the nineteenth century positivist/idealist dichotomy had succeeded only in rehabilitating it. For despite the stated declarations of both authors to walk some kind of middle path in this age-old dispute, this chapter has shown that both can be better understood as having merely stripped some of the more implausible arguments away from either side, leaving the central division intact. Between Gardiner's desire to rescue a nomothetic approach to history from one of its most potent criticisms and Walsh's stated intent to find a "plausible" idealism, both authors were still recognisably foot-soldiers for the positivist and idealist traditions respectively.

245 Maurice Mandelbaum, 'Historical Explanation: The Problem of "Covering Laws",' History and Theory. Vol. 1, No. 3 (1961). pp.229-230. 


\section{Chapter Three \\ "The Rise of Narrative"}

Where Chapter Two attempted to examine the intellectual transformation undergone by the philosophy of history in response to the covering law assault, Chapter Three will seek to deal with the narrativist movement which was its eventual result. Growing from Walsh's hesitant first steps, narrativism would go on to become one of the leading concepts in the philosophy of history, and remains so even to this day. Our first aim in this chapter will be to attempt to show something of how narrative came to this prominence. This will be achieved through close readings of the work of several prominent philosophers of history who used narrative as a device by which the creaking old edifice of empathic idealism might be abandoned, yet subsumption into the nomothetic sciences avoided. By doing this, we shall see that there were two ways in which this narrative vision of history was articulated. First - as we shall see in the examples of William Dray and Arthur Danto - there was an attempt to build a narrative philosophy of history which adhered to the logical principles of analytical philosophy. That is, authors like Dray and Danto attempted to offer an explanatory mechanism that was unique to history, but still empirically grounded and logically defensible. While their authors perceived such systems as separate from the sciences, they were still in some sense compatible with them. History still explained, in other words. It merely did so using its own unique methods and concepts. This is a continuation of the kind of argument we saw deployed by W. H. Walsh in the previous chapter, and is what we shall mean by the term "epistemic-narrativism." The second way in which narrative was deployed, however, was to emphasise the overlap in meaning between the words "narrative" and "fiction." We shall see examples of this approach in the work of W. B. Gallie and Louis Mink. This approach marginalised or ignored entirely the difficult problems of method and justification with which authors like Dray and Danto were wrestling, in favour of declaring history a predominantly literary exercise - the narratives of which could thus claim little or no correspondence with the past. History did not explain so much as it emplotted. This, in turn, is the intended referent of the term "literary-narrativism."

Regardless of which of these approaches are deployed, however, the second aim of Chapter Three will be to demonstrate that, for all of these authors, narrative was valued as the basis for a philosophy of history precisely because it seemed to provide a good fit for the form of historical explanation, yet was not considered a concern that 
science could have. This useful quality helps to explain why narrative succeeded in the wake of the Popper/Hempel thesis. Yet this key axiom upon which narrativism was predicated itself flowed from the assumption that science was only the pursuit of general laws from which particular truths might be deduced. Whatever role narrative played in history - literary or epistemic - it certainly didn't appear to fit that definition. Therefore, while there was argument regarding the exact nature of narrative and the precise nature of its explanatory role in history, it became an unchallenged axiom that history - so long as it were based in narrative - simply could not be science. This also helps to explain why the literary-narrative view, in the form of the so-called "linguistic turn," has more recently emerged as the dominant strand in contemporary philosophy of history. For epistemic-narrativists like Dray and Danto were (like Walsh) largely unable to provide a convincing epistemic account of what narrative was, and thus how historical explanation functioned. And the reason for that failure, Chapter Three will argue, was the nomothetic assumption. For where literary-narrativists could choose to simply ignore questions of explanation and justification by asserting that history was essentially fiction, epistemicnarrativists could afford no such luxury. And yet, having used the nomothetic assumption to cut off narrative from the sciences, epistemic-narrativists could not then draw upon the intellectual resources of science to provide better definitions of narrative. Defining narrative in scientific terms was simply not considered. It couldn't be, as the very reason for the development of narrative philosophy of history in the first place was as an alternative to the scientism seen as the covert aim of the covering law model. The examples of Chapter Three, therefore, will bring our examination of the nomothetic assumption throughout twentieth century philosophy of history up to the present. This will conclude Part One of this thesis and complete our demonstration that there is both a persistent nomothetic assumption running through much of modern philosophy of history, and that said assumption has played an important role in the definition and self-image of history as a discipline.

An excellent place to begin our examination of the isolation of narrativist philosophy of history from the sciences is with the work of William Dray. A former pupil of W. H. Walsh, Dray was situated squarely in the middle of the emerging narrative movement. His work on historical explanation owes a clear debt to Walsh, yet is not uncritical of him. More importantly, Dray's own work built on several of Walsh's chronically underdeveloped ideas, including narrative. Dray attempted to articulate, 
in a way that Walsh had not, in just what sense a narrative might be said to actually explain. In addition to this, Dray also directly and thoroughly tackled the question of the role of nomothetic laws in history. In his 1957 book Laws and Explanation in History, ${ }^{246}$ Dray offered a detailed examination of the relevance of the covering law position for historians, squarely challenging both strong covering law theory and the weaker variant which argues that the theory might be made to fit historical explanations with only minor modification. With respect to the latter argument, Dray takes particular aim at Patrick Gardiner, using his introduction to position Laws and Explanation as a reply to Gardiner's The Nature of Historical Explanation. ${ }^{247}$ This makes Dray even more valuable as an example, given that we have already seen something of Gardiner's vision of historical explanation in the previous chapter. But while acknowledging Gardiner's concessions to "what the historian actually does" in his modification of covering law theory, Dray ultimately argues that the covering law model cannot possibly capture all aspects of historical explanation without being modified into non-existence. ${ }^{248}$ The model itself, Dray argued, was "so misleading that it ought to be abandoned as a basic account of what it is to give an explanation." With this in mind, Dray set about the task of discrediting any possibility of applying covering law theory to history, arguing that its rigorous application would have the result that "more will sometimes be read into an historical example than is actually there," as well as causing "important features which are there" to "pass unnoticed." 249

\section{William Dray's Model of Historical Explanation}

As a strident critic of the application of covering law theory to history then, Dray was clearly no friend of the nomothetic neo-positivists. But neither was he a defender of empathic idealism. While sympathetic to empathy as a means of contextualising what one has learnt about an historical actor - that is, as a source of understanding rather than of actual new information - Dray was careful to argue that historical explanation must ultimately be defensible in terms of evidence:

It is therefore worth my denying explicitly that what I have called rational explanation is in any damaging sense beyond empirical inquiry... it has an inductive, empirical side, for we build up to explanatory equilibrium from the evidence. To get inside Disraeli's shoes the historian does not simply ask himself:

246 William Dray, Laws and Explanation in History. Clarendon Press: Oxford, 1957.

247 Ibid., pp.13-21.

248 Ibid., p.29.

249 Ibid., p.19. (emphasis in original) 
'What would I have done?'; he reads Disraeli's dispatches, his letters, his speeches.... ${ }^{250}$

Dissatisfied with both the positivist and idealist approaches, Dray set out to formulate a model of historical explanation which did not depend on either. His work on this problem began with his 1954 paper 'Explanatory Narrative in History.'251 Here, Dray stated the general problem as follows:

In thus insisting that any logically reputable explanation must be 'covered' by general statements of some kind, exponents of the model make no secret of the alternative account which they wish to forestall. It is the view, often found in philosophizing about history, that what is needed in order to explain a historical subject matter is not general knowledge of the kind the various sciences provide, but a special sort of insight, which will enable the individual connections between events to be 'seen' immediately. ${ }^{252}$

This whole dichotomy is totally misconceived, Dray argued, for there are "certain logical features of what we would ordinarily not hesitate to count as explanation" which are "not what even the modified model of Professors Popper and Hempel would lead us to expect." ${ }^{253}$ Also of particular interest here is Dray's use of the term "logical." This is a key feature of Dray's style of argument, for, by using this term, he sought to argue that in many cases (including the historical) explanation could be satisfactorily logically justified without recourse to general laws. In other words, Dray was reluctant to let the covering lawyers claim a monopoly on the logical property of explanation and, by decoupling logic from laws, was attempting to claim it back. In this respect, Dray's efforts represent a classic statement of autonomous epistemicnarrativism. Dray's approach to achieving this kind of middle way, however, is not to dilute covering law theory into irrelevance (as Gardiner effectively did), but instead to lower the bar for what constitutes explanation. Or, more accurately, to argue that the bar was never set all that high to begin with:

The chief contention of the covering law theorists is that to explain something, it must be shown to be necessary. By contrast, I shall argue that, in many contexts, including some historical ones, a request for explanation is satisfactorily met if the event in question is shown to be possible; there is no need to go on to show that it was necessary as well. ${ }^{254}$

250 Ibid., p.129. (emphasis in original)

251 William Dray, 'Explanatory Narrative in History,' The Philosophical Quarterly. Vol. 4, No. 14 (January 1954). pp.15-27. This paper later appears in a rewritten (but still clearly recognisable) form as the final chapter of Laws and Explanation in History. See: Dray, Laws and Explanation in History. pp.156-169.

252 Dray, 'Explanatory Narrative in History,' p.16.

253 Ibid., pp.16-17.

254 Ibid., p.17. (emphasis in original) See also: Dray, Laws and Explanation in History. p.157. 
This Dray called "how possibly" explanation, as opposed to the "why necessarily" explanation of the nomothetic sciences. ${ }^{255}$ Dray formulates this model, in both his 'Explanatory Narrative in History' paper and in the final chapter of Laws and Explanations in History, with reference to a seemingly inexplicable baseball catch. The example itself was sourced from a 1952 issue of Maclean's Magazine, and Dray quotes it in full:

An announcer broadcasting a baseball game from Victoria, B. C., said: "It's a long fly ball to centre field, and it's going to hit high up on the fence. The centre fielder's back, he's under it, he's caught it, and the batter is out." Listeners who knew the fence was twenty feet high couldn't figure out how the fielder caught the ball. Spectators could have given them the unlikely explanation. At the rear of centre field was a high platform for the scorekeeper. The centre fielder ran up the ladder and caught the ball twenty feet above the ground. ${ }^{256}$

This, Dray argued, has the appearance (and, more importantly, performs the function) of an explanation. But the form of that explanation is something that the models of neither the covering law theorist nor the idealist can adequately capture. ${ }^{257}$ In 'Explanatory Narrative in History,' Dray argued that there was no appeal in this example - not even implicitly - to any kind of covering law. High-level "historical" laws - such as "in baseball... fielders usually catch long fly balls" - will not suffice to explain this particular instance, Dray points out, as the radio audience will likely already be aware of the relative prospects for fly ball catches. The problem with this example is that, prior to its explication, it presents a unique difficulty for such generalisations. That is, it is the perplexing nature of this catch which requires explanation and not every other (presumably non-miraculous) catch. The generalisation is therefore, Dray argues, superfluous:

... although we may assume that there is nothing to wonder at in the fact that catches are very often made, there is a real mystery about this particular one... No generalizations about fielders catching long flies are of explanatory value... until this prior problem is solved. And once the audience learns about the scorekeeper's platform, it would be superfluous to call the generalization to mind - and not superfluous only in the practical sense allowed by Popper and Hempel when they admit that the appeal to law in explanation may be 'implicit.' For the law is then logically superfluous; the explanation which is required has already been given. It is complete..$^{258}$

One might attempt to evade this conclusion by protesting that the motions of the

255 Dray, Laws and Explanation in History. p.164.

256 Dray, 'Explanatory Narrative in History,' pp.17-18. See also: Dray, Laws and Explanation in History. p.158.

257 Dray, 'Explanatory Narrative in History,' p.18,23.

258 Ibid., p.18. (emphasis in original) 
baseball, and even the atomic constituents of the players, obey basic laws of physics and could therefore be said to be law-governed. But, Dray counters, this is quite simply irrelevant. To demand a higher standard of explanation (i.e., one that sought a nomothetic "why necessarily" rather than "how possibly" explanation) for this catch would "only be appropriate in the face of a further demand for explanation, and one of a different type." ${ }^{259}$ Dray is similarly unconvinced of the possibility of the catch being explained via empathic divination of the inner life of an historical agent. For the problem of the miraculous catch is simply not the kind of problem empathy can solve. Certainly it meets many of the requirements that empathic idealism might insist upon. That is, it is a highly particular event involving human activity and a human actor whose motivations might be reconstructed. Yet, Dray argues, to approach the problem this way - whether based on empathy or something more empirical (such as Gardiner's dispositional analysis) - is simply inappropriate. It is quite simply the "wrong sort of answer to give to the demand for explanation which arises out of the circumstances supposed here." ${ }^{260}$ Neither nomothetic positivism nor empathic idealism, in other words, can provide tools to deal with an event of this kind, and so another alternative must be formulated. This is the niche towards which Dray's "how possibly" explanation is aimed. Dray makes the further connection between "how possibly" explanations and the concept of narrative as follows:

The fact of historical procedure which it was said would be illuminated by the distinctions that have been drawn was that, when asked for an explanation of a certain event or state of affairs, the historian often responds by telling a story. The claim I wish to make is that the narrative he offers sometimes explains in the 'how' rather than the 'why' sense. ${ }^{261}$

Dray believed, in other words, that he had arrived at a sound epistemic argument for the assertion that history proceeds by narrative. Moreover, his "how possibly" / narrative solution possessed the additional advantage of tracking actual historical practice much more closely than either the covering law or the idealist theories could. "Historians," he writes, "are well aware of the importance of the narrative form in which their conclusions are usually expressed, and they often emphasize this when they come to theorize about their subject." ${ }^{262}$ Dray could thus plausibly claim that his "how possibly" /"why necessarily" distinction potentially provided an explanatory model which might lend real epistemic legitimacy to

259 Ibid. (emphasis in original)

260 Dray, Laws and Explanation in History. p.159.

261 Dray, 'Explanatory Narrative in History,' p.24.

262 Ibid. 
history. This was because, for Dray, the "how possibly" account of how a particular event/object came to happen/exist in the manner in which it did is effectively identical to what historians have meant by the term "narrative." Narratives were, in other words, reducible to "how possibly" explanations:

An historical explanation may thus amount to telling the story of what actually happened, and telling it in such a way that the various transitions... raise no eyebrows. The story is told in such a way that presumptions of the form, 'But surely that couldn't have happened!,' are rebutted in advance. Answers to likely objection are built into the narrative, which may thus have explanatory force... ${ }^{263}$

From this example, it is clear there is much which is compelling about Dray's "how possibly" definition of narrative. It preserves traditional historical questioning and practice, retains the general/particular division philosophers of history were so keen to defend, and uses the concept of narrative to avoid having to adopt the more unpalatable implications of either covering law theory or empathic idealism. Indeed, Part Two of this thesis will show that Dray was in many ways quite correct about the potential gulf between the necessity of laws and their ability to resolve the finer details of the historical past. But there is also much Dray omits. As the Introduction has argued, his attempt to offer a principled epistemic definition of narrative suffers from a lack of what might be called deep structure. He makes no attempt at all, for instance, to offer any principled mechanism for the confirmation or falsification of narratives. Historical accounts, he writes, "build up to explanatory equilibrium from the evidence." 264 Yet without any given way to use evidence to move from "how possibly" to "what actually happened," Dray's method seems woefully incomplete in one of its most important areas. ${ }^{265}$

This problem is compounded by Dray's lack of clarity as to whether narrative explains in any causal sense. This is a potentially catastrophic failure, especially for a mode of explanation that Dray claims to be as fundamental as nomothetic "why" explanations. ${ }^{266}$ For by questioning whether the term 'cause' means anything at all in historical explanations but not asking a similar question of the sciences, Dray is effectively ceding any strong sense of causal explanation to the nomothetic (i.e., "why necessarily") sciences. In Laws and Explanation in History, for example, Dray argues that causal explanations in history are problematic in a way that causal

263 Ibid., p.27. (emphasis in original)

264 Dray, Laws and Explanation in History. p.129. (emphasis in original)

265 Dray, 'Explanatory Narrative in History,' p.27. (emphasis in original)

266 Ibid., p.20. 
explanation through laws is not:

Historians use the notion to draw attention to some necessary condition which, for one reason or another, is considered important in the context of writing. To say that the word is ordinarily used 'vaguely' or 'loosely' is thus misleading. We should say rather that it has its own peculiar logic, which happens to be different from that invented for it by some philosophers. It cannot be tightened up in either the metaphysical or scientific ways without changing its function; and the reformed notion could not, in any case, be employed without bringing historical narrative to a halt. ${ }^{267}$

But this raises the question: what else could we possibly mean by the term explain? Dray's own model seems instead to favour the arguments of later literary-narrativists like W. B. Gallie, who have argued that the explanatory role of narrative is to render events intelligible - to show that certain events need not have caused surprise. In such a model, the nomothetic causes are comparatively unimportant. They are like the laws of physics which presumably underpinned all of the components of Dray's improbable baseball catch - present but not really relevant. There is, of course, nothing inherently flawed about such a model. Dray himself says as much, arguing that there is "nothing wrong with calling anything less than a set of sufficient conditions a cause." ${ }^{268}$ If we actually do call "anything less than a set of sufficient conditions a cause," however, Dray seems to be arguing that we are using the term in a uniquely historical way, with its own "peculiar logic." But it is difficult to see why this should be the case. It does not seem problematic to state that the cause of, for example, an automobile accident was the failure of the brakes on the vehicle in question. There are any number of basic laws of physics here which can help explain how and why a brake failure can lead to an accident. But surely it is not a unique brand of "peculiar logic" to simply say that the brake failure "caused" the accident. Nor is it problematic to proceed further down the causal chain and submit evidence that the "cause" of that failure was, for example, rooted in the financial inability of the car's owner to perform adequate maintenance. Neither of these are complete explanations - for that we really would need to include the laws of physics - but the fact is that both statements do provide causal information. More importantly, they do so without being required to invoke a special sense of the word "cause." And even if such a sense of the word "cause" were required, Dray is not clear about what it might be, preferring instead to stake the explanatory capacity of narrative on criteria of intelligibility - the relating of a narrative in "such a way that the various transitions...

267 Dray, Laws and Explanation in History. p.112.

268 Ibid. (emphasis in original) 
raise no eyebrows." 269

\section{Dray and the Nomothetic Assumption}

An assessment of the underlying reason for these shortcomings of Dray's model will require a deeper examination of how Dray perceived the relationship between the "how possibly" (narrative) and the "why necessarily" (scientific) modes of explanation. And, in this respect, Dray was comparatively sophisticated, at least when compared with the philosophers of history we have examined so far. For instance, Dray was careful to point out that he saw no meaningful basis upon which to claim that any one of these explanatory models had primacy over the other. "I see," he states, "no point in going on to ask whether one or other is the more 'fundamental' type. Having given the one type of explanation, it very often makes sense to ask for (although it may not always be possible in practice to give) one of the other type." 270 They are answers, Dray writes, to "different kinds of questions," and therefore have "quite different logical functions." Thus, covering law theory cannot claim to be the universal form of explanation. In fact, not only is it "not the universal type of explanation," Dray argues, "it is not even the right sort of thing to be such a type." ${ }^{271}$ It is merely, Dray appears to be saying, one voice in a choir. This pluralistic and egalitarian approach to explanation had the ancillary implication, however, of calling into question the role of laws in any knowledge generating field, scientific or otherwise. Laws have their place, Dray is essentially arguing, but laws alone can never constitute a complete explanation. This, it would seem, makes Dray one of the first major twentieth century philosophers of history to be explicitly unconvinced that nomothetic, generalising explanation was a necessary criterion for doing science:

There is, in fact, some reason for thinking that what the covering law theory gives us is the criterion of a technical sense of 'explanation' found only in narrowly scientific discourse, perhaps only among certain philosophers of science.... Whether a sense of 'explain' is widely employed among theoretical scientists which means no more than 'bring under a general law' I cannot claim to know, although I suspect that it is at any rate less widespread than the philosophers in question would lead us to believe. ${ }^{272}$

Here Dray is seemingly suspicious that the shortcomings he saw in terms like "explain" and "cause" when they were applied to narrative might possibly spill over

269 Dray, 'Explanatory Narrative in History,' p.27. (emphasis in original)

270 Ibid., p.20.

271 Ibid., p.23.

272 Dray, Laws and Explanation in History. p.76. 
into the sciences as well. This might appear at first glance to be a means by which we might allow "how possibly" and "why necessarily" explanations to co-exist in science (and thus presumably in history as well). For if laws could not be complete explanations in any field, then presumably even strongly nomothetic sciences such as physics would sometimes be required to make use of "how possibly" explanations. On what basis could we then claim a fundamental distinction between history and the sciences? Seemingly aware of this line of argument, however, Dray takes explicit steps to thwart it. For while Dray was critical of what he saw as the over-reliance of covering law theorists on explicitly nomothetic physics as the paradigm of a pure science, he was not entirely ready to abandon the bifurcated vision of science and history such nomothetic assumptions had been used to establish.

To this end, while Dray postulated a plurality of explanatory models, each serving the needs of a different kind of questioning, he also made it abundantly clear that there was still a peculiarly scientific mode of explanation which remained incompatible with history. And, more importantly, that mode was still primarily concerned with generalisation. For in the absence of a universal requirement for laws, Dray argued, there must still be something which can act as an explanatory mechanism for "how possibly" type questions as they might occur in the sciences. This, for Dray, was the role of general theories:

For although... it is not my purpose here to assess the adequacy of the covering law model in scientific contexts, it would appear to be at least arguable that reference to a scientific theory may be explanatory in the ordinary sense, while reference to a generalization is not. In so far as reference to a theory does give an explanation - in science or elsewhere - it seems to me that it does so not for the quasi-inductive reasons suggested by Gardiner and others, but because it is a means of satisfying just the kind of pragmatic demands which we have been discussing. ${ }^{273}$

In essence, Dray is arguing that in those cases where the "how possibly" mode is appropriate for the sciences, general theories perform explanatory work in place of laws. For example, a case of food poisoning might be difficult to explain purely in terms of known laws, but is readily explicable in terms of the germ theory of disease. Theories themselves might (and perhaps even must) rest upon laws, but they also

273 Ibid., p.79. (emphasis in original) Note also that the "pragmatic demands" that Dray is citing here is essentially a shorthand reference to his previously examined arguments regarding the need for a mode of explanation above the crudely nomothetic, even if the phenomena in question actually are ultimately law governed. In other words, even if we explain the miraculous baseball catch using only the laws of physics, we haven't really explained it in the pragmatic sense required by the sheer complexity of the subject matter. See: Dray, Laws and Explanation in History. pp.72-73. 
allow their component laws to be effectively bypassed. Thus high-level explanation is facilitated without a descent into nomothetic complexities. Of the nature of scientific theories specifically, Dray argued that they were required to satisfy two criteria. First, "they must increase our predictive power, i.e., have the characteristic of generality," and second, "they must explain the phenomena, i.e., have intelligibility." ${ }^{274}$ This is an interesting argument, in that it seeks to preserve prediction in the absence of laws while simultaneously recognising that one need not have a strictly nomothetic theory in order to make predictions. The theory of evolution by natural selection, for instance, cannot be stated nomothetically. Thus it cannot be used to predict, for example, the exact body configurations of future organisms. But it can be used for other forms of prediction, such as that famously attributed to the British scientist J. B. S. Haldane, who, when asked what might constitute evidence against evolution, is said to have replied, "fossil rabbits in the Precambrian." 275 While of uncertain attribution, this is nonetheless a sound prediction. Evolution really does predict that no fossil rabbits - indeed, no organism at all of the organisational complexity of a rabbit - should be found in rock strata of that era. In just this way, Dray argues, theories enable "us to tell 'a likely story'." And it is this, Dray claimed, which distinguished history from the sciences. For in history, "explanations are seldom given by means of, or in terms of, theories." 276 In fact, a "theory of the subject matter," Dray asserts, "may excuse an investigator from explaining a thing historically." Historical explanations are only invoked where "what is to be explained cannot be understood merely by referring to such systematic general knowledge." $277 \mathrm{He}$ continues:

We give theoretical explanations where our knowledge of the subject matter allows explanatory interpolation; we give historical ones where no such interpolation is licensed - where we have to refer to the peculiar history of what is to be explained. ${ }^{278}$

This makes some sense, especially when considering Dray's contrast between "how possibly" and "why necessarily." We need to explain the seemingly miraculous baseball catch historically. No systematic law or general theory will help us to make sense of that particular event. But Dray seems to tacitly define historical explanation as an area in which theory is not only not present, but irrelevant. Historians "often

274 Dray, Laws and Explanation in History. pp.79-80. (emphasis in original)

275 Richard Dawkins, The Greatest Show on Earth: The Evidence for Evolution. Bantam: London, 2009. p.147.

276 Dray, Laws and Explanation in History. p.80.

277 Ibid., p.84. (emphasis in original)

278 Ibid. 
explain," Dray argues, "by means of, or in terms of, a theory, but there is nothing in the nature of such explanation which need persuade us that we cannot explain satisfactorily without one." ${ }^{279}$ However, by insisting that one of the key characteristics of theory is generality, Dray is effectively invoking the familiar argument that science is the study of the general,and history the particular. It would be "very natural," argues Dray, "to draw a sharp contrast between historical explanations and all theoretical ones." 280

But in setting up such a division, Dray invites the question: is the historical/narrative mode really a species of explanation that science can never encounter? Consider the following example. Approximately 65 million years ago, a significant fraction of all life on Earth perished (geologically speaking) quite suddenly, including - most famously - the dinosaurs. For geologists, this event marks a convenient boundary between what are known as the Cretaceous and Tertiary Periods. This event is often referred to in shorthand as the $\mathrm{K} / \mathrm{T}$ boundary or the $\mathrm{K} / \mathrm{T}$ extinction. ${ }^{281}$ There are several competing explanations for why this extinction might have occurred, although only two enjoy significant levels of empirical support. The first is the meteor impact hypothesis, which cites as evidence the remains of an impact crater near Chicxulub in the Yucatan region of Mexico which dates to the appropriate time period, and the elevated presence of the rare metal iridium in clays of $\mathrm{K} / \mathrm{T}$ age. From this it is hypothesised that an object approximately 10 kilometres in diameter struck the Earth at the K/T boundary. Ejected material from this impact is believed to have caused sudden and severe climate change, which led to mass extinction. The second theory is more gradualist, citing increased volcanism toward the end of the Cretaceous (perhaps in the formation in India known as the Deccan Traps, which is thought to have produced large quantities of lava at that time) as driving the climatic changes which led to the extinction.

By Dray's own logic, these are examples of historical explanation attempting to address a specifically "how possibly" problem. And indeed, it is difficult to disagree with this. The real question is: does that make them inherently unscientific? By Dray's

279 Ibid., p.81.

$280 \mathrm{Ibid} .$, p.84. (emphasis in original)

$281 \mathrm{~K}$ is an abbreviation for the Cretaceous Period derived from the German name Kreidezeit, whereas $T$ is an abbreviation representing the Tertiary Period. It is worth noting that the term Tertiary Period is now no longer in wide use among geologists. The time period it represented is now distributed between two periods, the Paleogene and the Neogene. Thus, the extinction event might also be correctly referred to as the K/Pg event. 
logic, even though the language of theory is present, neither of the two theories on offer possesses the required quality of generality. Rather they are aimed at the explication of one particular event - just one extinction among the several our planet has endured. They aim to show, in Dray's words, that such an extinction event was possible and thus "need not have caused surprise." 282 Moreover, both are only technical theories to the extent that they mobilise other scientific concepts in service of their own explanatory project. In Dray's terms, a properly theoretical - and thus properly scientific - explanation would be one that assimilated the $\mathrm{K} / \mathrm{T}$ extinction into a wider theory of extinctions in general. But such a theory, were it even possible, would, as Dray has said, "excuse" the "investigator from explaining... historically." 283 In that case, neither of these theories of the $\mathrm{K} / \mathrm{T}$ extinction would have any need to exist at all, unless it was as history rather than science. Thus, in Dray's terms, we would be more correct in speaking of the meteor impact narrative rather than the meteor impact theory. And yet, it seems entirely appropriate to refer to the above examples as not only theories, but as theories which belong firmly in the domain of the sciences. Such is the price of insisting on broad generality as a necessary criterion of scientific theories. More importantly, if these theories of the K/T extinction really are narratives in the sense Dray would understand them, then we might also wish to point out that we are not required to equivocate or otherwise hedge our use of the word "cause" in advancing them. These two theories are enquiring - in the strongest sense of the term - into the causes of the K/T extinction, requiring no "peculiar logic" to do so. This raises several questions. Why does Dray insist that his model is separate from the sciences? If it is not strictly necessary to use general theories to do explanatory work even in acknowledged sciences such as geology and paleontology, then has Dray's "how possibly" model not offered us another way to explain which is independent of any one discipline? What is to stop us from granting Dray's "how possibly" narratives the status of scientific theories? After all, that is how the various attempts to explain the causes of the $\mathrm{K} / \mathrm{T}$ extinction are referred to. Where did Dray's insistence on the generality of theory come from if its only contribution was to wall history off from the wider world of science?

The answer would appear to be, once again, the nomothetic assumption. Dray's substitution of general theory for general law, while perhaps making for a better definition of science than the strictly nomothetic-deductive model can provide,

282 Dray, 'Explanatory Narrative in History,' p.17.

283 Dray, Laws and Explanation in History. p.84. (emphasis in original) 
ultimately fails to underscore an impermeable boundary between history and science. Or, more specifically, it fails to do so if we approach it with a more modern understanding of scientific theory and practice. Yet Dray seems to have invoked this substitution of theory for law for no other reason than to erect just such a boundary. This seemingly perplexing move can only be made sense of when considered in the light of the nomothetic assumption. For, if that assumption were accepted by Dray, then allowing the walls between history and science to become permeable would be functionally equivalent to conceding the central argument of the covering lawyers and be thus committed to finding a way to apply both general laws and general theories to human history. From our previous examination of his work, it is clear that Dray did not think that this could be successfully done. The justification of such a boundary was therefore essential if Dray was to clear a space for history in which he might argue for a separate mode of explanation based on his ideas of narrative. So while Dray, it seems, did not himself accept a purely nomothetic vision of science, he remained committed enough to the worldview that vision had been used to establish to attempt to re-legitimise it by other means. This was the purpose of his suggested division between general theories and historical particularism. But, as we have seen, as a criterion for demarcation it excludes too much.

Indeed, the fact that even someone as sceptical of the nomothetic-deductive model as Dray had a clearly identifiable vestigial variant of it underwriting his account of historical explanation, represents good evidence that narrative separatism was quickly becoming a sublimated axiom among philosophers of history, regardless of their expressed view of the nature of science and its relationship to history. Any model which was based on narrative as a means of explanation, it was effectively assumed, could not be scientific - irrespective of whether or not one thought of science in explicitly nomothetic terms or not. Despite having argued against the centrality of laws as agents of explanation, Dray had nonetheless constructed his model of historical explanation in such a way as to maintain the division which that centrality had engineered. In just this manner, philosophy of history began to move from its mid-twentieth century period of intense debate over the nature of both history and science into a period in which narrative philosophy was ascendant, and the question of history's relationship to science was considered effectively settled. Philosophy of history was moving down a path of narrative separatism, which would ultimately culminate in a rhetorical reversal of fortunes in which narrative 
theorists and philosophers would claim that, rather than history being subsumed into the sciences, the reverse would be far more appropriate.

We will see more of this argument later in this chapter when we come to the work of the philosophers of history Louis Mink and Hayden White, as well as the philosopher and historian of science Thomas Kuhn. It will suffice to say for the moment that Dray, writing in 1957, certainly did not intend to go as far as that. Yet that is where all attempts to claim narrative as a totally separate mode of knowledge would ultimately end up, if only because the task of adequately defining narrative epistemically while still maintaining a clear narrative separatism (and thus preserving historical autonomy) was exceedingly difficult. The literary interpretation of the term 'narrative,' however, had the advantage of at least seeming intuitively plausible. Moreover, if history really were separated from the sciences by its use of narrative (an assumption that was seemingly becoming received wisdom) then what need was there to define narrative in anything other than its own terms? Epistemicnarrative was hard. The likening of the meaning of "narrative" with "fiction," on the other hand, seemed, if not exactly licensed, then at least permitted. For if narrative was not seen as scientific in any sense, then what reason could there be to prefer a scientific - or even epistemic - interpretation of it? To illustrate this crucial shift in perspective, we shall now turn to the example of W. B. Gallie, one of the first narrativist philosophers of history to take a distinctly literary approach to the definition of the term. Gallie's example will prove instructive here not only because of his literary leanings, but also because of his attempt to actively claim the failure of scholars like Walsh and Dray to adequately define the term "narrative" epistemically as evidence for his own views.

\section{W. B. Gallie and The Literary Interpretation of Narrative}

As a philosopher of history, W. B. Gallie was - like Dray, Gardiner, and Walsh before him - ostensibly concerned with finding some middle way between the perceived extremes of idealism and covering law positivism. His principal work devoted to this end was his 1964 book Philosophy and the Historical Understanding. ${ }^{284}$ Much like Walsh

284 W. B. Gallie, Philosophy and the Historical Understanding. $2^{\text {nd }}$ Edition. Schocken Books: New York, 1968. It should be noted that much of this book had previously appeared before 1964 as academic papers. See: W. B. Gallie, 'The Historical Understanding,' History and Theory. Vol. 3, No. 2 (1963). pp.149-202. See also: W. B. Gallie, 'Essentially Contested Concepts,' Proceedings of the Aristotelian Society. New Series, Vol. 56 (1955-1956). pp.167-198. 
and his desire to find a "plausible idealism," however, Gallie was, in practice, far more sympathetic toward the idealists than the covering lawyers. He makes this abundantly clear in the preface to the 1968 second edition of Philosophy and The Historical Understanding:

The writing of this book was an essay in revivalism. I wanted to breathe new life into a way of philosophising which had shot up vigourously around the turn of the last century... The central idea of that movement, of which Windelband and Rickert and later Croce and Collingwood were the main spokesmen, was that the way we understand history is basically the same as that in which we understand all purposive thought and action, and radically unlike the way in which we understand natural phenomena as instances of some scientific law or theory. ${ }^{285}$

The reason this "way of philosophising" required "new life" at all, Gallie argued, was because previous idealist philosophers had failed to find a "sufficiently clear-cut and arresting starting-point from which to shake the entrenched presuppositions of the dominant empiricist epistemology" of that time. This had, in turn, relegated their arguments to the level of mere "methodological concern... peripheral to the main issues of philosophy." Such concerns were, from Gallie's perspective, far beneath the dignity of history. Proper "historical understanding," as Gallie called it, was potentially relevant to "the whole range of human knowledge." 286 Previous philosophers of history had failed to comprehend this expanded role for history, Gallie argued, as they had focused too heavily on the justification of historical conclusions.

To make sense of this claim, it must be remembered that, at the time at which Gallie was writing, almost all debate in the philosophy of history consisted of arguments as to whether the truth of an historical proposition was underwritten by logical entailment (as in the covering law approach), empathic understanding (as in classical idealism), or some other as-yet-unknown mechanism. Concerns with such technical minutiae, in Gallie's opinion, had prevented philosophers from forming a truly comprehensive historical epistemology which might survive outside of history departments. "With hardly an exception," he argues, philosophers of history "persistently confuse delineations and analyses of historical understanding - or, if it be preferred, the task of marking it off from the kind of understanding that is achieved in the sciences - with the problem of its vindication..." ${ }^{287}$ In other words,

285 Gallie, Philosophy and the Historical Understanding. p.1. 
Gallie did not see the definition of what was science and what was history as resting solely on methods of justification (and by extension, explanation). Instead he saw history and science as entirely different epistemologies. So completely different, in fact, that it was meaningless to argue over some arbitrary border between them. Rather than attempt (as Walsh and Dray had) to show that narrative could function as an explanatory mechanism in history, Gallie instead argued that historical knowledge had no need for - or even an ability to impart meaning to - the concept of "explanation." This did not mean, however, that Gallie did not have an opinion on the form of properly historical knowledge. The native form in which knowledge ought to be expressed on the historical side of the history/science divide, he argued, was narrative. And narrative was ultimately, for Gallie, a species of story. Indeed, it was this quality of story which separated historical knowledge from the sciences. "If it is true," he argued, "that in the physical sciences there is always a theory, it is no less true that in historical research there is always a story." ${ }^{288}$ And the reason historical epistemology had failed to realise this, Gallie claimed, was because no fully developed concept of narrative had yet been offered. This, in turn, had made questions of justification more complicated than necessary:

... I find it astonishing that no critical philosopher of history has as yet offered us a clear account of what it is to follow or to construct an historical narrative. And yet such an account is plainly essential to any successful answers to more complicated questions regarding either the nature or the vindication of historical thinking. The effects of this omission are as great as those that we might expect if in philosophies of science we were to find no discussion of measurement or of controlled observation. ${ }^{289}$

Gallie saw the correction of this failure as his unique contribution to the postcovering law rehabilitation of idealism. Due to this idealist sympathies, however, Gallie was heavily influenced by R. G. Collingwood's famed division between the "inside" and "outside" of historical events. He thus sought to frame his work as a corrective to Collingwood's idealist thesis, rather than its undertaker. ${ }^{290}$ To do this, Gallie chose to define his vision of narrative as a mode of explanation purely for the "inside" of events - those aspects of history inextricably bound up with human thoughts and intentions. This philosophical commitment, however, left Gallie with a very different problem to solve than any faced by Walsh or Dray. Rather than building a concept of narrative as a mind-external construction from empirical

288 Ibid., p.72.

289 Ibid., p.12.

290 Ibid., pp.56-59. 
evidence, Gallie's vision of narrative was designed primarily to be a direct replacement for empathy, intentionally reproducing an idealist emphasis on the inner workings of human cognition. A narrative, for Gallie, was exclusively about human actions, and could only be interpreted - or "followed" - if this was so. And it was this facet of Gallie's narrativism which provided the distinction between historical and scientific understanding:

The events that lie back of the origin of language, of the family, of law and government are obvious examples. Now these events might conceivably be reconstructed anyhow in schematic outline, by biological or psychological theorists, working from evidence that is appropriate to their methods and theories. And such reconstructions might, conceivably, profoundly affect our ways of thinking about all human beings and human societies. But would we regard them as history? I do not think so. For presumably these hypothetical reconstructions would deal with changes in human life that were not subject to conscious purpose and control. And it is certainly part of our idea of history that it shall deal with human actions, efforts and purposes which we can recognise as akin to our own. Hence the supposed biological or psychological reconstructions would at best supply part of the naturalistic background of history, along with many other biological, geological and astronomical descriptions. ${ }^{291}$

In order to devise a definition of narrative which might adequately express such uniquely historical understandings of human conscious purpose, Gallie turned to another human-centric construction - the concept of story. For Gallie, narratives were essentially stories which possessed an additional quality of standing in some kind of relationship to historical evidence. While Gallie was certainly aware of the importance of this evidential relationship, he argued that it was not evidence or the manner of its use which made historical knowledge different from the sciences. ${ }^{292}$ Instead it was this property of narrative - of story. All that this achieves, however, is a transference of the requirement for definition from one term to another. To make any sense of Gallie's account of narrative, therefore, we must examine what he means by the term "story."

"Every story," Gallie argues, "describes a sequence of actions and experiences of a number of people, real or imaginary." These narrative subjects are then "presented in some characteristic human situation," which they must influence or alter through some deliberate action. This often gives rise to a "predicament, calling for urgent thought and action from one or more of the main characters." This conflict then "brings the story to within sight of its conclusion." This is only one aspect of a story, 
however, as a story must also possess an intelligible logical development. This development, however, is more than merely "understanding words, sentences, paragraphs, set out in order." Rather it is to "understand the successive actions and thoughts and feelings of certain described characters with a peculiar directness, and to be pulled forward by this development almost against our will." This initial definition might be too flimsy for general discussion, Gallie concedes, but it is broadly defensible as a "rough sketch-map of the area." Gallie then goes on to offer better definitions of three of the key terms laid out in this map: "conclusion," "following," and "interest." 293

"Conclusion" argues Gallie, is a fundamental property of story (and, by extension, narrative), which represents the outcome of historical understanding, and is "a different kind of conclusion from that which is synonymous with 'statement proved' or 'result deduced or predicted'." ${ }^{294}$ Likewise, to "follow" a narrative is not merely to predict the conclusion to which it is leading, or to see that "some earlier event necessitated a later one," but instead to see "that a later event required, as its necessary condition, some earlier one." 295 This lends intelligibility to a narrative, which is the basis of its ability to be followed:

... almost every incident in a story requires, as a necessary condition of its intelligibility, its acceptability, some indication of the kind of event or context which occasioned or evoked it, or, at the very least, made it possible. This relation, rather than the predictability of certain events given the occurrence of others, is the main bond of logical continuity in any story. ${ }^{296}$

In this respect, Gallie's "following" resembles Dray's rejoinder to relate events so that they "need not have caused surprise," related in a literary rather than a causal vocabulary. Gallie's quality of "interest," however, has no clear antecedents. For Gallie, the desire to follow a narrative comes from a quality of "interest" in its conclusion. "The conclusion of a story," he argues, "guides our interest almost from the start." When one is introduced to the principal characters of a story, Gallie claims, one begins "so to speak, to live in them and with them, we are willing to go with them, to follow them, in almost any direction. They interest us, and all we can ask is 'What will happen to them now?' and 'What will happen to them next?'” And this interest ultimately, Gallie argues, naturally becomes an investment in the story's

293 Ibid., pp.22-23.

294 Ibid., p.23.

295 Ibid., p.26.

296 Ibid. 
conclusion: "'How will things turn out for them in the end?"'297 This interplay of interest and conclusion Gallie refers to as "teleologically guided" attention. ${ }^{298}$

"Can this analysis of story," Gallie asks, "help us to articulate what is peculiar to historical understanding?" Moreover, is an "element of story or narrative... essential to all history"? Gallie answers in the affirmative in both cases. It should be noted, however, that Gallie almost immediately moves to qualify this. For given the immense variety of material which might legitimately called history (even counting only that which meets Gallie's criteria of concern with purposive human action), the criteria of narrative would have to be a good deal more flexible than this. Gallie argues, however, that "a great deal of historical literature is ancillary to or parasitic upon history of a more central and substantial kind." ${ }^{299}$ Such "ancillary" history consists of "not only the production of lists, accounts, diary jottings, etc., as evidence for or against some generally accepted conclusion" but also:

... the kind of book or article which sets itself the modest purpose of filling in the background to certain major and already deeply studied events, and again the ever-increasing amount of discussion between leading historians as to the proper or most profitable line of approach to and interpretation of different topics and periods. ${ }^{300}$

Such historical material, Gallie argued, could safely be dismissed from consideration as merely providing support for those more important histories which "treat of some major achievement or failure of men living and working together, in societies or nations or any other lastingly organised groups." Although the dry style and emphasis on the complexities of causation might cause even this kind of history to offend "against both romance and simplicity," and while also conceding that "every genuine work of history is also a work of reason, of judgement, of hypotheses, of explanation," Gallie nevertheless maintained that history was "a species of the genus Story" because its appreciation and usefulness of such works were realised through "following" and "interest." 301 Gallie contrasted this view with understanding in the sciences:

To appreciate, and in a proper sense, to use, a book or a chapter of history means to read it through; to follow it through; to follow it in the light of its promised or

297 Ibid., p.28. (emphasis in original)

298 Ibid., p.64.

299 Ibid., p.65.

300 Ibid.

301 Ibid., p.66. 
adumbrated outcome through a succession of contingencies, and not simply to be interested in what resulted or could be inferred as due to result from certain initial conditions. Both the natural and the social sciences are particularly and properly interested in results in this sense, since it is their logically required and predicted results that prove their laws and hypotheses right or wrong. The systematic sciences do not aim at giving us a followable account of what actually happened in any natural or social process: what they offer us is idealisations or simplified models of the sorts of thing that should have happened, if their currently accepted laws and theories are to be trusted, and from which further testable deductions can be made. But history, like all stories and all imaginative literature, is as much a journey as an arrival, as much an approach as a result. Again, every genuine work of history is read in this way because its subject-matter is felt to be worth following - through contingencies, accidents, setbacks, and all the multifarious details of its development. And what does this mean if not that its subject-matter is of compelling human interest... ${ }^{302}$

That is, histories can only be made sense of as a whole. If one wishes to properly understand a work of history, one cannot merely skip to the final page and read the concluding remarks. The same is not true, Gallie claims, in scientific works.

And so we arrive at a fairly traditional understanding of history as a particularistic study of past human affairs. But, Gallie argued, his addition of a developed concept of narrative to the philosophy of history has important additional consequences. For by defining historical understanding as flowing from the component concepts of narrative, Gallie claimed to have brought the philosophy of history out of the methodological ghetto to which it had traditionally been relegated, and allowed it to be applied anywhere his narrative criteria are met. Thus "history," Gallie argued, "conceived as a form of understanding, has a proper concern with every other field and form of knowledge and understanding." ${ }^{303}$ All knowledge-generating disciplines have experienced historical development to get to their present moments, and these developments, being temporal and particular, could only be understood historically. Which, for Gallie, was functionally equivalent to saying that they could only be understood through narrative. Much of the rest of Philosophy and the Historical Understanding is devoted to arguing this epistemological point. Traditional approaches to epistemology, Gallie argued, had focused on the static and timeless, either by "equating what is knowable with what is unchanging (e.g., the Parmenidean One, the Platonic Forms, the Cartesian simple natures)" or by "restricting knowledge and indeed all genuine thought within necessarily fixed limits (e.g., Kantian a priori categories...)." Because of this, philosophy had often

302 Ibid., pp.66-67.

303 Ibid., p.7. (emphasis added) 
chosen to ignore the "constantly changing and expanding empirical content" implied by such limits, focusing instead on the "fixed conceptual framework, which is enshrined in and imposed by the categories of thought or of language." 304 Both approaches, Gallie argued, ignore history almost totally. And it was to this failure which Gallie offered narrative and the concept of historical understanding as a corrective. Narrative was, for Gallie, a way of formally conceptualising change as knowledge.

It is this facet of Gallie's philosophy of history which he saw as providing a way to move beyond the old idealist/positivist dichotomy. By attempting to define history as exclusively narrative, and linking it - via the axiomatic assumption of an inherent human interest in narrative/story - to human conscious purpose, Gallie believed that the naïve intuitionism of empathy was averted. This is because the human interest in "following" a narrative and in its conclusion was a necessary component of the definition of narrative itself. It was 'built-in,' so to speak, and thus a problem of form rather than justification. The idealist flavour of history was thus preserved, and the problem of empathy being used to attempt to justify historical descriptions avoided. This constituted Gallie's third way, and was the basis for his entire philosophy of history. One area Gallie's narrative did not address, however, was the provision of some mechanism by which narrative could be said to explain. We have already seen how Walsh and Dray struggled with this question. Gallie's way of dealing with this seemingly crucial aspect of historical knowledge, however, was to use the literary dimension of his vision of narrative to argue that explanation was simply not an issue history was required to address. This was just one way in which a literary vision of narrative could be used to evade the kinds of difficult questions epistemic accounts were required to answer.

\section{The Role of Explanation in Gallie's Model of Narrative}

Where historical understanding was, in Gallie's words, "the exercise of the capacity to follow a story," his vision of the role of explanation was somewhat different. For Gallie, historical narratives only invoked explanation when it was required to make a narrative followable. To follow an historical narrative, Gallie argued, "requires the acceptance, from time to time, of explanations which have the effect of enabling one

304 Ibid., p.6. (emphasis in original) 
to follow further when one's vision was becoming blurred or one's credulity taxed beyond patience." This was the "peculiar and all-important role of explanations in history." ${ }^{305}$ Despite being described as "all-important," however, it is clear that this role is auxiliary to the purpose of history, rather than being the purpose itself. ${ }^{306}$ This assertion, however, can only be made if one accepts Gallie's argument that history (and thus historical understanding) is separated from the sciences by its narrative nature, and can therefore operate entirely independently of its epistemic requirements. Previous philosophers of history, Gallie argued, had fallen into error by failing to grasp this, and had thus assumed that history and the sciences took place in the same epistemic territory:

There has been a persistent tendency, even in the ablest writers, to present historical explanations as so many curiously weakened versions of the kind of explanation that is characteristic of the natural sciences. To speak more exactly, it is claimed or assumed that any adequate explanation must conform to the deductivist model, in which a general law or formula, applied to a particular case, is shown to require, and hence logically to explain, a result of such and such description. ${ }^{307}$

This was deeply misguided, Gallie argued, as both history and historical understanding were oriented toward fundamentally different ends. Indeed, even if an "historic incident or development" provided "a model instance of some scientific law," the historian might:

... remark that the developments he has described conform exactly to the law in question. But there is no compelling reason why, in his role of historian, he should do so; and if he does, he will mention it as something incidental to his main job, which is to present the development as part of a followable, and on the evidence acceptable narrative. ${ }^{308}$

This is a picture of historical and scientific understanding starkly divided according to the nomothetic assumption. Scientific understanding, for Gallie, was about explanation in terms of laws. Historical understanding, on the other hand, was about intelligibility through narrative. This, in Gallie's view, provided several advantages, not least of which was the ability to claim that history simply did not need a model of explanation. Explanation was something that sciences - and only sciences - did. Thus Gallie could claim not to need to even address the question of whether or not narratives could be said to explain the events they described. Certainly a narrative

305 Ibid., p.105.

306 Ibid., p.107.

307 Ibid., p.105.

308 Ibid., pp.108-109. 
could involve some sort of explanation, but this would be "incidental" to its main purpose. And on those occasions when it was necessary, the explanation so offered was presumably underwritten by laws and theories from the sciences, because that is what explanation means. Once again, then, we can see the nomothetic assumption being indirectly used to shape the philosophy of history.

Gallie's decision to evade questions of explanation and justification altogether also left him free to re-adopt the idealist emphasis on human action and thought in history without being forced to assert some form of empathy as an epistemological guarantor of its explanatory power. For there was, in his view, no explanation taking place which required such a guarantee. Yet Gallie's entire philosophical construction depended on his basic assertion that the very concept of narrative itself (not merely his own definition of it) was utterly hostile to the possibility of explanation. And that assertion was, in turn, based upon the inability of previous narrativists to adequately define the concept in such a way as to show it to be explanatory. Of such previous attempts at narrativism, Gallie writes:

... our contemporary analysts leave us, and leave the weight of their argument, resting entirely upon our familiarity-bred, intuitive, unanalysed and indeed undiscussed notion of what an historical narrative is and of its resemblances and differences to other basic forms of communication. ${ }^{309}$

Given our previous examination of the examples of Walsh and Dray, we might certainly agree with Gallie's sentiment that their attempts to articulate a vision of narrative were unconvincing. It is worth remembering, however, that their attempts were doubly so for Gallie. For his stated understanding of what constituted genuine explanation was similar to that of the covering lawyers - the ability to show that something was a necessary consequence of a general theory or law. Where Dray, as we have seen, was prepared to at least consider intelligibility as constituting explanation, Gallie was not. The unreasonably high bar the nomothetic-deductive method had erected for what constituted an explanation, coupled with the failure of previous narrativists to offer anything approaching a comprehensive definition of narrative, led Gallie to believe that the concept of narrative simply could not function in the epistemic sphere. Their failure, in other words, had licenced the abandonment of the epistemic dimension of narrative altogether. For whatever the failings of Gallie's definition of narrative, at least it was a definition. Moreover, such a literary

309 Ibid., p.19. 
definition of narrative could be seen (in the light of the nomothetic assumption) as the only way in which a narrative vision of history could be made to work. Thus we can see that Gallie's decision to abandon epistemology and pursue a literarynarrativist path through the idealist/positivist dichotomy was due, at least in part, to a strongly held nomothetic assumption regarding science.

\section{Gallie and Narrative Determinism}

Unfortunately, Gallie's breaking up of narrative into concepts rooted in human cognition - including "interest," "following," and "conclusion" - was to have additional far-reaching consequences for contemporary philosophy of history. For this emphasis on human interpretation meant that the terms themselves could shift in meaning, depending on the time and place in which they were used/interpreted. Thus it was possible that the definition of narrative itself could change over time. Not only was the evidentiary material by which we know the past open to interpretation, in other words, so were the very meshes and nets by which it was to be organised. This was made possible by the particularism inherent in the concepts themselves. Take, for instance, Gallie's most flexible concept - "interest." As we have already seen, Gallie's approach to history allowed him to focus on human intentionality without any concomitant requirement to explain human actions. This was essential because, in Gallie's view, explanation, being characteristic of scientific understanding, must necessarily be accomplished through the use of general laws and theories. Producing an explanation of human action, therefore, would require a general law or theory of human actions, the possibility of which Gallie believed was self-evidently absurd. There was no single fixed theory by which to explain human action, he argued, only "interest." And who could say what might interest any particular individual/group at any time? Such concepts could not be formalised or otherwise reduced to generalities:

... there is no history of human beings or societies that cannot and do not, in an extended sense of the phrase, speak to us: that do not belong with us in a single no matter how fragmentary - communication system. Thus there is no single study or method of study of the human past per se. To be studied as history, a set of past human actions must be felt by members of some human group to belong to its past, and to be intelligible and worth understanding from the point of view of its present interests. ${ }^{310}$

310 Ibid., p.52. (emphasis in original) 
In other words, if human conscious purpose is presupposed in narrative - and thus in history - it is not an epistemic stretch to then define narrative/history purely in terms of human appreciation/interest. Thus, by Gallie's own argument, while we can say that "interest" is fundamental to narrative, we can say nothing more concrete about it. The complexity which effectively renders every moment in history unique forbids it. The same is true of the qualities of "following" and "conclusion." One might argue that terms incapable of such refinement are correspondingly weak as definitions. In Gallie's view, however, such terms simply do not require any further definition or formalisation of any kind, and would resist any attempt to provide it. This is the basic shape of Gallie's more widely known argument regarding "essentially contested concepts." These are concepts like "art" or "democracy," the borders of which are intuitively clear, but the more precise content of which is capable of endless revision and debate. In the case of such concepts, Gallie argues, such ceaseless redefinition and argument is not a sign of imprecision or conceptual weakness, but is a true expression of the most basic nature of that concept. Hence the essentially in "essentially contested." The "proper use" of essentially contested concepts, he writes, "involves endless disputes about their proper uses on the part of their users." 311

Removing explanation as a goal for history thus effectively paved the way for what was to become a far more literary understanding of history. For example, if "following" (i.e., intelligibility) rather than explanation was the proper object of historical understanding, then the quality of the written narrative description itself that is, how well it realised the goal of intelligibility - could potentially become a central concern. Thus it is with Gallie that we first begin to see a shift in emphasis from the realist/empirical realm to the realm of narrative itself - from content to form. Nor is this limited only to the definitional components of Gallie's narrative. Its most tangible (and arguably dangerous) manifestation is to be found in Gallie's weakening of the notion of "one historical world" - that is, the realist axiom by which no two true historical accounts could fundamentally contradict either one another (or indeed any true conclusion made in the sciences). This idea, which was so important in the work of Gardiner, Walsh and Dray, Gallie instead thought of as:

... an intellectual ideal or device which is essential for the practice of history as we know it; but its location, if it must be given one, is in the heads, because in the

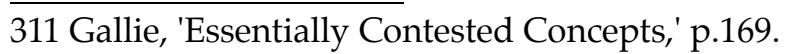


hopes of historians. To speak more exactly: the one historical world is an idea without any definite descriptive content, indeed it is not an empirical idea at all. ${ }^{312}$

This represents nothing less than the transference of what had previously been seen as a strong empirical/epistemic issue to the realm of form and convention. In this way, the concept of narrative, decoupled from epistemology and aligned with the literary, began to be seen as having power to determine content rather than merely describe it. This, in turn, was possible because Gallie's definition of narrative (and thus all historical understanding) placed such strong emphasis on the perceptual machinery of human beings. Gallie's qualities of "interest," "conclusion," and "following," were effectively meaningless without some reference to human cognition. A narrative must be of interest to somebody, followable by somebody. They cannot be understood apart from this. ${ }^{313}$ And given the "essentially contested" nature of the basic components of Gallie's narratives, the failure of a work of written history could be ascribed to either a flaw in evidence or logic, or to the assessor's disagreement with the author's ability to engender "interest" and/or "following." Form and content are thus blurred together. Thus implied constantly throughout Gallie's work is the idea that narratives were inextricably linked with human consciousness in a way that scientific knowledge was not. And it was this focus on human perception which was the driver of this greatly expanded role for formal construction in historical knowledge.

Gallie's definition of narrative, therefore, represented a radical attempt to dissolve the (perceived) problem of intuitionist revival versus nomothetic scientism. That Gallie sought to accomplish this by denying that explanation had any place in history was certainly inventive. But by predicating his model on human ideals of interest and followability, Gallie had effectively smuggled a different set of supposedly selfevident intuitionist ideas in through the back door. These ideas, moreover, had been implicitly licenced by the assumption that history was utterly removed from scientific understanding by its complexity and inability to be captured in general systems. More importantly, the form of Gallie's narrative was viewed as so flexible (due to the complexity of human interests which underpinned it) that decoding the form itself became a significant part of historical study. These charges would likely not have worried Gallie, of course, as it was clearly his intention to formulate history as a mode of knowledge based on story, fully cognisant of all the connotations the term

312 Gallie, Philosophy and the Historical Understanding. p.59.

313 Ibid., p.23. 
carried. But from such a beginning was born the school of philosophy which viewed history as a primarily literary phenomenon. This was the thread which would provide a rationale for the "linguistic turn" in history and ultimately led to the narrative determinism of Louis Mink and Hayden White. If explanation in science could be shown to encompass a non-nomothetic vision of explanatory narrative, however, then this turning away from epistemic issues in history would become unsupportable, and the requirements which Gallie and subsequent narrativists were happy to dismiss as problems of scientific rather than historical understanding would begin to reassert themselves. Or, put another way, if Gallie and subsequent literary-narrativists are wrong about science, then they are wrong about history. And, as we shall see in Part Two, they have been very wrong about science indeed. Purely epistemic approaches to narrative, however, were not to be defeated quite so easily. In order to demonstrate this, let us now turn to the case of Arthur Danto, a multidisciplinary philosopher whose work in the philosophy of history attempted to offer precisely the kind of epistemic definition of an explanatory narrative which Gallie claimed had been lacking from the philosophy of history.

\section{Arthur Danto and the Logic of Narration}

In Arthur Danto's writing on the philosophy of history can be found perhaps the best and most complete attempt to clearly define what narratives are, how they relate to historical evidence, and how they can function as explanations. Exactly the kind of questions, in other words, that Gallie and subsequent literary-narrativists would choose to abandon or otherwise marginalise. Because of this, Danto's 1965 work Analytical Philosophy of History stands essentially alone in the field. ${ }^{314}$ While, as we shall see, the conclusions Danto reached were not particularly revolutionary - due in part to his nomothetic assumptions regarding science - his work in articulating a logical form for narrative description is remarkable for its sheer depth alone. Indeed, the criticism we have already levelled at the unwillingness and/or inability of Walsh, Dray, and Gallie to properly define narrative in anything other than oppositional terms (that is, primarily useful because it wasn't science) cannot be credibly levelled at Danto. Analytical Philosophy of History was oriented almost entirely toward such definitional questions. Danto's approach to this problem was to show, by paying the

314 Arthur C. Danto, Analytical Philosophy of History. Cambridge University Press: Cambridge, 1965. Reprinted in 2007, with additional commentary, as: Arthur C. Danto, Narration and Knowledge (including the Integral Text of Analytical Philosophy of History). Columbia University Press: New York, 2007. All citations here will be from this 2007 version. 
kind of close attention to definitions which had hitherto been lacking, that many seemingly intractable issues in the philosophy of history were based on little more than the conflicting usage of terms like "explanation" and "significance." Thus, the Analytical Philosophy sought to dissolve problems rather than "solve" them in any traditional sense.

Many of the old structures of idealism are rejected in Danto's analysis. His rebuttal of empathy/re-enactment was comprehensive. His argument against any meaningful difference between 'plain' and 'significant' narrative (to use Walsh's phraseology) similarly so. His analysis of the class of arguments which insist that the "the past" is possessed of a special nature, which requires a wholly different epistemological approach from that of the sciences, was ruthlessly efficient and presaged similar work in the philosophy of science by such philosophers as Peter Kosso. Largely spared Danto's critical appraisal, however, was the notion of narrative as a peculiarly historical property which might be usefully contrasted with a science oriented exclusively toward generality. Thus, despite his sophistication in other areas, Danto essentially reproduced the narrative separatism of his predecessors. "The difference between history and science," Danto argued, "is not that history does and science does not employ organizing schemes which go beyond what is given. Both do. The difference has to do with the kind of organizing schemes employed by each. History tells stories." ${ }^{\prime 315}$ Danto's notions of science, therefore, were deeply implicated in his definition of both narrative and history as a whole.

Danto constructed his model of history by collecting together the consequences of a series of careful definitional arguments regarding what it is to call something "history." And these arguments are worth examining here in some detail, as they explicitly contrast historical knowledge with that of the sciences at every step. More specifically, Danto sought to identify what history did that the sciences did not, and to build his definition of both history and narrative upon any points of difference so identified. This not only reveals Danto's own presuppositions about science, it also effectively renders his entire vision of history dependent upon the correctness of those presuppositions. Before even beginning to speculate as to the nature of narrative and historical explanation, however, Danto sought to isolate exactly what a narrative would be required to explain and what might safely be jettisoned. To do this, he

315 Danto, Narration and Knowledge. p.111. (emphasis in original) 
devoted a chapter of the Analytical Philosophy to establishing a firm logical difference between what he called "substantive" and "analytical" philosophies of history. Danto drew this distinction in order to make a clear point about the nature of historical knowledge. "Substantive philosophers of history," were, Danto argued, like historians in that they were "concerned to give accounts of what happened in the past." But where historians had this as their only aim, Danto claimed, substantive philosophers of history sought "to give an account of the whole of history." And this (since one can only assume that history is an ongoing concern and that the events of today will be fodder for the historians of tomorrow), must necessarily include the future. Thus, writes Danto, the "substantive philosophy of history is an attempt to discover a kind of theory concerned with the... notion of the whole of history." These theories could be either descriptive or explanatory. A descriptive theory would attempt to "show a pattern amongst the events which make up the whole past, and to project this pattern into the future," whereas an explanatory theory would be additional to this, an attempt to "account for this pattern in causal terms." Danto compares the difference between these two approaches to the difference between the descriptive theory of planetary motion offered by Kepler, and the explanatory approach (via universal gravitation) of Newton. ${ }^{316}$

Yet, Danto argued, all attempts at such "substantive" philosophies of history had been manifestly unsuccessful. The reasons for this, he argued, were two. First, because philosophies of history have been (when compared to laws and theories in the sciences) "unspeakably inept, with almost no power to predict." And second, because such an analogy reduced the actual practices and products of the discipline of history to the level of mere data-gathering - useless without further synthesis. In other words, the "substantive" approach divorced the making of factual statements from their interpretation. In such a view, the tightly focused historical monograph or journal publication which makes up the bulk of modern historical scholarship would be equivalent to the tables of data from which, for example, Kepler distilled his laws of planetary motion. Yet, to say that there were not arguments being made and interpretation of evidence being performed in even the most minutiae-obsessed of historical publications, Danto argued, was absurd. Historical explanation, whatever its nature, could not only be taking place at the level of grand laws. For this reason, Danto concluded that history must be some other form of knowledge underwritten

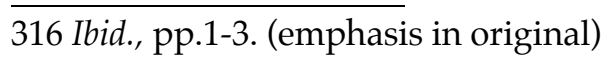


by an entirely different explanatory process. "If we think," he wrote, "of ordinary historical accounts (and not even just the best of these), they seem to be highly developed instances in their own genre, satisfying criteria applicable to that genre, and throwing into relief the way in which philosophies of history fail miserably to satisfy the criteria for a scientific theory." ${ }^{1317}$ This, of course, begged the question as to just what "genre" history belonged to if historical accounts/explanations could not be captured by the nomothetic model. The answer, Danto asserted, lay in the concept of narrative. From a dissatisfaction with past attempts to replicate the nomothetic ideal of science within history, therefore, Danto began to construct his narrative alternative. But before saying precisely how narrative operated, Danto first had to define it in such a way as to allow the exclusively past-focused academic history he wished to preserve to be separated from the grand "substantive" philosophies of history he wished to exclude. Moreover, he also had to make sure that both might be firmly distinguished from the nomothetic sciences. Or, put another way, he had to make history historical. Danto achieved both of these goals through the concept he variously called "meaning" or "significance."

\section{'Significance' as the Basis for Danto's Narrative}

Danto's concept of "meaning" /"significance" was the most basic building block of his definition of narrative. It was not only the most fundamental property of narrative, but also the single basic characteristic which was to firmly and completely divide historical from scientific knowledge. All historical accounts, Danto argued, employed some sense of "meaning," whereas explanations in the sciences did not. Philosophies of history, he wrote:

... tend to give interpretations of sequences of happenings which are very like what one finds in history, and very unlike what one finds in science. Philosophies of history make use of a concept of interpretation which it seems to me would be grossly inappropriate in science, namely a certain concept of meaning. ${ }^{318}$

From the route by which Danto has arrived at not only the need to separate history and science but the method ("meaning") by which he has done so, we can see a clear acceptance of a nomothetically conceived science in which the "power to predict" is a required test for membership. Danto is effectively pointing out that the reason substantive philosophies of history (such as those of Vico, Hegel, or Marx) have

317 Ibid., p.5. (emphasis added)

318 Ibid., p.7. 
failed when judged by the standards of nomothetic science is because they simply aren't science, despite their focus on reduction and prediction. For even these substantive accounts, Danto claims, are working instead within an entirely different mode of knowledge. That is, they are producing narrative accounts of the past, oriented around a central idea of "meaning" or "significance." And it is this idea, Danto argues, which is both the source of the illegitimacy of substantive philosophies of history, and the key to successfully formalising narrative as an epistemology.

On the surface, Danto's arguments for the necessity of "meaning" or "significance" as concepts seem similar to those of Gallie. Gallie, it will be recalled, chose to define narrative in terms which relied specifically on the machinery of human cognition in order to gain any content at all. Danto's vision of "meaning," however, was more empirically grounded. For Danto, the terms "meaning" and "significance," when applied to historical events/objects, acquired content not from some unknown process of the human mind, but from other events/objects. More specifically, an earlier event/object acquired a sense of "significance" because it had some important causal relation to a later event/object. Thus the concept of meaning, Danto argued, must be logically and inherently temporal. "It is only retrospectively," he writes:

... that we are entitled to say that an episode has a given specific meaning, and then only with respect to the total work. But information concerning the total work is just what we lack when we are going through it for the first time: then, if something strikes us as meaningless, we have to wait and see whether it is so: and if something seems to us to have a certain meaning, then again, we must wait and see if we are right. We are often obliged to revise our views concerning the meaning of an episode, in the light of what happens afterwards. This sense of meaning has application in history too. Now that the French Revolution is over, we can say what was the significance of the Tennis Court Oath - something which even the participants in that event might have been wildly wrong about. ${ }^{319}$

In this way, Danto both introduces and justifies the intuitively familiar form of narrative as some kind of account over time. Simultaneously, Danto also succeeds in logically justifying the stipulation that a narrative can only be created about events in the past of the person who produces it. This definitional move not only captures the exclusive focus of actual historians on the explication of events in their own past, but also has the additional advantage of showing the efforts of substantive philosophers of history to be deeply misguided. For the temporal nature of "meaning" and/or "significance" would mean that the substantive philosopher of history who wants to

319 Ibid., p.8. 
discern the pattern behind the whole of history, which must necessarily include the future (in its capacity of history-to-be), is making judgements regarding the meaning and significance of events that have not yet occurred. Or, if they have occurred, without the re-contextualisation that subsequent events might provide. For even if the event/object is extremely ancient, it might yet acquire some new significance on the basis of some future event or discovery. Consider, for example, the added significance for evolutionary biology that certain dinosaur fossils (those creatures of the suborder Theropoda) acquired after compelling evidence was discovered that they were the ancestors of modern birds. ${ }^{320}$ It is precisely this possibility of indefinite future addition/revision which is the source of the illegitimacy of the substantive philosophy of history, argues Danto. The substantive philosopher of history "is one who speaks about the future in a manner which is appropriate only to the past, or who speaks of the present in the light of a future treated as a fait accompli." 321 This, for Danto, was a profound abuse of the possibility of historical knowledge, and was due (at least in part) to a desire to force history into the likeness of nomothetic science. And yet that which made such speculative work illegitimate - the temporal nature of any concept of "meaning" and/or "significance" - was also that which justified "ordinary" historical work.

Danto's idea of a specifically historical "meaning" or "significance" is also fundamentally connected to narrative. "To ask for the significance of an event, in the historical sense of the term," Danto argued, "is to ask a question which can be answered only in the context of a story." 322 And so it was narrative which, for Danto, was the basis of this unique form of historical knowledge. This was in stark opposition to scientific form of knowledge, which was instead concerned with prediction and general laws:

The mode of organizing events which is essential to history does not, I shall argue, admit of projection into the future, and in this sense the structures in accordance with which these organizations are effected are not like scientific theories. ${ }^{323}$

So, in sum, historical knowledge deployed concepts of "meaning" and "significance" which, according to Danto, had no place in the sciences. Moreover, it was those same

320 This hypothesis can be traced back to the nineteenth century - specifically to Thomas Henry Huxley himself. Truly compelling evidence however, did not emerge until the development of cladistic methods of anatomical comparison during the 1960s. See: Luis M. Chiappe, Glorified Dinosaurs: The Origin and Early Evolution of Birds. John Wiley \& Sons: Hoboken, New Jersey, 2007.

321 Danto, Narration and Knowledge. p.9. (emphasis in original)

322 Ibid., p.11. (emphasis in original)

323 Ibid., p.15. 
qualities which prevented prediction, and thus - via a nomothetic assumption regarding science - disqualified history from being a science. And, because the event itself and the subsequent event by which it must acquire said significance are necessarily temporally separated (even if only by a very short time), the significance of events could only be told as a story in time - which Danto called a narrative. Moreover, Danto argued, the fact that historical events acquired their significance in terms of other events meant that it was logically impossible for any account of the past to be complete (in the sense of requiring no further revision). For some future event might occur which would lend new significance to a past event, and thus require the revision of relevant historical accounts. Thus Danto has also provided a consistent logical defence for the endless revision and shifts in perspective which characterise the historical enterprise. If one accepts the flow of his logic, it seems, one is committed to a view of history reminiscent of the (almost certainly apocryphal, but instructive nonetheless) anecdote usually attributed to the Chinese statesman Zhou Enlai. When asked (supposedly by Richard Nixon in 1972) about the impact of the French Revolution on Western civilisation, Zhou - a former student of French history - is alleged to have replied, "it is too soon to tell."

\section{Danto and the Explanatory Power of Narrative}

In order for Danto's model of narrative to be an epistemic model, however, he is required to say something regarding how narratives relate to explanation. Without such an account, his own work on explanation is subject to precisely those failures which led Gallie to turn away from the epistemic possibilities of the narrative form altogether. Danto's approach to this problem is both prescient and unique, and will have important implications for Part Two of this thesis. The problem with past attempts to integrate narrative and explanation, Danto argued, was that narrativists like Walsh and Dray had insisted on the narrative form and the issue of explanation as being separate issues. And this, Danto claimed, was simply incorrect. At best it demonstrated a lack of seriousness regarding narrative as an epistemic alternative to laws. One did not, for instance, demand a further account of why nomothetic laws constituted explanations. This is because explanation is part of the very definition of what a law is. So why was narrative assumed to be so weak as to be required to define itself in terms external to itself? This would seem to be a case of narrativists tacitly accepting the inferiority of narrative even as they ostensibly worked to defend it. 
Much better, Danto argued, to seek the explanatory content of the concept itself.

In order to demonstrate this, Danto examined the classic example of the separation of narrative and explanation as represented by W. H. Walsh's proposed difference between "plain" and "significant" narrative. "Plain" narrative, it will be recalled from Chapter Two, being "an exact description of what happened," and "significant" narrative being aimed "not merely at saying what happened but also at (in some sense) explaining it." 324 This division, Danto pointed out, separated narrative and explanation, meaning that the two concepts had to be separately defined and justified. Danto was unconvinced by such arguments, however, and instead argued that to relate any kind of narrative at all was explanation, thus collapsing these two processes into one. ${ }^{325}$ This approach had two key advantages. First, it removed the need to integrate conceptually separate discussions of explanation with narrative. And second, it removed the requirement to see history as a transformational method (i.e., a process which took the past as input, and produced "proper" history as output). For Danto, narrative was a much more fundamental process than that. In fact, Danto argued, narrative is that which takes place whenever time-separated events are described. And that description, no matter how seemingly trivial, represents an explanation insofar as it links these events in some way.

Central to these arguments for history as a process which produced narrative, Danto argued, was the idea that an account of the past containing no explanatory content was not only possible, but practical. Such an account was what Walsh had called "a description of the facts restricted to a straightforward statement of what occurred." 326 From such descriptions, Walsh's argument runs, historians fashioned interpretations - higher level structures which somehow explained the transformations that the chronicle merely described. "This is," Danto responds, "a distinction I am unable to accept. For I wish to argue that history is of a piece... there is nothing one might call a pure description in contrast with something else to be called an interpretation." 327 If it is a narrative at all, Danto argued, then it must contain some interpretive (i.e., selected according to some criteria of meaning/ significance) content:

324 W. H. Walsh, An Introduction to the Philosophy of History. Third (Revised) Edition. Hutchinson \& Co.: London, 1967. p.32.

325 Danto, Narration and Knowledge. p.119.

326 W. H. Walsh, "Plain' and 'Significant' Narrative in History,' The Journal of Philosophy. Vol. 55, No. 11

(May 1958). p.480.

327 Danto, Narration and Knowledge. p.115. 
I shall say, then, that any narrative is a structure imposed upon events, grouping some of them together with others, and ruling some out as lacking relevance. So it could not be a distinguishing mark of any given kind of narrative that it does this. $^{328}$

Danto pushed this argument much further, arguing that descriptions of even seemingly trivial events/objects must contain explanatory content. It is not even possible to say, he argues, without involving this fundamental temporal property of narrative, that a person is performing an activity like "planting roses." They might, so far as an eyewitness might report after a moment's glance, "just be putting a seed in a hole when we describe [them] as 'planting roses,' or simply turning screws when we describe [them] as 'repairing the radio'." 329 Such statements Danto called "narrative sentences." Such sentences, in Danto's broadest definition, "refer to at least two time-separated events though they only describe (are only about) the earliest event to which they refer." ${ }^{330}$ Such sentences are explanatory in the sense that if we were to enquire as to why someone was, at that very moment, putting a seed in a hole, the reply "they are planting roses" would carry some explanatory power. Narrative sentences can be made to explain still further if we choose to draw specifically causal links between earlier events and later ones. Similarly, narrative sentences can also have a colligatory function - drawing together disconnected events/objects (such as "simply turning screws") into a higher level theoretical description ("repairing the radio"). And in this sense too, explanation is performed.

Danto's "narrative sentences" are also unique in that their truth value depends upon the time at which they are uttered. Therefore, given the constant re-contextualisation which (as we have already seen) must always be possible with respect to assessments of historical significance, the class of true statements it is theoretically possible to make about any given past event/object can only grow with temporal distance from that event/object. There must, therefore, be many more true statements which can only be made after an event/object than there are true statements which could have been made at the time. From this it follows that the vast majority of true statements about the past will - being made in hindsight and with selection for significance involve temporal displacement, and must therefore (by definition) be narrative sentences. This, coupled with Danto's axiom that one cannot claim to predict (or to know what will be of significance in) the future, means that the range of true 
statements which one might make about any given past event logically extends from the historian's own present as far back into the past as available evidence will take you. Thus narrative is better understood as a fundamental property of historical descriptions themselves, and not an explanatory mechanism which is later applied by historians to the raw material of the past.

\section{Danto's Narratives Considered as Theories, and Their Relationship to The Scientific}

In this sense then, Danto is offering a view of history where almost every statement made about the past constitutes a miniature theory which collects evidence in support of some conclusion. How can we know that someone is "planting roses"? Because we have several pieces of evidence which we might draw together under that term. Danto calls such terms "project verbs." 331 According to this model, an historical entity such as "the Second World War" represents a large narrative theory in support of which many pieces of evidence - in the form of a myriad of other narrative sentences and project verbs - can be cited. No-one is saying, of course, that the very occurrence of the war itself could plausibly be falsified at this stage. In that respect, one might think of it as an extremely successful theory! But to what extent are we justified in referring to those events under that name? Which events/objects should be included and which left out? For what reasons? Can we ascribe any properties to "the Second World War" as a whole, and if so, by what evidence? This is Danto's vision of history: the deployment of interlaced and interlocking "narrative sentences" and "project verbs" in order to organise and explain the significance of past events. In Danto's view, evidence never stands alone, it must always be evidence for something. And that something is not given, or not only given, by the evidence itself. Temporal separation (and the issues of significance which arise from it) ensures this. But this raises the question: in what way do these kinds of theoretical structures differ from those in the sciences? Danto's answer is to assert that narratives must be localised in terms of subject. They tell a particular story, in answer to particular historical questions:

I have been endorsing the view that narratives may be regarded as kinds of theories, capable of support, and introducing, by grouping them together in certain ways, a kind of order and structure into events. A narrative, so considered, is nevertheless localized as to space and time, it forms an answer to an historical

331 Ibid., p.161. (emphasis in original) 
question, and is accordingly to be distinguished from a general theory which is not thus localized, and is not therefore an answer to an historical question. ${ }^{332}$

And so we arrive at essentially the same argument as that made by Dray. In order for theories to be scientific, Danto argues, they must have the quality of generality. They cannot be localised.

But the similarity of Danto's argument to Dray's leaves him vulnerable to the same objection: how does a theory like "the Second World War" differ from a theory like "the K/T extinction"? Both are highly localised and unique clusters of related historical events. Both presumably have narrative explanations. Why then is one history and the other science? It would seem that, yet again, the possibility that there might be scientific questions with narrative answers is simply not considered. One might counter, of course, that the Second World War is history (rather than science) because it concerns the actions of human beings. But this is not an argument which can be established from Danto's model of narrative alone. In the case of the $\mathrm{K} / \mathrm{T}$ extinction, any number of narrative sentences could be offered which would satisfy Danto's broad definition of the term. Even a comparatively high-level statement such as "a meteor impact approximately 65 million years ago caused the extinction of the dinosaurs," for example, satisfies Danto's definition. That is, it concerns two timeseparated events, but is only about the earlier. Moreover, it clearly contains explanatory content. As we have already seen, however, Danto made it very clear that he considered the use of narrative to be the only difference between history and the sciences. "The fact," he wrote, "that these sentences may constitute in some measure a differentiating stylistic feature of narrative writing is of less interest to me than the fact that use of them suggests a differentiating feature of historical knowledge." 333 Thus Danto's idea of narrative does surprisingly little heavy lifting in service of his history/science division, despite this being the very division he invoked it to establish. Narrative for Danto was a tool for following the threads of localised, particular events, and was thus well suited to human history. But that does not explain why it should be considered only a property of human history. Only in opposition to a purely generalising vision of science could narrative justify such a separation. And if this assumption regarding science were to prove false, then so would the division. This is not to say that Danto's view of history is not useful (for it is potentially profoundly so), only that it rules itself apart from the sciences unjustly. 
Certainly, Danto succeeded in producing a compelling analytic reconstruction of the logic of temporal (i.e., narrative) statements. But, adhering as he did to a nomothetic assumption regarding science, he was unable to see the wider potential significance of that work.

Having attempted to argue that narrative (i.e., historical) and nomothetic (i.e., scientific) explanations were entirely separate, Danto leaves himself with the task of showing how these two explanatory models can co-exist. Danto wishes to argue that narratives can and do explain. He also, as we have seen, wishes to argue for the epistemological autonomy of history. And lastly, he appears to have endorsed that realist 'one world' axiom by which history and science, despite their separation, could not materially conflict. "The claim," he wrote, "that there are two distinct kinds of events - scientific events, which can be predicted and explained, and historical events, which cannot - is erroneous. There are not two classes of events, but perhaps two classes of descriptions." ${ }^{334}$ When considered in light of the nomothetic assumption, however, these aims seem to exhibit some tension. The method by which Danto attempted to resolve this tension and render these two classes (the narrative and the nomothetic) compatible was through the weakening of the tacit assumption that a nomothetic explanation represents a complete explanation of any given phenomenon. He does this by demonstrating that a nomothetic explanation cannot explain any given phenomenon across all of its possible descriptions. "There are," Danto argues, "explananda which logically presuppose general laws, and explananda which do not." 335 Nomothetic explanations are thus only ever partial. This leverages to Danto's advantage his prior claim that true descriptions of any given object/ event are potentially limitless (if only due to the possibility of later re-contextualisation):

Phenomena as such are not explained. It is only phenomena as covered by a description which are capable of explanation, and then, when we speak of explaining them, it must always be with reference to that description. So an explanation of a phenomenon must, in the nature of the case, be relativized to a description of that phenomenon. But then, if we have explained a phenomenon $E$, as covered by description $D$, it is always possible to find another description $D^{\prime}$ of $E$, under which $E$ cannot be explained with the original explanation. If there are indefinitely many possible descriptions of a phenomenon, there may be indefinitely many possible explanation of that phenomenon... ${ }^{336}$

Explanation by means of a general law does not therefore exhaust the possible space

334 Ibid., p.178. (emphasis added)

$335 \mathrm{Ibid} .$, p.218. (emphasis in original)

$336 \mathrm{Ibid}$. (emphasis in original) 
of explanation for any single phenomenon. By way of illustration, Danto offers the example of Prince Rainier III of Monaco's marriage to Grace Kelly. "During the celebration of the last fete nationale monegasque," he writes, "the streets were decorated, as one would expect, with the flag of Monaco. But side by side with these were to be found American flags." One might wonder - why only American flags? Why not German or French? This is a fact which - at least for those uninitiated to the facts of the marriage - requires explanation. Such an event, Danto argued, could in principle be covered by a law. Perhaps something like: “whenever a nation has a sovereign of a different national origin than its own citizens, those citizens will, on the appropriate occasions, honour that sovereign in some acceptable fashion." Stating the presence of the flags, Kelly's country of origin, and the appropriate nature of the fete as initial conditions, one might - in theory - deduce the result. This should, Danto argued, satisfy even Hempel - if only as an explanation sketch. ${ }^{337}$ A problem arises, however, when one attempts to view this law as predictive. For given only the above law and the fact that Grace Kelly was of non-monegasque origin, one would be entitled to deduce only that some honour would be paid to her. One would not have sufficient information to derive the specific form of that honour. "One can," Danto points out, "honour a foreign-born sovereign without necessarily putting out the flags of that sovereign's native country." In other words, the law is not enough to explain the specific fact of the flags, for the same law could potentially cover any number of other potential honours. Thus the law does not logically guarantee the observed outcome. ${ }^{338}$ This is not to say that the law is useless, merely that it is incomplete. It can only explain under certain descriptions, which correspondingly limits its applicability. And it is the role of narrative, Danto argued, to explain those details and cases which laws cannot cover:

... narratives, rather than being simply explanation sketches which mark the place where laws are to be inserted, might instead be regarded as the result of taking an explanation sketch which makes use of general laws already, these marking the place where the description of an event is to be inserted. That is, where we are certain of the law but uncertain as to what precisely happened, the narrative then consisting in an account in which the general knowledge of what kind of thing must have happened is replaced by the specific knowledge of what specific thing, of the required kind, in fact occurred. ${ }^{339}$

Thus, even if specifically historical laws do govern history, and even if those laws one day became known, the historian's task would not be materially altered:

337 Ibid., pp.220-222. (emphasis in original)

338 Ibid., p.226-228.

339 Ibid., p.238. (emphasis in original) 
... the task of history itself would still be to tell the story of what precisely happened, even if the story should fall under a general historical law as an instance, and even if the law should be known. History alone would be able to exhibit the amazing variety of temporal wholes which none the less all fall under a single historical law. Our fascination with the details of the past would, if anything, increase. ${ }^{340}$

Thus is Danto's rapprochement accomplished. In order to provide a truly complete description of any phenomenon, one would require both laws and narratives. However, while compelling, this argument fails to address the underlying problem of why it is that nomothetic explanations are assumed to be the exclusive province of science, and narratives are assumed to be concerns that science can never have. Danto has argued eloquently for two fundamental modes of explanation rather than one. What he assumes rather than proves, however, is that only one of those modes ought to be considered science. The difference which makes the difference is, Danto claims, the presence of narrative. But, as we have already hinted at in the case of the $\mathrm{K} / \mathrm{T}$ extinction, the use of narrative in sciences like geology, paleontology, and evolutionary biology is not only possible, but often highly desirable. For the kinds of questions asked by these acknowledged sciences are just as likely - perhaps even more so - to strain the boundaries of what nomothetic explanation can accomplish as any question in human history. Why should they not also avail themselves of Danto's insights? Danto's model is thus an extremely successful one in almost all respects. It admits the existence and validity of nomothetic explanation, and effectively reconciles narrative with it without compromising the explanatory power of either. Indeed, as Part Two will show, Danto anticipates much of the substantive content of work done in the philosophy of science by authors like David Hull and Peter Kosso. Where Danto differs from these later philosophers of science, however, is in his insistence that scientific explanation can only be performed by means of nomothetic laws, and that the use of narrative must therefore shift historical knowledge into some parallel explanatory universe. This effectively renders parochial that which has the potential to be a general logic of all temporal phenomena. This is, once again, the result of a nomothetic assumption, uncritically held.

\section{Thomas Kuhn's Revision of the Nature of Science}

In actuality, Danto's seemingly uncritical acceptance of the nomothetic assumption

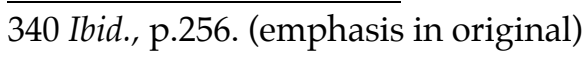


was, as he himself has admitted, largely an accident of timing. In an introduction added to a 1984 reprint of Analytical Philosophy of History, Danto wrote: "the Analytical Philosophy of History was conceived and written on the cusp, as it were, of a profound revolution in the philosophical conception of science." 341 That revolution was the transformation in the perception of science wrought by the publication of Thomas Kuhn's The Structure of Scientific Revolutions. ${ }^{342}$ Prior to the profound change in scientific thought this work ushered in, Danto argued, philosophy of history had been little more than an extended discussion of the applicability of a nomothetic model of knowledge to history. The basic premiss of that model, however, passed largely unquestioned. It was, Danto argued, "more or less assumed by Hempel's opponents... that the model was quite adequate for explanation in the natural sciences." What Kuhn represented then, was a "systematic questioning of this entire conception of natural science." ${ }^{343}$ He accomplished this through what Danto called a "historicization" of the philosophy of science:

Instead of history being connected to the wider body of science by a logical Anschluss, the natural sciences themselves became matters for the kinds of interpretation the earlier theorists had identified as the methodological prerogative of the human sciences: ways of reading the world. To be sure, there now really was a unity of science, in the sense that all of science was brought under history rather than, as before, history having been brought under science construed on the model of physics. ${ }^{34}$

In other words, Kuhn had shown (to Danto's satisfaction at least) that history was fundamental not merely to the philosophy of science, but to science itself. Because of this, Kuhn argued, static, timeless structures (such as the idea of general laws) could no longer claim to adequately represent the whole of scientific knowledge. Narrative, Danto argued, had "become focal to the philosophy of science itself, construed in the post-Kuhnian period as a thoroughly historical undertaking." The Analytical Philosophy of History had therefore been written at an awkward time, Danto wrote, as the "structures it works with and against were inherited from the philosophy of science as practiced by Hempel." ${ }^{345}$

By the 1980s, Kuhn's Structure had become the most cited English-language academic work of the twentieth century. ${ }^{346}$ Because of this, and because Kuhn's work has been

341 Ibid., p.ix. (emphasis in original)

342 Thomas S. Kuhn, The Structure of Scientific Revolutions. University of Chicago Press: Chicago, 1962.

343 Danto, Narration and Knowledge. p.x.

344 Ibid., p.xi. (emphasis in original)

345 Ibid., pp.xii-xiii.

346 E. Garfield, 'The 250 most-cited authors in the Arts and Humanities Citation Index, 1976-1983,' 
ably and amply discussed elsewhere, there is no need to consider the specifics of his argument here. It will suffice merely to say that the Structure of Scientific Revolutions was successful in cultivating a historical dimension within the philosophy of science. Kuhn accomplished this by building a model of science from a historical analysis of its past transformations, rather than attempting - as had been the norm in earlier philosophy of science - to establish a static structure of ideal scientific theory and practice. Central to Kuhn's argument was his contention that science did not progress in a linear fashion. Nor was science a steadily increasing accumulation of reliable knowledge which could all be described and understood within a single explanatory model. Kuhn instead postulated that science was periodically transformed - the "revolutions" of the title - by new overarching worldviews, which did not merely add to previous knowledge but displaced it. Kuhn called such worldviews paradigms. By choosing this term, Kuhn states:

... I mean to suggest that some accepted examples of actual scientific practice examples which include law, theory, application, and instrumentation together provide models from which spring particular coherent traditions of scientific research. These are the traditions which the historian describes under such rubrics as 'Ptolemaic astronomy' (or 'Copernican'), 'Aristotelian dynamics' (or 'Newtonian'), 'corpuscular optics' (or 'wave optics'), and so on. ${ }^{347}$

This meant that the way reality was described in scientific models was a factor in the kinds of questions scientific theories/laws could ask, and the kinds of conclusions they could intelligibly formulate. And these descriptions, Kuhn argued, need not be continuous. For example, the Ptolemaic description of astronomy and the Copernican description were both - despite being models of a real system - theoretically incommensurable. ${ }^{348}$ It was impossible, in other words, to understand one paradigm from the conceptual viewpoint of another. ${ }^{349}$ Different paradigms would have different ideas of what constituted evidence for a proposition, for instance, or even different ideas of what a valid proposition was. Copernicus and Ptolemy, for example, would have seen something very different in the same sunset, and would have drawn from it somewhat different conclusions regarding the motion of the Earth - or the lack thereof. Paradigms are required to be internally coherent, but need not be coherent with each other.

Current Contents. Vol. 48 (December 1986). pp.3-10.

347 Kuhn, The Structure of Scientific Revolutions. p.10.

348 Ibid., pp.111-112. For more on the Copernican/Ptolemaic example specifically, see: Kuhn, The Structure of Scientific Revolutions. pp.67-69.

349 Kuhn, The Structure of Scientific Revolutions. p.103. 
The implication of this incommensurability argument, however, also extended to the explanatory models of science themselves. For if paradigms really were incommensurable, then one could hardly expect the knowledge generated across all paradigms to conform to a single nomothetic-deductive model. Indeed, if this were the case, it would constitute direct evidence against Kuhn's conclusions. This immediately called into question the positivist doctrine of the methodological unity of knowledge - the claim that all knowledge must be of the same (preferably nomothetic) form. Kuhn had effectively opened up the possibility that different paradigms could have different explanatory models. As a result, the Hempelian model of explanation came to be accorded far less respect in both the philosophy of science and the philosophy of history. From being a paradigm case that any model of historical explanation had to either accommodate or plausibly divorce itself from, it became merely another voice in the choir. This, it should be remembered, was no bad thing. As Part Two will demonstrate, the doctrinaire insistence that something like the Hempelian model could capture all of scientific practice was far too reductive. In this sense, Kuhn had provided plausible theoretical backing to the idealist concept of autonomous epistemic domains. More importantly, he had done so from within the philosophy of science rather than history. This meant that he could not be seen as a partisan when cited in the service of disputes in other disciplines, and perhaps explains - at least in part - his popularity as an authority among the humanities.

By bringing a historical dimension to the sciences, however, Kuhn did not intend to destroy science or grant licence to the total abandonment of epistemology. In fact, the expanded role Kuhn saw for historical method and enquiry in the sciences represented exactly the kind of dissolution of barriers between the two fields that this thesis would seek to achieve. For Kuhn, the closing of the gap between history and science was not a radical demotion of one over the other. For example, in a postscript to a later edition of The Structure, Kuhn writes:

To the extent that the [Structure of Scientific Revolutions] portrays scientific development as a succession of tradition-bound periods punctuated by noncumulative breaks, its theses are undoubtedly of wide applicability. But they should be, for they are borrowed from other fields. Historians of literature, of music, of the arts, of political development, and of many other human activities have long described their subjects in the same way. Periodization in terms of revolutionary breaks in style, taste, and institutional structure have been among their standard tools. If I have been original with respect to concepts like these, it has mainly been by applying them to the sciences, fields which had been widely 
thought to develop in a different way. ${ }^{350}$

This hardly seems a damning assessment for the possibility of scientific knowledge. Indeed, having made this argument, Kuhn immediately goes on to reaffirm a belief in realism and the possibility of scientific progress. He writes:

This book was intended also to make another sort of point, one that has been less clearly visible to many of its readers. Though scientific development may resemble that in other fields more closely than has often been supposed, it is also strikingly different. To say, for example, that the sciences, at least after a certain point in their development, progress in a way that other fields do not, cannot have been all wrong, whatever progress itself may be. One of the objects of this book was to examine such differences and begin accounting for them. ${ }^{351}$

In light of these statements, it seems far more reasonable to conclude that Kuhn believed history and science were deeply intertwined and complementary, rather than profoundly epistemically mismatched. It would thus seem that it was only if one already had a particularly low opinion of the epistemic possibilities of historical knowledge that statements like the above looked like any threat to scientific realism. In order to see the intrusion of history into science as a disaster, in other words, one needed a view of history more like Gallie's literary-narrativism than Walsh, Dray or Danto's epistemic-narrativism. Gallie, it will be recalled, had a view of historical understanding as not only infinitely interpretive and dependent on human subjectivity, but also as almost entirely disconnected from epistemology. For anyone holding such a dim view of the possibilities for historical knowledge, its intrusion into the sciences could hardly be seen as anything less than a total disaster for the latter's privileged epistemic position. The intrusion of a more epistemic-narrativist view, however, would mean little more than the taking down of a barrier between the historical and scientific worlds that had had no real reason to exist in the first place. To prevent science from being dissolved into irrelevance, in other words, Kuhn was in dire need of a principled epistemic model of history. This is not a problem he examined in depth, but the need for it is clear. Such a model would have to be, at a minimum, able to conceptualise change in a way that the static, timeless structures of the nomothetic-deductive method could not. It will be our contention that not only can some variant of Danto's epistemic model of narrative perform such a role, but that such a model of history should itself be understood as scientific. But by the time Kuhn had offered a window of opportunity for narrative and historical knowledge to 
be amalgamated into science without being forced into a narrow Hempelian model, long years of debate with that model had forced narrativism away from science and out of the epistemic sphere altogether. It was, quite simply, too late.

\section{Louis Mink, Hayden White and the Flight From Epistemology}

Consider, for example, the work of pioneering literary-narrativist philosopher of history Louis Mink. Like many others of his era, Mink began his career as a philosopher of history influenced by the covering law debate. "It could be said without exaggeration," he wrote in 1974, "that until about 1965 the critical philosophy of history was the controversy over the covering-law model." 352 Thus, Mink's own views were shaped, in just the manner our previous examples have suggested, by the view that he was opposing. In his 1966 article 'The Autonomy of Historical Understanding,',353 for instance, he argued as follows:

Common to all arguments that there is no irreducible difference between historical and scientific method is an acceptance of something like these propositions: (1)... there is a single logical mode of explanation. (This is the principle of the methodological unity of science.) (2) The explanation of any phenomenon involves its subsumption under general principles... Specifically, the explanation of a phenomenon requires showing the statement describing it to be a deductive consequence of a set of general laws... (This is the principle of explanation by hypothetico-deductive theory. $)^{354}$

Wishing to evade the consequences of such a strictly nomothetic view of science,

Mink went on to frame his own arguments about history in terms of autonomy:

... the primary assumption of the proto-science view is that there can be no legitimate mode of understanding not analyzable by an explicit methodology. If it can be shown that history is autonomous, and not proto-science, it must be done, I think, not by showing that there is some fact or set of facts which can be explained "historically" but not "scientifically," nor even by providing alternative models of scientific explanation, but by a critique of this assumption. ${ }^{355}$

The paper that followed was essentially a comparison of several features of historical practice which conflicted with a nomothetic view of science, and could thus be considered evidence of history's autonomy. Mink ultimately concluded that while

352 Louis O. Mink, 'The Divergence of History and Sociology in Recent Philosophy of History,' cited in: Richard T. Vann, 'Louis Mink's Linguistic Turn,' in History and Theory. Vol. 2, No. 1 (February 1987). p.2. (emphasis in original)

353 Louis O. Mink, 'The Autonomy of Historical Understanding,' History and Theory. Vol. 5, No. 1 (1966). pp.24-47.

354 Ibid., pp.28-29.

355 Ibid., p.30. 
history could be made to conform to something like the propositions above (if a certain amount of methodological immaturity were allowed), such a model would omit what he considered to be the most important aspect of history - interpretation. "A common theme," he argued, "runs through... the characteristics of historiography on which I have tried at least to focus attention: the idea of "historical synthesis" or "interpretive history"; and it is the special character of this as a mode of understanding which a theory of historical knowledge must recognize if the methodological autonomy of history is to be justified or preserved." 356 Mink's entire view of history, in other words, was defined in opposition to a nomothetic model of science. And although he did not (in this paper) offer his own model of history, he argued that one was necessary because of the inability of the scientific model to adequately capture historical practice.

One can hardly fail to notice the similarity of Mink's defence of historical autonomy to those seen in almost all of our prior examples. In each case, the autonomy of history was predicated on the inability of science to capture the kinds of questions historians routinely sought answers to. Mink also resembles many of our earlier examples in that he sought to base the knowledge generated by an autonomous history in the concept of narrative. Where Mink differed from those who came before him, however, was in his argument that narrative - in the sense of "story" - was a distorting lens. In this, Mink could be compared only to W. B. Gallie. For Mink, narrative was the key idea which separated history from science because it was itself a discursive structure which could not be separated from the evidence from which it was constructed. The "significant conclusions of historical arguments," Mink argued, "are embedded or incorporated in the narrative structure of historical writing itself; they are not propositions for which the historian provides an array of evidence, but the specific way in which the evidence is discursively ordered." Thus where scientific conclusions "dispense with their evidence," historical conclusions "contain theirs, as (narrative) structure contains content." ${ }^{357}$ This, of course, assumes the total transparency of scientific structures, which is itself highly questionable (to say nothing of also implying an acceptance of the nomothetic assumption). Putting this aside for the moment, however, Mink linked narrative to his concept of "synoptic judgement" as follows:

356 Ibid., p.46.

357 This citation is from an unpublished paper of Mink's entitled 'Historical Knowledge.' The manuscript is cited directly in: Vann, 'Louis Mink's Linguistic Turn,' pp.2-3. (emphasis in original) 
The fact to which any theory of knowledge must return is the simple fact that experiences come to us seriatim in time and yet must be capable of being held together in an image of the manifold of events. The steps of a proof, the actions of a narrative, the notes of a melody, and even the words of a sentence are experienced one after the other, but must be considered in a single mental act before they even constitute data for significant discourse. ${ }^{358}$

This was, for Mink, the defining problem of all history. How could the historian "communicate his experience of seeing-things-together in the necessarily narrative style of one-thing-after-another" ${ }^{359}$ And, more importantly, it was a problem that science simply could not have:

I have tried, therefore... to ask whether "history" differs from "science" not because it deals with different kinds of events and not because it uses models of explanation which differ from - or may include but go beyond - the received model of explanation in the natural sciences, but because it cultivates the specialized habit of understanding which converts congeries of events into concatenations, and emphasizes and increases the scope of synoptic judgement in our reflection on experience. ${ }^{360}$

Later in his career, however, as the fixation on a single, overarching model of explanation faded, we begin to see a change in Mink's work. Rather than comparing history with (and defining it against) an ideal model of scientific explanation, Mink instead began to consider history in the light of narrative fiction. For although history had a presumption of realism which fiction did not, Mink argued, history and fiction possessed in common "the characteristics, structure, order and devices of narrative form." ${ }^{361}$ The shift in tone between 'The Autonomy of Historical Understanding' and his 1970 paper 'History and Fiction as Modes of Comprehension, ${ }^{362}$ is particularly revealing in this respect. The concern of the earlier paper for how history and science might relate to one another was replaced in the latter by a blanket assumption of the complete autonomy of history from science, and a view of narrative as an agent for producing "comprehension" rather than explanation. ${ }^{363}$ In 'History and Fiction,' Mink argued that the "synoptic judgement" of which he had spoken in earlier work could be realised in three ways:

358 Louis O. Mink, 'Modes of Comprehension and the Unity of Knowledge,' cited in: Vann, 'Louis Mink's Linguistic Turn,' p.3. (emphasis in original)

359 Mink, 'The Autonomy of Historical Understanding,' p.44.

$360 \mathrm{Ibid} ., \mathrm{p} .47$. (emphasis in original)

361 Louis Mink, 'Letter to the Director, Center for the Humanities, Wesleyan University,' cited in: Vann, 'Louis Mink's Linguistic Turn,' p.4.

362 Louis O. Mink, 'History and Fiction as Modes of Comprehension,' New Literary History. Vol. 1, No. 3 (Spring 1970). pp.541-558. 363 Ibid., p.544. 
There are, I suggest, three... fundamental modes, irreducible to each other or to any more general mode. I shall call these the theoretical mode, the categoreal mode, and the configurational mode. They are roughly associated with types of understanding characteristic of natural science, philosophy and history... ${ }^{364}$

These are, Mink argued, the three possible ways in which "a number of objects can be comprehended in a single mental act." The theoretical mode comprehends them "as instances of the same generalization," a nomothetic mode that is "powerful but thin," and comprises all of the natural sciences. The categoreal mode comprehends them as "examples of the same category," as "both a painting and a geometry are examples of complex form..." It was this mode, Mink argued, which "Plato - and, in fact, most systematic philosophers - envisioned as an ideal aim." And lastly, the configurational mode, which comprehends things "as elements in a single and concrete complex of relationships." It was this mode, Mink argued, which was governed by narrative, and had as its constituent members both history and fiction. It "is in this configurational mode," he wrote, "that we see together the complex of imagery in a poem, or the combination of motives, pressures, promises and principles which explain a Senator's vote..." 365 The most important aspect of these modes, however, was their incommensurability. All three were incompatible, Mink argued, because "each has ultimately the totality of human experience, or if one prefers, the 'world of fact' as its subject matter." In this view, these three modes represented something much like Kuhnian paradigms - different ways of reading the world entire which, while internally coherent, could not be translated into the terms of the others. From this Mink derived a view of academic disciplines forever estranged:

One can see, in this light, that what are called "disciplines" are actually arenas in which the partisans of each mode contend for dominance, each with its own aim of understanding, identification of problems, and privileged language. ${ }^{366}$

For Mink, this represented an answer to all prior questions of how historical explanation might be made to fit with the scientific. History could not only not answer such questions, it did not have to. History was simply not required to be concerned with anything outside of its own mode. "If it is true," Mink argued, "that the three modes are incompatible as ultimate aims, we must abandon hope of achieving an eclectic or panperspectival outcome..." ${ }^{367}$ By adhering only to this configurational mode of narrative, however, Mink's history found only fiction for

364 Ibid., p.549. (emphasis in original)

365 Ibid., pp.550-551.

366 Ibid., p.552.

367 Ibid. 
company. This meant that it was now fiction which was the proper article of comparison for the definition of history. "We could learn to tell stories of our lives from nursery rhymes, or from culture-myths if we had any," Mink argued, "but it is from history and fiction that we learn how to tell and to understand complex stories, and how it is that stories answer questions." 368 Thus Mink's philosophy of history began to wrestle more and more with questions of how the narrative chosen (or imposed) by an historian might determine the past being described. And of the usual grounds for distinguishing history from fiction, he began to equivocate:

It is not illuminating to distinguish history as true or as having a referent, from fiction as imaginary, or as not having a referent - despite the fact that the birth and death of Bismarck are reported in public records and the birth and death of Leopold Bloom are not. Individual statements about the past may be true or false, but a narrative is more than a conjunction of statements, and insofar as it is more it does not repudiate a complex past but constructs one. ${ }^{369}$

Mink's views regarding the relationship between history and fiction were to prove highly influential ${ }^{370}$ on the philosopher of history Hayden White, whose 1973 book Metahistory: The Historical Imagination in Nineteenth-Century Europe ${ }^{371}$ has since become a classic of contemporary philosophy of history. White's thesis went a good deal further than Mink's, however, and without Mink's apparent reluctance. In the preface to Metahistory, White clearly laid out his theoretical commitments:

In this theory I treat the historical work as what it most manifestly is: a verbal structure in the form of a narrative prose discourse. Histories (and philosophies of history as well) combine a certain amount of "data," theoretical concepts for "explaining" these data, and a narrative structure for their presentation as an icon of sets of events presumed to have occurred in times past. In addition, I maintain, they contain a deep structural content which is generally poetic, and specifically linguistic in nature, and which serves as the precritically accepted paradigm of what a distinctively "historical" explanation should be. ${ }^{372}$

Borrowing explicitly from literary theory, White argued that this deep "poetic" structure was manifested in written history through the use of organising principles called "tropes," of which there were four basic kinds - metaphor, synecdoche, metonymy, and irony. These tropes, White argued, effectively determine the kinds of

\footnotetext{
368 Ibid., p.558.

369 Louis O. Mink, 'Narrative as a Cognitive Instrument,' from a talk given in Chicago in 1974, cited in: Vann, 'Louis Mink's Linguistic Turn,' pp.9-10. (emphasis in original)

370 Indeed, Richard Vann, working from a letter White wrote to Mink in 1970, has talked at some length of Mink's influence on White. See: Vann, 'Louis Mink's Linguistic Turn,' pp.6-8.

371 Hayden White, Metahistory: The Historical Imagination in Nineteenth-Century Europe. Johns Hopkins University Press: Baltimore, 1973.

372 Ibid., p.ix.
} 
explanations and interpretive structures which will be considered permissible. "Each of these modes of consciousness," he writes, "provides the basis for a distinctive linguistic protocol by which to prefigure the historical field and on the basis of which specific strategies of historical interpretation can be employed for "explaining" it." 373 Literary considerations, in other words, intrude upon epistemological concerns. But this is not the unavoidable interpretive component introduced by human minds attempting the study of anything beyond themselves and which might be corrected with diligence and sound epistemic method. For White, the literary/poetic structure which underpinned the entire concept of narrative was sufficient to render historical realism effectively impossible. Among the enumerated general conclusions White offered in the preface to Metahistory, for example, he wrote: "the best grounds for choosing one perspective on history rather than another are ultimately aesthetic or moral rather than epistemological." The "demand for the scientization of history," therefore, "represents only the statement of a preference for a specific modality of historical conceptualization, the grounds of which are either moral or aesthetic, but the epistemological justification of which still remains to be established." 374 This is narrative determinism of a most extreme sort. Rather than the balancing of form and content envisioned by earlier literary-narrativists like Gallie and Mink, we see instead the denial of the possibility of true historical content altogether. Moreover, the subsequent popularity of Metahistory among both historians and philosophers of history in the late twentieth century suggests that many found this assessment at least plausible. ${ }^{375}$ This, put briefly, is how a perceived demotion in the status of science as a whole (when it was only the much narrower claim that the nomotheticdeductive method was the only possible form of scientific knowledge which was ever under serious dispute) was combined with the ongoing assumption that narrative was an inherently anti-scientific concept to produce an environment in which epistemic concerns were no longer deemed worthy of serious attention among philosophers of history.

On first consideration, this approach seems counterintuitive. But, if one accepts certain premisses, it does make some sense. Historical narratives must, given their

373 Ibid., p.xi. For more detail regarding White's concept of tropes, see: White, Metahistory. pp.31-38. 374 Ibid., p.xii.

375 This is, of course, difficult to quantify. Nevertheless, there are good reasons to think that White's Metahistory - if not his later work - was disproportionately influential among historians and philosophers of history for at least the twenty years immediately after it was first published in 1973. See: Richard T. Vann, 'The Reception of Hayden White,' History and Theory. Vol. 37, No. 2 (May 1998). pp.143-161. 
frequently linguistic mode of expression, be able to be analysed (at least partially) in terms of their literary qualities. The question then arises: how much emphasis does one place on those qualities as determining historical content. There are two potential paths to take here - two potential relationships between language and the world. As Arthur Danto has argued:

In one relationship, language stands to reality merely in the part-whole relationship: it is among the things the world contains, and is merely a further element in the order of reality. In its other relationship, language stands in an external relationship to reality in its entirety. ${ }^{376}$

The first relationship, seeing language as something to be studied scientifically along with the myriad other things of the world, would return history to the sciences. The second would not. Bear in mind, however, that the scientific study of language - for those who held the nomothetic assumption - seemingly required the reduction of that language to laws. This not only seemed impossible, it also violated the separatist impulse which, as we have seen, was the primary motivation for the establishment of narrativism in the first place. Therefore, Danto's second option - the positioning of language outside of reality - was seen as the only possible position. And in that view, the goal of the philosophy of history could not be the linking of statement with reality - that was impossible - but of narrative with statement. This was, put simply, how the so-called linguistic turn in philosophy of history was justified. But notice that, even here, the nomothetic assumption still persists. In fact, it is on display even in Mink's later work, where he devotes an entire pillar - the "theoretical" - of his tripartite model of comprehension to it. It seems, therefore, that all post-Kuhnian philosophy (and sociology) of science had accomplished was to render scientific explanation a concern that philosophers of history no longer believed they were required to attend to. In this sense, despite views of science finally beginning to change, the damage had been done. All that was achieved was the entrenching of narrativist assumptions of autonomy. At no point had a genuine debate over the relationship between history and science taken place. Only the idea of static and timeless laws had been rejected, not the idea of science as a whole. The nomothetic assumption, however, had caused any possible difference between those two positions to be overlooked. As L. B. Cebik has observed:

In short, current narrative theory and phenomenological analysis misconstrue epistemology's relationship to narrative theory by focusing upon one sort of

376 Danto, Narration and Knowledge. p.305. 
epistemic theory. In rejecting covering-law epistemology (and most countercovering-law versions), they ignore epistemology's more general concerns in which science, explanation, objectivity, proof, and reference begin as problemata, not as presuppositions... If we ignore history's regulative commitment to telling the truth (however we analyze the term) and to being bound within the limits of reliable evidence, then of course history becomes no more than a variant of literature... ${ }^{377}$

By seeing epistemology as epitomised by the idea of laws, in other words, philosophers of history generally (and narrativists in particular) had taken history's nomothetic failures as evidence of its utter separateness from epistemological issues generally. But, as we shall see, laws are not the only tool in science's toolkit.

Before we close the book on both the nomothetic assumption and Part One of this thesis, it should be remembered that it is not our intention here to castigate philosophers of history for not anticipating key developments in the philosophy of science. For while non-nomothetic views of science were beginning to take shape as early as the 1830s, one could not claim that they held any kind of ascendancy - then or now. Instead, the aim of this chapter has been to show how contemporary philosophy of history has arrived at its present condition, with particular emphasis on the key role perceptions of science played in that account. This, as will be seen, is necessary in order to show the relevance of the arguments which will be presented in Part Two. Indeed, the role of science becomes even more strikingly evident when one considers the present state of discourse within popular philosophy of history. At the time of writing, the claims and counterclaims surrounding the postmodern/linguistic turn in history represent terrain already extremely well explored - both in historical and philosophical terms. This being the case, there has been no need to cover it again here. But it will no doubt be familiar to the reader that many historians and philosophers have strongly resisted the recent linguistic emphasis in contemporary philosophy of history, and a significant number have attempted counterattacks in print against that approach. Their arguments have often tended, however, to be pleas for historical realism as "common sense" rather than well-reasoned bottom-up approaches to its defence. ${ }^{378}$ Instead of attempting to justify historical realism, for

377 L. B. Cebik, 'Understanding Narrative Theory,' History and Theory. Vol. 25, No. 4. (December 1986). p.59. (emphasis added)

378 Examples of such work include: Richard J. Evans, In Defence of History. Granta Books: London, 1997. Arthur Marwick, The New Nature of History: Knowledge, Evidence, Language. Palgrave: Hampshire, 2001. Keith Windschuttle, The Killing of History: How a Discipline is Being Murdered by Literary Critics and Social Theorists. Revised and Expanded International Edition. Macleay Press: Paddington, 1996. Perez Zagorin, 'History, the Referent, and Narrative: Reflections on Postmodernism Now,' History and Theory. Vol. 38, No. 1 (February 1999). pp.1-24. 
example, such accounts have focused on the potentially dire consequences were it to be abandoned. "If any considerable number" of historians were to adopt the relativist and literary conclusions of the postmodernists, writes Perez Zagorin in a polemic published in the journal History and Theory, then it would become:

... difficult to see how the larger society could continue to place any trust in the veracity and sincerity of history as a genuine discipline of knowledge directed to the human past. By the same token the latter would also be rendered incapable of performing its vital and ever more necessary intellectual function in the schools, universities, and wider culture of today's world. ${ }^{379}$

In the same breath, it is also often concluded that it is the results of history practised in the traditional mode which provide the best argument for its correctness. "Although they are being assailed on all sides," Keith Windschuttle writes, "there is still enough work produced by empirical historians to confirm the worth of what they are doing and to establish that the complete victory of their opponents would amount to a massive net loss for Western scholarship." ${ }^{380}$ It is the contention of this thesis that, despite an obvious glib circularity, such claims really are correct. However, apocalyptic warnings that 'you will miss us when we're gone' do not themselves constitute an account of historical epistemology. In other words, these oppositional accounts have suffered from an inability to offer a plausible alternative. Having absorbed exactly the kind of historical separatism which Part One of this thesis has detailed, they are simply not equipped to offer any well-grounded theoretical alternative for how history should be practised and understood. Wishing to resist the assertion that history is literature, and yet unwilling to counter with the assertion that history is science, they have found themselves caught between two fires - and have been easy prey for the more philosophically literate proponents of the linguistic approach. A discussion between Zagorin and the literary-narrativist Keith Jenkins in the pages of History and Theory, for example, finds Zagorin responding to Jenkins arguments ${ }^{381}$ - which, despite their obscurity and somewhat dubious merits, were at least philosophically literate and worthy of a reply in kind - with an almost petulant dismissal of any kind of philosophy in history:

Much of what Jenkins has to say represents an attempted imposition and usurpation of philosophy upon history. History, or historiography, is an independent empirical discipline of great sophistication with a long tradition

379 Zagorin, 'History, the Referent, and Narrative,' pp.10-11.

380 Windschuttle, The Killing of History. p.223.

381 Keith Jenkins, 'A Postmodern Reply to Perez Zagorin,' History and Theory. Vol. 39, No. 2 (May 2000). pp.181-200. 
behind it, which has given rise to many masterpieces. It is in no need of instruction or reform by philosophers or philosophical neophytes. If philosophy is to have a fruitful relationship with history, it must accept the historian's methods and ways of thinking as it finds them. ${ }^{382}$

This throwing out of the baby with the bathwater effectively doubles as an assertion that historical realism and the methods by which it is realised in historical accounts are somehow self-evident. This is the basis of what might be called the "history as common sense" defence. Such a reply is not entirely without merit, of course. We have already seen Walsh and Dray attempt to provide philosophical models which adequately capture existing historical practice. But in those cases, Walsh and Dray were attempting to arrive at a comprehensive philosophical justification which might have been used to justify historical realism and thus oppose Jenkins directly. Zagorin, on the other hand, is arguing that the truth of his position is so obvious as to render such work unnecessary. It is the intention of the remainder of this thesis to show that the way out of this dilemma is simple: show that history is a science. This has not been done, as we have seen, because the acceptance of the nomothetic assumption had convinced many that it couldn't be done. If this nomothetic emphasis is seen as the myopic argument that it is, however, then it becomes possible to argue that history is a science among the company of disciplines such as geology, palaeontology, and evolutionary biology. In order to accomplish this, however, two tasks remain. First, it must be shown that such a non-nomothetic, narrative-based definition of science is possible. And secondly, it must be shown that history does not conflict with such a definition. It is to these epistemic tasks which we now turn.

382 Perez Zagorin, 'Rejoinder to a Postmodernist,' History and Theory. Vol. 39, No. 2 (May 2000). p.201. 



\title{
Part Two
}

\author{
"Taking Narrative Seriously" \\ Epistemic Narrative \\ and the Philosophy of Science
}





\section{Chapter Four \\ "The Nomothetic Model and the Historical Sciences"}

The second half of this thesis has been designed as an extension of the argument of the first. Part One has argued that there has been a systemic nomothetic assumption regarding science among twentieth century philosophers of history, and that this assumption influenced their assessments of history's borders in such a way as to seemingly require a hard separation between historical and scientific knowledge. Building on this, Part Two will seek to demonstrate that the removal of this outdated and incorrect nomothetic assumption allows for the construction of a unified model of explanation in which a formal separation between history and the sciences is neither required nor possible. There is also a sense, however, in which Part Two will introduce a certain symmetry by re-examining the central concern of Part One from the opposite direction. Where the first half of this thesis has dealt with the understanding of science among philosophers of history, it is the intention of the second half to examine the understanding of history among philosophers of science. The purpose of this is twofold. First, it must be shown that the nomothetic model has not only failed the discipline of history, but has also failed many key branches of the sciences. In other words, not only is the nomothetic model not applicable to all knowledge, it is not even adequate to describe all of those fields which are unproblematically recognised as sciences. This, it will be argued, is evidence less of failure than of incompleteness. To this end, Part Two will examine the approach taken by scholars in some of those fields which have been poorly served by a nomotheticdeductive model of explanation - with a particular emphasis on the intersecting fields of geology, paleontology and evolutionary biology. Particular emphasis will be placed on how these sciences felt a kinship with history, often invoking the similarities of their fields with history as a potential solution to the bind the nomothetic model had placed them in.

The second of our purposes in Part Two will be to show that there has been a key difference in how philosophers of history and philosophers of science have approached this problem of history. While philosophers of history have tended to use the nomothetic model as evidence for a fundamental difference in kind between historical and scientific knowledge, philosophers interested in the historical sciences have not had that luxury. Feeling a kinship with history was one thing, claiming that geology was history quite another. And it is this contrast which provides the desired 
path forward. Because of the unavailability of this comparatively easy way out, it is the philosophers of these historical sciences who have produced compelling models of narrative as an epistemic device rather than merely a literary one. The overarching purpose of Part Two as a whole, therefore, is to take the model of narrative produced by these philosophers of science and show that it can be applied to the kinds of explanations historians have traditionally been concerned with. Subsequent chapters will examine the potential narrative solutions offered by philosophers and historical scientists to the problems the nomothetic model presented them with, and consider how they might be generalised into a model of narrative explanation relevant to both science and history. This chapter, however, is the beginning of this overall project, and will focus on providing a brief demonstration of the unsuitability of the nomothetic model for the fields of geology and evolutionary biology, as well as the hostility with which those fields have frequently been treated by nomothetic philosophers of science. Also of interest to us in this chapter will be the attitude of geologists, biologists (and philosophers of same) toward history. It will be demonstrated that, even from their earliest beginnings, philosophers of these sciences often identified more closely with history than with nomothetic sciences like physics. This, it will be argued, represents a problem for any claim the nomothetic-deductive model might make to represent the entirety of science.

\section{Some Brief Remarks on Contemporary Epistemic Philosophy of History}

Before we begin the work of Part Two in earnest, however, it is worth taking some time to make clear that the previous chapter must not be taken to imply that the philosophy of history has now become entirely a literary affair, with either positive engagement with that fact or withdrawal in disgust being the only possible options. Nor should it be assumed that the remainder of this thesis is orienting itself as a sole beacon of hope against some imagined postmodern tide. Much has already been written, both for and against, that literary-narrativist view of history, and it is not the intention of this work to rehearse these arguments again. The previous chapter has merely sought to illustrate how the literary-narrativist perspective has been shaped by the arguments it has opposed. This has been done in order to lay bare the underlying assumptions involved so that, by correcting them, we might unite narrativism and epistemic (i.e., scientific) philosophy of history. But first, we must take a moment to recognise that, despite the exclamations of many modern 
methodological textbooks, philosophy of history which chooses to focus on the epistemic issues of historical study rather than literary poetics is still being written.

This point is worth emphasising because, as the philosopher of history Aviezer Tucker has rightly argued: "it has become something of a ritual, a mystic communion of sorts, to commence long discussions of the philosophy of history with an analysis of its neglect and decline, of why philosophers have 'grown tired of it."'383 Such claims, however, are almost entirely without empirical merit. With respect to both book publications and journal articles, Tucker's own investigations (circa 2001) found evidence of substantial growth rather than decline, leading him to conclude that "the sense of gloom and doom of some philosophers of history reflects the academic status of the philosophy of history, rather than the actual (booming) research, publishing, and demand for reading in the field." ${ }^{384}$ Tucker came to some sociological conclusions regarding this, arguing that it was, at least in part, "an academic phenomenon that reflects the faults and weaknesses in the structures of institutionalized philosophy and historiography," rather than "a decline in actual research activity, public interest in the field, or the significance of the problems and topics of the field." In fact, he writes, "it is quite amazing that so much research is conducted with so few economic or social incentives." 385 Given Tucker's conclusions regarding the realities of publication in the philosophy of history, however, it also seems likely that at least some of the philosophers who have spoken of "neglect and decline" are not simply unaware of the fact that much philosophy of history is being published, but that they consider the kind of material which is being published to be, in some crucial sense, illegitimate. That is, such material as is being published is considered - by a certain audience - to be so misguided as to not really count as philosophy of history at all. Such is the seriousness of the gulf which has arisen between the literary and epistemic camps.

Despite the now-antique nature of the positivist/idealist argument upon which it is ultimately based, therefore, it seems there remains a deep schism in the philosophy of history between the literary-narrativists and those who have favoured an emphasis on epistemology. The question that this thesis is interested in, however, is what lies at the root of this disagreement, and whether there is any productive way

383 Aviezer Tucker, 'The Future of the Philosophy of Historiography,' History and Theory. Vol. 40, No. 1 (February 2001). p.37.

384 Ibid., pp.38-39. (emphasis in original)

385 Ibid., p.43. 
forward. And in this respect, the analysis of L. B. Cebik is particularly illuminating. Written during the comparatively early days of the postmodern debate, Cebik's 1986 paper 'Understanding Narrative Theory'386 neatly contextualises the disconnect between narrativist and epistemic philosophers of history, even if it cannot fully explain it. Cebik summed up the state of the field (at that time) as follows:

... in the interests of literary criticism, [Hayden] White would leave to epistemologists "the question of the veracity of a certain type of discourse, with respect to the 'object-world' of which it speaks." Likewise, in the concentration upon history's explanatory function, Hempelians largely ignored everything in historical narrative that they could not translate with ease or by force into causal statements. ${ }^{387}$

Cebik was interested in whether some sort of reconciliation of these opposing views might be possible and, towards that end, identified two "major difficulties" which stood in the way of such a project: "the denigration of epistemology and its interests," and "the failure to develop a comprehensive view of what a theory of narrative should contain in its finished state." 388 While the latter claim is selfexplanatory, Cebik defined "the denigration of epistemology" as the "general view that epistemology deserves little place within contemporary narrative theory." Such a view, Cebik argued, effectively equated "questions of objectivity and proof with questions on the methods of science." ${ }^{389}$ This, as seen in the previous chapter, meant that narrativists - having already convinced themselves that history was entirely outside of the sciences by virtue of the stark incompatibilities between narrative and the nomothetic form they assumed scientific explanation must take - were effectively granting themselves permission to declare problems of "objectivity and proof" simply irrelevant to the discipline of history.

Such anti-epistemic assumptions not only rendered narrative theory incomplete, Cebik argued, but were also problematic from a purely definitional point of view. For if the word "history" was to retain anything even close to the meaning it had had in the past, then questions of reference and justification could hardly be ignored. If, as we have already seen Cebik argue in the previous chapter, "we ignore history's regulative commitment to telling the truth... and to being bound within the limits of reliable evidence, then of course history becomes no more than a variant of

386 L. B. Cebik, 'Understanding Narrative Theory,' History and Theory. Vol. 25, No. 4 (December 1986). pp.58-81.

387 Ibid., p.58.

$388 \mathrm{Ibid}$.

389 Ibid., pp.58-59. 
literature..." ${ }^{390}$ Or, put another way, the conclusion of literary-narrativist philosophers of history regarding the purely literary nature of the subject is possible only by ruling out-of-bounds anything which might endanger that conclusion. The literarynarrativist is therefore forced into one of two conclusions. If they wish to defend White's brand of literary-narrative argument as a complete theory, then they are forced into just such a begging of the question. If, however, they concede that epistemic factors must play at least some role in historical research and writing, then they are forced to admit that purely literary theories of narrative must necessarily be incomplete. Cebik articulated this dilemma more elegantly. "Narrative creation," he wrote, "must either fold back upon basic conceptual structures or be left floating amid merely aesthetic clouds." 391 The problem was that these two approaches to philosophy of history - the literary and the epistemic - had become disconnected. So disconnected that, as hinted at above, each camp had trouble accepting the work of the other as actual philosophy of history - as opposed to a mere shifting of the problems of history into the philosophy of literature or the philosophy of science. ${ }^{392}$

Cebik hinted at the emergence of this disconnect, and even traced its origin to incompatible understandings of epistemological issues. In terms of outlining the shape of a potential solution, however, he argued only that if narrative really was a better descriptive model for history than any other, then the concept would have to be somehow reunited with epistemic issues such as reference and justification in order to be be considered a viable philosophy of history. "Any comprehensive theory" of narrative, Cebik wrote, "must accommodate both the justificational and the creative elements of narrative, the activities leading to narrative, and reflection upon the finished narrative." ${ }^{393}$ The first half of this thesis, by demonstrating a pervasive nomothetic assumption regarding science among philosophers of history on both sides of the debate, has supported and extended Cebik's argument that epistemic factors lie at the root of this disconnect by throwing some light on the precise nature of those factors. The half of this thesis which remains will attempt to address Cebik's subsequent argument that the previously problematic relationship between narrative and epistemology must be clarified and given deep structure in order for narrative to be taken seriously as a mode of historical explanation rather than merely a literary affectation.

390 Ibid., p.59. (emphasis added)

391 Ibid.

392 Tucker, 'The Future of the Philosophy of Historiography,' pp.44-45.

393 Cebik, 'Understanding Narrative Theory,' p.59. 
Before we begin this task, however, we must say something about why contemporary epistemic approaches have failed or otherwise fallen out of favour when compared with those of the literary-narrativists. For it is almost certainly the case that many modern epistemic projects in the philosophy of history have been undertaken with similar aims to that of this thesis - cognisant of the ascendancy of narrative, yet unsatisfied with its epistemic dimensions and eager to find a productive way forward. Why did they fail to convince? And, more importantly, why should we succeed where they have not? There are many possible epistemic and sociological factors which might contribute to answering such a question, and we do not have the space to examine them all here. We shall therefore have to content ourselves with pointing out that modern epistemic philosophy of history has tended to suffer from precisely the same problem as that which has plagued the narrativist view - a misunderstanding of the boundaries and possibilities of narrative itself. The literarynarrativists, as we have seen, had begun to claim (by the late twentieth century at least) that the presence of narrative - regardless of precisely how it was defined necessarily undermined the possibility of history being able to make unproblematic true statements about the past. This, given the arguments encountered in the previous chapter, is perhaps unsurprising. What is surprising is that modern epistemic philosophers of history largely came to hold exactly the same assumption. They have, in other words, almost universally assumed that the very concept of narrative itself could have no place in any epistemology which wished to be taken seriously. And because of this, they have attempted to purge all traces of it from history. They were not so much epistemic-narrativists, it might be said, but merely epistemic. It will be the contention of Part Two, however, that this is profoundly mistaken. For, as Cebik has reminded us, any epistemic philosophy of history which does not take narrative seriously is, at best, severely handicapped.

This tendency to view epistemological respectability and narrative as mutually exclusive has naturally led many epistemically-minded philosophers of history to attempt to restore the former by excising the latter. To do this, however, some other way of conceptualising and underwriting historical knowledge had to be found. This has led to a profusion of potential attempts to produce philosophies of history which were epistemically well-grounded. There were many ways in which this was done. Indeed, almost every author who has attempted it has had their own unique 
approach. The first and most obvious, if somewhat atavistic, way was to attempt yet another rehabilitation of the nomothetic-deductive model of science in such a way as to allow its application to history. We have already examined a similar position in Chapter Two using the example of Patrick Gardiner. More modern exponents of this position have included Murray Murphey ${ }^{394}$ and Clayton Roberts. ${ }^{395}$ This approach, however, has proved unconvincing for the same kinds of reasons we have already hinted at in Part One - the triviality of the laws involved, and the inability of the model to deal with the kinds of structures historians actually use. As Murray G. Murphey wrote in a review of Clayton Roberts' book, for example, the "elaborate system of causally linked events and conditions" which Roberts had offered as a model of historical explanation "does not provide what one usually finds in historical works: narrative interpretations." ${ }^{396}$ Other philosophers - presumably more familiar with more modern philosophy of science - have made attempts to link history with non-nomothetic scientific explanation. These have included, for instance, attempts to render historical explanation as a special case of evolutionary biology, ${ }^{397}$ or to link historical explanation to the Bayesian model of statistical inference. ${ }^{398}$ Many of these philosophers have, in undertaking such reductions, considered themselves to have adequately justified the claim for a scientific history. Other epistemic philosophers of history, however, have not, preferring to keep their epistemic philosophy of history separate from science for other reasons. ${ }^{399}$ Others still simply have not devoted all that much attention as to where the vision of history they offer fits in terms of a relationship to science or literature. ${ }^{400}$ What these approaches have all shared,

394 Murray G. Murphey, Our Knowledge of the Historical Past. Bobbs-Merrill: Indianapolis, 1973.

395 Clayton Roberts, The Logic of Historical Explanation. Pennsylvania State University Press: University Park, Pennsylvania, 1996.

396 Murray G. Murphey, 'Review of The Logic of Historical Explanation by Clayton Roberts,' American Historical Review. Vol. 102, No. 4 (October 1997). p.1118.

397 For example: William H. McNeill, 'Passing Strange: The Convergence of Evolutionary Science with Scientific History,' History and Theory. Vol. 40, No. 1 (February 2001). pp.1-15.

398 For an example of this approach, see: Aviezer Tucker, Our Knowledge Of The Past: A Philosophy of Historiography. Cambridge University Press: Cambridge, 2004. pp.95-100.

399 For example: Leon J. Goldstein, Historical Knowing. University of Texas Press: Austin, 1976. Leon J. Goldstein, The What and Why of History: Philosophical Essays. E. J. Brill: Leiden, 1996. See also: Luke O'Sullivan, 'Leon Goldstein and the Epistemology of Historical Knowing,' History and Theory. Vol. 45, No. 2 (May 2006). pp.204-228.

400 In this camp we might include the work of C. Behan McCullagh, who has written extensively on the mechanisms by which historical accounts can be justified, but without feeling it necessary to explicitly position his work on any one side of the history-as-science/history-as-autonomousepistemology debate. See: C. Behan McCullagh, Justifying Historical Descriptions. Cambridge University Press: Cambridge \& New York, 1984. C. Behan McCullagh, The Truth of History. Routledge: London \& New York, 1998. In fact, McCullagh has also written on precisely that neglect of the epistemic dimension of narrative which Cebik has identified. See: C. Behan McCullagh, 'The Truth of Historical Narratives,' History and Theory. Vol. 26, No. 4, Beiheft 26: The Representation of Historical Events. (December 1987). pp.30-46. This paper, while illuminating, has little to say about the central concern of this thesis - the deeper structure of narrative and how it might attain epistemic legitimacy. 
however, is a blanket dismissal of narrative as a serious explanatory mechanism. As Aviezer Tucker has written, the "important issue is not whether historiography is a narrative (it is obvious to me that some parts of it are and others are not), but the relation between historiography (whether narrativist or non-narrativist) and its evidence." ${ }^{401}$ This quote is revealing not only for its dismissal of an entire class of philosophy with the glib "it is obvious to me," but also for its apparent unwillingness to even consider that narrative might be anything other than the literary way in which historical conclusions (properly justified by some other mechanism) were presented.

But this position ignores the fact that not only does the concept of narrative seem to be considered relevant to historians and philosophers of history - at least when judged by the sheer popularity of the approach - it also seems to describe historical practice and the shape of historical accounts a good deal better than, for instance, covering laws or Bayesian statistics. Surely then, a better solution would be, as Cebik has suggested, to attempt to reunite concepts of narrative with the kinds of epistemic concerns postmodern narrativists have largely rejected. Or, in other words, to revive the epistemic-narrativist premisses of projects like those of Dray and Danto. This will not, however, require us to abandon our commitment to arguing for history as a science. In fact, it is precisely that commitment which will allow us to succeed where Dray and Danto failed. This is because we will consciously and deliberately abandon the presumption of narrative separatism which has been such a prevalent and destructive result of the nomothetic assumption. We will recognise, in other words, that an epistemically respectable and properly scientific vision of history is possible without the rejection of narrative.

This is why we have expended such effort in Part One making clear the role of the nomothetic assumption in the conceptual separation of history and science. For by dissolving that assumption, we must also dissolve any impermeable barrier between history and the sciences, and are thus free to make use of more recent developments in the philosophy of science which have embraced narrative as an explanatory concept. This will allow us to offer a sense of narrative which is not only epistemically legitimate, but which is equally at home in human history as it is in historical sciences such as geology and evolutionary biology. We will show, in short,

401 Tucker, 'The Future of the Philosophy of Historiography,' p.51. 
that history is a science. In order to begin to realise this goal, however, we must now turn our attention to both the theory and practice of the sciences. This will be our primary focus for the next two chapters. For while we are ultimately interested in how philosophers of the historical sciences both arrived at and justified narrative as an appropriate explanatory mechanism for their fields, we must first see why they felt the need to undertake such a search in the first place. To this end, the remainder of this chapter will be devoted to a brief historical sketch - using the earth sciences and biology as examples - of precisely how the nomothetic model of explanation has failed much of what we now think of as science.

\section{The Failure of the Nomothetic Model to Adequately Capture Scientific Practice}

The modern concept of a law of nature has been defined by the philosopher of science Peter Kosso as a "claim that associates a general kind of thing with a particular behaviour or property." Such laws, Kosso states, "identify natural kinds in the world and imply a causal connection between being that kind of thing and having the associated property or behaviour." 402 While this definition leaves out a great deal of detail relevant to specialists, it is adequate for our purposes. Kosso's definition is particularly valuable as it makes clear that a natural law need only imply (as opposed to define) a causal connection. Modern laws, in other words, are essentially descriptive. Newton's laws, for instance, might describe the motion of a falling body, but they are agnostic as to what causes bodies to fall. This has not always been the case, of course, but according to an historical analysis of the concept by the historian of science Jane Ruby, the most important aspects of this usage were largely in place by 1540 , with the related idea of laws as uniquely mathematical descriptions able to be found as far back as Roger Bacon's thirteenth century work on optics. ${ }^{403}$ By the close of the seventeenth century, however, the idea of mathematical laws had come to dominate - even define - the scientific approach. The main reason for this, it seems, was its success. In the seventeenth century alone, the historian of science Friedrich Steinle has observed, an "impressive number of what we now see as classical examples for laws of nature were established... Kepler's astronomical laws, Galileo's laws of free fall and of motion of pendulums, the law of inertial motion, the laws of impact, the sine-law of optical refraction, Boyle's law of the compression of

402 Peter Kosso, Reading the Book of Nature: An Introduction to the Philosophy of Science. Cambridge University Press: Cambridge, 1992. p.190.

403 Jane E. Ruby, 'The Origins of Scientific "Law",' Journal of the History of Ideas. Vol. 47, No. 3 (JulySeptember 1986). pp.341-359. 
air, Hooke's law of the spring of elastic bodies, and Newton's law of gravitation." 404 Each one of these examples represented a phenomenally successful systematisation and mathematical formalisation of some invariant aspect of nature. Put simply, the approach worked. Key aspects of nature could be accurately described and modelled, even if the precise nature of the underlying causes were still matters for speculation.

In addition to these practical successes, the concept of laws was also aided by the active dissemination of the idea in the writings of several of its most successful practitioners. In his analysis of the idea of law in the work of Galileo, Descartes, Francis Bacon, Boyle, and Newton, for instance, Steinle has argued that while each author exhibited some important differences in their published formulations of the idea of laws (usually with respect to the relationship between laws and actual causes), together they represented the most prominent agents in the "formationprocess" of a coherent law-based view of science. ${ }^{405}$ Such influential philosophical explications, when coupled with highly successful work (often by the same authors) in actually establishing examples of such laws, contributed to the rapid and widespread adoption of the concept as the most fundamental premiss in the philosophy of science. By the close of the seventeenth century, the historian and philosopher of science Edgar Zilsel has argued, references to "laws" of nature had become commonplace, being clearly identifiable in the work of British scientists and philosophers such as Wallis, Wren, Hooke, Halley, Cotes, and Bentley, as well as European figures such as Baruch Spinoza and Christian Huygens. ${ }^{406}$ Perhaps unsurprisingly, however, the most influential single figure in this "formationprocess" was Isaac Newton. As the historian of science Ernan McMullin has argued in his 2001 paper 'The Impact of Newton's Principia on the Philosophy of Science,'407 the success and sophistication of Newton's 1687 work Philosophiae Naturalis Principia Mathematica, led to its almost immediately being considered an exemplar of scientific method and practice. Such was the influence of this work, McMullin argued, that a "variety of morals for the philosophy of science" were drawn from it by subsequent philosophers. McMullin examined three examples of this influence in detail, ultimately concluding that: "these philosophers were at one in believing that the

404 Friedrich Steinle, 'The Amalgamation of a Concept - Laws of Nature in the New Sciences,' in Friedel Weinert (ed), Laws of Nature: Essays on the Philosophical, Scientific and Historical Dimensions. De Gruyter: Berlin \& New York, 1995. p.316.

405 Ibid., p.354.

406 Edgar Zilsel, 'The Genesis of the Concept of Physical Law,' The Philosophical Review. Vol. 51, No. 3 (May 1942). pp.270-273.

407 Ernan McMullin, 'The Impact of Newton's Principia on the Philosophy of Science,' Philosophy of Science. Vol. 68, No. 3 (September 2001). pp.279-310. 
mechanics of the Principia could be held up as a model of the sort of knowledge to which the investigation of the natural world should aspire." 408 Newton's influence was not only felt among philosophers, however. There is reason to believe his views regarding science and law were also influential among practising scientists. In all of those British and European uses of the term "law" which Zilsel had identified, for example, Steinle was able to identify clear traces of Newton's descriptive and mathematical usage in each of them. This is not to say that it was Newton's idea of laws alone which became canonical, of course, but merely that Newton had given an idea with a long and complicated genesis "a particularly clear and influential voice." ${ }^{409}$ And from this paradigmatic expression of the idea, Steinle writes:

The pretension of combining systematic empirical enquiry and strict mathematical formulation is from then on inextricably involved in the concept of laws. The concept outlined by Newton serves as starting point for further developments in the $18^{\text {th }}$ and $19^{\text {th }}$ century. In the course of these developments the concept of law undergoes profound changes. Some essential aspects are altered, even disappear, such as the theological commitments; others arise and become important, like statistical considerations. The driving forces of this development are manifold and complicated, all the more so as the field of investigation widens and spreads in many different directions. ${ }^{410}$

Ultimately, however, this widening and spreading of the "field of investigation," as Steinle phrased it, would take the sciences into areas the ideal of laws could no longer be stretched to accommodate. For while the concept of laws was certainly capable of remarkable development and adaptation, there were practical limits to its ability to model certain classes of otherwise reliable knowledge - limits which first became apparent in the patchwork of disciplines which was to eventually become the earth sciences.

\section{The Nomothetic Model and the Early Earth Sciences}

By the eighteenth century, the idea of laws had become fully and completely synonymous with the very concept of explanation itself. To illustrate this, let us briefly consider Denis Diderot and Jean le Rond d'Alembert's Encyclopédie (Ou Dictionnaire Raisonné Des Sciences, Des Arts et Des Métiers), published between 1751 and 1772. This famed document of Enlightenment knowledge and values, which itself claimed to be nothing less than a record of all human knowledge, divided its

408 Ibid., p.281.

409 Steinle, 'The Amalgamation of a Concept,' p.362.

410 Ibid. 
contents into three broad categories: "history," "philosophy" and "poetry." 411 These descriptors differed markedly from their modern interpretations, however. "History" in the Encyclopédie, argues the historian of the geosciences Martin Rudwick, "embraced all those sciences that aimed to describe the diversity of the world; "philosophy" incorporated those that sought to explain how the world works." 412 This, Rudwick pointed out, had conceptual consequences for scientific practice at the time:

As Diderot's chart shows, there was a major distinction between two complementary ways of studying the natural world. "Natural history" dealt with the description and classification of natural phenomena and natural objects of all kinds. "Natural philosophy" - or what Diderot called the "science of nature" included the causal and mathematical relations between natural phenomena, as well as mathematics itself. ${ }^{413}$

And while it may be, as Rudwick asserts, that these "two kinds of study were regarded as being of equal importance, profundity, and difficulty," this division would ultimately leave the earth sciences caught between two fires. In order to illustrate this, we must briefly examine the structure of the earth sciences before their modern synthesis.

In the latter half of the eighteenth century, Rudwick argues, there were "four fairly distinct sciences... concerned with the material objects and phenomena of the earth." Three of these four - Mineralogy, Physical Geography, and Geognosy - were "concerned primarily with the description and classification of the diversity of terrestrial things and were therefore treated as branches of natural history." However, the fourth - Earth Physics - attempted to deal instead with "the causal explanation of the materials presented by any of the other three, or at least with the regularities or "natural laws" displayed by their occurrence." This was (at least according to the Encyclopédie) a fundamentally different kind of enquiry. "Since the four sciences of the earth," Rudwick writes, "straddled the major boundary between natural history and natural philosophy, there was at the time no obvious need for a single term to denote them collectively." ${ }^{414}$ And even if there had been such a need, it seems unlikely an appropriate term could easily have been found. For, when considered in the strictly

411 Diderot and D'Alembert's overall schematic is reproduced in: Martin J. S. Rudwick, Bursting the Limits of Time: The Reconstruction of Geohistory in the Age of Revolution. University of Chicago Press: Chicago \& London, 2005. pp.50-51.

412 Ibid., p.49. (emphasis in original)

413 Ibid., p.52. (emphasis in original)

414 Ibid., pp.58-59. 
nomothetic terms of the philosophy of science at the time, only "Earth Physics" was even the right kind of enquiry to be called scientific. "Earth Physics," however, was also the most troubled of the four disciplines. "The problems were obvious," Rudwick writes, "but in many cases the solutions were highly ambiguous or just plain speculative." This was due, in no small part, to the fledgling nature of the field. But the limited possibilities for systemic isolation and/or experiment, not to mention the uncertainty involved in assigning mathematical values to geological properties, also played a role. "It is not therefore surprising," Rudwick argues, "that many of the savants who studied the physical features of the solid earth devoted more of their time and energy to description and classification: often they relegated their causal conjectures to an appendix, sometimes with an apology for straying into the field of speculation." 415

These problems of method notwithstanding, the ultimate goal of all of these nascent earth sciences in the late eighteenth century was still a nomothetic synthesis - a unified system which reduced the observed geological features of an entire planet to the consequences of set of laws and/ or processes. The aim, Rudwick argues:

... was to emulate on a terrestrial scale the achievement of Newton in the realm of celestial mechanics. It was to discover the one and only true explanation of how the earth works, just as Newton was believed... to have discovered the one and only true theory to explain the movements of the sun and its planets... under the law of universal gravitation. ${ }^{416}$

Given the realities of actually practising earth physics, however, it seemed highly unlikely that the "one and only true theory" would actually consist of laws in any recognisably Newtonian sense. For, as Rudwick points out, while "Earth Physics" struggled with "lawlike 'dispositional regularities' that might point towards causal explanations," any large scale explanation for the observed features of geology would have to be something rather different. Rudwick refers to this as a "Theory of the Earth." ${ }^{417}$ For our purposes, however, the most important aspect of this debate was that the potential usefulness of such a system could be seen even among those earth scientists whose primary focus was purportedly restricted to description and classification. The desire for a "Theory of the Earth," in other words, cut neatly across the history/natural philosophy boundary:

415 Ibid., pp.114-115.

416 Ibid., pp.133-134.

417 Ibid., p.133. 
In fact, to describe the more restricted kind of study as if it were an end in itself is rather misleading, for such work was usually undertaken as a means towards a much more important end. The ultimate goal of many savants concerned with the sciences of the earth was to construct what they called a "system" or high-level theory about the earth. This would not merely be a theory to explain specific features, such as the elevation of mountains, the consolidation of rocks, or the emplacement of fossils, important though such problems were. On the contrary, a system would try in principle to include all such limited explanations within a single overarching causal theory. ${ }^{418}$

The Newtonian impulse is, of course, clearly present in such systems. But this is hardly surprising given that, at that time, the nomothetic model effectively was science. However, additional questions and complications naturally arise when one contemplates the possibility of a theory which might explain on the scale of an entire planet. Would this much coveted "Theory of the Earth" turn out to be a single, simple natural law? If so, could it be used to predict? Or for calculation? Or would such a theory be better understood as the uncovering of the processes which had operated over time to bring about the observed geology of the present? But there could hardly be only one such process. And if such a theory was not a "law" per se, what was its relationship to laws? From even such a cursory contemplation of what a "Theory of the Earth" would require, it seems reasonable to conclude that these nascent earth sciences were, from their very beginnings, blurring the line between natural history and natural philosophy. Indeed, it is precisely this observation which provides the central argument for Rudwick's book. Because of the difficulties - both conceptual and practical - of taking the mathematical, nomothetic approach, Rudwick argues, "the sciences of the earth became historical by borrowing ideas, concepts, and methods from human historiography." 419

This borrowing, however, was not from the speculative Enlightenment philosophers of history, but from the late eighteenth century "erudite histories of more limited scope, based on detailed critical study of massive documentary evidence." ${ }^{420}$ Also inspirational were the historical practices of chorography and antiquarianism - the "detailed scholarly description of specific localities or regions; in effect, local geography," which often included the examination of not only textual sources but also artifacts such as "ancient buildings, megaliths, and earthworks." ${ }^{221}$ Such borrowings, Rudwick argues, collectively represent some of the earliest evidence of

418 Ibid. (emphasis in original)

419 Ibid., p.181. (emphasis added)

420 Ibid., p.182.

421 Ibid., p.186. 
the inadequacy of the narrow nomothetic conception of science when applied to historical questions. More importantly, this inadequacy was not (or not entirely) due to the lack of developed methods such as were then available in disciplines like physics and chemistry. In many cases, the mismatch between nomothetic theory and the reality of the earth sciences was due instead to the fact that what the earth sciences desired in terms of theory simply had more in common with history:

The varied genres of erudite or "antiquarian" history... were based on detailed concrete evidence, whether texts or artifacts. They were histories compiled bottom-up, not deduced top-down. They claimed to describe the particularities of how human events had truly happened, where and precisely when... They described specific events, and sequences of events, that could not possibly have been predicted in advance, or even retrodicted afterwards. Their sheer contingency was due not only to the uncertainties of all human actions and decisions, but also to the unpredictable complexities of natural circumstances surrounding human lives: the first recorded eruption of Vesuvius, with its catastrophic effects at Herculaneum and Pompeii, stood as a vivid reminder of that ineluctable contingency. So if erudite or antiquarian history were to be used as a model or analogy for recovering and reconstructing the history of nature, it would bring with it a strong sense of history as a contingent and unpredictable sequence of events, rather than as any kind of intrinsically predictable or "programmed" temporal development. ${ }^{422}$

The human world, in other words, was not the only place where one found contingency to such an extent that the tight systematisation and prediction upon which the nomothetic ideal was predicated were rendered not only impossible but irrelevant. Rudwick goes on to identify this consciously historical program in the work of several scholars of the late eighteenth century, including one of the pioneers of fossil analysis, Francois-Xavier Burtin. Burtin's work, Rudwick observes, was especially replete with historical analogy. For Burtin, fossils were the "coins," the "documents," and the "monuments" of the natural world," to be "deciphered" and "read." ${ }^{423}$ Clearly then, from the very beginnings of the earth sciences, the nomothetic model of science has acted to theoretically alienate a great deal of legitimate research regarding the operations of the Earth. And the problem would only grow worse.

\section{The Nomothetic Model and the Earth Sciences in the Nineteenth Century}

Gradually, as the eighteenth century gave way to the nineteenth, the conclusions of the disparate patchwork of disciplines which would become the modern earth

422 Ibid., p.193. (emphasis in original)

423 Ibid., p.201,203. 
sciences were beginning to interlock, leading the disciplines themselves to begin to fuse together. The philosophy of science, however, had changed comparatively little. The changes that Steinle has identified in the basic concept of natural laws - such as the abandonment of theology and the arrival of statistics - were both necessary and welcome, but they were hardly fundamental reforms. ${ }^{424}$ They certainly were not sufficient to permit laws to adequately model a discipline whose area of interest was riddled with multiple, chaotically interacting processes which had little or no causal relationship with one another. Because of this, Rudwick's observed alignment between geology and history remains detectable well into the nineteenth century. Charles Lyell's introduction to the first chapter of his hugely transformative and influential Principles of Geology $y^{425}$ is particularly revealing in this respect, drawing explicit parallels with history in both method and intent:

When we study history, we obtain a more profound insight into human nature, by instituting a comparison between the present and former states of society. We trace the long series of events which have gradually led to the actual posture of affairs; and by connecting effects with their causes, we are enabled to classify and retain in the memory a multitude of complicated relations - the various peculiarities of national character - the different degrees of moral and intellectual refinement, and numerous other circumstances, which, without historical associations, would uninteresting or imperfectly understood. As the present condition of nations is the result of many antecedent changes, some extremely remote and others recent, some gradual, others sudden and violent, so the state of the natural world is the result of a long succession of events, and if we would enlarge our experience of the present economy of nature, we must investigate the effects of her operations in former epochs. ${ }^{426}$

This citation, while instructive, does not represent evidence that Lyell wished to see geology as part of history. Lyell's commitment to both the scientific status of geology and the nomothetic ideal of science remained. On the very same page of the Principles, for example, Lyell argued that through geological research into past events, "we acquire a more perfect knowledge of its present condition, and more comprehensive views concerning the laws now governing its animate and inanimate productions." $^{427}$ That Lyell should recognise history at all, however, was highly significant. For Lyell's work was considerably more than the mere classifying of fossils or the naming of geological strata. The Principles of Geology also represented a sophisticated set of causal theories which could account for a myriad of geological

424 Steinle, 'The Amalgamation of a Concept,' p.362.

425 Charles Lyell, Principles of Geology: Being an Attempt to Explain the Former Changes of the Earth's Surface, by Reference to Causes Now in Operation, Volume One. John Murray: London, 1830.

426 Lyell, Principles of Geology. p.1.

$427 \mathrm{Ibid}$. (emphasis in original) 
observations - a "Theory of the Earth." With respect to the divisions of knowledge the nomothetic sciences had inherited from earlier centuries, such an active seeking for causes moved Lyell's geology from the realm of natural history into that of natural philosophy. Yet Lyell's introduction seemed to make it clear that he considered the Principles to be engaged in an essentially historical enquiry. ${ }^{428} \mathrm{He}$ retained, as almost all nineteenth century scientists did, a commitment to the ideal of laws. But this could not disguise the fact that Lyell's work - which represented not only his own work, but the collected labours of a vastly matured earth science - contained little that actually resembled such laws.

This mismatch between theory and practice did not go unnoticed by Lyell's critics. While generally supportive of his work, critics such as the nineteenth century geologist Adam Sedgwick and the philosophers of science William Whewell and John Herschel were nevertheless uncomfortable with the theoretical gulf between Lyell's causal theories and actual quantifiable laws. This scepticism, moreover, was directly attributable to their philosophical commitment to a purely Newtonian vision of science. As the philosopher Michael Ruse has written of Herschel:

Herschel's paradigm science was Newtonian astronomy, with its appeal to quantitative laws and its hypothetico-deductive (axiomatic) structure; and certainly the Lyell of the Principles of geology, subtle and successful though his strategy may have been, did not produce a theory with precisely quantified laws bound together in a deductive framework. ${ }^{429}$

Of Whewell, Ruse writes: "like Herschel, Whewell thought that Newtonian physics is the finest of sciences... the one that should serve as the model for all the other sciences, including geology." These doctrinaire commitments led both philosophers to a kind of gentle scepticism with respect to Lyell's claim to have produced truly causal explanations for the geological features of the Earth. While neither Herschel nor Whewell could deny the magnitude of Lyell's achievement, the mismatch between what Lyell had delivered and what science was expected to look like meant they could hardly pronounce his work an unqualified success either. As Ruse writes, "although Herschel still felt that geology as compared with astronomy was immature, he obviously found in the Principles things which he thought essential to

428 Martin J. S. Rudwick, 'The Strategy of Lyell's Principles of Geology,' Isis. Vol. 61, No. 1 (Spring 1970). p.8. See also the second volume of Rudwick's history of the early earth sciences: Martin J. S. Rudwick, Worlds Before Adam: The Reconstruction of Geohistory in the Age of Reform. University of Chicago Press: Chicago \& London, 2008. pp.297-300.

429 Michael Ruse, 'Charles Lyell and the Philosophers of Science,' The British Journal for the History of Science. Vol. 9, No. 2 (July 1976). p.121. 
good science." Similarly, Whewell praised Lyell for bringing an account of causes to what he saw as little more than the mere description and classification of previous geologists. "Given the fact that earlier geologists had gathered a great deal of phenomenal information about the world inorganic and organic," Ruse argues, "Whewell allowed that Lyell had practically transformed the study of its causes." Whewell's endorsement, however, was sharply circumscribed. "Although Whewell thought Lyell's methodological approach had proved incredibly successful," Ruse writes, "he thought that, when applied to this world of ours, it must be hedged with severe limitations." 430

The limitations at which Whewell had hinted were those concerning the general applicability of Lyell's conclusions, given that they clearly could not fulfill the requirements of nomothetic laws. The Victorian geologist Adam Sedgwick, on the occasion of his second anniversary address to the Geological Society of London in 1831, summarised these misgivings as follows: "this theory confounds the immutable and primary laws of matter with the mutable results arising from their irregular combination." ${ }^{431}$ This statement not only captures the historical character of much of Lyell's geology - driven as it was by the contingency created by multiple interacting processes and events - it also expresses precisely why philosophers of science were uncomfortable with it. Similar objections, Rudwick has argued, are reliably identifiable across a broad cross-section of Lyell's critics. "They claimed," Rudwick writes:

... that Lyell, in arguing for the "uniformity" of nature, had confused the highly complex processes of geological agency with the basic physico-chemical "laws of nature" on which they were founded. The latter, they agreed, must indeed be assumed to be stable from and to eternity; but the former might have varied greatly in power and intensity in the course of geohistory, and only a close empirical study of the surviving traces of their action could or should settle the question one way or the other. ${ }^{432}$

This class of criticisms is instructive insofar as it is entirely accurate, yet can only have any rhetorical force if one considers the proper form of all scientific conclusions to be nomothetic. For the variation in "power and intensity" of past geological processes could easily be the result of other processes (or even singular events) unrelated to those being studied. Consider, for example, how the geological

430 Ibid., pp.125-126.

431 Adam Sedgwick, 'Address to the Geological Society' (1831), cited in: Rudwick, Worlds Before Adam. p.333.

432 Rudwick, Worlds Before Adam. p.345. 
processes of the Earth were potentially disrupted by the impact of the meteor at the $\mathrm{K} / \mathrm{T}$ boundary. No laws of geology alone could have predicted that impact - coming as it did from deep space. Yet no account of Earth's history could be complete without mention of it. We will examine this line of argument in greater detail in Chapter Six. Suffice it to say at present that there is no practical way to accurately isolate the laws at work in such situations without having to bring those laws acting upon the entire universe into play as well. The only way to fully conceptualise such systems is historically. Lyell's mistake, therefore, was not to be found in his work, but in his desire to present that work as having fulfilled the nomothetic ideal of science.

Adding further insult to injury, however, was the failure of the philosophy of science to revise or amend its nomothetic stance in response to the achievements of even such a consummate scientist as Lyell. The result was a continued disconnect between geological practice and scientific orthodoxy. In some cases, theory was abandoned almost entirely. The philosopher of geology David Kitts has argued, for instance, that later nineteenth century geologists - particularly the influential American geologist Grove Karl Gilbert - came to believe that geologists did not utilise the traditional structures of science in the pursuit of their work at all. Gilbert, Kitts argued, was a particularly active contributor to the "establishment, during the last quarter of the nineteenth century, of a methodological view that persists to this day." This was the view that geology as a science was not organised around the concept of natural laws. ${ }^{433}$ This, in turn, contributed to a sense in geology of being abandoned by the mainstream philosophy of science, and has given rise to a certain insularity within the discipline. As Kitts has observed, "it is interesting to note that many of the geologists who extol the virtues of Gilbert profess to find nothing in contemporary philosophy of science which illuminates the problems of geological knowledge." 434 Even today, it seems, there is a lingering sense of alienation from theoretical issues prevalent among geologists and their theorists. As recently as 2008, the geographer and historian of geology Robert John Inkpen has argued:

Given the limited philosophical basis available within geosciences, practitioners have tended to focus on the practice of doing the field work, collecting the data, carrying out the analysis and getting an answer they are comfortable is relevant to the question. In environmental reconstruction, for example, the focus remains on

433 David B. Kitts, 'Grove Karl Gilbert and the Concept of "Hypothesis" in Late Nineteenth-Century Geology,' in Ronald N. Giere \& Richard S. Westfall (eds), Foundations of Scientific Method: The Nineteenth Century. Indiana University Press: Bloomington \& London, 1973. p.265. 434 Ibid., p.266. 
the identification of traces of the past and their construction into a plausible description of the past and how it has changed. The philosophy is seen as something that can be worked out later if anyone is really that interested. ${ }^{435}$

Moreover, in the absence of any serious philosophical attention being devoted to geology, Inkpen has argued, a tendency has arisen in which geological practice is seen as dictated not by a strong philosophy of science but by "a history of tradition guiding the hand of the operator and requiring no further scrutiny." ${ }^{436}$ It is impossible not to note the similarity between this conclusion and the similarly facile argument that historiography is a "craft" rather than a science or a set of methodological principles. Whether found in geology or history, this amounts to little more than a discipline granting itself permission to be unreflective. ${ }^{437}$

\section{The Nomothetic Model and the Biological Sciences in the Nineteenth Century}

A similar tension to that observed in the work of Charles Lyell can also be seen in that other towering achievement of nineteenth century science - the 1859 publication of Charles Darwin's On The Origin Of Species By Means Of Natural Selection. ${ }^{438}$ Despite its immense success as a work of science, it can be argued that Darwin's work too had a distinctly historical slant to it which was difficult to reconcile with a nomothetic model of science. Darwin was thus also vulnerable to some variant of Sedgwick's accusation of confusing "the immutable and primary laws of matter with the mutable results arising from their irregular combination." ${ }^{439}$ The similarities between these two cases are more than merely superficial, however. Like Lyell, Darwin also had a pronounced tendency in The Origin to talk of science nomothetically in terms of its chiefly discovering laws, despite his own conclusions frequently failing to satisfy the classical definition of the term. In the closing pages of The Origin, for example, Darwin listed the "laws" which he argued had interacted to make the higher principle of natural selection possible:

It is interesting to contemplate an entangled bank, clothed with many plants of many kinds, with birds singing on the bushes, with various insects flitting about, and with worms crawling through the damp earth, and to reflect that these

435 Robert John Inkpen, 'Explaining the Past in the Geosciences,' Philosophia. Vol. 36, No. 4 (2008). p.496.

436 Ibid.

437 Tucker, 'The Future of the Philosophy of Historiography,' p.53.

438 Charles Darwin, On The Origin of Species by Means of Natural Selection, or the Preservation of Favoured Races in the Struggle for Life. John Murray: London, 1859.

439 Adam Sedgwick, 'Address to the Geological Society' (1831), cited in: Rudwick, Worlds Before Adam. p.333. 
elaborately constructed forms, so different from each other, and dependent on each other in so complex a manner, have all been produced by laws acting all around us. These laws, taken in largest sense, being Growth with Reproduction; Inheritance which is almost implied by Reproduction; Variability from the indirect and direct action of the external conditions of life, and from use and disuse; a Ratio of Increase so high as to lead to a Struggle for Life, and as a consequence to Natural Selection... ${ }^{440}$

But, despite the language of laws being employed here, there is also a sense in which Darwin clearly positions his own original contribution of Natural Selection as a law ${ }^{441}$ arising from the interaction of multiple unconnected (yet interlocking) laws and processes operating at lower levels. He was, of course, quite justified in thinking this. More than a century and a half of progress in the biological sciences has subsequently shown Darwin to have been correct about the discernibly and predictably law-governed physical and chemical character of many of the above processes. This is especially impressive given that Darwin, writing in the nineteenth century, could have had no strong evidence at all for the molecular basis which was later shown to govern that "Inheritance which is almost implied by Reproduction." Darwin spoke of these underlying laws frequently in The Origin, referring to them variously as "dimly seen" or "complex and little-known." ${ }^{442}$ He knew very well they must exist, but of their exact nature he could have known nothing.

The interaction of these laws and processes with the "indirect and direct action of the external conditions of life," however, was much more problematic. Presumably such "external conditions" were also (ultimately) law-governed, but it was hardly possible to systematise and predict their effects. Nor were the laws and processes which governed such environmental factors in any sense proximate to those molecular processes which drove reproduction. To illustrate this, let us return again to our example of the $\mathrm{K} / \mathrm{T}$ meteor. This impact, and the extinctions it is thought to have caused, could hardly fail to have had profound consequences for the survival of organisms alive at that time - whether through climate change, for instance, or through the extinction of a key predator allowing their prey to flourish and become dominant. Yet the properly nomothetic causes of that impact are not to be found in biology, but in the comparatively far-removed physics of gravitation acting upon

440 Darwin, On The Origin of Species by Means of Natural Selection. pp.489-490.

441 As Richard England has argued, while "Darwin at first considered natural selection to be a natural law," he had come to hold "rather different views by the time the Origin was published in 1859."

See: Richard England, 'Natural Selection, Teleology, and the Logos: From Darwin to the Oxford Neo-Darwinists, 1859-1909.' Osiris. $2^{\text {nd }}$ Series, Vol. 16, Science in Theistic Contexts: Cognitive Dimensions (2001). pp.274-275.

442 Darwin, On The Origin of Species by Means of Natural Selection. pp.5,11-12,472. 
objects in space. If even the physics of deep space objects might sometimes be counted as among the "external conditions of life," arrayed alongside more traditional environmental processes such as climate and predation, then said "external conditions" could hardly be reduced to their own precise laws. Put simply, while the molecular processes of life proceeded in a satisfyingly systematic manner, the environment in which they operated was - from the point of view of biology - a chaotic mess of competing laws and processes, any of which might potentially have an impact on the differential survival of organisms which was at the heart of natural selection. The end result, Darwin wrote, was the arrival of a field of enquiry which was quite incomplete without some acknowledgement of contingency and history:

When we no longer look at an organic being as a savage looks at a ship, as at something wholly beyond his comprehension; when we regard every production of nature as one which has had a history; when we contemplate every complex structure and instinct as the summing up of many contrivances, each useful to the possessor, nearly in the same way as when we look at any great mechanical invention as the summing up of the labour, the experience, the reason, and even the blunders of numerous workmen; when we thus view each organic being, how far more interesting, I speak from experience, will the study of natural history become! $!^{443}$

Just as with Lyell, however, this historical dimension of Darwin's work did not go unnoticed by his critics. Indeed, it was often precisely this historicity which was mobilised in service of his dismissal. Such objections, once again, could only carry weight if one accepted the assumption that the nomothetic form was the ideal expression of science. As we might expect from our example of Lyell, however, this assumption remained pervasive during Darwin's time. The Origin, published after the most influential nineteenth century philosophies of science and proving difficult to accommodate within their nomothetic structures, was thus received quite poorly among theorists and philosophers of science. Indeed, the reception which was to greet Darwin - even when confined to philosophical issues alone - was to prove even harsher than that which was accorded to Lyell.

In his paper examining Darwin's reception by the nineteenth century philosophers of science John Stuart Mill, William Whewell, and John Herschel, the philosopher of biology David Hull argues that all three men had formulated their views regarding the nature of science with the desire to "provide an explicit and detailed analysis of

443 Ibid., pp.485-486. 
science consonant with the great achievements in physics which had preceded them." ${ }^{444}$ This being the case, it is perhaps unsurprising to find that all three philosophers rejected Darwin's conclusions. Whewell rejected the The Origin almost entirely, primarily on religious grounds. ${ }^{445}$ And while Herschel and Mill were willing to at least entertain the possibility of species transmutation, both rejected Darwin's mechanism for being insufficiently law-like. "Chance variation," Hull writes, "sounded too much like the absence of law. The introduction of new species might be by law but not the law of higgledy-piggledy." ${ }^{446}$ But as we have already seen - and as Hull has also pointed out - Darwin had repeatedly stated in The Origin that by "chance variation," he did not mean to imply an "absence of laws governing these variations," but that "whatever these laws might be, they were unknown..." 447 However, it was precisely this lack of knowledge which was the problem. For while Darwin had repeatedly affirmed his ultimate commitment to the nomothetic model of science within it, The Origin had broken new ground with respect to the sheer scope of its conclusions. To say nothing of the immense theoretical distance between natural selection itself and the laws upon which Darwin perceived it as being based. ${ }^{448}$ Put simply, both Darwin and Lyell had shown it was possible to produce scientific models and theories which could not even name their most fundamental laws, and yet were not prevented from doing useful explanatory work by this.

This is not to say that the difficult - if only in nomothetic terms - nature of biology was entirely without allies among philosopher of science. Yet even Darwin's staunchest ally, Thomas Henry Huxley, had private misgivings about natural selection. Five years before Darwin's publication of The Origin, for instance, Huxley had argued:

How then has this notion of the inexactness of Biological science come about? I believe from two causes: first, because in consequence of the great complexity of the science and the multitude of interfering conditions, we are very often only enabled to predict approximately what will occur under given circumstances; and secondly, because, on account of the comparative youth of the Physiological sciences, a great many of their laws are still imperfectly worked out. ${ }^{449}$

444 David L. Hull, 'Charles Darwin and Nineteenth Century Philosophies of Science,' in Ronald N.

Giere \& Richard S. Westfall (eds), Foundations of Scientific Method: The Nineteenth Century. Indiana University Press: Bloomington \& London, 1973. p.115. (emphasis added)

445 Ibid., p.118.

446 Ibid., p.125.

447 Ibid., p.125.

448 For a more fully realised analysis of this point, see: John F. Cornell, 'Newton of the Grassblade?

Darwin and the Problem of Organic Teleology.' Isis. Vol. 77, No. 3 (September 1986). pp.404-421.

449 T. H. Huxley, 'On The Educational Value of the Natural History Sciences, 1854' in T. H. Huxley, The 
Such a defence is, while well-intentioned, ultimately unconvincing. In reply to the charge that biology was not sufficiently lawful, Huxley was essentially saying 'wait and see.' This did little more than shift the burden of proof into the future. One might therefore wonder if the arrival of Darwin's mechanism of natural selection might have seemed like a vindication to Huxley - the arrival of the first of the laws he had hoped for. Yet there is reason to believe that Huxley, while supportive of Darwinian evolution in general, was sceptical regarding the sufficiency of natural selection as its mechanism. This scepticism, moreover, was specifically predicated on the inability of natural selection to function in the law-like manner that the Newtonian view of science would seem to demand. As the historian of science Mario Di Gregorio has argued, Huxley was persuaded of the value of evolution "only as a working hypothesis in respect to the phenomena of organic nature," and only supported the theory in public "as a kind of 'program' worthy of serious consideration but not yet ready for broad application because of natural selection, its basic tenet." ${ }^{450}$ In the wake of one of the most influential scientific works ever published, in other words, which had explained so much while assuming so little, Huxley was still driven by his nomothetic commitments to 'wait and see.'

Another example of philosophical discomfort with Darwin's biology came from the famed geologist, mathematician, and disciple of Whewell, William Hopkins. His 1860 review of Darwin's On The Origin of Species in Fraser's Magazine, for instance, strongly attacked Darwin for precisely the failing Huxley had only hinted at. For Hopkins, natural selection could be little more than descriptive speculation, because "explanation" - as opposed to "mere description" - required a demonstration that the phenomenon in question was a necessary consequence of known laws of nature. ${ }^{451}$ This commitment to a nomothetic ideal of science, as the historian M. J. S. Hodge has argued, almost entirely determined Hopkins' assessment of Darwin:

For, of course, the only candidate for a physical cause that he [Hopkins] finds there is natural selection; but no explanation is achieved by this, because there is no acceptable proof that, in the initial conditions obtaining, this "force" has necessitated any of its supposed effects. Moreover, since the law of common descent is, considered on its own, only a "descriptive" law, it can have, Hopkins

Essence of T. H. Huxley: Selections from his Writings. Cyril Bibby (ed). St. Martin's Press: New York, 1967. p.53.

450 Mario A. Di Gregorio, 'The Dinosaur Connection: A Reinterpretation of T. H. Huxley's Evolutionary View,' Journal of the History of Biology. Vol. 15, No. 3 (Autumn 1982). pp.397-398.

451 William Hopkins, 'Physical Theories of the Phenomena of Life,' cited in: M. J. S. Hodge, 'England,' in Thomas F. Glick (ed), The Comparative Reception of Darwinism. University of Chicago Press: Chicago \& London, 1988. pp.23-24. 
insists, no explanatory power to solve problems in biogeography and comparative anatomy. It was, manifestly, his ontology as much as his methodology that sustained Hopkins's dissatisfaction. Explanatory causes had to be for him either Newtonian forces or some other agents that, like them, lawfully mediate between God and matter. ${ }^{452}$

This, Hodge argued, was an example of how "a commitment to Newton and to God could... lead very directly to a rejection of Darwin." This is not to suggest that all objections to Darwinian biology were so motivated, however. In fact, according to Hodge, nineteenth century objections to Darwinian biology could be understood as arising from four distinct areas. First, from the theologically inspired objections of those such as William Whewell. Second, from a group Hodge called "unambitious, conservative naturalists who... dismissed all theorizing as inconclusive, divisive speculation." Third, from the lay community of "popular, religious, or literary critics" who could claim "no regular membership in the researching community." And lastly, from "anyone like Hopkins" who "measured theoretical innovations in biology against the arguably irrelevant standards of Newtonian science." ${ }^{453}$ Given that the first three of these groups represented rejections for less than empirically sound reasons, it was only this final category which presented any real threat to Darwin. And yet objections from that same quarter were effectively dominated by concerns that Darwin's work represented a troubling mismatch between theory and practice. Concern about the implications and verifiability of Darwin's ideas were one thing, concerns as to whether they could adequately be called science at all were quite another. Regardless of whether Newtonian standards were "irrelevant" or not, rejection from people like Hopkins and scepticism even from champions like Huxley was ultimately an expression of discomfort with Darwin's work based less on its content and more on its perceived fit with some ideal form. And given that Darwin's work has since come to represent some of the most successful scientific practice in the history of biology or any other science, one cannot help but wonder whether it was not this ideal form which was at fault.

\section{Contemporary Nomothetic Objections to Darwinian Biology}

The more difficult (that is to say, historical) implications of Darwinian biology continued to experience a great deal of philosophical resistance in the early to mid twentieth century. Especially hostile were those philosophers of science associated

452 Hodge, 'England,' p.23.

453 Ibid., pp.23-24. 
with logical positivism - that mid-century movement which had also produced Hempel's legendarily troublesome 'The Function of General Laws in History.' During this period, mainstream philosophers of science were often so hostile toward Darwinian biology, that the philosopher of biology David L. Hull devoted one of the earliest papers in his career purely to their rebuttal. Published in 1969, the nowclassic 'What the Philosophy of Biology is Not,' was a review of the contributions (or the lack thereof) made by orthodox philosophers of science to issues relevant to the biological sciences. ${ }^{454}$ The real power of this paper, however, came not from Hull's dissection of the substantive arguments about biology made by the philosophers he examines, but from his explication of their serious factual errors regarding even the most basic aspects of that biology. "One striking feature of the remarks made by philosophers about biology," Hull argued, "is how frequently they are misinformed." 455 To this observation we might only add that it is equally striking just how often such dismissals of Darwinism were rooted not only in ignorance, but also in the doctrinaire expectation that all real science should look and act like nomothetic physics. Mario Bunge, for instance, in a paper exploring the quality of simplicity in scientific theory, argued the following of Darwinian natural selection:

What gave Darwin's theory of evolution through natural selection the victory over its various rivals, notably creationism and Lamarckism? Darwin's theory was in part logically faulty (remember the vicious circle of the "survival of the fittest"); it contained several false or at least unproven assertions ("Each variation is good for the individual," "Acquired characters, if favorable, are inherited," "Sexual selection operates universally"); it had not been tested by observation, let alone by experiment on living species under controlled conditions... it's explanatory power was clearly smaller than that of its rivals (irrefutable theories have the maximum post factum explanatory power); it had no inductive basis but was, on the contrary, a bold invention containing high-level unobservables. And, if these were not enough to condemn the theory, Darwin's system was far more complex than any of its rivals. ${ }^{456}$

Against this seemingly damning assessment, Hull proceeded to show that almost all of Bunge's assertions regarding natural selection in the above quote were not only errors of argument, but errors of fact. In spite of the "tiresome regularity" with which the argument of logical circularity is made, Hull argued, "it has little foundation."

454 David L. Hull, 'What Philosophy of Biology is Not,' Synthese. Vol. 20, No. 2, Methodological Problems in Biology (August 1969). pp.157-184. This paper has also appeared as: David L. Hull, 'Essay Review: What the Philosophy of Biology is Not,' The Journal of the History of Biology. Vol. 2, No. 1, Explanation in Biology (Spring 1969). pp.241-268. Subsequent citations here will refer to the former.

455 Hull, 'What Philosophy of Biology is Not,' p.157.

456 Mario Bunge, 'The Weight of Simplicity in the Construction and Assaying of Scientific Theories,' Philosophy of Science. Vol. 28, No. 2 (April 1961). pp.143-144. (emphasis in original) 
For while the claim that "the fittest tend to survive can be made viciously circular if fitness were determined only by means of actual survival or into a tautology by defining 'fitness' exclusively in terms of actual survival," Hull argued, "biologists do neither." Of Bunge's purported examples of Darwin's false and/or unproven assertions, Hull argued that Darwin demonstrably held none of them. And with respect to Bunge's claim that Darwin's theory had no inductive base, Hull stated simply: “one wonders what Bunge can mean by 'inductive basis' if Darwin's 30 years' labor in attempting to support his theory and all the data marshalled in the Origin provided no inductive basis." While these points were not of critical importance for the overall argument of Bunge's paper, Hull argued that his comments nonetheless represented evidence of an "obvious disinterest in evolutionary theory" as a properly scientific proposition. "It is certain," Hull wrote, "that he would not treat quantum theory in such a cavalier fashion." ${ }^{457}$

Much of Hull's paper consisted of just this kind of factual debunking, often of targets even softer than Bunge. As was the case with Bunge, however, many of the factual errors he pointed out were only rarely truly significant relative to the matters of philosophy at issue. In the second half of the paper, however, he reframes his question. "Enough has been said," Hull wrote, "to show how unsuccessful contemporary philosophers have been in extracting the consequences of biology for philosophy. What of the other side of the coin? Have philosophical analyses of biology provided any insights into biological phenomena, any clarity which biologists themselves have been unable to provide...?" But in this respect also, Hull found the philosophy of science to be sadly out of touch with biological reality, continuing to argue over archaic issues such as vitalism and teleology which had long been conclusively settled among actual biologists. "From the point of view of contemporary biology," Hull stated bluntly, "both vitalism and teleology are stone cold dead." ${ }^{458}$ One biological issue in which philosophers of science were interested, Hull argued, was the possibility of reductionism. This philosophical interest was decidedly not for the benefit of biology, however. Instead it was seen as an avenue by which logical positivists hoped to salvage the purported universality of the nomothetic model in the face of a century of sustained failure by biologists to deliver the laws that Huxley had so long ago promised. Biology was being used, in other words, as a paradigm case in a wider discussion of the nature of explanation.

457 Hull, 'What Philosophy of Biology is Not,' pp.158-159.

458 Ibid., p.163. 
Reductionism, as applied to biology, was concerned with the basic question of "whether biology was in some sense reducible to chemistry and physics and what such a reduction entailed." The then-recent discovery of the molecule DNA was the primary catalyst for this. As Hull has observed, "during the last 30 years, a process has been under way in genetics which fulfills all the requirements of what both scientists and philosophers have in mind when they speak of reduction. A biochemical explanation is being produced for phenomena which have been explained previously in terms of classical Mendelian genetics." ${ }^{459}$ Philosophers and biologists, however, disagreed over the significance of this. For biologists, this was significant in terms of its possible applications in genetics, but was not of any overarching relevance:

It may well be true that in principle all macroscopic phenomena are governed by deterministic laws and that all these laws can be organized into a deductive hierarchy, but biologists do not have these laws. The laws which give substance to the claim that an organism which did not survive was nevertheless exceedingly fit are currently not deducible from evolutionary theory and are formally independent of it. $^{460}$

That is to say, biology could do useful work without being reduced to physics and/or chemistry. For biologists, evolutionary theory was legitimate even without knowledge of how it was linked to properly nomothetic general laws. More importantly, while the three revolutions in biology represented by Darwin's discovery of natural selection, Mendel's work on genetics, and the discovery of DNA, had all massively increased the explanatory power of biology, they had not succeeded in eliminating the basic contingency inherent in biological evolution. They were not, in other words, predictive in the classical sense. Biologists might therefore have been forgiven for wondering just how advanced biology would have to get in order to be taken seriously as a non-nomothetic science. For some philosophers of science, on the other hand, the possibility of a complete reduction provided hope that, if biology could not produce its own laws, it might at least be shown to be the necessary applied product of more fundamental known laws of chemistry and physics. This is not to say, of course, that biology did not have any generalisations, large-scale theories, or law-like statements. That was not the problem. The problem was the insistence by nomothetically inclined philosophers of science on prediction as a necessary

459 Ibid., pp.164-165.

460 Ibid., p.167. (emphasis added) 
consequence of explanation. And this requirement made such generalisations as did exist illegitimate. As Hull has argued:

During the last decade or so, biology has been forced briefly to the center of the stage in the philosophy of science because of the relevance of explanation and prediction in evolutionary studies to a remark made by Hempel and Oppenheim in their classic paper on the logic of explanation. After setting out four conditions of adequacy for scientific explanation, they state that the same formal analysis applies to scientific prediction as well. ${ }^{461}$

To be fair, by the time Hull was writing, the Hempelian model was already under attack from many quarters. But this argument that truly scientific explanation should be "symmetrical" was a point upon which evolutionary biology had been attacked before, and would be again. As such, it is worth mentioning here. Briefly put, the symmetry thesis was the assertion that an explanation was only truly scientific if it could have (even if only theoretically) predicted the events it explains. One might explain some unique and unrepeatable event after the fact, for instance, but the explanation so offered - in order to be valid under the symmetry thesis - ought to have been able to demonstrate ahead of time (i.e., predict) that the event was necessary. The form of the explanation in both cases should be identical. The only difference between a prediction and a post facto explanation is the relative time at which it is given. And this symmetry, as Hempel and Oppenheim famously argued, was a crucial component of science:

It is this potential predictive force which gives scientific explanation its importance: only to the extent that we are able to explain empirical facts can we attain the major objective of scientific research, namely not merely to record the phenomena of our experience, but to learn from them, by basing upon them theoretical generalizations which enable us to anticipate new occurrences and to control, at least to some extent, the changes in our environment. ${ }^{462}$

But this would hardly be possible in any discipline without the availability of highly precise general laws and principles. Evolutionary biology also suffered from the additional handicap of being unable to - whether by experiment or repeated observation - ameliorate the contingency which abounded in the kinds of long-run systems it attempted to make sense of. The symmetry thesis was thus a test that evolutionary biology quite simply could not pass. As Hull has argued, the "significance of biology for this controversy in the philosophy of science is that biologists frequently set forth what they take to be explanations of the evolutionary $461 \mathrm{Ibid.}$. p.165. The "classic paper" Hull is referring to here is: Carl G. Hempel and Paul Oppenheim, 'Studies in the Logic of Explanation,' Philosophy of Science. Vol. 15, No. 2 (April 1948). pp.135-175. 462 Hempel and Oppenheim, 'Studies in the Logic of Explanation,' p.138. 
development of certain groups when they readily admit they could not have made much in the way of any reasoned predictions in the matter." 463 This meant that, if we accept Hempel and Oppenheim's logic, evolutionary biology would be required to be completely reduced to physics and/or chemistry if it wished to be considered capable of anything even approximating a properly scientific explanation. From this it would follow that biologists - Darwin, Mendel, Watson, and Crick included - have yet to succeed in offering a single genuinely scientific explanation. Given the remarkable contributions of these biologists to human knowledge, this seems almost comically unfair. As Hull has argued, whatever the outcome of the discussion surrounding reductionism, it was clear that biology was not being taken on its own terms. "As gratified as biologists may be for the attention that one of their theories had at last received from first rate philosophers of science," Hull wrote, "the actual nature of evolutionary inferences was investigated none too intensively. What biologists actually did in producing certain putative explanations rapidly became peripheral to the issue of whether or not these formulations were truly explanations." 464

Or, it might be added, whether evolutionary biology was even science at all. For it was on similarly nomothetically inspired grounds of symmetrical prediction that Karl Popper, in his 1974 paper 'Darwinism as a Metaphysical Research Programme,' famously declared that "Darwinism is not a testable scientific theory but a metaphysical research programme - a possible framework for testable scientific theories." 465 Popper based this controversial argument on what he interpreted as the ability of Darwinian theory to explain the outcome of any observation:

... assume that we find life on Mars consisting of exactly three species of bacteria with a genetic outfit similar to that of terrestrial species. Is Darwinism refuted? By no means. We shall say that these three species were the only forms among the many mutants which were sufficiently well adjusted to survive. And we shall say the same if there is only one species (or none). Thus Darwinism does not really predict the evolution of variety. It therefore cannot really explain it. ${ }^{466}$

It seems that for Popper, like Hempel and Oppenheim, an assertion must be fully predictive (i.e., symmetrical) in order to be considered an explanation. This would therefore seem to be little more than yet another example of the rejection of

463 Hull, 'What Philosophy of Biology is Not,' p.165.

464 Ibid., pp.165-166.

465 Karl Popper, 'Darwinism as a Metaphysical Research Programme,' in P. A. Schilpp (ed), The Philosophy of Karl Popper: Volume One. Open Court: LaSalle, Illinois, 1974. p.134. (emphasis in original)

466 Ibid., p.136. (emphasis in original) 
Darwinian evolution motivated by an a priori commitment to the nomotheticdeductive model of science. But there is more we might profitably say about Popper's case. For while the hypothetical example Popper offers might very well be genuinely ambiguous, it seems disingenuous to propose two situations, both of which Darwinian evolution could theoretically explain (and thus be unable to choose between) and therefore conclude that Darwinian evolution can explain any possible observation and justify all possible outcomes. Michael Ruse makes precisely this point at length in his 1977 article-length refutation of Popper's "evolutionary" philosophy ${ }^{467}$ In addition to this structural failure in Popper's argument, however, Ruse also finds in his work several extremely serious factual errors with respect to basic biology, leading him to conclude that Popper could "draw his conclusions only because he is abysmally ignorant of the current status of biological thought." Thus, Ruse argues, Popper's “criticisms of biology are without force and his suggestions for its improvement are without need." 468 The philosopher Robert J. Richards has since noted that, in the wake of just such counterarguments, Popper had largely retreated from his position by 1978 and had been compelled to "admit evolutionary biology into the temple." But this reversal, Richards argued, was seemingly political rather than philosophical. For even setting aside his basic errors of biology, there was still the problem of the symmetry thesis inherent in the nomothetic-deductive model to contend with. There was, Richards writes, "no good reason why he should have succumbed to ecumenism. Evolutionary biology still does not meet the logical criteria that Popper proposed for science." 469

From the selection of examples offered here, it should by now be clear that the classical nomothetic model of science has a long history of failure in both the geological and biological sciences. That failure, moreover, has not been a catalyst for the revision or replacement of that model. Instead it has been used as a cudgel to call into question the basic legitimacy of both sciences, as though it were their fault for not living up to the ideal. Nor are these the only sciences from which examples might have been drawn. But this thesis has no need to further reinvent the wheel. For our purposes, what is important is the demonstration that, at the root of this general hostility toward such historically focused sciences is the assumption that a science 467 Michael Ruse, 'Karl Popper's Philosophy of Biology,' Philosophy of Science. Vol. 44, No. 4 (December 1977). pp.643-646. 468 Ibid., p.638.

469 Robert J. Richards, 'The Structure of Narrative Explanation in History and Biology,' in Matthew H. Nitecki \& Doris V. Nitecki (eds), History and Evolution. State University of New York Press: Albany, 1992. p.20. 
must make use of general laws in order to be genuinely explanatory. Moreover, glib claims by nomothetic philosophers of science that such disciplines are merely awaiting their inevitable theoretical reduction to more fundamental (i.e., nomothetic) sciences have acted to engender a 'wait and see' approach to any counter-example which has threatened nomothetic orthodoxy. This is not only logically dubious in the sense that it allows the nomothetic-deductive model to claim success no matter what counter-examples it is presented with, it also fails to recognise the insights historical sciences which have not (or not yet) been so reduced have been able to provide. This is another way of saying that while the nomothetic position will very likely prove correct in the long run, geologists and evolutionary biologists (among others) have science to do right now, and require a principled way in which to go about doing it. To this end, we must examine the kinds of practical models philosophers and practitioners of these sciences have developed in order to describe and guide their work in the absence of any strong philosophical guidance. We will examine an extended example of just such a solution in the following chapter, with a view to showing how historical sciences have attempted to generate theories regarding single events / objects and submit them to meaningful empirical confirmation.

In the examination of the "actual nature" of explanatory practice in the historical sciences which occupies Chapter Five, particular emphasis will be placed on attempts to offer historical accounts which could also maintain a scientific legitimacy. For while philosophers of the historical sciences were required to account for contingency in their attempts to model historical explanation, they could not, as philosophers of history had done, use this requirement as an excuse to abandon science altogether. This in turn meant that the claim of the nomothetic-deductive model to be universal had to be directly challenged. Thus the first stirrings of a historical, narrative approach to science would lead ineluctably to a philosophical challenge against one of its most central tenets. As Robert J. Richards has argued, the reason that evolutionary biology did not meet Popper's nomothetic criteria for science was because "it is historical and suffers from the presumed disabilities of all history attempting to pass as science." ${ }^{470}$ But such disabilities, Richard continues, are imagined rather than actual. This is because they arise from trying to force historical explanations into a nomothetic form when it is the reverse which is more appropriate:

... Hempel got it just backwards: it is not that history can offer only explanation 470 Ibid. 
sketches, but that nomological-deductive accounts - insofar as they can be detected in such sciences as geology, paleontology, astrophysics, anthropology, and evolutionary biology - provide only narrative sketches; the covering law model yields sound explanations only insofar as that skeleton can be fleshed out imaginatively with the sinew and muscle of the corresponding narrative. ${ }^{471}$

If the common basis of the sciences Richards has listed above is their historical focus - and this seems a more than reasonable conclusion - then, he claims, their explanatory mechanisms must involve narrative to some degree. For only narrative, Richards argues, can take account of the kinds of contingencies and interlocking chains of causality inherent in such historical explanations. David Hull came to a similar conclusion, arguing not only that narrative is the best mechanism available for understanding and explaining historical developments, but also that historical explanations need not strive for some arbitrary threshold of generality in order to be considered legitimate:

... I argue that explanations in terms of particular circumstances are perfectly legitimate and set out what might be termed a Particular-Circumstance Model of scientific explanation. Of course, there may be some general laws lurking around in the background somewhere, but the particular circumstances carry the explanatory load. ${ }^{472}$

One can hardly fail to notice the similarity of these arguments to the rapprochement between laws and narrative suggested by Arthur Danto. Unlike Danto, however, what these philosophers are suggesting is not only that a model of scientific explanation which expands upon the traditional nomothetic-deductive form is possible, but that such a model uses narrative as a central mechanism. More importantly, the means by which this argument can even be made at all is through the weakening of the nomothetic assumption. If Roberts and Hull are correct about this, then the two main reasons narrativist philosophers of history have offered for why history cannot be considered scientific - the inability to produce or otherwise make use of general laws, and the inherently unscientific nature of narrative - are effectively neutralised. And given the elimination of these objections, the question immediately arises: could such a scientific model of narrative also be applied to the study of human history as we currently know it? If so, the potential rewards are immense. At the very least, the kinds of tensions between historical explanation and the scientific ideal detailed in Part One will be dissolved. Similarly, the retreat into a

471 Ibid., p.23.

472 David L. Hull, 'The Particular-Circumstance Model of Scientific Explanation,' in Matthew H. Nitecki \& Doris V. Nitecki (eds), History and Evolution. State University of New York Press: Albany, 1992. p.70. 
literary definition of the term "narrative" among contemporary philosophers of history would be revealed as an unnecessary response to an illusory problem. For if a broadly inclusive concept of narrative could be made scientifically respectable, then its role in the construction of historical accounts need not immediately banish those accounts to the subjective ghetto of the humanities. And finally, and perhaps most significantly, the age-old question as to whether history is a science will be, if not answered, then at least forever reframed in a way far more conducive to future progress. 


\section{Chapter Five \\ "The Science of Stories"}

The previous chapter has begun our overarching task of dismantling the nomothetic assumption by showing the inability of the nomothetic-deductive ideal upon which that assumption is based to adequately model even all of those fields which are unproblematically considered scientific - let alone be exported to more controversial areas such as history. The task of this chapter, therefore, will be to build on this insight by examining a real example of how historical scientists - in the face of a seemingly indifferent philosophy of science - have attempted to conceptualise and justify the kinds of explanations they actually offer. More specifically, this chapter will argue that such an example of internal theorising can provide us with the broad outline of a conceptual approach to science which not only emphasises narrative, but which can also claim sufficient methodological sophistication to submit narratives to some empirical test. The result, as we shall see, is an approach to science which does not rely directly on general laws, yet can still produce robust conclusions and mitigate ad hoc explanations. This will leave for the following chapter only the requirement to argue that such a model can be successfully generalised and thus be made available to the study of human history. Instead of imposing a theoretical model from the top down, in other words, we will see how an alternative model has emerged from within the historical sciences themselves. One might ask how this approach differs from that of W. H. Walsh, who argued that his own colligation would provide "a proper characterization of what historians in fact do, their actual procedure being taken as decisive in this matter." 473 We have, after all, already examined Walsh's proposed solution to precisely this problem and have found it wanting. Walsh, however, was forced by the nomothetic assumption to argue for a historical separatism that his ideas could not sustain. This was not an option available to those who first sought to model the practices of the historical sciences. Evolutionary biologists and geologists, in other words, could not merely decree themselves a narrative (and therefore literary) enterprise which was not required to adhere to the epistemic standards of the sciences. There has never been, for instance, an idealist theory of geology which has argued that rocks (rather than human beings, as in traditional idealism) were somehow exempt from the ultimate strictures of the laws of physics.

473 W. H. Walsh, "Plain' and 'Significant' Narrative in History,' The Journal of Philosophy. Vol. 55, No. 11 (May 1958). p.480. (emphasis added) 
Because historical scientists were thus forced to face the reality of the nomothetic model's success in other fields, there simply could not be any serious claim (such as Dray might have made, or even Danto) that laws were outright hostile to the practice of biology, geology, or any other historical science. Philosophers of the historical sciences were required to be more accommodationist than that. David Hull has argued, for example, that his "Particular-Circumstance" model "exhibits the same form" as the classical Hempelian nomothetic-deductive model but "with its emphasis reversed." ${ }^{474}$ This suggests that there is still some role for laws in Hull's model of narrative explanation. Similarly, of the common argument that geology is an immature "protoscience" waiting for the equivalent of its Newton, the philosopher of geology David B. Kitts has replied: "the Newton of geology has been here and gone. His name was Isaac Newton." ${ }^{475}$ We will have more to say about such arguments in Chapter Six. For now it will suffice merely to say that at no point in the extended example we will examine in this chapter is a complete rejection of the nomothetic-deductive model being proposed. For that model has enjoyed quite spectacular success in other fields, and must therefore remain a key part of any credible philosophy of science. This point of view is critical to the overall argument of this thesis. Hull and Kitts are not suggesting that, because of a failure to adequately function in a nomothetic fashion, their respective fields must be fundamentally divorced from science. They are arguing instead that, in order to cover those historical cases it has hitherto dismissed or been otherwise unable to accommodate, the philosophy of science requires extension. What follows then is an extended example of one particular attempt to model a narrative approach to explanation in the historical sciences in which just such concerns were considered and an attempt to establish some kind of principled alternative offered. We will begin first by examining the model itself and the applied example of scientific narrative it claims to have offered. We shall then extend that applied example into the present in order to see how well it has in fact performed as an explanatory method. The result will be a roughly chronological journey through an account of scientific explanation spanning nearly 70 years, which will convincingly demonstrate that a formal narrative model of scientific explanation is not merely desirable but indispensable.

474 David L. Hull, 'The Particular-Circumstance Model of Scientific Explanation,' in Matthew H. Nitecki \& Doris V. Nitecki (eds), History and Evolution. State University of New York Press: Albany, 1992. p.79.

475 David B. Kitts, The Structure of Geology. Southern Methodist University Press: Dallas, 1977. p.xiv. 


\section{An Account of Narrative Explanation in Evolutionary Biology}

One of the earliest attempts to formally conceptualise the kinds of explanations historical sciences actually offer and the methods by which they were constructed was that of the Canadian philosopher T. A. Goudge. Goudge was also notable for being among the first to explicitly argue - in both his 1958 paper entitled 'Causal Explanations in Natural History'476 and his 1961 book The Ascent of Life $e^{477}$ - that these explanations took a recognisably narrative form. Goudge's 1958 paper, for example, opened with the following:

There are certain empirical sciences such as geology, paleontology and biology whose subject-matter is partly historical. They investigate phenomena which originated and existed for varying periods of time in the remote past... One aim of these sciences is to describe as fully as possible each of the phenomena in question by utilising available evidence. Often, however, this evidence is fragmentary. Hence a particular phenomenon may have to be reconstructed by supplying conjectured details to fill in the gaps. In addition to describing, they also formulate causal explanations of the phenomena with which they deal. ${ }^{478}$

However, Goudge argued, then-contemporary philosophy of science had "done less than justice" to such sciences by insisting that they could not give actual explanations unless they invoked general laws. In an attempt to rebut this argument, Goudge sought to leverage the tacitly implied link in positivist philosophy between nomothetic explanations and causal explanations. Goudge argued that if he could provide an example of a causal explanation which did not involve laws, then the logical necessity of that link would be called into question. More importantly, such a demonstration would show that, if only in theory, at least one additional class of explanation was possible. Goudge thus sought to demonstrate that "causal explanations do occur in natural history," and that at least some of these explanations possess "logical features which differentiate them quite sharply from causal explanations which apply a general law or set of laws to particular events." ${ }^{479}$ This being Goudge's aim, he needed (theoretically, at least) to establish only a single example of a causal explanation which somehow transcended those fundamental laws which might be applied to it. The rest of Goudge's relatively short (and

476 T. A. Goudge, 'Causal Explanations in Natural History.' The British Journal for the Philosophy of Science. Vol. 9, No. 35 (November 1958). pp.194-202.

477 T. A. Goudge, The Ascent of Life: A Philosophical Study of the Theory of Evolution. George Allen \& Unwin, Ltd.: London, 1961.

478 Goudge, 'Causal Explanations in Natural History.' p.194.

479 Ibid. 
admittedly "exploratory" ${ }^{480}$ ) paper was therefore devoted to devising such an example. But first, Goudge made a familiar argument with respect to the historical sciences:

When a biologist investigates a phenomenon of natural history, what he frequently wants to explain is an individual occurrence, something which has 'come to be' or 'ceased to be' just once. The phenomenon is therefore non-recurrent, and hence not subject to controlled experimentation. The precise circumstances under which it arose or disappeared, including the temporal interval involved, cannot be duplicated. Its spatio-temporal boundaries are impossible to specify exactly. ${ }^{481}$

As readers will recall from Part One, similar arguments from uniqueness have been well-rehearsed among philosophers of history, who have often used them to argue that human history cannot be scientific. Such arguments coming from a biologist, however, would lack a certain amount of credibility. Hence Goudge's subsequent approach is instructive. Despite the limitations imposed by this functional uniqueness, he writes, the evolutionary biologist must attempt to "reconstruct the causal conditions which were operative," and "arrange them in an explanatory pattern." 482 Goudge has argued, in other words, for the use of narrative as a valid scientific tool for explanation in such unique and unrepeatable cases. More importantly, he has argued that the succession of events which might make up such a narrative can, if composed of properly causal statements, be meaningfully scientific. A causal explanation is thus not (or at least not necessarily) an additional step that one performs over and above the reconstruction of a narrative sequence, but is the very sequence itself. This, it should be noted, is consistent with the definition of narrative offered by Danto in Chapter Three.

What then made a narrative substantively different from a more traditional (i.e., nomothetically derived) explanation? This was, for Goudge, a matter of logistical necessity. Causal explanations - speaking in the philosophical jargon of "necessity" and "sufficiency" - should either: " $(a)$... indicate those conditions temporally prior to (or simultaneous with) P which are independently necessary and jointly sufficient for the occurrence of $\mathrm{P}^{\prime \prime}$ or " $(b) \ldots$ indicate those conditions temporally prior to (or simultaneous with) $\mathrm{P}$ which are jointly sufficient but not independently necessary for the occurrence of P." ${ }^{483}$ The first of these approaches explains $\mathrm{P}$ in terms of necessary conditions - those without which $\mathrm{P}$ cannot occur - and is thus somewhat more

480 Ibid., p.196.

481 Ibid., p.195. (emphasis in original)

482 Ibid.

483 Ibid. (emphasis in original) 
conducive to nomothetic explanation. For example, it was a necessary condition of the Great Fire of London that the Earth's atmosphere contain oxygen. This was not a sufficient condition, however, as the presence of atmospheric oxygen does not guarantee large fires in London (or indeed anywhere else). Goudge's "(a)" model would therefore require the collection of enough necessary conditions to isolate a singular event. Due to this emphasis on necessity, however, these conditions can only be nomothetic laws or otherwise exceptionless generalisations. This requirement, as we have seen in Part One, has a tendency to allow only the most obvious and implicit laws - as is the case in the above hypothetical example of atmospheric oxygen and the Great Fire. It is therefore far from clear that enough necessary (and only necessary) conditions could be amassed in order to arrive at the kind of explanation historians and historical scientists are typically seeking.

Goudge's " $(b)^{\prime \prime}$ model, however, is slightly but crucially different, choosing to arrive at an explanation through a plurality of non-necessary conditions which together add up to a sufficient cause. This is much closer to the familiar form of historical explanations. An historian might argue, for instance, that the Second World War had multiple causes - the Great Depression, unresolved tensions resulting from the earlier Treaty of Versailles, and so on. None of these causes acting alone, however, could be said to have caused the war. In that sense, they were not individually sufficient. But, when acting in concert, the Second World War was their result. This is much closer to a true narrative model, Goudge argued, but was still an ideal only rarely approached in actual historical explanation. "The causal explanations with which I am concerned," Goudge wrote, “are at best approximations to schema $(b) . "$ In other words:

... they are explanations which seek to formulate a possible sufficient condition of $\mathrm{P}$ by specifying as many of the necessary and contingent contributory conditions of $\mathrm{P}$ as can be discerned or imagined. Sometimes the sufficient condition is first entertained in a vague form, and then its vagueness is gradually reduced by 'filling in' a number of the necessary and contributory conditions which it embraces. This also increases its testability, as I will try to show. But the strict requirements of schema $(b)$, let alone $(a)$, are never met. Hence a large degree of flexibility attaches to the notion of causal explanation in natural history. ${ }^{484}$

From the perspective of a nomothetic model of science, however, there is another difficulty with Goudge's " $(b)^{\prime \prime}$ schema. For it is difficult to see how schema " $(b)$," even in its ideal form, need invoke laws. Certainly it could. But it does not appear to 484 Ibid., p.196. (emphasis in original) 
need to do so. To illustrate this, Goudge made extensive use of an example first offered in 1933 by the paleontologist A. S. Romer. This example is worth examining in some detail here, as it represents a paradigm case of the kind of historical and narrative reasoning with which this thesis is concerned. It concerned the famous evolutionary explanation Romer postulated for the emergence of the first land vertebrates - those "primitive amphibians which inhabited fresh-water pools and streams in Carboniferous and Devonian times, and which possessed rudimentary limbs." ${ }^{485}$ Romer phrased the problem he was trying to solve as follows:

Why should the amphibians have developed these limbs and become potential land-dwellers? Not to breathe air, for that could be done by merely coming to the surface of the pool. Not because they were driven out in search of food, for they were fish-eating types for which there was little food to be had on land. Not to escape enemies, for they were among the largest animals of the streams and pools of that day. ${ }^{486}$

Romer's subsequent attempt to answer this question, however, takes a recognisably narrative form:

The Devonian, the period in which the amphibians originated, was a time of seasonal droughts. At time the streams would cease to flow... If the water dried up altogether and did not soon return... the amphibian, with his newly-developed land limbs, could crawl out of the shrunken pool, walk up or down the stream bed or overland and reach another pool where he might take up his aquatic existence again. Land limbs were developed to reach the water, not to leave it. ${ }^{487}$

From this, Romer was able to forge a plausible connection between the conditions which might have given rise to the first amphibians ${ }^{488}$ and the further progress of terrestrial life as evidenced by the fossil record:

Once this development of limbs had taken place, however, it is not hard to imagine how true land life eventually resulted. Instead of immediately taking to the water again, the amphibian might learn to linger about the drying pools and devour stranded fish. Insects were already present and would afford the beginnings of a diet for a land form. Later, plants were taken up as a source of food supply... Finally, through these various developments, a land fauna would have been established. ${ }^{489}$

\footnotetext{
485 Ibid.

486 A. S. Romer, Man and the Vertebrates. $3^{\text {rd }}$ Edition. University of Chicago Press: Chicago, 1941. p.47. 487 Ibid., p.48.

488 It should be noted that the more inclusive term now used to denote these early limbed creatures is "tetrapod" rather than "amphibian." This term is more precise in that it implies only the presence of limbs. "Amphibian," on the other hand, carries with it additional connotations which are not relevant here. This thesis will henceforth use the former term, except in the case of direct citations from those who have not.

489 Romer, Man and the Vertebrates. p.48.
} 
The development of limbs and the ability to make use of the opportunities that dry land afforded, Romer argued, was therefore the result of a "happy accident." 490 Goudge had the following to say of this attempt to account for the selection pressure which drove tetrapod evolution:

This piece of reasoning has a number of distinctive features. Although it is part of a scientific discussion, it is not concerned to discover or to confirm a general law. It does not establish any new empirical fact which is simply to be added to the store of human knowledge. It does not make an explicit, positive prediction about what will be found by future investigations, though there is a sense in which it makes certain negative predictions... What the reasoning does is to propose a theoretical pattern... This pattern presents an intelligible sequence of events such that the phenomenon to be accounted for 'falls into place' as the terminal phase of the sequence. The phenomenon ceases to be isolated, and is connected in an orderly way with states of affairs which led up to it. ${ }^{491}$

Romer's explanation, in other words, would seem to be a clear example of a recognisably narrative model of explanation applied to what is clearly a scientific question. More importantly, Goudge argued, such narrative explanations were (in the context of evolutionary biology at least) not only necessary, but unable to ever be totally subsumed by nomothetic explanations. "Since the aim is to make these events intelligible as unique, non-recurrent phenomena," he wrote, "recourse must be had to historical or 'narrative' explanations." This was because the singularity of such situations prevented their "being treated systematically in terms of general laws." Narrative explanations were therefore unavoidable wherever "singular events of major importance for the history of life are being discussed." 492 Given this conclusion, two questions quite naturally arise. First, to what extent is this narrative model different from (rather than merely a special case of) the nomothetic-deductive model? And second, is this actually a satisfactory explanation from the point of view of empirical testability? We shall now examine both of these questions in turn.

\section{Narrative as a 'Special Case' of the Nomothetic Model}

The counter-argument that the kind of narrative explanation Goudge is offering is actually a special (i.e., incomplete) case of the nomothetic model is one that, perhaps unsurprisingly, is often raised by defenders of the covering law model. The covering law argument is, after all, predicated on declaring those explanations which do not

490 Ibid., p.47.

491 Goudge, 'Causal Explanations in Natural History.' p.197.

492 Goudge, The Ascent of Life. pp.70-71. 
conform to the model - whether in biology, history, or anywhere else - to be incomplete "explanation sketches." This is taken to mean that, were more information available, a "proper" explanation (i.e., one with clear reference to laws) could be found. Or it could be argued that the laws in such "sketches" were merely implicit rather than explicit and that the resulting explanation, while perhaps fit for some purposes, was not, in some important sense, finished. Michael Ruse, for instance, has attacked both Romer and Goudge (as well as narrativism in general) on precisely these grounds. "Taken completely in isolation," Ruse argues, "Romer's account of the evolution of the land-vertebrates falls short of being an adequate explanation." ${ }^{493}$ This is because Romer did not establish that the evolution of landcapable vertebrates via the path that he proposed was necessary. "Not only," Ruse writes:

... was the development of limbs not the only response which might have been made to droughts by organisms like the amphibians (i.e., organisms which needed water), it was not the only response which such organisms in fact made to droughts. Another group of organisms, lung-fish, when faced with a situation similar to the amphibians, developed the ability to remain during droughts in a dehydrated state of suspended animation baked in the mud at the bottom of dried up pools... Why did not the amphibians evolve in a similar manner, rather than going the way that they actually did? Until this question is answered we will not have a sufficient condition for the actual evolutionary event which did occur, and thus... we will not have a totally adequate explanation. ${ }^{494}$

From this it seems clear that, in true covering law fashion, what Ruse requires from an "explanation" is the exclusion of all other possibilities. In other words, necessity. And the only known way in which to achieve this, he writes, is to make use of timeless and universal general laws:

Let us look in a little more detail at some of the questions which Romer's 'explanation' invokes - questions which suggest that despite the conditions which Romer gives, the evolutionary path of the vertebrates might have been other than that which it actually was. Consider the following three. Why should the amphibians be able physically to develop limbs at all? Why, at first, was it so important for the amphibians to stay in water? Why, later, even though there was food on land, did the amphibians not remain far more tied to their pools than they did? $?^{495}$

Answers to such questions are necessary, Ruse argues, in order to produce an explanation which (to leverage Ruse's own example) allows for the development of

493 Michael Ruse, The Philosophy of Biology. Hutchinson \& Co.: London, 1973. p.84. (emphasis in original)

494 Ibid. (emphasis in original)

495 Ibid., pp.84-85. 
limbs in the first tetrapods, but precludes that same development in lungfish. This is simply unachievable, Ruse argues, without laws and relevant generalisations:

... I fail to see how any of the questions posed can be answered without making some reference to laws. Consider the first question, why amphibians should be able to develop at all. To answer this, even briefly, one must necessarily sketch some of the principles of genetics... One must explain the nature of mutations, how these affect the physical characteristics of organisms, how these can be passed on from one generation to the next, and how such new characteristics can spread throughout a group. ${ }^{496}$

Not only is Romer's explanation therefore reducible to laws, Ruse claims, the same must also be true of any explanation which adheres to Goudge's model of narrative. "If Romer's explanation is to be considered adequate, even with respect to Goudge's model of narrative explanation," Ruse states, "we must assume that there is an implicit reference to law." 497 With respect to the theoretical likelihood that all biological explanations must depend on general laws, there is no reason to doubt Ruse. But even if the relevant laws were known, the narrativist might reply, they are not - or are not the only - agents of explanation in Romer's account. This creates a clear need for some other kind of explanation. Ruse is thus castigating narrative for failing to fulfill the criteria of necessity demanded by the covering law model. But why should it seek to? Ruse's criticisms succeed only in highlighting a problem narrative was never intended to solve. For what is being explained in Romer's example is not the general response of creatures to drought, but the particular response of one group - the first tetrapods. Ruse therefore succeeds only in showing that he is either unwilling or unable to understand explanation in anything other than in terms derived from the covering law model.

Keeping this in mind, what can one accurately say about the relationship between Goudge's model of narrative and laws of nature? Before we attempt to address this question, it must once again be stressed that the assertions of Ruse and other covering law theorists that laws are somehow implicit in any explanation is almost certainly true. Narrativism is, in other words, compatible with the possibility of a deterministic universe. But to claim this as evidence for the universality of the nomothetic-deductive method is to duplicate Ruse's mistake by assessing one model of explanation by the standards of another. Narratives are about explaining the transformations of a central subject through contingent circumstances - the tracing of 
a path taken. This is what is meant by Goudge's insistence that they explain singular occurrences. So while it is undeniably tempting to argue that there is something lawlike about the behaviour Romer has attributed to those early tetrapods, that claim would belong to an entirely different mode of explanation. So even if it were possible to accurately say something like: "animals in environment $x$, tend to evolve according to principle $y, "$ it would be irrelevant. For Romer is not saying (nor is he required to say) that all vertebrates exhibited this particular adaptation. He need not even suggest that most of them did. He need only claim that those which did survived to reproduce, and attempt to give a reason for this. This hardly seems lawlike. And yet it is this singular combination of events which is doing the work of explaining, so to speak. There are many possible historical paths the earliest tetrapods could have taken in order to arrive at their currently observed place in the fossil record. A truly narrative explanation must therefore seek to work out which was the actual path taken among the many that were possible. In this sense, Dray's distinction between "how possibly" and "why necessarily" explanations seems entirely appropriate - with the "possibly" being a commendably modest reference to the unique difficulties of narrative confirmation, which we will discuss later in this chapter.

All of this is essentially another way of saying that Romer was talking about a state of affairs which - when considered on any level of enquiry above that of the most fundamental laws of physics - might be true, but did not have to be. Hence his use of the term "happy accident." But, if there need not be (or need not only be) hard and fast laws underlying a narrative explanation, how can we know whether any given narrative explanation is correct? For if there are no laws which guarantee the necessity of the particular events so narrated, then we know that, by definition, things could have been different. It would have violated no known law, in other words, for Romer's tetrapods to have adopted some other evolutionary strategy. Mutations are, after all, random. ${ }^{498}$ Or they might have failed to adapt and have disappeared from history. It is also possible that it was not rudimentary limbs alone which ensured the success of the early tetrapods, but merely pure luck that some crucial ancestor did not dry out and die on a journey between pools (or that some potential competitor/predator did). Nor is Romer's pool-hopping explanation the only possible evolutionary strategy for surviving droughts. For not every population

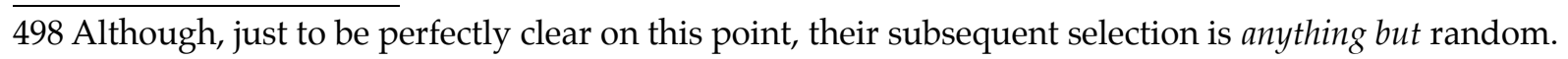


of creatures finding themselves in similar conditions evolves limbs. Ruse's own example of the lungfish attests to this. None of these counterfactual examples, it must be stressed, could have been conclusively ruled out by the use of known law(s) of nature alone.

A defender of the covering law model might, at this point, reply that these kinds of contingencies represent the harsh realities involved in working with probabilistic laws, and that there must still exist some way in which to formalise likely responses to selection pressure on the gene pool of any given animal. Perhaps there is. But the narrative explanation is navigating within - rather than defining outright - the phase space of possibilities here. Better defining the extent of that space will always be helpful. For the narrativist, this is the primary function of statistical inference and laws of nature. It was not an option for early vertebrates to develop anti-gravity organs, for example. We can confidently assert this because such organs would violate known laws of physics, not because we have so far failed to find their fossils. At some point, however, we will want to know not what the allowable space for vertebrate evolution was, but which path within that space a single group actually took when others were potentially available. Stephen Jay Gould, in one of his many musings on the nature of historical explanation in his book Wonderful Life, makes this argument as follows:

Historical explanations take the form of narrative: $\mathrm{E}$, the phenomenon to be explained, arose because D came before, preceded by C, B, and A. If any of these earlier stages had not occurred, or had transpired in a different way, then E would not exist (or would be present in a substantially altered form, $\mathrm{E}^{\prime}$, requiring a different explanation). Thus, E makes sense and can be explained rigorously as the outcome of A through D. But no law of nature enjoined E; any variant E' arising from an altered set of antecedents, would have been equally explicable, though massively different in form and effect. ${ }^{499}$

This emphasis on contingency, Gould argued, is why narrative explanations are of a different type entirely than even statistical/probabilistic nomothetic explanations. It is also why the implicit presence of laws in the background of narrative explanations is merely incidental. This is, as David Hull has phrased it, a "ParticularCircumstance" model of explanation - a philosophy of initial conditions.

In order to emphasise the parallel with human history, it will be instructive to briefly

499 Stephen Jay Gould, Wonderful Life: The Burgess Shale and the Nature of History. Hutchinson Radius: London, 1989. p.283. 
return to the example Arthur Danto offered of the American flags used to honour Grace Kelly on the occasion of her marriage to Prince Rainier III of Monaco. Danto's argument, it will be recalled, was that while it was at least plausible that the fact that Kelly would be honoured in some fashion could be covered by some kind of lawlike/probabilistic statement, it was far less plausible that the actual form of that honour could be so covered. There are, after all, a myriad of ways to honour a foreign-born sovereign. ${ }^{500}$ It might be the case, of course, that the choice of flags (rather than, say, the baking of a cake) was necessitated by the laws of physics in a totally deterministic universe. Such an argument, however, is beside the point. Neither scientists nor historians are in the habit of explaining tornadoes, the Russian Revolution of 1917, supply-side economics, or the Treaty of Tordesillas with respect to only the most fundamental postulates of quantum theory. Why should we be required to approach a royal wedding in such a way? Once again, narratives explain the path taken, not those which are closed. Here is Stephen Jay Gould again:

Am I really arguing that nothing about life's history could be predicted, or might follow directly from general laws of nature? Of course not; the question that we face is one of scale, or level of focus. Life exhibits a structure obedient to physical principles. We do not live amidst a chaos of historical circumstance.... Invariant laws of nature impact the general forms and functions of organisms; they set the channels in which organic design must evolve. But the channels are so broad relative to the details that fascinate us! The physical channels do not specify arthropods, annelids, mollusks, and vertebrates, but, at most, bilaterally symmetrical organisms based on repeated parts. The boundaries of the channels retreat even further into the distance when we ask the essential questions about our own origin: Why did mammals evolve among vertebrates? Why did primates take to the trees? Why did the tiny twig that produced Homo sapiens arise and survive in Africa? When we set our focus upon the level of detail that regulates most common questions about the history of life, contingency dominates and the predictability of general form recedes to an irrelevant background. ${ }^{501}$

The narrative and nomothetic approaches must not only be consistent, in other words, they must be inextricably woven together. All possible event/objects must, in principle, be able to be explained in both ways. At certain high levels of focus, however, there will simply be too much variation possible within the confines of the appropriate laws to allow explanation only in terms of those laws to be a practical reality. More importantly, this would be true even if humankind possessed a hypothetically perfect understanding of all of the laws which underpin the operation of every aspect of the universe.

\footnotetext{
500 Arthur C. Danto, Narration and Knowledge (including the Integral Text of Analytical Philosophy of History). Columbia University Press: New York, 2007. pp.220-228. (emphasis in original) 501 Gould, Wonderful Life. pp.289-290. (emphasis in original)
} 
Confronted with the potential for conversion between the nomothetic and narrative modes, we might wish to ask: what is the signature of narrative? What conditions must be present in order to require its use? The answer is: contingency. Contingency is not, it must be stressed, an assertion of mere randomness. For contingency can (perhaps even must) be generated from the interaction of multiple predictable vectors of causation. It is this interaction, however, which produces the unpredictable (and thus unable to be isolated) events with which narrative must deal. If the course of biological evolution, for example, can be thrown into disarray by the arrival of a meteor (which can be understood as obeying known laws, albeit laws somewhat removed from the biological realm) then suddenly any strictly nomothetic account of evolution must now include the movement of extra-terrestrial bodies. This presents us with an infinite regress in which any purely nomothetic explanation of even the most trivial singular subject could theoretically be required to take account of the laws underlying every aspect of the entire universe. Worse still, this has the additional consequence of implying that, at least until every last fundamental law of the universe has been discovered and confirmed, nothing has ever truly been explained. By providing a principled way of modelling contingency through narrative, however, we are able to evade this unpleasant implication of a rigorously applied nomothetic worldview. More importantly, the concept of contingency enjoys the additional advantage of being entirely agnostic with respect to whether any given enquiry might be considered history or science. For, as Stephen Jay Gould has argued, contingency is found equally in both fields and is dealt with in the same manner - narrative. The methods of history essentially are the methods of science, and vice versa:

I am not speaking of randomness... but of the central principle of all history contingency. A historical explanation does not rest on direct deductions from laws of nature, but on an unpredictable sequence of antecedent states, where any major change in any step of the sequence would have altered the final result. This final result is therefore dependent, or contingent, upon everything that came before the unerasable and determining signature of history. ${ }^{502}$

With these arguments in mind, it becomes easy to see how narrative explanation could be not only desirable in the historical sciences, but unavoidable. More importantly, narrative explanations, while certainly containing implicit references to laws, do not actually use those implicit laws to do the bulk of their work. The

502 Ibid., p.283. 
historical sciences could therefore, theoretically at least, make use of true narrative explanation, as opposed to using narrative as a mere "sketch" for a "real" explanation to be realised later. From this we can reasonably conclude that the term "narrative" at least makes sense in a scientific context. But, if narratives are to function as actual scientific explanations, they need to be able to be confirmed. This leads us to the second of our earlier questions: empirical testability. Can a narrative explanation be sufficiently empirically justified to warrant being called a scientific explanation? Especially given that it must function (by our own definition of contingency) as a single thread within a forest of equally plausible possibilities? When navigating such a space, how could any one narrative ever be any more than speculation? More importantly, if one is building a narrative only from known facts, what could a narrative possibly add to those facts? It is to such empirical questions we now turn.

\section{Problems with the Confirmation of Narrative}

In considering the issue of how to go about the confirmation of narratives, it will be instructive to briefly reconsider Goudge's assessment of Romer's narrative explanation of tetrapod evolution. According to Goudge, Romer's reasoning was "not concerned to discover or to confirm a general law," or "establish any new empirical fact which is simply to be added to the store of human knowledge." Nor did it make "an explicit, positive prediction about what will be found by future investigations." Romer instead proposed a "theoretical pattern" which "presents an intelligible sequence of events such that the phenomenon to be accounted for 'falls into place' as the terminal phase of the sequence." ${ }^{503}$ This raises two key issues. First, if narratives do not make positive predictions, how can they be tested and accepted or rejected accordingly? And second, what are narratives? If they are not grist for the mill of some "higher" science, nor do they add "any new empirical fact" to the "store of human knowledge," then what function do they serve? In order to answer these two questions, let us further interrogate the example Goudge makes of A. S. Romer by extending the line of evidence for Romer's account of tetrapod evolution up to the present day. This will allow us to not only see how narrative explanations can be supported or overturned by familiar empirical means, but also how they can function as fully explanatory scientific theories.

503 Goudge, 'Causal Explanations in Natural History.' p.197. 
With respect to the first of these issues let us return again to Goudge's analysis of Romer. Romer's reasoning, Goudge argued, was composed of several interconnected elements:

What the reasoning does is to propose a theoretical pattern composed of accepted statements of fact ('The Devonian... was a time of seasonal droughts'), statements inferred from these statements of facts ('At times the streams would cease to flow...'), statements which are plausible conjectures about various occurrences ('The amphibian... could crawl out of the shrunken pool, walk up or down the stream bed... learn to linger about the drying pools and devour stranded fish...'), etc. $^{504}$

In Goudge's model, therefore, a narrative explanation is constructed as a kind of interpolation between and around known data points. It is the construction of a "theoretical pattern" which accounts for - perhaps a better term is unifies - available facts. This view is not without its problems, as we shall see, but for the purpose of beginning a discussion of narrative confirmation, it will suffice. The most important aspect of this interpolative picture of narrative is that it allows for some separation between the explanation itself and the facts/reasoning/evidence which support it. If this view is correct, then we might think of narrative as a kind of analysis or interpretation. Rather than verify the narrative itself, therefore, we might instead attempt to verify the facts upon which it rests.

Romer's explanation provides us with several isolable statements suitable for attempting to apply this reasoning. For instance, "the Devonian, the period in which the amphibians originated, was a time of seasonal droughts." Or, "insects were already present and would afford the beginnings of a diet for a land form." Such statements can be justified using evidence which is formally independent of any account of tetrapod evolution. The presence of fossilised insect skeletons in rock strata of the appropriate Devonian age, for instance, would be a reasonable basis for concluding that insects would have been available to form part of the diet of early land-dwelling animals. Somewhat more complicated would be the geologic evidence from which Romer concluded that the Devonian era was prone to drought conditions. If one wished to attempt to find evidence either for or against Romer's account, therefore, examining these kinds of statements and the independent evidence for them provides a comparatively easy way in which one might attempt to do so. Such a line of attack can be instrumental in the refinement of a narrative

504 Ibid. 
explanation, or it may succeed in discrediting it altogether. The success of this method, however, varies greatly depending on how vital the statement under examination is for the narrative in question. Similarly, there may also be issues of generality. For such supporting statements and their evidential basis are only rarely precisely defined by known general laws.

If one wished to use this method to challenge Romer's account of tetrapod evolution, for instance, one might attempt to show that the Devonian era was not a period of drought. If Romer's Devonian lakes did not periodically dry up, it could be argued, then the selection pressure necessary for his proposed account of tetrapod evolution could not have existed. This is no mere thought experiment, however. Richard Dawkins has discussed precisely this approach in his 2009 book, The Greatest Show On Earth. Romer, writes Dawkins, “envisaged annual droughts during which lakes and ponds and streams dried up." Fish that could survive on land were better placed to drag "themselves from a shallow lake or pond... to a deeper one in which they could survive until the next wet season." Unfortunately, Dawkins argues, "Romer introduced his theory with a preamble whose purpose was to show that the Devonian era was a time of drought. Consequently, when more recent evidence undermined this assumption, it seemed to undermine the whole Romer theory." 505 This is because, as the paleontologist Jennifer Clack argues in her 2002 work on tetrapod evolution Gaining Ground, 506 "scenarios to explain the evolution of limbs with digits were intimately tied to those speculating on the environment of the earliest tetrapods, and it is difficult to tease the strands apart." The earliest theories Romer's included - depended heavily on evidence from sediment formations from the late Devonian (when tetrapods were then thought to have evolved) known as "red-beds." These formations, Clack writes, "are layers of sandstone that often have a reddish color due to the presence of iron." Many such "red-beds," all dating from the Devonian era, have been identified in sites all over the world, and have "usually been interpreted as the result of arid or semiarid conditions." This was an interpretation thought to be supported by the independent observation that "comparable red-beds" of much later Permian and Triassic age contained plant fossils consistent with an arid climate. ${ }^{507}$ It therefore came to be assumed - as a kind

505 Richard Dawkins, The Greatest Show on Earth: The Evidence for Evolution. Bantam: London, 2009. p.165.

506 Jennifer A. Clack, Gaining Ground: The Origin and Evolution of Tetrapods. Indiana University Press: Indianapolis \& Bloomington, 2002.

507 Ibid., p.99. 
of limited covering law - that "red-beds" could be reliably correlated with particular climatic conditions. This assumption however, would prove to be false. Clack explains:

One of the most telling objections to the "drying pool" idea is that on closer examination, red-beds are found not to be invariably correlated with arid climates. In modern times, red-beds are found in low-latitude, tropical climates, and they are always associated with oxidizing conditions. This was realized as long ago as 1957... and has been corroborated many times since. The red-beds may be associated with rainforests or places where rainfall is high but confined to monsoonal periods. The conclusion from this is that red-beds are not really a good indicator of arid environments... ${ }^{508}$

But even if Devonian "red-beds" were indicative of arid climatic conditions, that fact would not be sufficient for confirmation of Romer's narrative. As Clack points out, "by no means do all Middle or Late Devonian sediments consist of red-beds. Some represent river and lake basins or nearshore deposits from lagoons that are rich in organic material, suggesting nearby forests." Spatially speaking, it could plausibly have been in these environmental niches that tetrapods first emerged from the water. Even if the Devonian was predominantly dry, in other words, it seems like overreaching to argue that it was dry absolutely everywhere. A similar problem exists in the temporal sense. Until very recently, the earliest known tetrapod fossils all dated to the late Devonian period. But, as Clack points out, they likely "evolved somewhat before that time, perhaps before the red-beds were deposited."509 Perhaps the tetrapods had already left the water by the time climatic change had made drought conditions the norm ${ }^{510}$ While each of these examples is plausible enough, they do lead us to question how essential drought really was to Romer's account. Is the removal of this line of supporting evidence really a fatal blow? Perhaps not. In his 2005 book, The Ancestor's Tale, Richard Dawkins argued as follows:

... I don't think Romer needed his Devonian desiccated. Even at times of no particular drought, there will always be some ponds shallow enough to be in danger of becoming too shallow for some particular kind of fish. If ponds three feet deep would have been at risk under severe drought conditions, mild drought conditions will render ponds one foot deep at risk. It is sufficient for the Romer hypothesis that there are some ponds that dry up, and therefore some fish that could save their lives by migrating. Even if the world of the late Devonian was

508 Ibid., p.101.

509 Ibid., pp.101-102.

510 This possibility has received some additional support recently with the discovery of preserved tetrapod tracks in Poland that place the water/land transition many millions of years earlier than had previously been guessed. See: G. Niedzwiedzki, P. Szrek, K. Narkiewicz, M. Narkiewicz, P. E. Ahlberg, 'Tetrapod trackways from the early Middle Devonian period of Poland.' Nature. Vol. 463, No. 7277 (January 2010). pp.43-48. 
positively waterlogged, one could say this simply increases the number of ponds available to dry up, thereby increasing opportunities for saving the life of walking fish and the Romer theory. ${ }^{511}$

Dawkins also points out that modern aquatic animals observed to have ventured onto dry land have usually done so "in humid, wet areas - that is, when conditions on land are 'good' for water animals, not poor as in the Romer hypothesis." 512 Further to this, he adds:

... there are plenty of other good reasons for a fish to emerge, temporarily or permanently, onto land. Streams and ponds can become unusable for reasons other than drying up. They can become choked with weeds, in which case, again, a fish that can migrate over land to deeper water might benefit. If, as has been suggested, contra Romer, we are talking Devonian swamps rather than Devonian droughts, swamps provide plenty of opportunities for a fish to benefit by walking, or slithering or flip-flopping or otherwise travelling through the marshy vegetation... ${ }^{513}$

While such possible scenarios remove the need for drought in Romer's explanation, Dawkins argues, they all retain "the essential Romer idea that our ancestors left the water, not at first to colonise land, but to return to water." 514 Even after the dissolution of one of the key supporting postulates upon which it was based, in other words, Romer's basic idea could still be plausibly defended. What about other lines of evidence? Perhaps evidence Romer had not known about or otherwise considered? For there is no reason why we should stipulate that the "statements of fact" which underpin a narrative can be only those which were explicitly stated in the original explanation. For any scientific explanation to be valid, whether nomothetic or narrative, it should be able to successfully account for newly discovered evidence.

To this end, consider more recently discovered evidence which has suggested the possibility that the first tetrapods need not have arisen in freshwater lakes and pools, but might instead have evolved in salt-water intertidal zones. As the biologist Keith Stewart Thomson has argued: "the evidence of environments of deposition and the patterns of distribution of Devonian lobe-finned fishes do not indicate that any of the major groups were primarily freshwater fishes." 515 This suggests that the most likely

511 Richard Dawkins, The Ancestor's Tale: A Pilgrimage to the Dawn of Life. Phoenix: London, 2005. pp.307-308.

512 Ibid., p.308.

$513 \mathrm{Ibid}$. (emphasis in original)

514 Ibid.

515 Keith Stewart Thomson, 'Ecology of Devonian Lobe-finned Fishes,' in A. L. Panchen (ed), The Terrestrial Environment and the Origin of Land Vertebrates: The Systematics Association Special Volume 
ancestors of the first tetrapods were capable of dwelling in saline waters - and there is no reason to assume that their descendants would have lost the adaptations which made this possible. To continue to advance the narrative that the first tetrapods were exclusively fresh-water dwellers would therefore seem to require significant additional explanation. It would, in effect, make two problems out of one. This led Thomson to question whether it could continue to be assumed "that the first Amphibia were in any sense fully freshwater animals." 516 In place of this assumption, Thomson advanced the alternative idea that the "first tetrapods evolved in continuously moist, well-vegetated environments, probably in coastal lowland estuaries where abundant fish food was available in the water." ${ }^{517}$ Clack, in turn, links this possibility to her own argument for the irrelevance of Devonian climate. For if the first tetrapods evolved in the intertidal zone, then whether or not there were drought conditions elsewhere can scarcely have mattered. ${ }^{518}$ Yet one might concede all of this and still defend some form of Romer's account. Perhaps these early amphibians hauled themselves from rock pool to rock pool in the intertidal zone? Or struggled back to the water after having been stranded at low tide? Tidal conditions, it might be argued, could have been even more conducive to the kinds of selection pressure Romer had envisaged.

Such questioning of the supporting material is the most conceptually straightforward way in which we can go about trying to gather evidence for or against a narrative explanation. As we have seen, however, it is of extremely limited effectiveness. The lack of available laws frequently mean that inferences cannot be used deductively. In fact, as the confusion over the climatic significance of "red-beds" has shown, the idea of deduction from generalisations in narratives can be not only difficult, but actively treacherous. What had been thought to be a correlation reliable enough to support a particular deduction turned out to be not incorrect, but simply not universal enough. This is the reality of the historical sciences. Such intrusions of contingency mean that, to use Goudge's terms, attempts to only falsify "accepted statements of fact," the "statements inferred from these statements of fact," and/or "plausible conjectures about various occurrences" are made extremely difficult. ${ }^{519}$ But such statements and

No. 15. Academic Press: London \& New York, 1980. p.187.

516 Thomson, 'Ecology of Devonian Lobe-finned Fishes,' p.216. This idea is also supported by the recent discovery of tetrapod trackways in Poland, as the tracks were found in rocks that appear to have been part of a tidal flat or lagoon. See: Niedzwiedzki, et. al., 'Tetrapod trackways from the early Middle Devonian period of Poland.' pp.43-48.

517 Thomson, 'Ecology of Devonian Lobe-finned Fishes,' p.187.

518 Clack, Gaining Ground. p.102.

519 Goudge, 'Causal Explanations in Natural History.' p.197. 
conjectures are not all that Romer's narrative is. For if such statements alone were sufficient to determine the form of a narrative explanation then it would hardly be necessary to give one. A mere listing of the relevant "statements of fact" would do the same job. A narrative must, therefore, involve some degree of interpolation some inference from the observed to the unobserved. Dawkins hints at this possibility when he argues that a swampy Devonian did not rule out "the essential Romer idea." ${ }^{20}$ It seems that it is this "essential" idea which unifies or otherwise makes sense of the "accepted statements of fact" and "plausible conjectures" which we have been examining so far. And so it is to this idea we must turn if we hope to identify a more potent means for confirming narrative explanations. The very resilience of the "essential Romer idea," however, presents us with a potentially serious problem. The fact that an almost complete refutation of his supporting arguments regarding Devonian drought still failed to discredit Romer is striking evidence of this. And so, in search of a better mechanism, we are led to the issue of narrative consequences, and to the question of prediction.

\section{Confirmation By Consequences}

Recall once again Goudge's argument that Romer's account of tetrapod evolution "does not make an explicit, positive prediction about what will be found by future investigations, though there is a sense in which it makes certain negative predictions." We will hear more from Goudge with respect to prediction later in this chapter. For now it will suffice to point out that Goudge's insight that what is not found could potentially be as useful as what was would ultimately prove extremely useful to his vision of the historical sciences. For this seemingly innocuous concept, if handled carefully, can be developed into a much more powerful method by which we might confirm or disconfirm narrative explanations in the absence of general laws. We will refer to it as confirmation by consequences. Put simply, the method is this: identify some observable additional consequence of the narrative account under investigation (preferably one not present in any of its competitors) and then seek evidence for that. Such a consequence, if well chosen, can have quite exceptional confirmatory power. Note also that we need not seek a positive consequence. We might postulate that, if a narrative is incorrect, we should not observe some consequence which we might reasonably expect to observe if that narrative were a

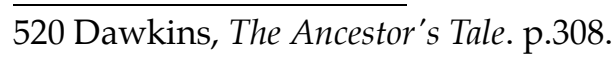


true account of the past. The logic will work either way. Indeed, it is through the deployment of just such a method that we are finally able to achieve something more than a mere rearrangement of the peripheral details of Romer's account.

Consider the following: if Romer were correct in his "essential" idea, a necessary consequence of his account would be a strong and direct link between the evolution of limbs and emergence onto land. Terrestrial motion would be, in other words, what limbs were evolved for. This is what his account necessarily implies, and can therefore function in a role something like Goudge's idea of a "negative prediction." Put simply, it tells us what we ought not to find. This adds additional constraints to the multiple possible readings of the available evidence, making a finite range of possible interpretations just that much more finite. In Romer's case, what we ought not to find is evidence of limbs in a creature which could not have used those limbs to move about on land - or at least could not have moved well enough to migrate between ponds. Were such evidence found, it would represent much stronger evidence against Romer's account than anything achieved by the "statement of fact" approach we have already examined. And, as it turns out, it was precisely this approach which ultimately led to the near total discrediting of Romer's "essential" idea in modern tetrapod paleontology. This is a comparatively recent development, however. Because all known tetrapod fossils seemed to support it, Romer's account - and thus the presumed consequential link between limbs and terrestrial movement - had actually remained eminently plausible right up until the late 1980s. These fossils, however, were comparatively few in number. In fact, there was only one species for which there were records of any real completeness - the creature known as Ichthyostega.

Examples of the tetrapod Ichthyostega were first found in Greenland in 1931 by the Swedish paelontologist Gunnar Säve-Söderberg, and preliminarily described by him in 1932. They date approximately to the upper Devonian epoch - approximately 374359 million years ago. By the standards of tetrapod paleontology, Ichthyostega fossils were comparatively numerous and adequate material was available to allow significant reconstruction. Despite this, the creature was not fully described until much later by another Swedish paleontologist and colleague of Säve-Söderberg, Erik Jarvik. Jarvik worked sporadically on Ichthyostega reconstruction from his first work on the creature's tail and hind limbs in 1952, until the publication of a much more 
detailed reconstruction in 1996. ${ }^{521}$ A lifetime of effort, all of which seemed to accord with the account Romer had offered. Although this was largely due to the fact that Ichthyostega was the only tetrapod fossil known in any detail until the 1980s and was therefore forced to bear a disproportionate interpretive burden. ${ }^{522}$ Jarvik's first reports on Ichthyostega showed a creature that, as popular science writer Carl Zimmer described it in a 1995 issue of Discover magazine:

... was an amphibian that still held on to signs of its fishy heritage. It was obviously a tetrapod, with limbs and digits to walk on, and sturdy shoulders to support them. No longer able to depend on a cushion of water, it had developed a sturdy rib cage to hold up its internal organs. But Ichthyostega also had a broad, flat, fishlike head and a small fin on the top of its tail. ${ }^{523}$

In other words, Ichthyostega seemed to fit well with Romer's account. It did not provide evidence sufficient to confirm it, but it was at least consistent with the essential idea of limbs developed as a means to return to water. Ichthyostega had legs that could facilitate motion - and thus it made sense to assume that motion was why the legs had evolved. In the late 1980s, however, a related fossil called Acanthostega, about which almost nothing was known, was coming to the attention of Jennifer Clack. Before Clack's work in Greenland, all that was known of Acanthostega were three partial skulls. ${ }^{524}$ They had been found by Säve-Söderberg and Jarvik in 1933, in the same suite of expeditions which had yielded the apparently far more abundant Ichthyostega. But, as there was not enough material with which to accomplish any significant reconstructive work, Jarvik did little more than name the species and set it aside. ${ }^{525}$ It remained obscure and incomplete until the possibility of recovering additional fossil material came to Clack's attention in the 1980s:

It emerged that back in 1971, a geology student had collected tetrapod specimens from East Greenland as part of a sedimentological study, and that the material was not of the more abundant Ichthyostega, but of the lesser known Acanthostega. Furthermore, his find, which consisted of the remains of three skulls in close association, made it clear that more material of Acanthostega could be recovered

521 E. Jarvik, 'On the Fish-Like Tail in the Ichthyostegid Stegocephalians,' Meddelelser Øm Grönland. Vol. 114, No. 2 (1952). pp.1-90. See also: E. Jarvik, 'The Oldest Tetrapods and Their Forerunners,' The Scientific Monthly. Vol. 80, No. 3 (March 1955). pp.141-154. E. Jarvik, Basic Structure and Evolution of Vertebrates. Academic Press: London \& New York, 1980. E. Jarvik, 'The Devonian Tetrapod Ichthyostega,' Fossils and Strata. Vol. 40 (1996). pp.1-206.

522 Jennifer A. Clack, 'The Emergence of Early Tetrapods,' Palaeogeography, Palaeoclimatology, Palaeoecology. No. 232 (2006). p.168.

523 Carl Zimmer, 'Coming Onto The Land,' Discover. June 1995. Available at: http://discovermagazine.com/1995/jun/comingontothelan523/; accessed 2 June 2011. For a more precise (but much more technical) assessment, see: Clack, Gaining Ground. pp.111-119.

524 Jarvik, 'The Oldest Tetrapods and Their Forerunners,' p.150.

525 Jarvik, 'On the Fish-Like Tail in the Ichthyostegid Stegocephalians,' pp.1-90. 
from the same site. ${ }^{526}$

Clack revisited the site in 1987 and recovered further fossils, ultimately amounting to an almost complete skeleton. And, after several years of analysis and reconstruction by Clack and her colleague Michael Coates, it became clear that Acanthostega clearly falsified Romer's account. It was precisely what should not have been observed had Romer's essential idea been correct. For Acanthostega, being a tetrapod, clearly possessed limbs. Indeed, the forelimb consisted of a recognisable radius and ulna, as well as eight distinct digits! ${ }^{527}$ It was, in any sense, a limbed animal - a true tetrapod. However, Clack concluded, the support structures for these distinct and jointed limbs were much too weak for them to have been able to facilitate terrestrial motion. Of the forelimb, she argued:

There is no true wrist or weight-bearing joint in this limb. Not only does this make an unlikely walking limb, but furthermore the pattern resembles that of its fish relative Eusthenopteron more than it does any other tetrapod. For this reason... the limb is seen as basically primitive, rather than one secondarily adapted for life in water. ${ }^{528}$

Clack came to a similar conclusion regarding the hind limb. "As with the forelimb," she argues, "the ankle shows no weight-bearing joint surfaces or planes of flexibility and seems clearly paddle-like." ${ }^{529}$ In other words, Acanthostega had highly developed, multi-jointed digits - which were attached to a weak and insubstantial wrist. Acanthostega could not, therefore, have walked on dry land. In the context of Romer's account, this is extremely difficult to explain. The only viable possibility for preserving Romer's account was to argue that Acanthostega was descended from a land-capable tetrapod creature in the process of returning to the water. But, as Carl Zimmer has argued, this seemed extremely unlikely:

How do you explain a land animal's body in an animal that couldn't survive on land? One possibility is that the animal had once come onto the land but, like some amphibians, had subsequently returned to a life underwater, where its skeleton had gradually weakened. That scenario seemed unlikely, though, when Clack and Coates found Acanthostega's gills. Tetrapods simply aren't supposed to have a fish's gills. Amphibians like salamanders retain some of the struts of bone in their neck, but these now anchor the tongue muscles. All the amphibians that returned permanently to the water developed external gills, feathery tissue stuck to these struts and extending out from the body. But Acanthostega had a full battery of gill struts in its neck. It even had a sheet of bone along its shoulders that

526 Clack, 'The Emergence of Early Tetrapods,' p.169. (emphasis in original)

527 Ibid., p.172.

528 Ibid. (emphasis in original)

529 Ibid. 
supported the rear wall of an internal gill chamber. The strong implication was that the animal still possessed an internal gill system. In other words, Acanthostega breathed like a fish. ${ }^{530}$

Highly developed gills in a creature supposed to have left the water and then returned seems implausible. A great deal of gradual adaptation (and therefore time) would have been required to evolve limbs suitable for movement on dry land - to say nothing of the additional time presumably required for those limbs to begin to atrophy upon return to the water. Yet no significant modification could be observed in Acanthostega's gill structures (at least from fossil evidence) from those of its fish ancestors and contemporaries. One could argue that structures within the gill could have re-evolved - but it is vanishingly unlikely (statistically speaking) that a structure evolved twice would possess the same form. The more plausible conclusion was that Acanthostega was a thoroughly aquatic creature. This had profound implications for Romer. As Clack states:

As a result of these discoveries, the scenario accounting for the acquisition of limbs and terrestriality changed from one in which a fish emerged onto land and subsequently evolved limbs from fins to one in which limbs with digits evolved while the animals still lived and moved predominantly in water, so that the limbs were viewed as an 'exaptation' co-opted for terrestrial locomotion only later. ${ }^{531}$

In other words, the fish-tetrapod transition did not happen in creatures adapting to land, but in creatures living in water. Limbs did not, as Romer's drying pond scenario would have it, evolve in response to selective pressures which favoured the ability to walk. It appears that limbs instead evolved for some other purpose and in response to some other pressure, and were only later repurposed for terrestrial motion. As the paleontologist (and one of the discoverers of Tiktaalik) Neil Shubin has written, it is even possible that "everything special about tetrapods - limbs, digits, ribs, neck, the lot - might well have evolved in water, not on land." ${ }^{532}$ A whole new account, in other words, would be required to explain how limbs had come about.

The question of why (and in response to what pressure) such structures evolved if they did not evolve specifically for terrestrial locomotion is an interesting one - and still the subject of much debate in the paleontological community - but it would be outside the scope of this thesis to carry this example any further. For our purposes,

530 Zimmer, 'Coming Onto The Land,'

http:/ / discovermagazine.com/1995/jun/comingontothelan523/

531 Clack, 'The Emergence of Early Tetrapods,' p.172.

532 Neil H. Shubin, 'The "Great" Transition,' in John Brockman (ed), Intelligent Thought: Science Versus The Intelligent Design Movement. Vintage: New York, 2006. p.85. 
what is important is that this line of reasoning effectively falsifies the essential premise of Romer's account. Given what is now known about Acanthostega, Romer's account of why limbs evolved and why they were successful simply cannot be correct. This is not to say that subsequent adaptation of these already evolved limbs was not driven by the kind of processes Romer had postulated. As Dawkins has reminded us, many contemporary water-dwelling creatures today engage in something much like the pond-hopping Romer had imagined. But such pressures could not have been what caused those limbs to arise in the first place, as the first creatures known to have possessed them could not have used them for anything more than a slow, painful dragging into the shallows. Thus the very evolutionary development Romer was trying to explain was no longer adequately addressed.

We have now seen in some detail how we might go about gathering evidence for or against a narrative account. Moreover, we have seen that the traditional model of positive future-focused prediction, while perhaps desirable, is not strictly necessary in order to test a scientific statement. Through the use of confirmation by consequences, we can reliably bring evidence to bear on accounts of singular and contingent events from the past, and can do so by recognisably narrative means in disciplines few would have trouble calling scientific. From this we can conclude that even Goudge's early and self-described "exploratory" outline of how narrative explanation can work in paleontology seems a better guide to historical explanation than any covering law contortion or model of colligation we have seen in Part One. More importantly, Goudge managed to accomplish this without resorting to naïve arguments that paleontology was a fundamentally different kind of knowledge from science. For this reason at least, his concept of scientific narrative is worth taking seriously.

\section{Narratives as Scientific Theories}

What then of the second key issue raised by Goudge's paper - that of the epistemic status of narratives and where they might fit within the wider scientific enterprise? As Goudge was careful to point out, Romer's explanation was not merely an anecdote to be counted for or against some greater natural law. Nor will this be the case for those more modern accounts which will come to replace it. How then should we think of such accounts? For a clue to this question, it seems appropriate to 
examine the approach of some of the scientists involved. Richard Dawkins, for instance, refers to Romer's account in The Ancestor's Tale as an "admirable theory" and the "Romer hypothesis." 533 Similarly, in Gaining Ground, Jennifer Clack also uses the term "theory," as well as both "scenario" and "explanation," in order to discuss various accounts of tetrapod terrestriality. ${ }^{534}$ Neil Shubin, in reference to both Romer's original account and to Clack's suggestion that tetrapod limbs evolved for life in the water before ever being co-opted for movement on dry land, uses the term "hypothesis." Indeed, Shubin even applies something much like the confirmation of consequences to Clack's hypothesis, arguing that she had "made a prediction that could be tested: Aquatic animals more ancient than this new find should have intermediate structures." 535 This prediction was subsequently vindicated by Shubin and his colleagues Edward Daeschler and Farish Jenkins with their 2004 discovery of just such an intermediate in the creature now known as Tiktaalik - the "fishapod" (as Shubin has called it) which seemed to neatly split the difference between Devonian lobe-finned fish and comparatively more developed creatures like Acanthostega.536 Tiktaalik exhibited exactly the kinds of structures which might be expected if Clack and Coates were correct in arguing that limbs primarily evolved to serve the purposes of life in the water. An article devoted to Tiktaalik in the 9 September 2006 issue of New Scientist magazine argues as follows:

Tiktaalik's front appendages, for example, end in a flat paddle, rather than fingers, so Shubin and Daeschler call them fins. But inside them, several rows of bones extend beyond the wrist region. The researchers are not prepared to call these fingers, because they cannot prove they are identical to the fingers of tetrapods... but the presence of anything remotely finger-like calls into doubt the widely held notion that fingers were a purely tetrapod innovation..$^{537}$

In other words, an aquatic creature possessed features which, according to the Romer hypothesis, should have been exclusive to more developed, land-capable tetrapods. That this was clear evidence in support of Clack and Coates was made clear by Clack herself in the same New Scientist article. "It's one of the those things," she stated, "you can point to and say, I told you this would exist - and there it is." 538 From this brief digression, then, it seems clear that the language being used among scientists involved in the relevant fields (such as Dawkins), and even among those involved

533 Dawkins, The Ancestor's Tale. pp.307-308.

534 Clack, Gaining Ground. pp.99-104.

535 Shubin, 'The "Great" Transition,' p.85.

536 Edward B. Daeschler, Neil H. Shubin, and Farish A. Jenkins Jr., 'A Devonian Tetrapod-Like Fish and the Evolution of the Tetrapod Body Plan,' Nature. No. 440 (6 April 2006). pp.757-763.

537 Bob Holmes, 'Meet Your Ancestor,' New Scientist. 9 September 2006. pp.37-38.

538 Ibid., pp.35-36. 
with the relevant discoveries themselves (Clack and Shubin), is that of "theory" and "hypothesis." Similarly, both Clack and Shubin have consistently used the language of confirmation and prediction in talking of their discoveries. It therefore seems entirely appropriate to start a discussion of the epistemic role of narrative here. Are narratives robust enough to support the kind of explanatory weight expected of scientific theories? In Goudge's limited assessment at least, it would seem that they are. In support of this, Goudge offers two arguments. The first addresses the issue of choosing a viable narrative to function as a theory in the first place. The second, the issue of testing it.

The first of these arguments is specifically concerned with countering the objection that a narrative cannot function as a "theory" because it is more like a "just so story" - an arbitrary post hoc rationalisation for what is already known or suspected. Goudge disputed this, arguing instead that an initial narrative theory emerges (albeit somewhat organically) from the initial pool of evidence one wishes to unite:

The choice of the over-all pattern as a possible sufficient condition of the phenomenon is made in the light of existing knowledge or reasonable inference therefrom. In the example quoted, the initial move is to eliminate certain alternative possibilities because they are incompatible with accepted facts. (The amphibians did not become land dwellers because they were driven out of the water by the need to breathe air, or to obtain food, or to escape from predators.) Another alternative (that the ability to live on land was an adaptation for continuing to live in water) is compatible with everything known. ${ }^{539}$

That the details of this reasoning are, from the modern viewpoint, almost certainly incorrect is irrelevant. It is clear from Goudge's argument that he considers the starting point for a narrative to be a kind of snapshot - a summation of the state of the art. One first constructs an account consistent with what is known. This is an operation tied to a particular time. This alone is not enough, however, potentially offering up an account so vague (i.e., "the ability to live on land was an adaptation for continuing to live in water") as to permit the kind of ad hoc extensions which would render it almost useless. Indeed, something like this process can be seen in the attempt to preserve Romer's theory by arguing that Acanthostega was in the process of returning from land to water. Principles of parsimony - that is, injunctions not to multiply explanatory entities beyond necessity - are extraordinarily helpful here, but there is no denying that such accounts are often vulnerable to charges of imprecision. However, narrative is not the cause of such issues, but their solution. For in order to 539 Goudge, 'Causal Explanations in Natural History.' p.200. (emphasis in original) 
remove the "paradoxical content" of such a high-level account, Goudge argued, as well as "reduce its vagueness," a "number of the component events are narrated in temporal sequence." In this way, Goudge puts the temporal dimension of narrative to work as a way to organise available evidence. The materials of the past are thus selected and organised not only according to "their relevance to the over-all pattern and their compatibility with the general body of scientific knowledge," but also according to "the demands of internal coherence imposed by the sequential character of the total narrative. The narrative has to tell a 'likely' story." 540

This hints at a potential answer to the charge that a narrative can add nothing of value to a collection of evidence. For we can use this requirement to preserve temporal coherence to argue that a narrative theory introduces additional constraints on the possible interpretations of that evidence. Effects must not, for instance, precede their postulated causes. Thus, a greater explanatory capacity can be gained by assessing evidence against an overarching narrative than would be the case if it were assessed in isolation. The relevant facts of Acanthostega's body plan by themselves, for instance, were capable of little explanatory work. Only when placed into a wider context - through their relationship to Romer's postulated narrative did they gain their significance. The fact that Acanthostega possessed the features it did at the time it did, in other words, is what made it evidence against Romer. The significance of Acanthostega would have differed radically had it been dated to a much earlier time period. Had Acanthostega (or a creature like it) been shown to have been contemporary with the Sarcopterygii lobe-finned fish, for instance, it would represent a powerful blow against the related theory that these fish were the ancestors of the tetrapods, and would point instead toward an earlier point of divergence. ${ }^{541}$ The explanatory significance of evidence is therefore strongly related to its place in the postulated temporal sequence. The use of narrative in such cases not only acts as a powerful organising structure for historical evidence, it also allows us to extract much more explanatory power from historical evidence. These are both key

540 Ibid.

541 It is worth noting that the discovery in 2010 of fossilised tetrapod tracks in Poland dating from a period some 18 million years earlier than the first tetrapods were previously thought to have evolved will likely bring about precisely such a reassessment of tetrapod evolution. As of the time of writing, however, the broader consequences of this trackway for post-Acanthostega theories of tetrapod origins have yet to be agreed upon. For the purposes of this thesis, however, this is not of crucial importance. We are more interested in the mechanism by which such narratives are confirmed or otherwise and have little invested in the precise outcome of this particular example. See: Niedzwiedzki, et. al., 'Tetrapod trackways from the early Middle Devonian period of Poland.' pp.43-48. 
desiderata of scientific theories.

Even if there were not such constraints on initial theory selection, however, it would be of little consequence. For one need not be overly concerned with where hypotheses come from, so long as - once arrived at - they can be meaningfully tested. This brings us to the second of Goudge's arguments for narrative as theories. Goudge stated the main potential objection to the verifiability of narratives as follows:

At this point it may be objected that if the above account is correct, then the causal explanations in natural history which have been discussed all suffer from a fatal defect. They are insusceptible to any sort of empirical testing. We can, indeed, ensure that a given theoretical pattern is internally coherent and compatible with existing knowledge. But since it involves no general laws and makes no positive predictions, we can never subject it to any verificational procedure. It remains a sheer conjecture about a past event. ${ }^{542}$

However, as our contemporary extension of Romer's example of tetrapod evolution has shown, this is quite simply not true. This chapter has shown that by assessing the potentially observable and/or testable consequences of a narrative, empirical support can be gained or lost and the theory in question correspondingly strengthened or weakened. Our argument is strengthened in this respect by the observation that, despite the fact that Goudge could not have anticipated subsequent developments in tetrapod paleontology, the method for narrative verifiability he offered in 1958 has turned out to be a fair description of the process by which Romer's account was eventually falsified:

To this objection the reply may be made that in as much as an explanatory pattern specifies a determinate sequence of events (or conditions), it restricts the possibilities with regard to what future empirical investigations will disclose. The pattern does, therefore, involve a number of negative predictions. It implies that certain phenomena will not turn up in any future enquiries (e.g. in paleontology, comparative anatomy, experimental biology, etc.) If one of these phenomena does turn up, it will invalidate or falsify the pattern. Hence, such causal explanations in natural history are testable, for nothing prevents their inadequacy from being detected, in the long run, if they are inadequate. Since Popper has given powerful reasons for believing that a distinguishing mark of a scientific theory is its falsifiability, i.e. the possibility of overthrowing it on the basis of empirical evidence, these causal explanations can be regarded as intrinsically no less scientific than (though in other respects quite different from) explanatory theories in the non-historical sciences. ${ }^{543}$

At this point, it must be stressed once again that it is the theory - the narrative - which

542 Goudge, 'Causal Explanations in Natural History,' p.201.

$543 \mathrm{Ibid}$. (emphasis in original) 
has provided this testability. It was only in the context of Romer's narrative theory that Acanthostega became an element of falsifying data. Therefore, it might reasonably be concluded that narrative accounts can not only function in a unifying capacity with respect to evidence, but also provide a method for verification that the examination of evidence alone cannot. They seem, in other words, to be viable candidates for being considered fully-fledged scientific theories in their own right. That is, narratives not only organise data into some coherent structure but go some way towards explaining it. Similarly, they can be made to submit to evidence. And, most importantly, narratives retain this theoretical character despite the fact that they are not generalised theories, but are instead theories of singular events. This calls into question the validity of any insistence - such as we have seen in the work of Dray and Danto that theories must have a quality of generality in order to be scientific. We will talk more about this in the following chapter.

If it is the case that narratives can function in the manner we have come to expect from scientific theories, then it would appear that the only viable opposition available to the nomothetic purist is to assert that narratives must either rely on or reduce to nomothetic explanations. This is a charge which has been leveled at narrative explanation many times before, and we have already encountered it in these pages. This is the assertion which underlies Hempel's concept of the "explanation sketch," for instance. But in this case, Goudge has argued for the usefulness of narrative as an explanatory mechanism in and of itself, rather than the kind of consolation prize covering law theorists have often imagined it to be. To successfully deploy a reductionist argument while simultaneously retaining the advantages of this model, one would be required to offer a nomothetic reduction which also acknowledged the usefulness of temporal sequence in explanation. Historically, nomothetic models which conceivably accomplish this have tended to focus on the reduction of each individual statement in a narrative account to its nomothetic components. This forms a "causal chain" in which each link is deducible from the previous. Goudge anticipated this class of objection, however, and countered by arguing that such an approach badly underestimates the importance of contingency to a narrative model of science. For the causal chain model, he wrote, relies on the assertion that "the statements making up the explanation must be capable, at least in principle, of being organised deductively." And this, Goudge argued, was quite simply the wrong model to have in mind. For such an image led to 
the marginalisation of "contextual considerations." This was important because "each explanatory pattern of the sort we are considering is less like a segment of an isolated causal line stretching back indefinitely into the past, and more like a portion of a complex historical network with an enormous number of cross-connections." 544

This image of a network, or perhaps a web, is apposite, as it captures the possibility of causes from far-removed causal systems interacting in unexpected cross-connections - such as a meteor intruding into biological evolution. To try to chart a single causal chain through such a network would be of limited explanatory value, as it would potentially miss these kinds of connections. There is, in other words, simply too much complexity and contingency in historical systems. We cannot identify every factor - every interaction between environment and organism - which produced Ichthyostega, Tiktaalik, and Acanthostega. To say nothing of showing that no other organisms were possible and that there were no contributing contingent factors of any importance. Our inability to rely on deductions regarding the climate of the Devonian is evidence of this. In order to explain that failure, we need not resort to the claim that climate is not a deterministic system the laws of which might, in principle, be known and understood. We are required only to point out that the interaction of the laws underlying weather and climate with the laws underlying potentially every other relevant natural system produces consequences which are effectively unique and functionally unpredictable. Even a complete nomothetic description of every aspect of the Earth's atmosphere, therefore, would be of little or no explanatory use without a complete nomothetic description of everything else.

With respect to tetrapod evolution, it might very well be the case that the entire lineage owes its survival to some factor outside of biological considerations altogether. Perhaps a harsher than normal winter caused a reduction in predator numbers, allowing a crucial mutation to survive among the lobe-finned fish. What use are deductions from the relevant laws of heritability if their outcomes might be radically altered by such events? Even if such contingencies were vanishingly rare, it would make no difference - they would still need to be accounted for at some point. If we are to get any grip at all on systems where such possibilities can be imagined, therefore, we need a way to deal with those systems that allows something to be true which did not have to be. We need to trace the path taken, while remaining aware that

544 Ibid., pp.198-200. (emphasis added) 
other paths were equally possible. In this sense, Goudge anticipated by some thirty years the central argument of Stephen Jay Gould's Wonderful Life. For, unless this complex feature of the world might be somehow excised, Goudge argued, the necessity for narrative would remain. He concludes:

I submit, then, that natural history does employ causal explanations, and that the most typical, being the sort I have attempted to describe, do not bring an individual phenomenon under a general law. Furthermore, these typical explanations seem to me wholly appropriate to the subject-matter with which natural history is concerned. The method used in constructing them is entirely sound. There is no superior method (e.g. that of physics) which ought to be substituted for it. Hence, no warrant exists for saying that all explanations found in the historical sciences are 'weak,' or for suggesting that these sciences are still at a rudimentary stage of development. Physics is not necessarily the adult form of every science, and natural history is not adolescent physics. ${ }^{545}$

The example we have examined here of historical science in action not only makes clear the need for an historical mode of explanation in the sciences, but also gives us some idea of the functions such explanations would be required to provide. Such a model must: deal with contingency and singular events, produce results which can function in the role of a theory, deal with multiple levels of generality and variable quantities of evidence, and submit itself to empirical testing. Given all of these requirements, Goudge's vision of narrative (or something like it) begins to look like a candidate well equipped for the task. It appears to model practice in the historical sciences well, and has the additional advantage of utilising an idea - the movement of time and the idea of cause and effect - which is both intuitively appealing to the human mind and seemingly a fundamental property of reality. So if we are to build, as Hull has argued we must, a philosophy of science with the traditional emphasis reversed, it seems plausible that something like Goudge's sense of narrative will deeply inform its structure. Having said this, there is much that Goudge omitted in his paper. He failed, for instance, to demonstrate the necessity of narrative (as opposed to any other mode), or to link it in any deep way with cause and effect. And this is to say nothing of the more than fifty years of philosophy of science undertaken since its publication. If we wish to build a more complete narrative model of science, therefore, we must examine subsequent developments in (non-literary) narrative philosophy. More importantly, we must rebut the obvious objection that the only reason narrative appears to fit so well with historical practice is because it is a post hoc rationalisation designed (with the benefit of hindsight) precisely in order to

545 Ibid., p.202. 
exhibit such a fit. This is a very serious objection indeed, and cannot be casually dismissed. In order to neutralise it, we must demonstrate that narrative is a necessary mode of explanation which is not only co-equal to the nomothetic mode, but is also concordant with our most fundamental understanding of the world. This is a purely theoretical task that only philosophy can attend to, and the chapter which follows will attempt to show how it might be done. 


\section{Chapter Six \\ "The Philosophy of the Science of Stories"}

Where the previous chapter has sought to demonstrate something of how historical scientists approach the work of explanation in fields awash with contingency and in which any laws (implicit or not) are frequently unable to be called upon for aid, this final chapter will focus on the work of those contemporary philosophers of science who have attempted to abstract a general theory of narrative from such practical insights. It is worth noting at the outset, however, that the recognition of narrative in the philosophy of science is still comparatively new. While the most basic tenets of narrative have, as previous chapters have shown, been around for quite some time, more generalised mechanisms of confirmation and observation are still actively being worked out. This is not merely the pursuit of detail for its own sake, however. The working out of such details in a philosophically coherent manner is absolutely crucial to any demonstration that a narrative model of explanation is something more than merely a post hoc convenience or a method fit only for producing "explanation sketches." Showing how these mechanisms have been conceptualised must therefore be among the tasks of this chapter. However, the newness of much of this philosophical work also contributes to a sense in which this chapter must also be a work of synthesis. Many of the theorists we will examine in this chapter have not yet even realised that their arguments form a coherent system when collected together, let alone perceived the scope and explanatory power of this emerging narrative dimension of science. The enforcement of such a realisation through the application of narrative to all those fields of enquiry which might benefit from it is, of course, beyond the scope of any one thesis. As part of a thesis on the philosophy of history, however, this chapter hopes to achieve some modest recognition of that power in the area of human history. Of course, the relevant philosophical issues even in a discussion of this circumscribed scope are still vast. This chapter, therefore, will restrict itself to demonstrating that a historical science based on narrative can satisfy the three key requirements identified in the Introduction. These are: "observation poverty" and the ability to gather empirical information about that which is to be studied, "central subjects" and the reality of the narratives which are the result of that study, and the non-arbitrary method of "confirmation by consequences" required to guard against ad hoc conclusions. Moreover, in addition to providing philosophically compelling arguments by which narrative can function in each of these areas, we must also demonstrate "nomothetic compatibilism." That is, we must 
make clear that such treatments as are offered retain the compatibility of narrative with existing philosophy of science.

\section{Peter Kosso and the Problem of Observation Poverty}

The first of the hurdles that any specifically historical approach to scientific enquiry must clear is the argument from "observation poverty." Specifically, this is the contention that any discipline which seeks to study events/objects from the past is critically hampered by a lack of direct accessibility to that past. To claim that this disadvantages only historical science, however, is to imply that the inverse is not the case. Nomothetic sciences like physics and chemistry, in other words, are thought to study materials which are present to observation in a way historical events/objects are not. Because of this, the subject matter of physics or chemistry might become the subject of systematic direct observation and/or controlled experiment. It is not (or is no longer) possible, on the other hand, to observe World War II. Or, as the historian Marc Bloch concisely stated in his book The Historian's Craft, "no Egyptologist has ever seen Ramses." ${ }^{546}$ The philosopher J. A. Passmore, in a consideration of historical objectivity, summarises this same argument with more precision:

... the scientist confronts the world as it nakedly is, whereas the historian sees it, always, through the medium of someone else's testimony - a testimony he can never... penetrate beyond, because the events the testimony describes are gone for ever. If a scientist doubts the testimony of some other scientist that when hydrochloric acid is poured on to zinc, hydrogen is produced, he can repeat the experiment for himself; if a historian doubts Ben Jonson's testimony about Shakespeare's character, he has no way of examining that character for himself... ${ }^{47}$

There are several points of interest in this citation. First, note the emphasis on observational/experimental chemistry as an exemplar of scientific practice. This is not uncommon in such arguments, and it comes as no surprise to further observe that this emphasis is usually accompanied by an assumption (whether tacit or explicit) that science is ideally a law-seeking enterprise. For example, R. G. Collingwood argued the following in The Idea of History: "the sciences of observation and experiment are alike in... that their aim is to detect the constant or recurring features in all events of a certain kind." ${ }^{548}$ This implicit link between laws and

546 Marc Bloch, The Historian's Craft. P. Putnam (trans). Manchester: Manchester University Press, 1954. p.48.

547 J. A. Passmore, 'The Objectivity of History,' in Patrick Gardiner (ed), The Philosophy of History. Oxford: Oxford University Press, 1974. p.148.

548 R. G. Collingwood, The Idea of History. Revised Edition. Oxford University Press: Oxford, 1994. p.250. 
observation/experiment exists because, as the philosopher of science Carol Cleland has argued, "hypotheses tested in classical experimental research are general in character." 549 They have to be, otherwise repeated experiment/observation would not be possible by definition. Far from being damning for the historical sciences, however, this reflects only the fact that classical experimental method was first developed in an era when the assumption of science as exclusively nomothetic went unquestioned. Only when interest in more historically oriented questioning began to gather (as we have seen in the previous two chapters) did the need arise for an alternative.

This issue is extremely important for the debate at hand, however, as the supposed source of this inability to observe and experiment flows from another assertion about the nature of historical science that we do wish to affirm - that of the singular nature of historical events. As the previous chapter has hinted at (and as we shall see David Hull argue later in this chapter), the unique/unrepeatable nature of historical events is not merely an incidental feature of historical science but is effectively what defines them as historical. This realisation necessarily forces us to concede several important tools of nomothetic science - most notably the possibility of experimental manipulation. It seems quite self-evident that we cannot affect past events, nor can we produce truly identical events in controlled conditions. Given that this is so, the question remains: must we cede observation along with experiment? If we do, then constructing and defending a general framework for historical science (of any kind) becomes vastly more difficult. Much hinges, it seems, on the status of observation with respect to the past. If it too represents an insuperable (or even merely de facto) barrier to historical enquiry, then it becomes very difficult to substantively refute arguments like those of Bloch and Passmore. Fortunately there are excellent philosophical reasons to think that this argument from observation poverty is based upon a naïve confusion between theoretical entities and the evidence for those entities, and is therefore without force. Such reasons have come to us from the philosophy of science rather than history, however, and have thus largely eluded a historical audience.

Perhaps the most compelling philosophical argument against observation poverty can be found in the work of the philosopher of science Peter Kosso, whose 1992

549 Carol E. Cleland, 'Historical Science, Experimental Science, and the Scientific Method,' Geology. Vol. 29, No. 11 (November 2001). p.987. 
paper 'Observation of the Past' ${ }^{\prime 550}$ and 2001 book Knowing the Past ${ }^{551}$ have both argued that the kinds of contrasts offered by Bloch or Passmore do not properly compare like with like. ${ }^{552}$ Citing Bloch's example of Ramses versus electron tracks in a cloud chamber, Kosso has argued:

... there is a deeper flaw in this contrast in that it is based on a mismatch between the objects of theoretical interest in history, for example Ramses, and the evidence, the tracks, for objects of theoretical interest in physics. The more genuine comparison of observational status would be between objects of theoretical interest, Ramses in the historical example and electrons in physics, or between evidential objects, the archaeological and textual remains on the one hand and the tracks in a bubble chamber on the other. ${ }^{553}$

Essentially, Kosso is making an argument similar to that of Arthur Danto, but from a scientific perspective which Danto had failed to consider. Danto, it will be recalled from Chapter Three, argued that all narrative statements were particularistic theoretical constructs, and that this particularity was what made them historical rather than scientific. "A term like 'Julius Caesar'," he argued, "enjoys, in historical work, somewhat the same role that 'electron' and 'Oedipus Complex' enjoy in physical and psychoanalytical theories respectively." 554 Given what we have learnt from Goudge in the previous chapter, we might further define "Julius Caesar" as a theoretical entity which functions as the best unifying explanation for a range of archaeological and textual evidence. This is precisely the manner in which Kosso would also have us think about ahistorical entities such as electrons - as theoretical entities the postulated behaviour of which unifies a broad range of diverse evidence, including tracks in a cloud chamber. The underlying pattern of reasoning in both cases, Kosso argues, is the inference of the occurrence/ existence of an event/ object as being the cause of a certain pattern of presently available evidence. By thinking in this way, Kosso argues, we can bring a consistent structure to all types of scientific enquiry. More importantly, such a structure is agnostic with respect to the relative generality of the theoretical entities in question. Electrons are effectively identical and replicable, and thus lend themselves well to the experimental/nomothetic mode of

550 Peter Kosso, 'Observation of the Past,' History and Theory. Vol. 31, No. 1 (February 1992). pp.21-36. 551 Peter Kosso, Knowing the Past: Philosophical Issues of History and Archaeology. Humanity Books: New York, 2001. Note that Chapter Two of this book is effectively a re-print (with some some revisions and extensions) of Kosso's 1992 paper. See: Peter Kosso, Knowing the Past: Philosophical Issues of History and Archaeology. Humanity Books: New York, 2001. pp.39-58. This thesis will cite from the 2001 version wherever possible.

552 Kosso, 'Observation of the Past,' p.23.

553 Kosso, Knowing the Past. p.41. (emphasis in original)

554 Arthur C. Danto, Narration and Knowledge (including the Integral Text of Analytical Philosophy of History). Columbia University Press: New York, 2007. p.79. 
explanation. Ramses or Julius Caesar, on the other hand, do not. But this is an entirely separate problem, as we shall see when we come to the work of Carol Cleland. With respect to the language of theory alone, Kosso argues that there is no difference between Julius Caesar and electrons. This, he argues, has extremely important implications for the purported difference in observability between historical and ahistorical entities.

The inability or unwillingness of many philosophers to think about historical entities in this kind of consistently theoretical way, Kosso argues, has created an artificial barrier between history and science. More importantly, it is precisely this confusion that underlies the entire class of "the past is gone and is thus unobservable" arguments. Eliminate this confusion, Kosso argues, and a fundamental unity of observational method begins to emerge which highlights deep structural commonalities between historical and scientific enquiry. While there might be practical and logistical reasons to separate history/archaeology from the sciences, Kosso argues, the argument from observation poverty alone is simply not sufficient to achieve a convincing theoretical distinction. ${ }^{555}$ Kosso begins the work of establishing this claim by once again offering a more scientifically literate view of an argument made by Arthur Danto. In Analytical Philosophy of History, Danto had pointed out that the various classes of "the past is gone" arguments do not establish anything about historical practices in particular, because - logically speaking - all observation is of the past:

Epistemologists never weary of pointing out that any perception, of anything, must, for purely physical reasons, occur at some time, however small, after the perceived event itself took place, that it takes some time, however little, for an impulse to reach the centres of perception, whatever these might be. ${ }^{556}$

The example Danto used to illustrate this was the contrast between astronomers witnessing "stellar explosions" which "took place as long ago as it has taken light to reach us," versus the witnessing of "terrestrial explosions," where the transmission of the relevant information via light waves is nearly instantaneous. It might be more natural, Danto argued, to talk of "witnessing" terrestrial explosions directly in everyday speech, but such talk is logically inconsistent and will not do for serious philosophy. In the case of the supposedly direct observation of a "terrestrial" explosion, Danto writes, "we know that some time, if not as much time as in the case 
of stellar explosions, must have elapsed between the time the explosion occurred, and the time at which we witness it." Given this, Danto argued, "the question is no longer whether it is possible to perceive past events, but whether... it is possible to perceive anything but past events." 557 This argument neutralises the claims of those who would single out human history (or any other historical science) for special derision, as precisely this problem of "pastness" must afflict anyone - whether in science or any other discipline - who attempts to observe anything. Some time, however small, must elapse as, for example, light travels from the slide to the eyepiece of a microscope. The fact that we are comfortable calling the data gleaned by microscopy 'observation' therefore implies that being in "the past" is not an impediment (in principle) to being observed. In fact, if we follow Danto's argument, it is a requirement. And this, as Kosso points out, is not merely the philosophical splitting of hairs, but is a fundamental constraint of the universe, made so by the finite velocity of light. 558

However, as Danto argued, it does not follow that because "all we witness are past events" that "we can now witness every past event." 559 Due to the constraints of the time and place in which an historian might find themselves, there will always be historical events beyond our reach. The information in question has passed beyond retrieval. Thus history must always find itself at some practical disadvantage due to observation poverty. "For some past events," Danto writes, "we are forever outside the required range for witnessing them, and this is now the case with the Battle of Hastings. The question then, is how we can know unexperienceable past events, events which are really 'dead and gone'." ${ }^{560}$ Danto's answer is (among other things) to adopt something of the language of theory we have just mentioned - the marshalling of evidence into theories about past events/objects as a way to "organize present experience." ${ }^{561}$ For the evidence is what we experience/observe, not the event/object itself. This is what drives Danto's arguments regarding how the past should be talked about and conceptualised. But underlying even Danto's arguments - as sophisticated as they are in comparison to those of Bloch or Passmore - is a subtle bias toward "witnessing" as an inherently superior method of gaining knowledge. Revisiting Danto's own example, it is possible to argue that all information regarding the Battle

557 Ibid. (emphasis in original)

558 Kosso, Knowing the Past. p.42.

559 Danto, Narration and Knowledge. p.42. (emphasis in original)

560 Ibid., pp.42-43.

561 Ibid., p.79. 
of Hastings has not passed out of reach. For if it had, nobody would know anything of it at all. Clearly this is not the case. There is ample evidence for concluding that there was such a battle and that it had certain significant outcomes. But this information, Danto seems to be suggesting, is known by something other than (and secondary to) "witnessing." This further implies that there is some meaningful de facto division between "observable" and "unobservable" which - even though without strict philosophical force - might still act to meaningfully separate studies of the "present" from those of the "past." Kosso wishes to argue that no such division is possible in any sense (de facto or otherwise) and that the theoretical manner in which Danto suggests we talk about history is actually sound practice in all scientific disciplines. To achieve this, Kosso asks a question that Danto did not - what exactly do we mean when we use the term "witness"?

The first point that Kosso makes is that an emphasis on "witnessing" or "observation" is effectively an elevation of the primary human senses - particularly that of sight - above any other method of receiving information. This light chauvinism not only assumes that light is a neutral transmitter of information, but also that light is the only information transmitting medium which might legitimately facilitate the exalted operation of 'observation. ${ }^{562}$ While this might seem intuitively satisfying, Kosso argues, it is not philosophically consistent. To illustrate this, he offers the example of observing a basketball game on television:

... consider the two different situations of watching the game live as it is being played, or recording the whole thing on a VCR and watching it later... In either case, we see the players, watch the good shots, and we see for ourselves who wins. The extra delay imposed by taping the game, the delay caused by allowing the information to sit idle for a while as patterns of tiny magnets on the tape, is not a significant epistemic factor in the observation of the televised event and does not undermine the contribution the observation makes to our knowledge of the game. ${ }^{563}$

The key difference here is not only the medium (or, more accurately, mediums) of information transmission, but also Danto's assertion that "all we witness are past events." For we cannot so easily say that the live game was "present" and the taped game "past." Kosso continues:

In both cases the image on the screen is of past events. It takes time for the light to

\footnotetext{
562 This is also true for the other primary senses of course, albeit less pronounced. Kosso concentrates on the example of sight/light, but the argument is effectively the same for the other senses. 563 Kosso, Knowing the Past. p.42.
} 
get from the ball to the camera, more time for the electronic signal to get from the camera to the transmitter, and so on to the electrons in the TV picture tube. So even the live picture lags behind the actual events, and the difference between watching a live broadcast and a taped version, in terms of the delay between event and observation, is a difference only of degree. ${ }^{564}$

There are two key points to take away from this example. The first is that, in both of these hypothetical situations, information is being carried from event to observer in multiple mediums, not all of which are meaningful (or even directly detectable) to human perceptual machinery. "Tiny pulses of electricity carry the information from the camera," Kosso points out, "and during that link in the interaction between object and viewer the image becomes momentarily lost from view." In the recorded game, moreover, the information "follows the additional encoded step of being cast as a pattern of micro-magnets, invisible and uninformative to the human viewer." It can reasonably be concluded, therefore, that observation need not only involve mediums to which human perceptual machinery is directly sensitive in order to be reliable and/or informative. For it could hardly be seriously argued that the kinds of epistemic difficulties outlined here fatally undermine the possibility of gaining reliable knowledge of televised sporting events. ${ }^{565}$

The second point to be gleaned from this example is the realisation that, as Kosso states, "while there is an upper limit on the speed of transmission of information, namely the speed of light, there is no lower limit." This is because information can, as the previous point suggests, move by other means. If light were the only medium for observation, then true observation of the past could only be of objects which were also extremely distant. The light from the Battle of Hastings, for instance, has long since left Earth and cannot be intercepted by any currently known method. The example of a recorded basketball game, however, provides an example of information moving much more slowly. Such a recording might, depending on the medium in which it is stored, store information effectively for several decades. Yet when it is eventually played back, we might still reasonably say that the relevant information has moved from the event to an observer - albeit much more slowly than for an observer watching the 'live' transmission. Bringing these two points together, we can therefore conclude that the term "observation," if it is to mean anything at all, must be defined in such a way as to allow for both the coding of information in potentially limitless ways, and the possibility of a significant time differential 
between event and observation. As Kosso phrases it, a better definition of the term will require attention "to the details of interaction between the object and the observer, and resisting the persuasion of the rough language of simply observing." This can be accomplished, Kosso argues, by "a careful tracking of the flow of information through interactions." 566

Kosso maintains that this peculiarly misleading aspect of language might be cleared up by extending the concept of "observation" to take into account the various processes/mediums which bring information to those perceptual systems we feel we can trust. Kosso refers to these additions to the language of observation as "accounting claims." If we adopt this language, Kosso maintains, we are no longer required to decide what qualifies as observable and what does not. This is replaced with the more nuanced requirement to provide an account of the method(s) by which a signal from an event/object reaches an observer. This leaves us not with a rigid divide between observable and non-observable entities, but a continuum upon which might be plotted the 'degrees of directness' of signal propagation. According to this view, one should not ask "is x observable?" or "is that really an observation of $x$ ?" but instead "about the information that is claimed in each case and how that information is transmitted from the object to the observer. The helpful answer to the question of observability is not the short yes or no but a longer account of the exchange of information and an assessment of the reliability of each exchange." In such a case, Kosso argues, one might think of scientific observation as "observation, all things considered." 567

This view clearly gives the lie to the misleading observable/ unobservable dichotomy. For the concept of observation via accounting claims is as equally amenable to observation via traditional light-chauvinistic means as it is to more indirect observations. Consider the comparatively unproblematic example of observing light through a plate glass window. In order to justify the claim that the sheet of glass is not distorting the image in such a way as to destroy or disfigure the information we are seeking, Kosso argues, we must have some knowledge of relevant principles of optics to use as accounting claims. It is equally necessary, however, to have available the accounting claims by which electron microscopes form images of DNA molecules, despite the fact these will involve processes other than light propagation.

566 Ibid., pp.43-44.

567 Ibid., pp.44-45. (emphasis in original) 
Similarly, much of what is currently known about the interior of the Earth is known by seismic reflection, which uses non-light wave propagation to reveal deep structures within the Earth's crust. In the case of the electron microscope, we might still be comfortable with the "rough language of simply observing." It seems much more problematic, however, to claim that we are "simply observing" inside the crust of the Earth. And such conceptual difficulties can only increase as our observations become more and more indirect. This indirectness does not automatically make observations less accurate, however, as the relative accuracy of an observation is determined by the quality of the accounting claims rather than their quantity. A long and complex chain of information interactions might exist between the observer and the event/object of interest. But if each of those interactions is highly reliable and conceptually well understood, then the resulting observation is not in any sense inferior to, for instance, the "observation" of light passing through a plate glass window. ${ }^{568}$

Questions of "the past" come into this system when one considers the speed of this information propagation. For, as we have already seen Kosso argue, "there is no lower limit" on this speed. ${ }^{569}$ It is possible to argue, therefore, that it is these slow transmissions which are disproportionately exploited in the historical sciences. That is, instead of indirectness being enforced by scale (as in the "observation" of electrons too small to see), it is enforced by the passage of time. But it does not follow from this that observation in historical sciences is a fundamentally different problem. It only seems to be so because of the confusion of terms discussed earlier. If one assumes that scientists really do observe electrons and DNA, then history must appear objectively inferior for being unable to observe Julius Caesar or Ramses. But this, as Kosso has reminded us, is an unfair comparison. Physicists never "see" electrons directly, just as an historian never "sees" Ramses. Both disciplines have to overcome considerable indirectness in making their observations. Historical observation, therefore, must also involve a "continuum of observability." ${ }^{570}$ Just as there is no non-arbitrary line between observable and unobservable in, for instance, physics, neither is there such a line in the historical sciences. Or, for that matter, human history. The various degrees

568 This is not to say, of course, that every scientist who uses a microscope (or looks through a plate glass window!) need have comprehensive knowledge of optics or atomic physics. Rather, these are claims that may remain implicit, but must be available in the event of some challenge to the accuracy of the observation and/or any conclusions drawn from it. See: Kosso, Knowing the Past. pp.45-46.

569 Kosso, Knowing the Past. p.43.

570 Ibid., p.49. 
of indirectness (and thus reliability) of documentary sources, for instance, has been a concern for historians since Thucydides. But these assessments, by assuming observation to be an activity that takes place exclusively in the present, have often assumed the difference between observation and hearsay to be a difference of kind rather than degree. Robert Atkinson, for instance, in paraphrasing David Hume, once wrote that "statements about the past are claimed necessarily to diminish in credibility as time goes on. First observation, then memory, then first-, second-, thirdhand testimony, and so on to the point of complete incredibility." ${ }^{571}$ But such a model, Kosso argues, would have greater credibility if it focused not on the number of stages, but on their quality:

Thus one's own memory may be no more credible than the testimony of an eyewitness, especially a witness with independent credentials as a competent, reliable, and even expert observer. This testimony is little different from a newspaper account by a reporter on the scene, which is in turn similar to an historical account... where the witnessing and faithful recording of events are independently accountable. The point is that objects of historical interest, like objects of scientific interest, fill out a tight spectrum in terms of indirectness in the process of observation. Rather than drawing a dubious dichotomy in this spectrum it is epistemologically more enlightening to analyze the various stages in the indirectness and their potential threat to the conveyance of information. ${ }^{572}$

When considered in this manner, Kosso argues, it is "surely misleading to claim that historical studies are constrained to study only what cannot be observed." 573 And it is even more misleading to make the somewhat softer argument that "the line between what is observable and what is not is much less clear in history than in other disciplines," as this makes the mistake of assuming that observation is any less problematic in other sciences. ${ }^{574}$ Thus Kosso concludes, "given the unclarity in the sciences... it is best to view the issue of observability as being equally unclear in history." ${ }^{\prime 575}$ If this is so, then one should be able to talk as easily of accounting claims and information interaction in the historical sciences as one can in the nomothetic. And this is precisely what Kosso argues. The traditional questions asked of written source material - for instance, "who wrote this and why?" - become, he writes, a starting point for the "process of accounting which plays an epistemic role exactly like the process of accounting for the formation of empirical evidence (information

\footnotetext{
571 Robert F. Atkinson, Knowledge and Explanation in History. Cornell University Press: Ithaca, New York, 1978. p.49.

572 Kosso, Knowing the Past. p.49.

$573 \mathrm{Ibid} .$, p.50.

574 Murray Murphey, Our Knowledge of the Historical Past. Bobbs Merrill: Indianapolis, 1973. p.151.

575 Kosso, Knowing the Past. p.50.
} 
through interaction) in natural science." ${ }^{576}$ He continues:

The credibility of a textual report is influenced by an account of the ancient author's access to the event (What did Herodotus see for himself, and which events did he relay from other witnesses?), the preparation of the text, and its treatment through time (Was it edited? Translated? Lost and retold?). The point is that the evidence presented in historical documentation... needs this kind of accounting. The meaning of passages is often revealed only in context with other claims about the past such as about related events or the author's motives. And the authenticity of a report, its justification, is based on claims about the witnessing of events, the honesty of the author, and the preservation of the text. These are the accounting claims in the historical case. They are themselves claims about the past, just as the accounting claims in a natural science are usually of entities and events too small to be seen. ${ }^{577}$

In this sense, the actual text of Herodotus is the unfocused stage between event and observer, and is not - conceptually speaking - any different from the temporary encoding of a television transmission as a pattern on some storage medium. As Kosso argues, the "information in the text is evidence of the past in the sense that an information-bearing signal has been conveyed through a series of interactions, beginning with the events themselves, through Herodotus and his informers, and eventually to us." The signal is not based on the transmission of light, and it is extremely slow, but if "neither of these features disqualifies observational information in the case of science," Kosso argues, "nor should it in the historical case." ${ }^{578}$ Therefore, Kosso concludes:

... the data in history, the tokens of written reports of the past, play an evidential role that is similar to the data in science, the images in microscopes, tracks in particle detectors, and the like. Both bear information of less accessible objects of interest and both are amenable to an analysis of the credibility and accuracy of that information in terms of an independent account of the interactions between the object and the final medium of information... As long as we understand the formation process, in science or in history, we can be quite liberal in allowing many kinds of signals to carry the information. ${ }^{579}$

If "accounting claims" really are the correct way to talk of observation in any science, historical or otherwise, then one of the logical consequences of this is to enforce an 'apples to apples' comparison between entities across the historical and nomothetic sciences. The mismatch of language that Kosso identified at the beginning of his paper therefore introduces an imbalance of observational power that is only apparent. This gives a false picture of what historical scientists can know and how they can

576 Ibid.

577 Ibid., p.51.

578 Ibid., p.51-52.

579 Ibid., p.52. 
know it. Scientists do not directly or "simply" observe electrons themselves. Instead they infer their existence and properties from the traces available to them - the debris of a particle accelerator, for example. Such traces are turned into "observations" through the use of accounting claims which document the interchange of information at each step of the process. And this, Kosso has argued, is equally true of any example of scientific observation. There is always some degree of indirectness. Why then, should it matter if that indirectness is enforced by scale (as in particle physics) or time (as in history), provided accounting claims are available which will enable us to span the resulting divide? In this sense, "electrons" or "DNA" are theoretical constructs that organise present experience, just as "Julius Caesar" or "The Korean War" do. Conceptualising observation in this way therefore significantly saps the force of the "past is gone" class of arguments.

\section{The Nature of Kosso's Accounting Claims}

This model of assessing the indirectness of observation - as opposed to dichotomising the world into observable versus unobservable - has the desirable consequence of unifying much of the language used to talk about both science and history. The reliance on "accounting claims" in this model, however, will require us to re-examine the issue of covering laws. For it would be tempting for a covering lawyer to argue that these "accounting claims" merely represent the means by which historical claims might be reduced to their implicit general laws. There are, however, several problems with this argument. First, the requirement for accounting claims in observation applies to all scientific disciplines, whether their primary mode of working is narrative or nomothetic. And second, any laws which might be invoked as accounting claims in a narrative explanation are not necessarily contributing to the explanatory content of that explanation. In Kosso's simple example of light passing through plate glass, for instance, the theories and laws of optics are not in any sense determining the information that light might be carrying. They are merely assessing the reliability of its passage. If we are looking through a plate glass window in order to identify whether an approaching person is someone we know, in other words, the relevant laws of optics have no bearing on the information at issue. Said laws are merely available, should they be required, to justify the belief that the glass does not distort or destroy the particular information we are looking for. Thus Kosso's model, in addition to its many other benefits, also provides us with a way to properly 
contextualise the role of laws in historical explanation, without being vulnerable to the charge of being a nomothetic system by stealth.

One potential stumbling block for applying Kosso's work to human history, however, would be any requirement for accounting claims to consist only of general laws and theories. This would prove an extremely difficult requirement for human history to meet. There is no suitably general theory of human psychology, for example, which might be used as an accounting claim for the inference of an historical actor's state of mind from their actions. From this one might argue that the claims of human history must therefore depend on non-general accounting claims, and that it is this which separates history from the sciences. Kosso clearly argues, however, that accounting claims are not required to be general laws or theories. All that is required of them is that they credibly (and independently) detail the transfer of some informative content to the observer:

In neither the scientific nor the historical case is the level of generality of claims an issue. In both cases, some accounting claims are quite general, for example about the transmission of light or about the fidelity of unintended textual information, and some claims are quite specific, as about the reflection of seismic waves from the western Pacific subduction zone or about the exploits of Herodotus. Nothing of epistemic significance depends on the level of generality. ${ }^{580}$

And so we are left with little with which we might separate history from the sciences - at least when it comes to observation and the use of evidence.

In closing then, let us summarise what Kosso's work is able to provide to those seeking a unified model of of narrative explanation. In Kosso we find a sound theoretical argument which not only standardises the language of observation across all sciences, but also makes clear the central role that the language of theory plays in observation. This frees us from some of the more ridiculous consequences of observation chauvinism. Specifically, we are no longer tempted to talk of studies of the past as fundamentally handicapped in comparison with the experimental sciences. For if the historian does not directly observe the storming of the Bastille in 1789, then neither does the physicist directly observe electrons. Kosso's language of indirectness and accounting claims is the correct way to talk in both cases. Moreover, the language of theory this new vision of observation enforces also allows us to more easily break our epistemic tasks into pieces, neatly separating theoretical claims from

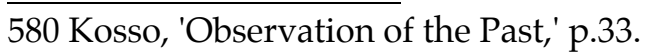


the observations on which they are based. Also of great value in Kosso's work is the argument that accounting claims are not required to be highly general in nature. This, when coupled with Danto's notion of historical statements as purely particularistic theories, paints a picture of explanation in which slavish attempts at reduction to laws or general theories are not only unnecessary, but also prone to distort or destroy the very information desired.

What Kosso does not do, however, is concern himself with the form of explanation. His conclusion that the explanatory power of accounting claims is not directly related to their generality clearly suggests he does not consider scientific explanation to be only a matter of general laws. But as to the nature of any additional explanatory form(s) which might underwrite explanation in those cases in which laws are not applicable, he does not speculate. Our purpose here, however, is to show that the nature of that non-nomothetic mode is narrative. The previous chapter has shown that narrative is at least an intuitively plausible solution for historical problems, but has offered no formal definition of narration. This oversight must now be corrected. And so it is to the second of the epistemic issues with which this chapter has tasked itself that we must now turn. We must provide a philosophically (rather than merely intuitively) convincing account of what narratives are, their permissible subject matter, and their relationship to nomothetic philosophy of science. To do this, we will draw upon the pioneering work of the philosopher of science David Hull.

\section{David Hull and Nomothetic Compatibilism}

Despite Kosso's sweeping revision of how history should be thought of and talked about in relation to the sciences, he left largely untouched those core questions of nomothetic explanation and historical separatism which have been at the core of the philosophy of history for much of the twentieth century. If historical explanations do not adhere to a nomothetic model, then are they really explanations? And if they are, then what logical framework describes them? As Part One has shown, differing answers to these fundamental questions lay at the very heart of the disconnect between the covering lawyers (who claimed that all explanation must be nomothetic in order to be worthy of the name), and the idealists (who claimed that the form of explanation in history differed so fundamentally from that found in the sciences as to be utterly incompatible with it). In both cases, the nomothetic assumption was 
paramount. The work of David Hull would be instrumental in resolving this apparent tension by dissolving the nomothetic assumption which had sustained it for so long. For Hull was of the view that there could not be two fundamentally incompatible notions of explanation. But he was also far from convinced that nomothetic explanations were the only form of explanation. "Perhaps," he wrote, "philosophers have been unable to discover the essence of beauty, goodness, horses, lemons, and games, but they have discovered the essence of scientific explanation, and it is subsumption under a scientific law." ${ }^{581}$ This assertion, Hull argued, seemed doctrinaire and rather too certain for philosophy - a discipline whose parameters and conclusions are notoriously in flux. Insisting that "explanation" as a precise philosophical term should refer only to a single (nomothetic) process seemed to Hull "as implausible as supposing that 'dishonesty' refers to a single type of human activity." He continues: "just as there are more ways than one to be dishonest, there may well be more than one way to explain something scientifically." 582

Hull's project then, was to identify those elements within science which could not be grasped nomothetically and attempt to formulate a way in which they could be grasped. To do this, he would argue that the notion of scientific explanation should be extended from a single form of explanation to a binary form. And this other explanatory mode, Hull argued, was already implicit in the nomothetic model itself. That classical form, it will be recalled from earlier chapters, calls for the explanation of a phenomenon by showing it to be a consequence of a known law (or laws) of nature. To make such a demonstration, however, all of the various contingent and contextual factors which define the problem must also be specified. If one wishes to use known laws of motion to, for example, calculate the future position of a planet, one must know its position either at the present moment or at some known time in the past. This and all other information which is relevant to the deduction but additional to the laws themselves are what is meant by "initial conditions" or "particular circumstances." This creates a binary system, but one with an inherent power imbalance between the two halves. For in such a classical nomothetic system it is the laws - and the laws alone - which do the explaining. In this view, as Hull phrases it, an "explanation entirely in terms of general laws could count as a genuine scientific explanation, but no concatenation of statements of particular circumstances could

581 David L. Hull, 'Central Subjects and Historical Narratives,' History and Theory. Vol. 14, No. 3 (October 1975). p.273. 582 Ibid. 
possibly explain anything." But this could also be seen as something of a philosophical bait and switch - a rhetorical sweeping of all the non-nomothetic elements of a calculation into a broad supporting role which was then largely ignored. For while "logical empiricists," Hull argued, "have spent considerable effort in attempting to characterize general laws... They have spent much less time examining the hodgepodge of statements that are lumped together under the rubric "particular circumstances."” But these statements, as Hull pointed out, are anything but the trivial matters this marginalisation implies, for they represent "everything in addition to general laws that is needed to carry out the derivation." At the very least, Hull argued, their precise role in scientific work was worthy of some philosophical attention. This was the basis of Hull's so-called "Particular-Circumstance" model of scientific explanation. ${ }^{583}$

This understanding of the classical model not only neatly frames Hull's approach to the problem of particularistic (and therefore narrative) explanation, it also addresses the issue of nomothetic compatibilism. Previous attempts at realising nomothetic compatibilism in human history have centred around the reworking of laws in order to allow for their application to particularistic cases. As we have seen in Part One, however, such attempts were of limited effectiveness. Hull, on the other hand, wished to investigate whether narrative explanations could be related not to the law half of the nomothetic binary, but to the other half - that of initial conditions/particular circumstances. Not only does this seem simply more appropriate as an approach (given the oft-cited singular nature of historical events) it also possesses many theoretical advantages. First, it does not require any denial of the efficacy of laws in their areas of competence. This is a distinct improvement over, for instance, Dray's approach. And second, it does not require any separation between history and the natural sciences. Hull presents instead a complementary vision in which both the narrative (particular) and the nomothetic (general) approaches are required in order to yield truly complete explanations. The only separation to be found between these two approaches is in the kinds of questions one chooses to ask of the world, as these will determine which mode the asker ought primarily to be concerned with. Most importantly for the purposes of this thesis, however, Hull's "particular-circumstance" approach to narrative explanation is far

583 David L. Hull, 'The Particular-Circumstance Model of Scientific Explanation,' in Matthew H. Nitecki \& Doris V. Nitecki (eds), History and Evolution. State University of New York Press: Albany, 1992. p.69. 
less hostile to disciplines - human history included - which have traditionally found themselves placed outside of the scientific circle due to their lack of laws. Indeed, Hull consciously builds up his model from issues which "arose in the context of human history," but which also "apply equally to all historical disciplines, for example, cosmology, geology, and paleontology as well as human history." 584

Hull's model not only succeeds in linking narrative to what is undeniably an extremely successful model of explanation, it can also be seen as providing some theoretical substance to the argument (encountered in the previous chapter) that the purpose of laws for the narrativist is to define the space of the possible in which narratives can exist. "General laws," Hull writes, "are relevant to historical explanations but not as premises from which the events to be explained are derived. Instead, they provide the theoretical context in which historical entities are individuated." ${ }^{585}$ As the basis for a general model of narrative, then, Hull's work seems very promising indeed. But there remains a good deal of definitional work to be done. A truly advanced theory of narrative, for instance, will have to not only demystify just what is meant by terms like "individuating" and "historical entities," but also answer additional questions such as: what is narration? What can be narrated and what cannot? Is there a single narrative form and logic broad enough to cover events ("the K/T extinction," or "World War II"), objects ("Mount Taranaki," or "the Rosetta Stone"), as well as people ("Kate Sheppard," or "the Buddha")? It is to Hull's attempts to flesh out his model by answering such questions that we must now turn. In order to retain optimal clarity, however, it will be helpful to approach Hull's work in a somewhat backwards fashion. That is, we must examine his account of what it is that is narrated before we can provide an adequate account of what narration is. This is because Hull's concept of "central subjects" is not only critical to an understanding of his work as a whole, but also definitionally contains and justifies an assertion absolutely fundamental to the concept of narrative - the uniqueness and singularity of their subjects.

\section{Hull's Concept of the Central Subject}

Hull first outlined his concept of a "central subject" in a 1975 paper entitled 'Central Subjects and Historical Narratives.' Due to the timing of its publication, this paper

584 Ibid., p.70.

585 Ibid. (emphasis added) 
saw Hull wading into a debate still dominated by a strong disconnect between covering lawyers and narrativists. By 1975, narrative had the upper hand, but was itself in the process of being transformed by those literary-narrativists who would come to dominate contemporary philosophy of history. Hayden White's Metahistory, for instance, was published in 1973. Similarly, Louis Mink's influential paper 'History and Fiction as Modes of Comprehension' was published in 1970, and had exercised considerable influence on White. Hull offered an alternative approach to narrativism based on a philosophy of science in which the nomothetic assumption was more realistically understood. His arguments, however, were not fated to wield anything like the influence of Mink or White. The central thesis of Hull's paper was that the doctrinaire assertion that explanation had only one (nomothetic) form had forced philosophers of history to "argue either that historical narratives do not concern unique sequences of events or else that they are not explanatory." Hull attempted to counter this view by arguing that this dichotomy was merely apparent and could be dissolved through a more careful definition of what a narrative was. "If historical narratives," Hull argued, "are viewed as descriptions of historical entities as they persist through time, then the currently accepted analysis of science need not be modified in order to account for the unity evident in historical narratives." This desire to work within the existing structures of science would lay the groundwork for his later work on narrative as the philosophy of "initial conditions." Hull therefore accepted at the outset precisely that assumption philosophers of history had almost unanimously rejected - that narrative was a valid mode of scientific enquiry in historical disciplines. Hull's primary task was to form a coherent philosophy of science around this. He knew from the very beginning, however, that a necessary consequence of his work would be the destruction of any formal separation of history and science. For, in Hull's view, while "each historical entity in and of itself is unique... entities of this kind are not peculiar to history." Thus Hull proceeds as Kosso did - emphasising the continuity of history and science and drawing his examples from both. ${ }^{586}$

A "central subject," Hull argues, is that which a narrative is about. ${ }^{587}$ Central subjects

586 Hull, 'Central Subjects and Historical Narratives,' p.254.

587 This idea is not unique to Hull. Something like it can be found in the work of Morton White and Maurice Mandelbaum. (See: Maurice Mandelbaum, 'Objectivism in History,' in Sidney Hook (ed), Philosophy and History: A Symposium. New York University Press: New York, 1963. pp.43-56., and Morton White, 'The Logic of Historical Narration,' in Sidney Hook (ed), Philosophy and History: A Symposium. New York University Press: New York, 1963. pp.3-31.) Hull, however, was the first to see that the idea required no separation between history and the sciences. 
are the defining characteristic of narrative, for not only do they provide a basis for the uniqueness of historical entities, they also act as a way to control issues of selection and significance. The materials of the past from which narrative descriptions might be constructed are, theoretically speaking, finite. This suggests that the number of possible narratives which might be used to describe those materials must also be finite. But, as Danto has argued, there is always a possibility that a future event/object will recontextualise a past event/object, thus generating new potential narratives. If we allow this, then the number of potential combinations into which the traces of the past can be narratively described becomes effectively limitless. Central subjects, Hull argued, control this flux by acting as organising structures, forming the "main strand around which the historical narrative is woven," as well as helping to localise selection bias and determine the criteria of relevance for additional evidence. As to what constitutes an acceptable central subject, Hull has only one criterion. The most important definitional aspect of central subjects for Hull, is that they are individuals in the strong philosophical sense of that term. An "individual" in this sense, Hull argues, "is a particular, a thing which is denoted by its name and nothing else." 588 In other words, to be able to be narrated, a central subject must be a phenomenon for which a description exists under which that phenomenon is the only qualifying example.

Essentially Hull is offering this idea of a "central subject" as a way to identify events/objects which must be narrated from those that cannot. Narration is only an appropriate explanatory option, Hull is arguing, for those descriptions which produce a singular event/object. And the description used will depend on the questions asked and the information sought. Narrative is therefore a function of historical questioning. If we want to know, for instance, why nations go to war, then the appropriate descriptive entities for answering such a question are nations themselves. The relevant question/description singles out no nation in particular, however. The term "nation," as we define it, has multiple possible referents. Answering a question like this, of course, will likely proceed by examining narrative accounts of the reasons particular nations have gone to war. But in this case those narratives would ultimately be used as the raw material from which to generate some general explanation of the same form - if not the same specificity or precision - as a natural law. We might want, for instance, to create a generalised list of the broad

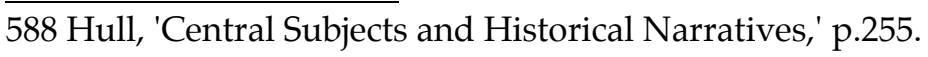


types of rationales for waging war, supported with historical examples. Such a project may seem a good deal removed from the ideal of general laws, but it is not so far removed as to be removed from the nomothetic mode of explanation altogether. The impulse to use abstraction in order to discern commonalities across multiple cases remains. The narratives themselves, however, are only possible for individual nations. By looking for this quality of uniqueness under a description, therefore, we are able to tell at the outset which descriptions/central subjects are amenable to narrative explanation and which are not. This correlation between the lack of a philosophical "individual" and the generalising impulse of the corresponding explanatory project, Hull has argued, is a highly reliable one. The specificity of description which gives rise to a central subject can therefore be taken to be a kind of signature of the necessity of narrative explanation. It can thus be made part of the definition of narrative explanation without philosophical difficulty.

\section{Central Subjects as Necessarily Historical Entities}

This definition of central subjects, while clever, leaves one key point unclear. It does not specify why the mode in which singular central subjects must be explained should be narrative. But this, Hull argued, was hardly in need of explanation. Narratives, following Danto, are inherently temporal. For Hull, this also made them inherently historical. Any event/object captured under a description in which it is a philosophical individual (and thus a central subject) must therefore also be what Hull called an "historical entity." If a philosophical individual is to be explained as such an individual, in other words, it must be explained historically. For if its definitional individuality precludes contrast or comparison, it can only be contextualised. How else could it be dealt with? An historical entity, Hull argued, must be a "coherent, unitary entity that either persists unchanged or develops continuously through time." This does not require any recourse to essentialism, however, as "for an historical entity to remain the same entity no degree of similarity between earlier and later stages in its development is required, so long as this development is spatiotemporally continuous." Indeed, to detail such development in an historical entity is precisely the explanatory function of narrative. To illustrate this, Hull used the thought experiment of Moses. "Few," he remarked, "if any traits which characterized Moses when he was discovered by the Pharoah's daughter in the bullrushes also characterized him when he led the Israelites out of Egypt or when he died in sight of 
the Promised Land." Because of his spatial and temporal continuity, however, it remains possible to talk of Moses as both a theory and a central subject. "It is," Hull argues, "the link-on-link continuity of Moses' body (and to some extent his mind) that makes him a single individual and the same individual through time..." Conversely, Hull offered the example of the London landmark known as Big Ben. "Big Ben," he argued, "has changed very little since it was first cast, but this lack of change is not the reason it remains the same individual. Like all historical entities, it remains the same individual because of spatio-temporal continuity." 589 One should not mistake change, in other words, for a fundamental characteristic of narrative explanation. We might have comparatively little to say about Big Ben, and perhaps a narrative account of it might choose to focus on, for example, how it attained its iconic status. Even in such a circumscribed case as that, however, there is still a requirement for a central subject. And central subjects, when defined as individuals in the philosophical sense, require treatment as historical entities.

Of course, when limited to human beings and large clocks, this idea of central subjects as historical entities seems relatively straightforward. As we have already seen, however, it begins to seem a good deal more problematic when applied to more abstract entities. Hull apparently realised this, almost immediately cautioning that the "notion of an historical entity becomes less intuitively clear when it is extended to include lineages, social movements, and the like." In order to clarify this point, Hull used the biological concept of a "species" as an example of both central subject and historical entity. Individuals of any given species, Hull argued, are "paradigm cases of historical entities." This much is made clear by the example of Moses. But what of the entire species called Homo sapiens? This presents a problem, Hull argued, in that an entire species has traditionally been seen as a general entity. But this need not necessarily be the case. For while we frequently wish to treat individual examples of Homo sapiens as members of a general class - for example, in the practice of medicine - there are also perspectives and descriptions under which Homo sapiens, as a whole, can be seen as an individual. And under those descriptions, Hull argued, Homo sapiens can be seen as both an historical entity and a viable central subject for narrative. This initially seems counter-intuitive, Hull argued, as traditionally "logicians have treated organisms and species of organisms as two very different sorts of things." In modern logic, that difference has been expressed as "the class-membership relation." That is,

589 Ibid., p.256. 
organisms are individuals and "their names are proper names." Species, on the other hand, are "classes and their names are common nouns to be defined in terms of their essential traits." For example, the title "Cygnus olor" is a proper name awarded to any creature possessing the traits we associate with that species. Or, as Hull put it, any "large, white aquatic bird with a long neck and a hoarse, honking call." This is a classic application of the kind of logic served up by the nomothetic philosophy of science in general (and by logical positivists like Hempel in particular) in that it makes a sharp distinction between the particular and the general, defining the former exclusively in terms of the latter. ${ }^{590}$

Evolutionary theory, however, has frequently forced biologists to adopt a more historically conscious perspective. This is because the "class-membership" view breaks down almost entirely when applied to populations of individuals evolving over time. For the evolution of one species into another is a profoundly gradual affair - the accumulation of tiny genetic changes over time. Any one generation, if examined, differs very little from its immediate progenitors. Yet, given enough generations, the differences may become significant enough to erase even the suspicion of common ancestry. If a species is to be defined as essentially a series of traits, however, then where is the line of exclusion to be drawn? When the organism ceases to exhibit just one of the essential traits - an Ur-swan that had not yet evolved its distinctive honk? Perhaps, but this would result in a huge number of supposedly distinct species that actually differed very little. Moreover, for continuous qualities like size or length of neck, the decision as to what constitutes "large" or a "long neck" could only be arbitrary. This approach thus replaces one definitional problem with several. Perhaps the line should be drawn when the organism no longer exhibits several of the required traits? In this view, Hull argues, "Moses was the individual who did enough of the most important things that Moses was supposed to have done." Or, alternatively, "swans are those birds which have enough of the most important traits characteristic of swans." But this raises questions as to the usefulness of traits as species identifiers at all. ${ }^{591}$

While defining a species as a suite of traits might work well enough when confined to the animal economy as observed over small intervals of time, it clearly does not exhaust the possible descriptions of what a species is. The problem here is not that 
the right way of thinking about and enumerating traits has yet to be found, although this field has improved immeasurably since Hull published his paper. Instead it is a problem of essentialism - an insistence on defining species in purely general terms. Richard Dawkins has described this biological essentialism as the treating of "tapirs and rabbits, pangolins and dromedaries, as though they were triangles, rhombuses, parabolas or dodecahedrons." The rabbits we encounter in the world, according to this view, "are wan shadows of the perfect 'idea' of rabbit..." ${ }^{592}$ And this, it would seem, is born out of an emphasis on generality. All that a rabbit is, in other words, is defined by those qualities it has in common with other rabbits. By way of contrast, Dawkins offers the evolutionary view:

If there is a 'standard rabbit,' the accolade denotes no more than the centre of a bell-shaped distribution of real, scurrying, leaping variable bunnies. And the distribution shifts with time. As generations go by, there may gradually come a point, not clearly defined, when the norm of what we call rabbits will have departed so far as to deserve a different name. ${ }^{593}$

In fact, Dawkins points out, "after a hundred million years it may be hard to believe that the descendant animals ever had rabbits for ancestors." 594 Yet at no point were the traits of one generation all that different from those of the previous. Considered over time then, the concept of static traits is clearly inadequate. Equally clearly, tinkering with such an idea is not enough. It must be revised - or at least augmented. The solution Hull proposed was to define what a species is historically. In this view, the traits a species possesses at any one moment in time are not assessed according to some Platonic criteria for membership, but seen as dependent on the ancestry of that species. These traits will seem to cluster, of course, but this is because of the ancestordescendant relationship. We have effectively replaced the merely assumed concept of the static and essential trait with a genuine understanding of the accretion of historical transformations. Species are thus more naturally (and more accurately) defined by tracing their link-on-link - or rather ancestor-on-ancestor - development. Therefore, Hull concluded, "both organisms and species are historical entities." 595 And this analysis, Hull argued, could easily be applied to any historical entity whether traditionally considered as history or science:

Similarly, many common-sense classes in other areas might profitably be

592 Richard Dawkins, The Greatest Show on Earth: The Evidence for Evolution. Bantam: London, 2009. p.22.

593 Ibid.

594 Ibid., p.23.

595 Hull, 'Central Subjects and Historical Narratives,' pp.258-259. 
conceptualized as historical entities, specifically the central subjects of human history. Protestantism might not seem much like an individual, but if it is to perform the function of a central subject, it must be interpreted as such. As Herbert Butterfield observes in his criticism of the Whig interpretation of history: 'Sometimes it would seem that we regard Protestantism as a Thing; a fixed and definite object that came into existence in 1517...' Protestantism surely has no fixed and definite limits but it is a thing, an historical entity. ${ }^{596}$

In other words, we can very often treat what has traditionally been regarded as a general form as an individual - and thus a viable central subject for historical narration. And this, Hull argued, is possible for any philosophical individual. This is precisely the logic which lies behind the rendering of what appear to be highly general entities - such as "warfare" or "Russia" - into central subjects which might be narrated. After all, insisting that "warfare" or "Russia" has a constellation of fixed and immutable traits is precisely the kind of misplaced generalisation which, while it might be possible in a limited sense, is unlikely to achieve a deep understanding of either. We would, for the most part, be better served in our studies of these concepts to instead examine their unique spatio-temporal (i.e., historical) development. It must be remembered, however, that adopting such a temporal viewpoint does not necessarily provide a universally better approach to explanation. In Hull's example, for instance, one can imagine situations in which a static view of a species as a constellation of traits would be not only desirable, but essential. Similarly, it is foolish to suggest that we would not want to know something of the common characteristics of "warfare" if they were at all discoverable. ${ }^{597}$ Hull's goal, in other words, was not to supplant, but to augment. For by trading the ability to generalise, we potentially gain a much deeper understanding of the individual. Hull, in a later paper, referred to this as the difference between "subsuming a particular under a general law," and "individuating the particulars being subsumed." 598

By "individuating the particulars," however, it is important to note that Hull was not talking about a process entirely independent of laws. Like Gould, he argued that "laws are relevant to historical explanations but not as premises from which the events to be explained are derived." Instead, Hull argued, the laws and general theories of

\footnotetext{
596 Ibid., p.259. (emphasis in original) The original citation can be found in Herbert Butterfield, The Whig Interpretation of History. Penguin: Harmondsworth, 1973. p.43.

597 For one interesting example of an attempt to say something general about the human activity of warfare, see: Doyne Dawson, 'Evolutionary Theory and Group Selection: The Question of Warfare,' History and Theory. Vol. 38, No. 4, Theme Issue 38: The Return of Science: Evolutionary Ideas and History (December 1999). pp.79-100.

598 Hull, 'The Particular-Circumstance Model of Scientific Explanation,' p.77.
} 
science "provide the theoretical context in which historical entities are individuated." ${ }^{599}$ This is not an endorsement of ineliminable randomness fouling up a deterministic machine, however, but merely another way of approaching the same phenomena - whether they are governed by known laws or not. Treating a planet as a point mass, for instance, allows for their treatment according to the mathematics of motion. But Mars, for example, is much more than simply a point-mass, and there are many other ways in which we might describe and understand it - many of which will not require (or allow) the use of nomothetic laws. Most importantly, however, both points of view are explanatory. Whatever the advantages of the evolutionary view, the generalist view of species continues to do useful work in biology every day. This does not imply, however, that any given phenomenon will yield equally to both approaches. "Ideally," Hull argued, "we would like to possess both general laws and theoretically significant historical entities, but sometimes we have to be content just with tracing historical entities through time." 600 Thus, we might reasonably conclude that, depending on the information being sought and the available evidence, most scientific disciplines will favour one explanatory approach over the other. This matches the observed situation in the scientific spectrum very closely.

Over the course of this chapter and the previous, we have argued for a vision of science in which we might treat any truth claim, regardless of its generality, as a theory. We have also argued that arguments of observation poverty offer no credible philosophical obstacle to this. From such a liberal beginning, we might then use Hull's criterion to decide, on the basis of the individuality of the appropriate description of the truth claim in question, whether it is a fit subject for narrative individuation or for nomothetic generalisation. This is the current state of our model. With respect to those subjects which are appropriate for the narrative model, we now face two remaining tasks. First, we must construct the narrative. And second, we must attempt to confirm or disconfirm it. We have already offered some broad hints as to how both of these steps might be accomplished. With respect to the definition of narration, we have suggested that it consists in tracking the historic interactions of the multiple laws, events, objects, and other influences which are relevant to a central subject. Similarly, we have also seen the beginnings of a solution to the problem of confirmation in Chapter Five's example of tetrapod evolution. We will have a good deal more to say regarding confirmation when we discuss the work of Carol Cleland 
later in this chapter. For now, we must turn our attention to the first of these outstanding steps - providing a more formally acceptable definition of what constitutes narration.

\section{What is Narration?}

Any formal definition of narrative which might hope to satisfy our condition of nomothetic compatibilism would be wise to begin with the "particular-circumstance" model advanced by Hull. This model, it will be recalled, was loosely defined by Hull as an inversion of the traditional emphasis of the nomothetic-deductive model on laws over initial conditions. By reversing this emphasis, Hull claimed, we can provide a principled way of "individuating the particulars." More importantly, the mechanism by which this reversed model must necessarily operate constitutes a good formal definition of the term "narrative." ${ }^{001}$ Such a definition must satisfy our requirement for nomothetic compatibilism, given that it effectively is the nomotheticdeductive model. To show how narrative flows from this inversion of the traditional direction of reasoning, let us consider just how the nomothetic method works in an abstract sense. A nomothetic-deductive account, in the classical sense, generates general theories and laws from the assessment of what is common to a group of individuals, and then seeks confirmation by applying those theories and laws to individuals as yet unexamined. Narratives reverse this process. A narrative is not the abstraction of a single law or theory from all relevant individuals, but is instead the application of all relevant theories and laws to a single individual. Moreover, in keeping with the "particular-circumstance" nomenclature, we might also note the explanatory outcome is similarly inverted. That is, we are interested in how the central subject came to be what it - and it alone - is, rather than being interested only in the properties it shares with every other event/object in its class. The narrativist philosopher of science Benjamin Jeffares uses the example of a potted plant on a windowsill. Suppose this plant, Jeffares argues, were to sprout weeds. How would one go about explaining this? With reference to the work of the philosopher Kim Sterelny, Jeffares argues that there are two ways to approach this problem:

Sterelny has suggested there is a distinction between actual sequence explanations of history, where one tracks the minutiae of causes and effects, with robust process explanations, where one utilises higher levels of processes that one can compare

601 Ibid., pp.70,75-76. 
across cases. ${ }^{602}$

This "actual sequence" versus "robust process" vision of explanation corresponds well with Hull's vision of "particular-circumstance" explanation. More importantly, both accounts can be understood as being complementary to the nomothetic-deductive model. A "robust process" explanation for the presence of weeds in a potted plant, Jeffares argues, might be as simple as: "people tend to have their windows open at a time of the year when some species of plants disperse wind blown seeds." This is, of course, far short of what we might call a law - hence the more modest term "robust process." Despite the acknowledgement of uncertainty this term embodies, however, a "robust process" still exhibits the broad generalising intent which is the hallmark of nomothetically inspired explanation. As Jeffares remarks, "such regularities can explain not only the appearance of weeds in my potted plant, but also in yours." Moreover, by linking the appearance of weeds to the opening of windows, the same cited regularity can also help explain why one person might have more weeds in their potted plants than another - perhaps they spend more time with their windows open? This kind of explanation embodies the nomothetic approach, even if it does not take its ideal form. Sterelny's "actual sequence" approach, on the other hand, is useful in cases where such generalising process explanations cannot be applied, or for which we simply desire greater detail. An "actual sequence," Jeffares argues, can be defined as a "unique explanation that cites the particular variables and unique contingencies of history." ${ }^{\prime 03}$ Such actual sequences, Jeffares argues, are precisely what is meant by the term "narrative":

An actual sequence account of how a particular weed got into my plant pot, would force the describer to detail the events that allowed a windborne seed to get into the soil of the particular pot in question. On such and such a day, the house owner left the window open. It was windy that day, and a particular weed was dispersing seed, one of which drifted in through a window... Such an explanation might well be very difficult, although not impossible to confirm in detail, but it would account for the facts of this particular instance. ${ }^{604}$

This sequence, Jeffares argues, would represent a "narrative that accounted for a state of affairs: the presence of a weed in a particular pot plant." In order to obtain this level of detail, however, note that we must give up any possibility of the resulting explanation being generally applicable. And yet the regularities which also underwrite

602 Benjamin Jeffares, Testing Times: Confirmation in the Historical Sciences. PhD Thesis, Australian National University, 2008. p.24.

603 Ibid., p.25.

604 Ibid. 
the general "robust process" account are all still at work. In fact, these basic laws and theories can even be pressed into service in order to help verify Jeffares' narrative. The basic laws of physics are at work on the airborne seeds, for instance, as are the biological facts of seed dispersal. Climate must also play a role, as the airborne dispersal of seeds is a good deal more difficult in the rain. The list goes on. What is happening here is that, following Hull, we are inverting the classic nomotheticdeductive model, and in doing so, defining narrative. This definition is as follows: an ideal narrative details all of the interactions of all relevant laws and generalisations upon an individual central subject. This is our formal definition of the term, which satisfies both the requirement for nomothetic compatibility and the long-held conviction among historians and historical scientists that their proper task is the investigation of unique particulars. It also possesses the additional advantage of providing a principled account of the broad sense of narrative we saw Mark Day deride as "thin" in the Introduction. For the above definition is entirely agnostic regarding the exact nature of its possible central subjects. They might be water molecules, human beings, ideas, buildings, organisations, or nations. All that Hull's model requires is that they be philosophical individuals. It would be difficult to conceive of a more flexible and inclusive definition of narrative than this.

If this definition of narrative consists merely in the viewing of any given problem from a different direction, however, it might be argued that there is simply no need for narrative - even if it is a theoretically valid mode of understanding. This is, to some extent, a valid criticism. In Jeffares' example at least, the difference between the two modes is purely one of focus. In other words, both the "robust process" and the "actual sequence" are roughly equal in explanatory power. There is thus no compelling reason to choose the narrative over the nomothetic. For if there really is nothing exceptional about the means by which the weeds got into Jeffares' hypothetical potted plant, then why would we ever have need of anything other than a "robust process" account? After all, it provides a much more concise account of the particular event, with the added bonus of potentially covering a large number of other events of a similar type. In cases like this, it would seem, narrative explanation is merely a long-winded way of explaining something which might be explained far more easily with a simple reference to some general principle. In this way, one might argue for narrative as a decidedly inferior mode of explanation. 
This is not always the case, however. There are two possible situations which potentially make the use of narrative explanation not only desirable, but even necessary if we wish to have any explanatory information at all regarding an individual event/object. The first of these is introduced by the requirement to explain some observed complication or outright exception to a general process. As an example of this, Jeffares suggests the case of a potted plant "in an air-conditioned office without opening windows." It is difficult to imagine a general process by which stray seeds might find their way into such environments, although there are many different narrative "actual sequences" by which this could plausibly occur. Perhaps a windborne seed was carried into the building after having alighted on an office worker's clothing while they were on their way to work? Or perhaps a seed made the torturous (and unlikely) trip through the building's air conditioning ducts to the potted plant in question? In either case, no outright abrogation of any natural law is required. In fact, if such an abrogation were required in order to justify an actual sequence, then that would be excellent grounds for considering that sequence falsified.

Despite this, however, we would not expect seeds to survive the trip through byzantine air conditioning structures often enough to be able to effectively generalise that process - especially given how radically such ducting varies from building to building. We could, if we wished, seek confirmation from lower-level laws and theories - those concerning airflow, turbulence and the like - in order to show that such a trip was possible. We might even conduct experiments to this effect. Perhaps a large quantity of seeds could be dumped directly into the air-conditioning ducting of an office building, the large input being used to raise the likelihood of a successful passage through the system. This would (in theory) allow an estimate of the statistical likelihood of such a trip. But any overall generalisation regarding how seeds get into air-conditioned offices would have to be so vague as to be almost useless. More importantly, even if such a generalisation were possible and could be applied to the explanation of any particular contaminated plant, it would be quite transparently inferior in terms of explanatory power to a narrative explanation properly constructed and supported. This is because there are too many other "actual sequences" that could not be covered by such a generalisation. Perhaps our theory about the offending seed coming into the building on a workers clothing was correct after all. In that case, our hard-won and exception-filled generalisation regarding air- 
conditioning ducts would tell us nothing useful. In such cases, we should be more than willing to give up broad generalised processes in favour of a detailed - but particular - account.

Smoothing out such wrinkles in the operation of nomothetically inspired generalisations, however, is hardly a sound basis for assigning narrative a co-equal status as a mode of explanation. To support this claim, we must turn to the second situation in which the use of narrative is necessary in order to obtain meaningful explanatory information regarding an event/object - those situations in which our central subject can only be understood in light of the interactions of multiple processes. This is narrative finally considered for its own sake, rather than merely as an aid to the nomothetic model. Jeffares summarises the approach as follows:

The past is complex, and when explaining the past we can rarely use a single robust process as an explanation. That's not to say that on occasion we don't cite a single robust process that has occurred in the past to explain something in the present... But in order to explain a state of affairs, the historical sciences must frequently construct an explanation that details a series of events. An explanation of a landscape cannot cite a single robust process. It is the result of a series of processes occurring one after another, frequently of quite different types. The rise and fall of a past culture cannot cite a single process; there is an interaction of a number of processes that lead to its downfall. ${ }^{605}$

This is precisely the kind of problem Hull's definition of narrative can help us to solve. Not only do Hull's "central subjects" provide a means by which to identify and define the individual which is to be narrated, his "particular-circumstance" model of narrative provides the conceptual framework in which such a narrative proceeds. Hull's argument that a central subject must necessarily be an historical entity also begins to fall into place here. Consider Jeffares' example of a particular "landscape." That which might be said about landscape formation in general only loosely constrains the possibilities of such a system. There are, in other words, a huge number of possible "actual sequences," as evidenced by the bewildering variety of landscapes observed on this planet. On the other hand, if we use narrative to try to determine what sequence did in fact take place in any particular case, we must give up any claim to generality. In order to obtain greater explanatory power, in other words, we are driven to consider a particular landscape. And any particular landscape must necessarily be understood as the result of a great number of interlocking and interacting processes and forces of varying degrees of influence. If we wish to see the

605 Ibid., pp.25-26. 
landscape we are examining as the outcome of such influences, how might this be done? One might offer an account of a single "moment" or time-slice of that landscape, and try to detail all of the forces that are/were being brought to bear on that landscape at that moment. But by trying to take all temporally extended information out of a description, we end up being able to explain almost nothing at all. To say that erosion has played a role in the observed shape of a particular mountain, for instance, is to necessarily imply some kind of narrative description. For in any single instant of time, erosion cannot be detected. This is because erosion is not a thing, to be seen or not seen, but a process. And processes operate over time. Thus the choice is not between some temporal information and none, but between a lot or a little. To show how a process like erosion has resulted in a particular formation is to show how it has operated over time and how it has interacted with other processes operating over the same period. Thus, we must treat individuals as historical entities if we wish to make them central subjects.

While the generality of this model of narrative is already considerable, it should nevertheless be pointed out that the permissiveness it makes possible with respect to possible central subjects also extends to those causal processes which might act upon them. We are not required, in other words, to place any theoretical limits at all on the nature of those processes which might be at work in any given narrative. In fact, given the way in which Hull has defined narrative, more precision would be limiting rather than liberating. If it is the role of the ideal narrative to detail the operation and interaction of all of the relevant processes, events, objects, laws, and theories which have interacted to produce a single central subject, then we must necessarily be extremely liberal as to the exact nature and scale of those processes. Indeed, as Kosso reminds us, we cannot even be sure we are dealing directly with processes at all. We might just as easily cite other singular events as causally influential upon the historical entity of interest. This is why the central subject is such a crucial idea for Hull. It provides the criteria of relevance - and thus the limiting conditions - for any given narrative. Beyond this, essentially any kind of law, process, event or object might potentially take on causal significance. The only permissible limit would seem to be the requirement that the influences in question be within the realm of the possible, and thus be somehow empirically accountable. It is this which makes narrative a scientifically legitimate process, regardless of whether it is found in paleontology or human history. And yet both Jeffares and Hull are still inclined to 
talk of human history and the "historical sciences" separately. Why is this? The answer to this question brings us face to face with the most serious difficulty facing the application of Hull's narrative model to human history.

\section{The Problem of Process versus Particular in Human History}

In offering his "particular-circumstance" model, Hull anticipated objections from those who felt that any model of historical explanation which retained any emphasis at all on general laws was unacceptable. He wrote:

This thesis is likely to evoke two polar responses. On the one hand, traditional philosophers are likely to insist that the only way to explain anything scientifically is by subsuming it under a law of nature. But these philosophers themselves present explanations in the absence of anything analogous to laws of nature... On the other hand, opponents of the Covering-Law Model are sure to complain that I give too much weight to laws of nature. Subsumption is neither necessary nor sufficient for explanation, even scientific explanation. In their more bumptious moments, these iconoclasts are led to exclaim that laws have nothing to do with scientific explanation. They are left, however, with the task of presenting some other model of scientific explanation. ${ }^{606}$

On the surface, it is difficult to disagree with this assessment. Part One has already shown something of the difficulties involved in providing an explanatory model of narrative which is wholly independent of the nomothetic sciences. Similarly, Chapters Four and Five have examined the inability of the nomothetic model to adequately encompass explanation in the historical sciences. Hull's model of narrative science appears to offer us a way through this impasse, but the emphasis it retains on general laws is potentially extremely problematic for our goal of applying that model to human history. For it is certainly true that Hull's inversion of the traditional model seems only to allow for the individuation and explanation of central subjects in terms of laws and general processes. But, as Hull observed in his 1975 paper, "anyone who has ever read any history is aware that historical narratives seem to possess a unity far greater than that justified by the causal laws one might have connecting the various incidents mentioned." ${ }^{607}$ This seeming contradiction makes it unclear as to whether human history as it is currently understood can explain according to the definition of narrative both Hull and Jeffares have endorsed. For it would be impossible to deny that human history relies much more heavily on explanation in terms of particular events/objects than on laws, theories, and other general processes.

606 Hull, 'The Particular-Circumstance Model of Scientific Explanation,' p.79.

607 Hull, 'Central Subjects and Historical Narratives,' p.260. 
Jeffares' own example of some of the influences on the fall of the Roman Republic shows this, listing factors such as "actions of ambitious politicians, economic growth outstripping administrative capacity" and "external political threats." 608 None of these factors would seem to lend themselves particularly well to explanations in terms of any kind of general process. Have we finally arrived at a reason to separate history from the sciences, even if only pragmatically? Certainly we have arrived at a point beyond which scientific narrativists like Hull and Jeffares are somewhat reluctant to proceed. With reference to his own definition of narrative, for instance, Hull argued that human history is disadvantaged as it "does not have much in the way of highly developed psychological or sociological theories to draw upon." 609 Similarly, Jeffares argues that "historical sciences do use regularities," albeit in a "fashion distinct from the experimental sciences." While Jeffares is very careful to allow that "those regularities are rarely law-like in the sense that positivists would recognise," being "much more restricted in scope," this is still a far cry from the seemingly lawless terrain of the "actions of ambitious politicians." ${ }^{610}$ While these misgivings were not enough for either of these scientific narrativists to explicitly exclude history from the sciences, they nevertheless imply that human history is to be relegated to the outer edges of scientific respectability. If we are to carry the kind of narrative practice advocated by Hull and Jeffares into human history, therefore, this problem will need to be addressed.

The process of modifying Hull's model of narrative in order to cope with particularistic causation must begin with a realisation of that model's theoretical purity. In actual practice, there are some limitations to its use. These come about because, in any area of historical practice, it is rare that the process knowledge we do have is sufficiently to constrain a system perfectly. In other words, the space of the possible allowed by our general knowledge is comparatively large, leaving a large number of possible "actual sequences." It is, as we have already argued, the very purpose of a narrative explanation to enquire which of these potential sequences was the one that really did take place. In the best case scenario, that sequence could be determined by studying the interaction of known processes, theories and laws alone. But the best case scenario is, sadly, exactly that. The resolving powers of the available general theories in any given historical discipline are rarely so strong. Indeed, if they

608 Jeffares, Testing Times. p.29.

609 Hull, 'Central Subjects and Historical Narratives,' p.264.

610 Jeffares, Testing Times. p.7. 
were, any narrative they produced would be essentially deduced from said laws and theories. This would be nothing less than a triumph of the nomothetic-deductive model, and would render any application of narrative theory utterly unnecessary. So we must ultimately conclude that the kind of case in which we have a perfect understanding of all of the relevant laws and processes which have interacted to produce a central subject represents the ideal form of the particular-circumstance model as Hull offers it. Just as the ideal form of the nomothetic-deductive model is the timeless and universal law which permits of no exceptions. In both cases, however, that ideal is rarely achieved.

Hull was seemingly well aware that no theory of narrative could be so removed from actual historical practice and still remain credible. He had claimed, after all, to have created a model in which "there may be some general laws lurking around in the background somewhere, but the particular circumstances carry the explanatory load." ${ }^{611}$ In an attempt to resolve this tension, he offered a conciliatory distinction between "historical reconstruction" and "inference from laws." Sadly, this distinction was to prove disproportionately unkind to fields such as human history. For disciplines like kinematic physics with "very powerful theories," Hull argued, "explanations are easy to produce." In other cases, such as sociology, even an abundance of observational and experimental data had not led to the same level of theoretical sophistication. "It is certainly true," Hull argues, "that Peeping Toms rarely molest, but such statements hardly have the same stature as the law of universal gravitation." That is, while such conclusions are general enough, they do not constrain possible human behaviour all that well. ${ }^{612}$ Therefore, such disciplines cannot be said to possess laws strong enough to allow the deduction of actual sequences according to the ideal form of Hull's model. Disciplines like population biology and meteorology represent "intermediary" cases, in that:

We understand the processes under investigation quite well, but so many variables are involved and changes occur so rapidly and erratically that inferences are difficult. In this connection, one often reads that evolutionary theory can be used to explain the past but not to predict the future. One difficulty with making inferences in evolutionary biology, not to mention other areas of science as well, is that too many contingencies are too important... ${ }^{613}$

In situations of this kind, Hull argues, we are required instead to reconstruct the

611 Hull, 'The Particular-Circumstance Model of Scientific Explanation,' p.70.

612 Ibid., pp.70-71.

613 Ibid., p.71. 
actual sequences of the past on the basis of evidence - what Hull calls "records" rather than infer what must have happened on the basis of theories and general laws alone. Of this concept of "records," Hull writes:

Although certain examples are clear enough, it is far from easy to make a general distinction between those phenomena that count as records and those that do not. Friday's footprint in the sand obviously implied the prior existence of a human being on the beach. The likelihood that any other natural phenomena could produce such a pattern is extremely small. Thus, a footprint can serve as a record of the past. ${ }^{614}$

On the other hand, Hull points out, if physicists were to discover "a container in which all the hydrogen atoms were on one side and all the atoms of nitrogen on the other, they would infer that in the immediate past a partition separated the two gases." In the case of the footprint, we have reconstructed the presence of a human being on the beach in the recent past through empirical records. In the case of the separated gases, however, the prior state of the system is being inferred from known processes and laws. The difference, Hull argued, is that records are records "because their particular makeup is more a function of the contingencies of their history than anything derivable from the theories governing them." ${ }^{615}$ Hull then used this distinction to argue that "inferring the past on the basis of process theories is different in kind from reconstructing the past on the basis of historical records." 616 The role of reconstruction from records, Hull argued, is really only to individuate those historical entities which are ranged over by process laws. And this distinction, he claims, must "apply to all historical endeavours." This would seem to relegate all heavily record-based/reconstructive disciplines - such as paleontology, human history, evolutionary biology and archaeology - as explaining in a fashion quite inferior to "process theories."

This inferiority is not merely apparent, however, for there is also a clear asymmetry of explanatory power inherent in this division. This is because, in narratives that are more inferential than reconstructive, we have processes, laws, and theories in order to help tell us which historical entities are "theoretically significant," rather than merely "commonsense." But where there are no known or obviously applicable theories and/or processes, Hull argued, we are in far less of a position to know this. We are unable to know if the historical entities/narratives we have constructed are,

614 Ibid.

615 Ibid., pp.71-72.

616 Ibid., p.74. (emphasis in original) 
for want of a better term, correct. Because of this, Hull deemed reconstructive narratives to be less explanatory (and thus less desirable) than those based on inference. We can, he writes, "produce historical explanations of commonsense entities such as people without much in the way of general laws governing their behaviour. However, if and when we do possess such theories, the explanations derivable from these theories must take precedence over our commonsense explanations." ${ }^{617}$ This is the position in which human history finds itself. For even a profoundly historical discipline like paleontology has the myriad theories and processes of biology to help decide where any given fossil might fit into the history of life on Earth. Human history would seem to have no such advantage. We might argue that the Battle of Austerlitz is a historically significant example of the class "battle," but we have no general theory of battles in order to legitimate this. This is essentially what Jeffares is arguing when he states that "historical sciences do use regularities." ${ }^{618}$ Human history, it would seem, does not. Or, at least, not to anything like the same extent. The question is: is this enough to exclude history from the sciences?

Fortunately, there are good reasons to think that some degree of reconstruction/ event causation is unavoidable in any example of historical science. In order to illustrate this, let us consider once again the example of the K/T extinction. The best currently available theory of that event argues that it was the result (at least in part) of climate change caused by a meteor impact. Explaining the $\mathrm{K} / \mathrm{T}$ extinction in this way, however, requires invoking the meteor strike as a particular - a unique event. And any particular is, by Hull's own argument, a potential central subject. If we therefore examine this meteor strike as a central subject in itself, the picture changes. At this level, the laws and processes involved become much more immediately relevant. Why did the meteor disrupt the climate? Because the kinetic energy it possessed coming into the atmosphere had to go somewhere when the Earth's surface brought it to a halt. The result was that energy causing part of the Earth's crust to temporarily change places with the sky. We know that particulates in the atmosphere can impact the climate, and so it is reasonable to conclude that this is was the result. These are all processes which are quite generalisable and very well understood. Yet the uniqueness and contingency involved in this event are never eliminated entirely. That is, while we might say that that meteor killed the dinosaurs, an identical meteor

617 Ibid., pp.77-78.

618 Jeffares, Testing Times. p.7. (emphasis added) 
arriving, say, five hundred million years earlier - while obeying the same physical laws - could not have had the same effect, for there were not yet any dinosaurs to kill. Thus, from the interaction of a well understood set of processes and laws, we have generated a particular with a clear element of contingency, despite our knowledge of those laws and processes. More importantly, we have generated a particular we can use in an explanatory capacity. Part of the explanation for the extinction of the dinosaurs (if the meteor impact hypothesis is correct) must be that a meteor struck the Earth at a particular time and in a particular location. This is the "actual sequence" part of the explanation. We can be quite sure that the meteor obeyed the relevant laws and set in motion the appropriate processes. Yet, in order to have had the additional effect of killing the dinosaurs, it had to have struck at that time. Thus we are still dealing with the underlying structures of nomothetic science - just at a single step removed. We have merely added a narrative explanation as an intermediate link - "that piece of debris, acting according to those laws, entered the atmosphere at that time, and struck in that place."

An event significant to the historian can therefore be understood as a process localised to a single occurrence. A significant meeting in the life of an historical actor, or a contingent event which derails a causal chain, can be understood as causally significant in exactly the same way as a known process or law might. This kind of event causation does not therefore pose a serious problem for the application of Hull's narrative model to human history. The reason for this is because singular events and objects themselves qualify as central subjects, and are thus explicable by the narrative process. Thus there is the possibility of recursion within Hull's model. We can use one narrative object - a central subject - as part of the explanation for another. This essentially gives scientific meaning to Danto's observation that narrative sentences function as particularistic theories and can themselves be collected together to render larger narrative constructions. Moreover, such particular historical moments, as Hull himself points out, are reconstructed by the historian from empirical evidence - "records." And records, he continues, are generated by "ordinary lawful processes." 619 Thus, we can construct a model of explanation the consistency of which is maintained by the assumption that our narrative constructions must ultimately cite, as Jeffares argues, "causal processes that are within the domains of the sciences." ${ }^{620}$ All that is required to satisfy Hull's model of 619 Hull, 'The Particular-Circumstance Model of Scientific Explanation,' p.72. 620 Jeffares, Testing Times. p.30. 
narrative is that, if we follow this chain down far enough, we reach general processes, theories and laws eventually. If we are to claim, in other words, that only the rules of science permit us to infer past events from present evidence, then we must also be ready to admit that some of those "rules" might actually be narratives. This allows us to give scientific meaning to, for instance, Kosso's claim that the generality of accounting claims is not directly proportional to their explanatory usefulness. This wrinkle in Hull's vision of narrative, however, has significant implications for how narratives are made answerable to evidence. And so it is to this final question of confirmation that we now turn.

\section{Carol Cleland, the Asymmetry of Causation, and Confirmation by Consequences}

What kind of confirmation logic does the theory of narrative we have so far advanced require? We already have a place to begin looking for an answer to such a question. T. A. Goudge, it will be recalled from Chapter Five, hinted at a method for long-term confirmation by consequences through what he called "negative predictions." ${ }^{621}$ And we have already shown how it was something very much like that method which was ultimately used to dismantle A. S. Romer's theory of tetrapod evolution. The question before us now is: can this vision of "negative" prediction be developed into a fully fledged logic of confirmation which is applicable to all historical study? This is a critical issue, for without such a generalisable method we will have no way to test our narrative theories for accordance with reality. This will effectively render our entire model of narrative useless. The remainder of this chapter, therefore, will be devoted to outlining how just such a general model of confirmation has emerged from the work of the philosopher of science Carol Cleland. Before we begin the work of exploring this mechanism, however, let us be clear about the criteria it must satisfy if it is to be of use to us. First, it will have to be compatible with the model of narrative we have just outlined. More importantly, it must be able to cope with the particularistic causation and nested narrative structures which we have argued are required for a model of narrative flexible enough to include human history. Second, we should be able to show that such a logic is somehow required, rather than merely a post hoc convenience. That is, it should be a demonstrable consequence of some fundamental feature of the world. And lastly, it should satisfy our requirement for nomothetic compatibilism. To this end, let us briefly return to the

621 T. A. Goudge, 'Causal Explanations in Natural History.' The British Journal for the Philosophy of Science. Vol. 9, No. 35 (November 1958). p.197. 
work of Benjamin Jeffares. Jeffares, in summing up his conception of narrative, offers us the following definition:

Narratives thus have the following character. They document the changes in state in a central historical subject. Those changes in states will be the result of the operation of particular processes. We may well speculate that processes are operating in tandem rather than sequentially. These processes might work at different levels and invoke causes from quite different domains. Volcanism and erosion are two rather different processes, and in a narrative recounting the formation of a volcanic island, we may well invoke both processes. Each process may well be linked to the final state of the island in its own way. ${ }^{622}$

As per the previous section, we will wish to make some revisions to this. For instance, we will need to acknowledge some degree of contingency by allowing for event causation. As well understood a process as volcanism might be, in other words, we must treat volcanic activity in that time and that place as (at least in part) a contingent event. We might also wish to add the observation that we can achieve such an explanation of why volcanic activity occurred in that time and that place by taking it as a central subject of its own, and inferring and/or reconstructing a narrative regarding the processes and events which caused it (and only it). This is what is meant by narratives being able to be nested in recursive structures. In addition to allowing narrative to become a much more flexible explanatory model, however, this nesting process also confers additional benefits for the process of confirmation. Jeffares continues:

At this point, we can begin to see how we can isolate our epistemic tasks, for tasks they are. In effect, we can break down our narratives into a string of processes or transformations. Each process can be viewed independently for the purposes of confirmation... A narrative is made up numerous sub explanations, all dealing with single transformations from one state to another. ${ }^{623}$

We do not need, in other words, to confirm an entire narrative at once. "The benefits," Jeffares argues, "of viewing a narrative in Hull's way, as a series of transformations, are that we can instead try to confirm individual nodes, the individual transitions within a narrative." ${ }^{624}$ That does not mean, however, that we can only confirm or disconfirm narratives at the level of minutiae. For not all "individual nodes" are of equal causal/explanatory importance. In Chapter Five, it will be recalled, various attempts to gather support for or against Romer's hypothesis were examined. All were, to use Jeffares' terminology, individual nodes in Romer's

622 Jeffares, Testing Times. pp.30-31.

623 Ibid., p.31.

624 Ibid., p.32. 
postulated narrative. Some, however, could be accounted for by only slight modification of Romer's account. Others - specifically, evidence gathered from Acanthostega and Tiktaalik - could not. This tells us that the choice of individual "nodes" or "transformations" is of profound importance when seeking to confirm a narrative. For if we don't have to confirm an entire narrative at once, nor do we have to confirm every single "sub explanation" either. A well chosen node will have disproportionate confirmatory power. This realisation is of crucial importance for the logic of historical confirmation.

The other requirement for building a logic of confirmation recalls the arguments of Peter Kosso. Kosso's argument, it will be recalled, was essentially that "observation" as a scientific term is not strictly a function of spatial and/or temporal proximity, but is instead a term that implies a chain of "accounting claims" which bring information from the event/object in question to the observer. In this sense, one cannot say that physics studies the observable and history the unobservable. For both disciplines have accounting claims between them and their observations. For the physicist it might be the relevant theories of light propagation and microscopy, and for the historian it might be the geology of fossilisation. In both cases, the term "observation" remains appropriate. From Kosso's viewpoint, therefore, one cannot distinguish physics from paleontology on the basis of observability. How then is such a distinction to be made? As this thesis has argued at various points, we can distinguish the nomothetic from the historical sciences with reference to intent. The nomothetically oriented sciences are interested in extracting generalities from their events/objects of interest. Because of this focus on what events/objects have in common, these disciplines are able to enjoy the advantages of experimentation. For, if we are ultimately interested in what properties all examples of an event/object share, then any single instance of that event/object will do. As Jeffares' argues, "the chemist can repeatedly observe the solubility of sugar in warm tea without having to reconstitute her sugar cube: another sugar cube will do the same job." ${ }^{625}$ Moreover, any generalities discovered in the course of such investigations should be as equally applicable to future instances of sugar dissolution as to those in the past.

The historical sciences, by contrast, are interested in aspects of the world which are singular and unique. But experimentation is logically of limited use to such sciences.

625 Ibid., p.14. 
If the aforementioned chemist had some reason to be interested in that particular sugar cube, for instance, then another one would not, by definition, "do the same job." Of course, it is difficult to imagine how we could come to have such an interest in a particular sugar cube. Consider instead the geologist who wishes to know how a particular rock formation came to be. In such cases, experimentation is impossible. For if a central subject really is an individual, there is definitionally no other example of it. This leaves little option but to attempt to unravel the causes of the central subject itself. The question that needs to be asked in such cases is: what causal events and processes interacted to produce this particular formation? We must, in other words, examine the subject with a narrative. This leads us neatly to Hull's "Particular-Circumstance" model, as previously examined. If we are to treat central subjects as historical entities, however, we must now ask whether there is some feature common to all historical enquiry which we might exploit for confirmation purposes. This property must be exceedingly broadly defined in order to cover all possible central subjects - which might, after all, be any individual unique under a description, from Protestantism to The Himalayas to Australopithecus Afarensis.

A good candidate for such a process is the observation that, in any example of historical explanation, we are engaged in a process by which we are postulating a pattern of past causes for evidence observed in the present. This is the case whether what is being explained is a rock formation, an archaeological site, a collection of fossilised remains, or a written document. Indeed, this is even the case when attempting to account for a central subject which no longer exists. For even to hypothesise that it once existed presupposes that we have some present reason to think it did. What makes historical sciences historical, then, is this postulation of a particular past cause (or pattern of causes) for observable contemporary evidence. In this sense, our narratives are essentially particularistic theories of how that particular constellation of contemporary evidence was produced. As the philosopher Carol Cleland has argued:

The focus of historical research is on explaining existing natural phenomena in terms of long past causes. Two salient examples are the asteroid-impact hypothesis for the extinction of the dinosaurs, which explains the fossil record of the dinosaurs in terms of the impact of a large asteroid, and the "big-bang" theory of the origin of the universe, which explains the puzzling isotropic three-degree background radiation in terms of a primordial explosion. Such work is significantly different from making a prediction and then artificially creating a 


\section{phenomenon in a laboratory. ${ }^{626}$}

This language of theory - seemingly common to all historical practice - would thus seem to be a good place to attempt to ground a similarly pervasive logic of confirmation for all historical enquiry. For it is precisely this direction of reasoning from present evidence backwards to past causes - which underlies not just the language of historical theory, but the entirety of narrative theory. This is in contrast to the direction of reasoning inherent in nomothetic science, which reasons forwards from causes to effects via general laws and/or theories. The question then becomes: can this unique directional feature of historical enquiry be exploited for the purposes of confirmation? Carol Cleland has argued that it can. And the unique feature which makes this possible, she argues, is the basic asymmetry between the two directions:

Localized events tend to be causally connected in time in an asymmetric manner. As an example, the eruption of a volcano has many different effects (e.g., ash, pumice, masses of basalt, clouds of gases), but only a small fraction of this material is required in order to infer that it occurred; put dramatically, one doesn't need every minute particle of ash. Indeed, any one of an enormous number of remarkably small subcollections of these effects will do. Running things in the other direction of time, however, produces strikingly different results. Predicting the occurrence of an eruption is much more difficult than inferring that one has already occurred..$^{627}$

The underlying idea here is that any single cause will almost always have multiple effects, but that the reverse is hardly ever true. ${ }^{628}$ This is what the philosopher David Lewis has dubbed the "asymmetry of overdetermination." ${ }^{629}$ And since one consequence of this asymmetry is that we do not need to catalogue every effect of a cause in order to determine the nature of that cause, this can be of immense use to the historian. Cleland invites us to consider:

... the difficulty involved in committing the perfect crime. Footprints, fingerprints, particles of skin, disturbed dust, and light waves radiating outward into space must be eliminated. Moreover, it isn't enough to eliminate just a few of these traces. Anything you miss might be discovered by a Sherlock Holmes and used to convict you. Finally, each trace must be independently erased. You cannot eliminate the footprints by removing particles of skin or, for that matter, one footprint by removing a different one. In stark contrast, preventing a crime from

626 Carol E. Cleland, 'Methodological and Epistemic Differences between Historical Science and Experimental Science,' Philosophy of Science. Vol. 69, No. 3 (September 2002). p.475.

627 Cleland, 'Historical Science, Experimental Science, and the Scientific Method,' p.989.

628 The classic example of multiple causes having a single effect is the firing squad - where multiple bullets from multiple guns all contribute to a single effect: the death of the victim. The comparative rarity of such examples, however, is compelling evidence for precisely the asymmetry that Cleland and Lewis argue for.

629 David Lewis, 'Counterfactual Dependence and Time's Arrow,' Nous. Vol. 13, No. 4 (November 1979). pp.473-475. 
occurring is easy... don't fire the gun. In other words, erasing all traces of an event before it occurs is much easier than erasing all traces of it after it occurs. ${ }^{630}$

More importantly, there are good reasons to believe that this particular feature of causation is a fundamental feature of the universe - or at least the universe above the quantum level. Its source has been the subject of some speculation, Cleland notes, but "there is general agreement... that it represents an objective and pervasive physical phenomenon at least at the macro-level of nature." ${ }^{631}$ And it is this pervasiveness, Cleland argues, which provides not only a confirmation logic for historical science, but also a philosophical justification for why historical enquiry must proceed in the manner it does. "Scientists engage," Cleland argues, "in two very different patterns of evidential reasoning and, although there is overlap, one pattern predominates in historical research and the other pattern predominates in classical experimental research." 632 As this thesis has often had occasion to observe, the perceived inability of historical research to fully utilise either the logic (laws) and method (experiment) of classical science has been at the root of either its perceived epistemic inferiority or its rhetorical banishment from the realm of the sciences altogether. Cleland, on the other hand, argues that it is "not an accident that historical research emphasizes one pattern and experimental research the other." More specifically, she argues that not only the existence but the character of both the narrative and the nomothetic modes are underwritten by this asymmetry of causation, and that, as "each practice is tailored to exploit the information that nature puts at its disposal, and the character of that information differs, neither practice may be held up as more objective or rational than the other." ${ }^{633}$ Let us now see how such claims might be given substance.

As Jeffares has already argued, classical experimental/nomothetic science proceeds from the desire to isolate what events/objects have in common, rather than what makes them unique. As Cleland states it, the "hypotheses investigated in classical experimental science postulate regularities among event-types." ${ }^{634}$ If we are interested in the properties that all sugar cubes share, in other words, then "any sugar cube will do." This leads logically to an emphasis on repeatability and

630 Cleland, 'Methodological and Epistemic Differences between Historical Science and Experimental Science,' pp.487-488. (emphasis in original)

631 Cleland, 'Historical Science, Experimental Science, and the Scientific Method,' p.989. See also:

Cleland, 'Methodological and Epistemic Differences between Historical Science and Experimental Science,' pp.489-490.

632 Cleland, 'Methodological and Epistemic Differences between Historical Science and Experimental Science,' p.474.

633 Ibid., p.476.

634 Ibid. 
predictability. For if "any sugar cube will do the same job," then we might repeat the dissolution as many times as we have sugar cubes. Moreover, we can also assume that any general pattern we notice will hold as well tomorrow as it did today. In this sense, predictions can be made for future cases which are as yet unexamined. This is the most basic justification for the structure of nomothetic science. The historical sciences, on the other hand, have no such generalising aim. To use Hull's language, they seek to establish (by both inference and reconstruction) the causes and contingencies which have given rise to some central subject. Our only stricture is that the central subject in question must be an individual, at least in the sense in which the enquirer is interested in it. How this is done, Cleland argues, might vary between disciplines, but always reduces to the postulation of past causes as an explanation for presently observable evidence. Thus, as Cleland puts it, "the hypotheses of prototypical historical science differ from those of classical experimental science insofar as they are concerned with event-tokens instead of regularities among eventtypes." This singular focus, Cleland argues, "helps to explain the narrative focus of many historical explanations." ${ }^{635}$ Of course, in the ideal narrative - as we have argued from Hull's model - we would still be able to derive each causal transformation of the central subject from some law or theory. Thus, the difference between the narrative and nomothetic would be merely semantic. However, as Cleland notes:

The complexity of the causal conditions and the length of the causal chain (connecting the cause to its current traces) bury the regularities in a welter of contingencies. Accordingly, it is hardly surprising that historical explanations often have the character of stories that, lacking reference to specific generalizations, seem inherently untestable. ${ }^{636}$

The presence of contingency, in other words, acts to complicate the operation of narrative in its ideal form. The required emphasis on particularity complicates matters even further, as it largely precludes the possibility of the kind of repeatable experimentation which would allow the separation of contingency from regularity. Thus the historical scientist is forced to try to work out, without the benefit of experiment, precisely that mix of contingencies, events, objects, processes, theories, and laws which combined to produce the constellation of evidence in which they are interested. They do this by producing narratives which relate the impact of these various forces upon the particular they are interested in - their central subject. They are, however, deprived of a means to isolate their central subject - or a system

635 Ibid., p.480.

636 Ibid. 
identical to it - and vary the causal influences at work one by one in order to determine their influence. The crucial question therefore remains: how can we responsibly speculate as to whether the narrative we have postulated is correct. This is the last remaining argument by which human history and the historical sciences might plausibly be shown to be logically inferior.

Cleland's answer to this question is broadly similar to the confirmation by consequences we briefly sketched in Chapter Five. Instead of prediction and experiment, Cleland argues, historical scientists "focus their attention on formulating mutually exclusive hypotheses and hunting for evidentiary traces to discriminate among them." The ideal goal of such an enterprise is to find what Cleland calls a "smoking gun." A smoking gun, she argues, "is a trace(s) that unambiguously discriminates one hypothesis from among a set of currently available hypotheses." ${ }^{637}$ More precisely, we seek an evidential consequence (trace) that should be exhibited by only a subset of the available narrative hypotheses. If it is found, then we have generated a reason to accept only those hypotheses which require the presence of that consequence/trace. In this sense, a smoking gun is nothing more than a particularly well-chosen evidential trace which exhibits disproportionate confirmatory power. A piece of evidence, in other words, that a narrative cannot be restructured around. An example of this was seen in Chapter Five. As we saw, the evidence which steadily accumulated over the course of the twentieth century calling into question Romer's assumptions regarding the climate of the Devonian era was not sufficient to disprove his main hypothesis. In Cleland's terms, we might say that the discovery that the Devonian climate was more temperate than had previously been thought was not a smoking gun. What was a smoking gun, however, was the subsequent discovery that early tetrapods possessed rudimentary limbs - or, more accurately, structures which would become limbs - yet could not have used these limbs for terrestrial locomotion. This represented a fundamental repudiation of Romer's hypothesis that limbs evolved in tetrapods specifically for terrestrial locomotion. We are driven instead to accept one of the alternative classes of hypotheses which postulate that the structures which became limbs in the first tetrapods evolved while the ancestor organisms were still exclusively water-dwelling. Cleland's model thus captures extremely well the kinds of confirmatory operations we saw in Chapter Five. All that remains is to tie this method to the asymmetry of causes. This must be done, as we have already

637 Ibid., pp.480-481. 
discussed, in order to meet the objection that the narrative method is merely a post facto rationalisation for the inferiority of historical enquiry to the experimental method.

Cleland argues that this difference in both methodology and confirmation structure is not merely arbitrary, but is a necessary consequence of the asymmetry of causation. In order to establish this, she returns to the most basic distinction between experimental and historical enquiry - that of the direction of reasoning. Despite their clear interrelationship, Cleland argues, the asymmetry of causation forces vastly differing methods on the two modes of explanation because the path from causes to effects is rarely identical to the path in the other direction. Recall Cleland's earlier example of a volcanic eruption. An eruption, she argues, has many more and different effects than causes. Moreover, given that any given cause is likely to have multiple effects, we do not need to catalogue all possible effects in order to infer that a particular eruption occurred. Reasoning in this direction, however, is necessarily particularistic. This is because finding ash deposits from Mount Saint Helens cannot and does not constitute evidence for the eruption of Mount Pinatubo. Remaining in the particularistic realm, it is also plain that predicting any particular volcanic eruption that is moving from causes to effect - is much more difficult. As we have already observed of particularistic (and thus narrative) explanations in general, there are so many potential interlocking causes and contingencies that contribute to any particular volcanic eruption that prediction becomes effectively impossible. This is the asymmetry of causation in action. When compared to the difficulty of prediction, it is much easier to show that a particular eruption has already taken place. This is why particularistic explanation is far more suited to reasoning backwards from effects to causes. We require only some of the multiple effects to infer back to a volcanic eruption. On the other hand, although the causes of the eruption might be fewer in number, we would need absolutely all of them - including contingent events - in order to have predicted it. Given that this is the case, we should logically expect this historical method to only be useful when reasoning in one direction - from effects backwards to causes. Thus, the asymmetry of causation helps us explain the methodology of historical research. It tells us two things, Cleland argues: "that a strikingly small subcollection of traces is enough to substantially increase the probability that a past event occurred, and that there are likely to be many such subcollections." Thus, she concludes, the "existence of so many different reliable 
possibilities for identifying past events provides the rationale for the historical scientist's emphasis on finding a smoking gun." 638

By contrast, the experimental/nomothetic sciences are forced to proceed very differently. For given the difficulty of predicting particular events in advance enforced by the asymmetry of causation, the experimentalist faces the problem of trying to isolate which contributing causes had which effect - as well as which were necessary for the effect to occur and which were not. This is because, Cleland argues, while effects overdetermine their causes, causes do not overdetermine their effects:

A good example is a short circuit that "causes" a house to burn down. Take away the short circuit and the house wouldn't have burned down; the short circuit "triggered" the fire. But the short-circuit isn't sufficient for the occurrence of a fire. Many other factors are also required, e.g., the presence of flammable material, absence of sprinklers. The absence of any one of these additional factors would also have prevented the fire, even supposing that the short circuit had occurred. In other words, the total cause of the fire includes more than the short circuit. Local events (such as the short circuit) which are normally identified as the causes of later events (a house burning down) underdetermine them; considered just in themselves, they are not enough (even given the laws of nature) to guarantee that their reputed effects occur. ${ }^{639}$

This, Cleland argues, is the "other side" of the asymmetry of causation. That is, while "erasing all traces of an event requires many separate interventions, a single intervention... is normally enough to prevent it from occurring in the first place." By either removing flammable material, preventing the short circuit or both, we can prevent the fire. In either case, as historians, we will have little trouble inferring that a fire took place. Identifying the exact cause is slightly more problematic, but again - as historians - we are free to invoke a combination of a short circuit, flammable material, and a lack of sprinklers. If, however, we are interested in reasoning forward from cause to effect, we have a much more difficult task, as to do so we will need to disentangle these causes. We might wish, for instance, to hypothesise that a short circuit caused the fire (via well understood accounting mechanisms in physics). Because this is underdetermined, however, we cannot be sure that the short circuit alone was responsible. It could be that the combination of the short circuit and the absence of sprinklers was responsible. If that is the case, we have over-attributed causal power to the short circuit, and have failed to effectively proceed from cause to effect. However, since we cannot install sprinklers and then burn the same house

638 Ibid., p.491.

639 Ibid., p.488. (emphasis in original) 
down again, the question becomes difficult to settle. In order to guard against these kinds of false positives/negatives, the experimental sciences are forced to attempt to replicate the cause as much as is possible, while varying/eliminating other possible contributing circumstances. Because of this, experimental method is only feasible for those phenomena that can be so replicated. Therefore, the experimental and/or nomothetic sciences are much more useful, by definition, in dealing with those properties of phenomena which are constant across multiple examples. That is, we can only experiment in cases where, to quote Jeffares again, "any sugar cube will do the same job." The asymmetry of causes thus not only explains historical method, but also neatly explains the focus upon generalisation and prediction in the forwardreasoning experimental sciences. As Cleland argues:

Just as the overdetermination of past events by localized present events explains the practice of prototypical historical science, so the underdetermination of future events by localized present events explains the practice of classical experimental science. The hypotheses tested in classical experimental science are generalizations (conjectured laws and theories), as opposed to statements about particular events... But they are only partial causes (triggers) of what subsequently occurs. Accordingly, there is a need to ferret out and control for additional factors that are relevant to the total causal situation; otherwise, the ostensible confirmations and disconfirmations of the target hypothesis may be mistaken... In brief, classical experimental research is best interpreted as an attempt to circumvent the inevitable underdetermination of experimental results by test conditions. ${ }^{640}$

The focus on generalisation in the experimental sciences, however, necessarily introduces an inability to deal with contingencies. We could, for instance, build a replica of our stricken house in all details but one - a sprinkler system. A short circuit could then be induced and the result observed. We might then conclude that the short circuit alone was sufficient to cause the house to burn down. But perhaps there was some external perturbation in the original circumstances which was not replicated in the experiment. Perhaps, for instance, the weather had been extremely dry in the days leading up to the original fire, which contributed to the willingness of the house to burn. Despite the fact that weather is a system presumed to obey all known laws of science, it is - consistent with our earlier argument in adapting Hull's model of narrative for use in more traditionally historical cases - a contingency. Moreover, it is a contingency which could influence the outcome of the experiment simply by being present in the original fire but not in the recreation. And if this is truly the case, then we may end up, once again, over-attributing causal power to some other factor. All of which is to say that contingencies, almost by definition, are 640 Ibid., p.494. 
difficult to spot and control for - and their presence therefore greatly complicates experimental science. Because of this, as we saw Gould argue in Chapter Five, contingency might reasonably be considered the signature of the narrative mode. However, in order to invoke that narrative mode, we must - as we have learnt from Hull - shift our focus from the general to the particular. That is, if we are to try to account for those causal factors which were effectively unique to the original fire, then we are no longer able to make such effective use of experimentally replicated circumstances. We must instead attempt to formulate a narrative of only the events contingent and process-governed alike - which took place in the original fire. And this not only means that we are required to address our new central subject in a particularistic way, it also means that the subject of our enquiry has already taken place. Thus, we are now forced to shift the direction of our reasoning - instead of trying to reason from cause to effect, we are now reasoning from effects back to causes. In this way, the asymmetry of causes which Cleland takes from David Lewis completely underwrites the methodology of both nomothetic and narrative modes of science.

It should be noted at this point that Cleland does not go so far as to speculate on the actual form of historical explanation. She does at one point suggest that this causal asymmetry is the reason historical explanations often have a narrative form. ${ }^{641}$ But she does not examine this in any detail. Indeed, at one point, she blithely interprets the term "narrative" in purely literary terms:

... historical methodology is often characterized... in terms of narrative histories. Analysis in terms of narrative histories does not, however, do justice to historical work in disciplines such as astronomy and geology that, like experimental physical science, do not involve even a prima facie appeal to purposes or ends. A more general understanding of the methodology of historical science and its differences from classic experimental science is badly needed. ${ }^{642}$

Here Cleland appears to assume, in precisely that manner we lamented in the opening pages of Chapter Four, that the mere presence of narrative implies an ineradicable subjectivism and corresponding lack of epistemic respectability. Indeed, with such an emphasis on "purposes" and "ends," Cleland would seem to have an understanding of narrative similar to that of W. B. Gallie. It seems reasonable, however, to attribute this comment to Cleland's unfamiliarity with that more recent philosophy of science which has attempted to better define the concept of narrative. 
Regardless of her reasons, we can clearly see that Cleland's work fits in very well with the more epistemically sound conception of narrative offered by Hull and Jeffares. We might even argue that Kosso, Hull, and Jeffares have effectively already provided precisely that "more general understanding of the methodology of historical science" which Cleland so avidly seeks - and have done so through a better understanding of the very narrative she was so quick to deride.

Despite this failure of imagination, however, Cleland has nonetheless added the final piece of the narrative puzzle to the work of Kosso, Hull, and Jeffares. This is manifested in several ways. First, her dispersal of causes lends itself well to Jeffares' requirement for the conceptual separation of causal chains, and the ability to isolate individual "nodes" in a causal chain/web. Cleland's "machinery," as Jeffares terms it $^{643}$ allows us to separate the causal processes/events by which, for example, footprints were left at a crime scene from the processes/events by which fingerprints were left at the same scene. Second, Cleland has provided a non-arbitrary philosophical justification for why Hull's two complementary approaches to the same scientific reality require such radically different methods. Third, Cleland's work seamlessly exploits both the standardised language of observation offered by Peter Kosso, and the language of theory advocated by Arthur Danto. And last, she has provided the logic by which narrative explanations can be meaningfully submitted to empirical tests without fear of being labelled ad hoc. Taken together, therefore, the work of all of the authors examined in this chapter can be synthesised into a complete model of scientific narrative explanation. At each of the three steps required to synthesise it, moreover, it has been shown that this narrative model does not offer any serious conceptual resistance to the inclusion of human history among the ranks of the sciences. More importantly, it achieves this without requiring any fundamental transformation of history into the dim likeness of the nomothetic-deductive ideal. It is this last point which is perhaps the most exciting, however, for it does not merely imply that history can be a science, it implies that it essentially already is. It is this theme which we will briefly take up in the conclusion.

643 The term "Cleland's machinery" is a shorthand borrowed from Benjamin Jeffares. See: Jeffares, Testing Times. pp.41-46. 


\section{Conclusion \\ "The Future of Human History as a Science"}

The basic assertion of this thesis - that the operations of human history can be fully captured within a recognisably scientific methodology and thus require no separate epistemology - is far from new. Similar assertions can be traced back to the arguments of nineteenth century positivist philosophers such as Henry Thomas Buckle and Auguste Comte, who sought the specifically historical laws by which human societies developed. ${ }^{644}$ Even earlier still, Enlightenment philosophers such as G. W. F. Hegel and Giambattista Vico examined human history with a view to extracting from it, if not laws, then some underlying general principle. ${ }^{645}$ Such arguments have been examined and re-examined over the years, and there is no need to rehearse them again here. Suffice it to say that these approaches have fallen out of favour for the simple reason of their failure. No reliable laws of history have ever been identified - or at least none that were not simple truisms or otherwise useless in the practical work of historical explanation. Historians opposing such strong positivism, such as Johann Droysen, have long argued that it was far more profitable for history to focus on the explanation of unique and particular circumstances. ${ }^{646}$ This focus on the particular, however, was almost always presumed to automatically remove history from the possibility of ever truly belonging to the sciences. And while debate concerning the scientific possibilities of history has never completely disappeared, the failure of any one nomothetically inspired approach to realising that possibility has remained. ${ }^{647}$ This failure, coupled with the compelling arguments made by the mid-twentieth covering lawyers against the idealist notion of empathy, resulted in the transplant of the historical concern with particularity into newer narrative philosophies of history. These new philosophies, however, like their idealist predecessors, were once again predicated on particularity being the proper focus for history. Because of this, they were seen as inherently and definitionally unscientific. This lack of epistemic foundations was ultimately to lead, via the tacit association

644 Henry Thomas Buckle, Introduction to the History of Civilization in England. Routledge: London, 1904. Auguste Comte, The Positive Philosophy of Auguste Comte. $3^{\text {rd }}$ Edition. Harriet Martineau (trans). Kegan Paul: London, 1893.

645 Giambattista Vico, New Science: Principles of the New Science Concerning the Common Nature of Nations. David Marsh (trans.) Penguin Classics: London, 2001. G. W. F. Hegel, The Philosophy of History. J. Sibree (trans.) Dover Publications: New York, 1956.

646 Johann Gustav Droysen, 'The Elevation of History to the Rank of a Science: Being a Review of The History of Civilization in England by T. H. Buckle,' in Johann Gustav Droysen, Outline of the Principles of History. E. Benjamin Andrews (trans.) Ginn \& Co.: Boston, 1893. pp.61-89.

647 Notable twentieth-century works guided by such a nomothetic impulse include: Oswald Spengler, The Decline of the West. 2 volumes. A. A. Knopf: New York, 1926 \& 1928., and Arnold J. Toynbee, A Study of History. 12 Volumes. Oxford University Press: London \& New York, 1948-1961. 
between "narrative" and the pejorative sense of the term "story," to the literarynarrativist view that history was primarily a variety of fiction.

From this long history it seems reasonable to conclude that the pervasive assumption that science must be a purely generalising enterprise has had profound consequences for the philosophy of history. The basic argument that history belongs to the sciences has not entirely disappeared, of course. However, those contemporary authors who would argue that history is, or should be, scientific - the author of this thesis included - are now highly unlikely to do so based on a strictly nomothetic model of science. This is primarily for two reasons. First, for the obvious reason that all attempts to identify historical laws (or to provide non-trivial historical explanations in terms of laws from other disciplines) have been of very limited success. And second, because more recent philosophy of science has finally begun to move away from the vision of physics as the ideal exemplar of what good science should look like. For these reasons, modern arguments for the scientific nature of history are far more likely to focus on other branches of the sciences as exemplars - exactly as this thesis has sought to do. There remains, however, a crucial difference between the arguments this thesis has made and other modern arguments for the scientific status of history. For what previous approaches to the problem of scientific history have had in common is their injunction to transform history in some way in order for it to attain its scientific promise.

Among Enlightenment and nineteenth century philosophers, this transformation of history into science was usually to be achieved through the identification and application of those laws which underwrote the processes of history. The covering lawyers of the twentieth century similarly argued that genuine historical explanation should consist in showing that historical events were the logical consequence of already existing laws. Among those twentieth and twenty-first century philosophers who advocate for the reconciliation of history with the sciences, there is admittedly no such overtly nomothetic argument. There is, however, a vestigial nomothetic assumption present in their continued emphasis on some sort of generalisation as the defining goal of science. This assumption has meant that, because existing historical practice does not share this generalising aim, a requirement to transform history has remained. The implication is that whatever existing historical practice might be, it is not science. This is the key assumption this thesis has sought to challenge by offering 
a narrative view of science which is also compatible with human history as it exists now. In order to fully appreciate the arguments which have led us to this conclusion, let us close this thesis with an examination of some of these contemporary transformation requirements. It is hoped that both the examination of the nomothetic assumption in Part One, and the attempt to provide a more nuanced understanding of the sciences in Part Two, will have provided suitable context in which to appreciate the quite remarkable myopia of these arguments. Similarly, it is also hoped that the obvious contrast between the work of the previous six chapters and the arguments on offer here will help to highlight the need for change. This is not a change in the basic principles of historical method, however. For these are remarkably sound, given their epistemic history. The required change is almost entirely conceptual. That is, the only transformation that history truly requires in order to realise its scientific potential is in the way historians think about history itself and its place in the wider context of human knowledge.

\section{The Requirement for Transformation}

One of the most well-known contemporary transformative arguments for scientific history can be found in the concluding chapter of Jared Diamond's book, Guns, Germs and Steel. Here Diamond argues that a scientific practice of history is possible but that the resulting discipline would not necessarily resemble history as we now know it. He begins from firm foundations, arguing that:

... the difficulties historians face in establishing cause and effect relations in the history of human societies are broadly similar to the difficulties facing astronomers, climatologists, ecologists, evolutionary biologists, geologists, and paleontologists. To varying degrees, each of these fields is plagued by the impossibility of performing replicated, controlled experimental interventions, the complexity arising from enormous numbers of variables, the resulting uniqueness of each system, the consequent impossibility of formulating universal laws, and the difficulties of predicting emergent properties and future behaviour. ${ }^{648}$

Overtly, there is nothing to object to in this assessment. Indeed, this thesis has argued similarly. What is it then, that renders the transformation of history a requirement? Diamond's reasons are plainly stated. "One cannot deny," he argues, "that it is more difficult to extract general principles from studying history than from studying planetary orbits." However, he continues, "the difficulties seem to me not fatal." 649 648 Jared Diamond, Guns, Germs and Steel: A Short History of Everybody for the Last 13,000 Years. Vintage Press: London, 2005. p.424. 649 Ibid., p.421. (emphasis added) 
This focus on the extraction of large scale general principles is the underlying theme of Guns, Germs and Steel (the book itself is an attempt to explicate "history's broadest pattern") and neatly encapsulates Diamond's vision of what history has to do in order to become scientific. Put simply, history must do whatever is required to overcome or otherwise ameliorate any barrier to the acquisition of these "general principles." And to do this, radical transformation would be required. Most notably, history would be required to assume a much broader temporal range.

Consider, for example, Diamond's discussion of prediction. "Prediction in history," he argues, "as in other historical sciences, is most feasible on large spatial scales and over long times, when the unique features of millions of small-scale brief events become averaged out." That is, historical science should be conducted at a much grander scale, in order to allow time to smooth over and average out any contingencies. This would better allow the identification and extraction of general principles. Thus historians could, Diamond argues, "recognize factors that made inevitable the broad outcome of the collision between American and Eurasian societies after 13,000 years of separate developments, but not the outcome of the 1960 U.S. Presidential election." ${ }^{650}$ Similarly, Diamond argues for a key method in historical science as the "natural experiment," where one compares naturally occurring "systems differing in the presence or absence... of some putative causative factor." Examples of such "experiments," Diamond argues, can be found in many existing sciences, including epidemiology and cultural anthropology. ${ }^{651}$ The purpose of studying these systems, Diamond argues, is to attempt to isolate the truly general principles at work in history from the merely contingent.

The problem with such "natural experiments," of course, is that they are vulnerable to contingencies affecting their outcomes. Or as Diamond phrases it, the "confounding effects of natural variation in additional variables besides the one of interest." For Diamond's generalising view, this is potentially highly problematic. He offers no definitive answer to this concern in his highly schematic conclusion, other than to refer to the "formalized procedures" for dealing with such problems which have emerged from several similarly afflicted disciplines. ${ }^{652}$ What Diamond does make clear is that, as with his account of prediction, the effects of contingencies in 
natural experiments must be somehow eliminated in order to extract the "general principles" that are the necessary aim of a scientific pursuit. This is because cultural and individual idiosyncrasies "throw wild cards into the course of history. They may make history inexplicable in terms of environmental forces, or indeed of any generalizable causes." ${ }^{653}$ It is the avoidance of just such contaminating contingencies, Diamond argues, that makes the much broader focus of Guns, Germs and Steel (and, by extension, any subsequent scientific treatment of human history) necessary. For if one accepts the validity of the generalising impulse as the fundamental defining characteristic of science, then even the most cursory study of current historical practice makes it clear that it is not merely desirable to transform history, but required.

This line of argument also leads quite naturally to the epistemic separatism which has been an ongoing theme explored in this thesis. For if we invert this kind of transformative argument, we are then forced to ask: what exactly is the epistemic status of those countless works of history which have lined the shelves of libraries for as long as there have been libraries? For if history as it is practised isn't able to be meaningfully connected with the scientific, then what is it? As the first three chapters of this thesis have argued, this question has been absolutely central to the philosophy of history since at least the nineteenth century. And, as we have seen, while there have been some spirited defences of historical autonomy from science - there has been little success in the establishment of a uniquely historical epistemology. Such arguments have only deepened the perceived epistemic divide and contributed to the abandonment of history to the ghetto of glorified fiction. Sadly, these are not the kinds of epistemic questions contemporary advocates for scientific history have felt compelled to address. Peter Turchin, for example, is an ecologist and mathematician who, like Diamond, advocates for the scientific practice of history. However, he goes further than Diamond by suggesting that the historical discipline as we now understand it may be beyond reform. In an essay published in Nature, Turchin argues, like Diamond, for a historical science modelled after the kind of highly generalising science that has its ideal expression in universal laws. "It is time," he argues, "for history to become an analytical, and even a predictive, science." 654 Precisely what he means by this is spelt out in his analogy of "splitters" and "lumpers," which translates into a crude shorthand for the familiar particular versus general view of science:

653 Ibid., p.420.

654 Peter Turchin, 'Arise “Cliodynamics",' Nature. Vol. 454 (3 July 2008). p.34. 
Every scientific discipline has its share of splitters, who emphasize the differences between things, and lumpers, who stress similarities in search of organizing principles. Lumpers dominate physics. In biology, splitters, who care most for the private life of warblers or the intricate details of a chosen signalling molecule, are roughly matched by lumpers, who try to find fundamental laws. Social sciences such as economics and sociology are rich in lumpers. Sadly, few are interested in applying analytical approaches to the past. History has an alarmingly small proportion of lumpers. ${ }^{655}$

Rather than transform this discipline of "splitters," however, Turchin suggests that it might be more beneficial to found an entirely new discipline, which he calls "theoretical historical social science" or "cliodynamics." "Let history continue to focus on the particular," Turchin argues. Cliodynamics, on the other hand, would "develop unifying theories and test them with data generated by history, archaeology and specialized disciplines such as numismatics." Turchin confronts the problem of contingency by arguing, like Diamond, that it is not fatal. For if it were true that contingency and complexity completely obscured any possible patterns in history, he states, "there would be no empirical regularities" available to find in any historical data of any kind. And this, Turchin argues, is simply not the case. The task of this "cliodynamics," then, is to identify such patterns and attempt to ascertain their causes. ${ }^{656}$

With respect to both of these authors, it must be clearly understood that their approaches represent extremely powerful methods with the potential to deliver real and useful results. The patterns Diamond, Turchin, and their colleagues have identified are quite real, even if their causes are still open to debate. Moreover, there can be no meaningful counter to Turchin's assertion that "not everything in history is contingent and particular." Both Turchin and Diamond are much better placed to seek and find structural regularities in the operation of history than any past positivist or covering lawyer, simply because they know where and how best to look. Moreover, it is doubtful that either author would give any regularities found by such methods so grandiose a title as "law." Indeed, nowhere in Turchin's essay, or in Diamond's entire book, do they speak of their conclusions in terms of laws. This alone, represents a vast improvement over the narrow nomothetic focus of the positivists and the covering lawyers. Instead Diamond and Turchin talk of "pattern" and "dynamics." This is a far more productive way to talk.

655 Ibid.

656 Ibid., p.35. 
What is problematic, however, is the insistence by both Turchin and Diamond that it is only this generalising, large-scale approach to history which can be called scientific. For by emphasising the desirability of highly general conclusions in which the contingent and particular have been stripped away, both Turchin and Diamond are forced to advocate the pursuit of methods capable of achieving this. These are, necessarily, those statistical methods which rely on large periods of time and space to smooth out the effects of the contingent. However, by only allowing for science as a generalising enterprise and thus seeking to ape the apparatus of the experimental method as far as possible, Turchin and Diamond are required to abandon existing historical practice almost entirely. Diamond argues in his opening pages, for example, that "it is impossible to understand even just western Eurasian societies themselves, if one focuses on them." For him, the "interesting questions concern the distinctions between them and other societies." ${ }^{657}$ But this represents a turning away from a truly staggering amount of information - nothing less than everything which can be said with any certainty about the history of the nations of western Eurasia without reference to other societies - the only failing of which is a stubborn resistance to (or irrelevance within) generalising abstractions. Moreover, it begs a further question: can the work of history as we now know it be called knowledge at all? While both Turchin and Diamond are formally silent on such questions, there is a clear implication that, whatever current history might be, it is beneath the concern of science. Turchin, for instance, concludes his essay as follows:

We must collect quantitative data, construct general explanations and test them empirically on all the data, rather than on instances carefully selected to prove our pet narratives. To truly learn from history, we must transform it into a science. ${ }^{658}$

This is as clear a dismissal of existing historical practice as one might want, as well as an expression of contempt for the narrative form. This implicit charge of bias and sophistry is, of course, potentially valid. Narrative explanation is certainly capable of such error. This is especially true when contemporary assumptions that it is little more than a form of literature ensure that it is never held to any higher standard! But this raises the question of how we can know anything about particular things at all. For if the kind of generalised knowledge Turchin has in mind is all that really counts as knowledge, then it would seem that human beings might be said to know very

657 Diamond, Guns, Germs and Steel. p.11. 658 Turchin, 'Arise "Cliodynamics",' p.35. 
little indeed. If science can only function on this general level, can anything scientifically defensible be reliably said by "splitters" without it being derived from some general principle or law? This seems unlikely, especially given the difficulty of applying such an approach in fields such as biology, geology, and archaeology. Such difficulties would seem to imply that this particularistic "splitter" knowledge is some other form of knowledge. But what other form of knowledge is there? It is in this light that Turchin's argument, while necessarily brief given the limited space available to him in Nature, appears particularly self-defeating. After all, he explicitly acknowledges in his opening paragraphs that "every scientific discipline" has "splitters" and "lumpers," and that splitters include those biologists "who care most for the private life of warblers." Presumably he is happy to still call such biologists scientists, however. Why then should those historians who choose to focus on a particular area of time and/or space be any different?

If we are to exclude from science all of those who are non-generalists, in other words, then why does Turchin allow for "splitters" within the sciences at all? More importantly, if they are to be allowed, what method is it that these scientific "splitters" are using? And whatever that method is, could it not be applied to history as well? This is precisely the question this thesis has been asking, and we have concluded that what human historians are doing shares the same underlying structure as what these "splitters" in the historical sciences are doing. More importantly, we have also argued that this underlying structure is precisely that narrative form which Turchin appears to hold in such contempt. But before we return to this point, we must briefly examine another strand of contemporary argument for the scientific transformation of history. This approach attempts to account for contingency in history in another way - by viewing history as an analogue of biological evolution. As will be shown, however, this approach is subject to the same conceptual blindness as those of Diamond and Turchin. For despite being able to accommodate something of the contingency of history and being far less focused on a classical vision of science as the pursuit of purely general conclusions, the evolutionary approach still advocates for a radical transformation of history.

\section{Evolution and Human History}

Just as the generalist approach of Diamond and Turchin did not emerge fully-formed 
from the skull of Zeus, but can be seen as merely among the most recent of attempts to effect some interface between history and the traditionally generalising vision of science, neither is the modern biological approach to the philosophy of history entirely without precedent. In the broadest sense, a biologically-inspired approach to the philosophy of history was first made possible by the publication in 1859 of Darwin's On the Origin of Species. The kinds of explanations Darwin's natural selection made possible seemed to suggest (as seen in Chapter Five) an approach to science a good deal more friendly to the historian than the more traditionally Newtonian/nomothetic mode. It was possible, in other words, for an explanation to be a good deal more historical than the ideal of physics might suggest, and yet still be scientific. This represented not an intrusion of science into history, but of history into science. As R. G .Collingwood argued in The Idea of History in 1946: "The victory of evolution in scientific circles meant that the positivistic reduction of history to nature was qualified by a partial reduction of nature to history." ${ }^{659}$ More recently, Alonso Peña has characterised the hopefulness with which Darwinian biology was greeted in the late nineteenth and early twentieth centuries as follows:

Here at last, was a scientific discipline that offered to provide the much desired rapprochement between science and history. Certainly, the new biology was a brand of science which explicitly addressed change and its mechanisms - as historians have always done. Moreover, and maybe this was its most alluring aspect, this was a type of formal qualitative science: capable of proposing hypotheses, identifying appropriate evidence, and suggesting experiments - all without the need of mathematics. As it were, this was a sort of reconciliation between the strictness of Newtonian physics and the chaotic human world with which historians habitually dealt. ${ }^{660}$

Since Darwin there have been a number of attempts to realise the goal of a scientific history through the incorporation of elements from evolutionary biology. However, none have resulted in a lasting, defensible vision of the relationship between science and history. As Peña puts it: "passing through the vast edifices of Spencer, Marx, Spengler, and Toynbee, we know now that this project was not successful. The social versions of Darwinian evolution were either too general, too simplifying, or too unfalsifiable to be properly regarded as a brand of 'scientific history."”661 Spencer's "social" Darwinism, for instance, attempted to apply evolutionary insights to human

659 R. G. Collingwood, The Idea of History. Revised Edition. Oxford University Press: Oxford, 1994. p.129.

660 Alonso Peña, 'On the Role of Mathematical Biology in Contemporary Historiography,' History and Theory. Vol. 38, No. 4, Theme Issue 38: The Return of Science: Evolutionary Ideas and History (December 1999). p.102. (emphasis in original) 661 Ibid. 
societies, arguing that the actions, both conscious and unconscious, of both individuals and societies as a whole were in actual, non-metaphorical, Darwinian competition. Despite these failures, as Chapter Five has shown us, there nevertheless remains much agreement between the methods by which both history and evolutionary biology proceed. The prospect of harnessing history to biology has therefore remained extremely appealing. The real question, however, is this: what is it that makes the two so similar? Is it because the facts of biology and human evolution are being directly and non-metaphorically expressed in human history? Or are they merely linked by some deeper common explanatory structure? This thesis has argued for the latter, and has attempted to offer an account of what that common explanatory structure is. As Matthew H. Nitecki, in the introduction of a volume entirely devoted to exploring the convergences between history and evolution, has eloquently argued:

The common element of evolutionary biology and history is the concept of change through time. Historians and evolutionary biologists seek to picture changing and dynamic processes, as they desire to reconstruct life from the remains of death. The historian gathers the extant fragments of past events, and imaginatively rebuilds those events from a few documents, some old letters, or from the pieces of cracked pottery. The evolutionist, such as the paleontologist, does precisely the same. From rock splinters bearing the dull imprint of once vivid organisms, one brings back to conceptual life whole populations - teeming hordes of strange creatures. Out of historical evidence the past is made present, whether the past is Caesar crossing the Rubicon or a trilobite crawling across the bed of a Paleozoic sea. In both cases historical explanations are similar and either none is, or both are, equally "good science"...662

The ways in which the analogy between history and evolution have actually been pursued, however, have been less than satisfactory. This is because, at least in the philosophy of history, such arguments from analogy have almost universally proceeded from biology into history. That is, attempts have been made to show that biological concepts crucial to evolution were being directly expressed in human history. Very rarely was any attempt made to proceed in the other direction. Rarer still was any attempt to identify the common form underlying both kinds of explanation. The prevailing assumption still seemed to be that biology was already a science, and if history wanted to be one too, it had best adhere as closely as possible to biological forms of explanation. And if there was a natural partnership between the two, then it was biology which was to be the dominant partner. It was, after all, closer to real

662 Matthew H. Nitecki, 'History: La Grande Illusion,' in Matthew H. Nitecki \& Doris V. Nitecki (eds), History and Evolution. State University of New York Press: Albany, 1992. p.6. (emphasis in original) 
science. Thus, despite the fact that evolution did potentially contain some key insights into how a science could look and act like while still being called a science, these insights were too often missed. The attempt to fashion history into the likeness of physics was replaced not with a more nuanced vision of science, but with an equally misguided attempt to subordinate history to biology.

A contemporary example of this style of reasoning can be seen in the work of William H. McNeill. McNeill was not primarily a philosopher of history, but was a pioneer in the field of modern large-scale environmental history - a then-emerging field which made the relationship between history and science of particular relevance. McNeill has detailed something of his views on the relationship of history and evolutionary biology in a 2001 paper entitled 'Passing Strange: The Convergence of Evolutionary Science with Scientific History.' ${ }^{663}$ In this paper, McNeill argues that the Darwinian revolution in biology was a part of a larger shift, in which the "old certainties of the Newtonian world machine" were "dissolved into an evolving, historical, and occasionally chaotic universe." McNeill is, in other words, not merely content to extend the evolutionary worldview by analogy to history, but to all of science. But, McNeill claims, there is a fundamental historicity which underlies the evolutionary worldview, and so it is really history, as opposed to physics or any other branch of the "hard" sciences, which is the most fundamental of disciplines. "It is time," he argues, "for historians to take note of the imperial role thrust upon their discipline by making a sustained effort to enlarge their views and explore the career of humankind on earth as a whole, thus making human history an integral part of the emerging scientific and evolutionary worldview." ${ }^{664}$ In order to be truly scientific, McNeill argues, history need not seek or apply laws, but it must orient itself in such a way as to allow its conclusions to fit neatly with those of these other scientific disciplines.

But despite this promising start, it quickly becomes clear that, despite the prominence he claims to give to history, McNeill actually requires a transformation of history through the wholesale importation of concepts from biology. At one point in his paper, for instance, while focusing on the perceived uniqueness of human language and its ability to accurately transmit meanings between individuals, McNeill argues that languages (and the ideas they express) are the appropriate focus

663 William H. McNeill, 'Passing Strange: The Convergence of Evolutionary Science with Scientific History,' History and Theory. Vol. 40, No. 1 (February 2001). pp.1-15. 664 Ibid., pp.1-2. 
for human history. And the manner in which historians should deal with this fact, McNeill claims, is broadly Darwinian:

What makes humans different from other forms of life is our capacity to invent a world of shared feelings and symbolic meanings and then act upon them in concert. Across the millennia of human life on earth, cooperative effort among larger and larger numbers of human beings proved capable of getting desired results more or less dependably. Moreover, agreed-upon meanings associated with any new skill or idea that worked better than before tended to spread and alter the way humans did things. Shared meanings, in other words, were capable of rapid evolution, radically outpacing older biological processes of genetic mutation and selective survival. ${ }^{665}$

This is an example of transfer by analogy. Such transfers can often be theoretically justifiable. Which is to say, McNeill's assertion cannot, and should not, be summarily dismissed as empirically suspect. It could very well be that McNeill - along with many other biologically inspired philosophers of history who hold similar views, are correct. The truth or falsehood of the assertion that the propagation of cultural ideas can be well understood using ideas borrowed from natural selection is not at issue at least not in this thesis. What is more important for our purposes is McNeill's less overt assertion. For it seems that, for McNeill, if history is the fundamental form of knowledge - then the fundamental form of history itself is Darwinian. The "process of symbolic evolution" he writes, "does not appear to be fundamentally different from biological evolution any more than biological evolution was fundamentally different from the physical and chemical evolution of the cosmos that preceded it." ${ }^{666}$ If this is true, it is implied, then historical knowledge can only be considered scientifically legitimate when it is offered in Darwinian form. Thus, despite the fact that evolutionary biology seems to offer, as Peña reminds us, a way to scientifically conceptualise change without the need for nomothetic and mathematical methods, its use was often taken to imply a requirement for history to be radically transformed in the likeness of science. "We must apprentice ourselves to the natural scientists," McNeill wrote, "and imitate them in making bold hypotheses if we are to understand the human career on earth more fully and develop ideas worth sharing with our scientific contemporaries." 667

At this point it might be objected that this thesis itself is guilty of a similar biological reductionism with respect to the example of tetrapod evolution given in Chapter

665 Ibid., p.7.

666 Ibid.

667 Ibid., p.6. 
Five. While informed by evolution, however, our example was not wholly determined by it. Further still, we might argue that the $\mathrm{K} / \mathrm{T}$ extinction, while invoking an evolutionary component in order to explain why species which depended upon a certain set of environmental conditions could not flourish in their absence, was just as much a narrative of the particular physics of a large mass moving in space. At this point, we need to ask what is doing the explaining in such narratives, and we are forced to conclude that it is not only evolution. The citation of evolution, in other words, is not what makes the $\mathrm{K} / \mathrm{T}$ narrative explanatory. And if this is the case, what then is the effective difference between a narrative theory regarding the processes and contingencies which led to the evolution of language, and a narrative theory which attempts to articulate the processes and contingencies which led to the fall of the Berlin Wall? What makes one scientific and the other not? For McNeill, it is because he has decided that Darwinian evolution is science, and if history proceeds through its cultural analogue, then it must be so as well. But this can only be an arbitrary choice. Could we not decide that only explanations which took the form of those in geology at some level were scientifically legitimate? Or archaeology? Or, in the classic nomothetic example, physics? After all, exactly the same selection of physics as the "proper" science to which all others should aspire has historically underpinned the entire nomothetic/covering law argument.

Darwinian evolution has much to recommend it to the historian, and it is certainly a far better fit than strictly nomothetic physics. But rather than slavishly trying to apply it to history, we should be asking just how it is that evolutionary biology goes about the business of explanation. More importantly, we must ask what status existing historical knowledge is to have if it cannot be rendered in Darwinian terms. For it seems clear that, just as was the case with Diamond and Turchin, much of what now constitutes history could find no home at all within a discipline which emphasises finding Darwinian analogues in human culture. Of course, it is important to once again stress that there is nothing fundamentally objectionable about this kind of Darwinian thinking. That is, McNeill's convergence of the sciences is real enough (if perhaps not of as messianic an importance as he might imagine). Moreover, just as was also the case with Diamond and Turchin, there are valuable insights to be gained from this kind of large-scale evolutionarily informed history. And there are good arguments which can and have been made for the applicability of the evolutionary analogy to culture. What is problematic is what such arguments and analogies omit - 
history as it is practised now.

\section{Final Words}

This thesis has been, in the broadest sense, an attempt to try to speak on behalf of that neglected historical knowledge. And it has done so not by attempting to transplant superficially similar methods and ideas from more "respectable" sciences like evolutionary biology into human history, but by seeking the underlying explanatory structure which makes evolutionary biology analogous to history in the first place. In these pages we have sought to show how the current meaning and practice of history - that which is left out in the cold by those transformative approaches to history - can be preserved, yet also realised as having the same fundamental narrative structure as that underlying not only evolutionary biology, but also such disciplines as geology, paleontology, and archaeology. For this purpose, the question of whether or not large-scale processes can be determined across continents, or whether culture can or cannot be understood as memetic, is simply irrelevant. As mentioned earlier, it is not the invocation of some aspect of a more well-accepted science - whether physics or biology - which makes historical explanation legitimate. For why should historians limit themselves to writing in some narrow evolutionary mould? Surely what it really means for history to be a science is for it to have access to any and every tool that other scientific fields have to offer, to be deployed in the service of that particularistic way of talking about the past which historical questions so often demand. We must take the best examples of knowing available to us and, rather than slavishly attempting to apply their language and methods to history, determine instead the underlying form they instantiate. Recall Nitecki's description of the convergence of history and evolution:

Out of historical evidence the past is made present, whether the past is Caesar crossing the Rubicon or a trilobite crawling across the bed of a Paleozoic sea. In both cases historical explanations are similar and either none is, or both are, equally "good science"...668

We have argued that it is a common method of explanation - narrative - which produces this convergence. Thus, if we are to call the work of the paleontologist science, then we must say the same of the historian. For it is the contention of this thesis that empirically justifiable knowledge, wherever it is found and whatever form

668 Nitecki, 'History: La Grande Illusion,' p.6. (emphasis in original) 
it takes, must - definitionally - be scientific knowledge. And, since historical accounts do explain and can be tested, our definitions of science ought to cover them. Thus, we require a definition of science which can cover history without the requirement for radical transformation (whether this transformation is to be on the part of science or history is immaterial). That such a definition exists, can account for the contingency of historical explanation, and exists without breaking the successful nomothetic structures of science was the argument of Chapters Five and Six. What does such a definition require us - as historians - to concede? Comparatively little. We must abandon only that outdated notion that science is purely a generalising and nomothetic enterprise. 



\section{Bibliography}

Allen, Garland E. 'Evolution and History: History as Science and Science as History,' in Matthew H. Nitecki \& Doris V. Nitecki (eds). History and Evolution. State University of New York Press: Albany, 1992. pp.211-239.

Ankersmit, F. R. 'Hayden White's Appeal to the Historians,' History and Theory. Vol. 37, No. 2 (May 1998). pp.182-193.

Ankersmit, F. R. 'Danto, History, and the Tragedy of Human Existence,' History and Theory. Vol. 42, No. 3 (October 2003). pp.291-304.

Ankersmit, F. R. 'Narrative and Interpretation,' in Aviezer Tucker (ed). A Companion to the Philosophy of History and Historiography. Wiley-Blackwell: Chichester, 2011. pp.199-208.

Atkinson, Robert F. Knowledge and Explanation in History. Cornell University Press: Ithaca, New York, 1978.

Beard, Charles A. 'Written History as an Act of Faith,' The American Historical Review. Vol. 39, No. 2 (January 1934). pp.219-231.

Beard, Charles. 'That Noble Dream,' The American Historical Review. Vol. 41, No. 1 (1935). pp.74-87.

Becker, Carl L. 'Everyman His Own Historian: Annual Address of the President of the American Historical Association, delivered at Minneapolis, December 29, 1931,' American Historical Review. Vol. 37, No. 2 (January 1932). pp.221-236.

Becker, Carl L. 'What Are Historical Facts?,' The Western Political Quarterly, Vol. 8, No. 3 (September 1955). pp.327-340.

Becker, Carl L. 'Detachment and the Writing of History,' in Phil L. Synder (ed). Detachment and the Writing of History: Essays and Letters of Carl L. Becker. Cornell University Press: Ithaca, New York, 1967. pp.3-28.

Ben-Menahem, Yemima. 'Historical Necessity and Contingency,' in Aviezer Tucker (ed). A Companion to the Philosophy of History and Historiography. Wiley-Blackwell: Chichester, 2011. pp.120-130.

Berry, Stephan. 'On the Problem of Laws in Nature and History: A Comparison,' History and Theory. Vol. 38, No. 4, Theme Issue 38: The Return of Science: Evolutionary Ideas and History (December 1999). pp.121-137.

Berry, Stephan. 'The Laws of History,' in Aviezer Tucker (ed). A Companion to the Philosophy of History and Historiography. Wiley-Blackwell: Chichester, 2011. pp.162-171.

Blaser, Kent. 'The History of Nature and the Nature of History: Stephen Jay Gould on Science, Philosophy, and History,' The History Teacher. Vol. 32, No. 3 (May 1999). pp.411430.

Bloch, Marc. The Historian's Craft. P. Putnam (trans). Manchester University Press: Manchester, 1954.

Blute, Marion. 'History versus Science: The Evolutionary Solution,' Canadian Journal of Sociology/Cahiers Canadiens de Sociologie. Vol. 22, No. 3 (Summer 1997). pp.345-364. 
Boyd, Robert and Richerson, Peter J. 'How Microevolutionary Processes Give Rise to History,' in Matthew H. Nitecki \& Doris V. Nitecki (eds). History and Evolution. State University of New York Press: Albany, 1992. pp.179-209.

Brown, Donald E. 'Human Nature and History,' History and Theory. Vol. 38, No. 4, Theme Issue 38: The Return of Science: Evolutionary Ideas and History (December 1999). pp.138157.

Buckle, Henry Thomas. Introduction to the History of Civilization in England. Routledge: London, 1904.

Bunge, Mario. 'The Weight of Simplicity in the Construction and Assaying of Scientific Theories,' Philosophy of Science. Vol. 28, No. 2 (April 1961). pp.120-149.

Bury, J. B. 'The Science of History,' in Harold Temperley (ed). Selected Essays of J. B. Bury. Cambridge University Press: Cambridge, 1930. pp.3-22.

Bury, J. B. 'Darwinism and History,' in Harold Temperley (ed). Selected Essays of J. B. Bury. Cambridge University Press: Cambridge, 1930. pp.23-42.

Bury, J. B. 'Causes of the Survival of the Roman Empire in the East,' in Harold Temperley (ed). Selected Essays of J. B. Bury. Cambridge: Cambridge University Press, 1930. pp.231242.

Bury, J. B. 'Cleopatra's Nose,' in Harold Temperley (ed). Selected Essays of J. B. Bury. Cambridge: Cambridge University Press, 1930. pp.60-69.

Butterfield, Herbert. The Whig Interpretation of History. Penguin: Harmondsworth, 1973.

Carr, E. H. What is History? Palgrave: Basingstoke, 2001.

Cebik, L. B. 'Understanding Narrative Theory,' History and Theory. Vol. 25, No. 4 (December 1986). pp.58-81.

Cheyney, Edward P. 'Law in History,' The American Historical Review. Vol. 29, No. 2 (January 1924). pp.231-248.

Chiappe, Luis M. Glorified Dinosaurs: The Origin and Early Evolution of Birds. John Wiley \& Sons: Hoboken, New Jersey, 2007.

Clack, Jennifer A. Gaining Ground: The Origin and Evolution of Tetrapods. Indiana University Press: Indianapolis \& Bloomington, 2002.

Clack, Jennifer A. 'The Emergence of Early Tetrapods,' Palaeogeography, Palaeoclimatology, Palaeoecology. No. 232 (2006). pp.167-189.

Clack, Jennifer A. 'The Fish-Tetrapod Transition: New Fossils and Interpretations,' Evo Edu Outreach. Vol. 2 (2009). pp.213-223.

Cleland, Carol E. 'Historical Science, Experimental Science, and the Scientific Method,' Geology. Vol. 29, No. 11 (November 2001). pp.987-990.

Cleland, Carol E. 'Methodological and Epistemic Differences between Historical Science and Experimental Science,' Philosophy of Science. Vol. 69, No. 3 (September 2002). pp.474-496.

Cleland, Carol E. 'Philosophical Issues in Natural History and its Historiography,' in Aviezer Tucker (ed). A Companion to the Philosophy of History and Historiography. Wiley-Blackwell: Chichester, 2011. pp.44-62. 
Cohen, Jack and Stewart, Ian. The Collapse of Chaos: Discovering Simplicity in a Complex World. Penguin Science: London, 2000.

Collingwood, R. G. 'Review of Harold Temperley (ed). Selected Essays of J. B. Bury,' English Historical Review, No. 46, No. 183 (July 1931). pp.461-465.

Collingwood, R. G. The Idea of History. Revised Edition. Oxford University Press: Oxford, 1994.

Comte, Auguste. The Positive Philosophy of Auguste Comte. $3^{\text {rd }}$ Edition. Harriet Martineau (trans). Kegan Paul: London, 1893.

Cornell, John F. 'Newton of the Grassblade? Darwin and the Problem of Organic Teleology.' Isis. Vol. 77, No. 3 (September 1986). pp.404-421.

Couse, G. S. 'Collingwood's Detective Image of the Historian and the Study of Hadrian's Wall,' History and Theory. Vol. 29, No. 4 (December 1990). pp.57-77.

Croce, Benedetto. History: Its Theory and Practice. Douglas Ainslie (trans). Russell \& Russell: New York, 1960.

D'Oro, Giuseppina. 'The Ontological Backlash: Why Did Mainstream Analytic Philosophy Lose Interest in the Philosophy of History?,' Philosophia. Vol. 36, No. 4 (2008). pp.403-415.

Daeschler, Edward B., Shubin, Neil H., Thomson, Keith S., Amaral, William W. 'A Devonian Tetrapod from North America,' Science. New Series, Vol. 265, No. 5172 (29 July 1994). pp.639-642.

Daeschler, Edward B., Shubin, Neil H., and Jenkins, Farish A. Jr. 'A Devonian Tetrapod-Like Fish and the Evolution of the Tetrapod Body Plan,' Nature. No. 440 (6 April 2006). pp.757763.

Danto, Arthur C. 'On Explanations in History,' Philosophy of Science. Vol. 23, No. 1 (January 1956). pp.15-30.

Danto, Arthur C. 'Review of Laws and Explanation in History by William Dray,' Ethics. Vol. 68, No. 4 (July 1958). pp.297-299.

Danto, Arthur. 'The Decline and Fall of the Analytic Philosophy of History,' in Frank Ankersmit and Hans Kellner (eds). A New Philosophy of History. Reaktion Books: London, 1995. pp.70-85.

Danto, Arthur C. Narration and Knowledge (including the Integral Text of Analytical Philosophy of History). Columbia University Press: New York, 2007.

Darwin, Charles. On The Origin of Species by Means of Natural Selection, or the Preservation of Favoured Races in the Struggle for Life. John Murray: London, 1859.

Dawkins, Richard. The Ancestor's Tale: A Pilgrimage to the Dawn of Life. Phoenix: London, 2005.

Dawkins, Richard. The Greatest Show on Earth: The Evidence for Evolution. Bantam: London, 2009.

Dawson, Doyne. 'Evolutionary Theory and Group Selection: The Question of Warfare,' History and Theory. Vol. 38, No. 4, Theme Issue 38: The Return of Science: Evolutionary Ideas and History (December 1999). pp.79-100. 
Day, Mark. 'Our Relations With the Past,' Philosophia. Vol. 36, No. 4 (2008). pp.417-427.

Day, Mark. The Philosophy of History. Continuum: London \& New York, 2008.

Day, Mark and Radick, Gregory. 'Historiographic Evidence and Confirmation,' in Aviezer Tucker (ed). A Companion to the Philosophy of History and Historiography. Wiley-Blackwell: Chichester, 2011. pp.87-97.

Destler, Chester McArthur. 'The Crocean Origin of Becker's Historical Relativism,' History and Theory. Vol. 9, No. 3 (1970). pp.335-342.

Di Gregorio, Mario A. 'The Dinosaur Connection: A Reinterpretation of T. H. Huxley's Evolutionary View,' Journal of the History of Biology. Vol. 15, No. 3 (Autumn 1982). pp.397418.

Diamond, Jared. Guns, Germs and Steel: A Short History of Everybody for the Last 13,000 Years. Vintage Press: London, 2005.

Dilthey, Wilhelm. 'The Rise of Hermeneutics (1900),' in Wilhelm Dilthey. Selected Works, Volume Four: Hermeneutics and the Study of History. Rudolf A. Makkreel and Frithjof Rodi (eds). Princeton University Press: Princeton, 1996. pp.235-258.

Donagan, Alan. 'Historical Explanation: The Popper-Hempel Theory Reconsidered,' History and Theory. Vol. 4, No. 1 (1964). pp.3-26.

Donagan, Alan. 'Review of Philosophy and the Historical Understanding by W. B. Gallie,' The Philosophical Review. Vol. 75, No. 2 (April 1966). pp.262-265.

Donagan, Alan. 'Review of Analytical Philosophy of History by Arthur C. Danto,' History and Theory. Vol. 6, No. 3 (1967). pp.430-435.

Dray, William. 'Explanatory Narrative in History,' The Philosophical Quarterly. Vol. 4, No. 14 (January 1954). pp.15-27.

Dray, William. Laws and Explanation in History. Oxford University Press: Oxford, 1957.

Dray, William H. Philosophy of History. Prentice-Hall: Englewood Cliffs, New Jersey, 1964.

Dray, W. H. 'Review of Analytical Philosophy of History by Arthur C. Danto,' Political Science Quarterly. Vol. 81, No. 3 (September 1966). pp.510-512.

Dray, W. H. 'On the Nature and Role of Narrative in Historiography,' History and Theory. Vol. 10, No. 2 (1971). pp.153-171.

Dray, William H. 'Colligation Under Appropriate Conceptions,' in William H. Dray. On History and Philosophers of History. E. J. Brill: Leiden, The Netherlands, 1989. pp.37-53.

Droysen, Johann Gustav. "The Elevation of History to the Rank of a Science: Being a Review of The History of Civilization in England by T. H. Buckle,' in Johann Gustav Droysen. Outline of the Principles of History. E. Benjamin Andrews (trans.) Ginn \& Co.: Boston, 1893. pp.61-89.

Elton, G. R. The Practice of History. Blackwell: Oxford, 2001.

England, Richard. 'Natural Selection, Teleology, and the Logos: From Darwin to the Oxford Neo-Darwinists, 1859-1909.' Osiris. $2^{\text {nd }}$ Series, Vol. 16, Science in Theistic Contexts: Cognitive Dimensions (2001). pp.270-287. 
Ereshefsky, Marc. 'The Historical Nature of Evolutionary Theory,' in Matthew H. Nitecki \& Doris V. Nitecki (eds). History and Evolution. State University of New York Press: Albany, 1992. pp.81-99.

Evans, Richard J. In Defence of History. Granta Books: London, 1997.

Fain, Haskell. 'History as Science,' History and Theory. Vol. 9, No. 2 (1970). pp.154-173.

Fogel, R. W. 'The New Economic History I: Its Findings and Methods,' The Economic History Review. New Series, Vol. 19, No. 3 (1966). pp.642-656.

Fracchia, Joseph and Lewontin, R. C. 'Does Culture Evolve?,' History and Theory. Vol. 38, No. 4, Theme Issue 38: The Return of Science: Evolutionary Ideas and History (December 1999). pp.52-78.

Futuyma, Douglas J. 'History and Evolutionary Processes,' in Matthew H. Nitecki \& Doris V. Nitecki (eds). History and Evolution. State University of New York Press: Albany, 1992. pp.103-130.

Gallie, W. B. 'An Interpretation of Causal Laws,' Mind. New Series, Vol. 48, No. 192 (October 1939). pp.409-426.

Gallie, W. B. 'Explanations in History and the Genetic Sciences,' Mind. New Series, Vol. 64, No. 254 (April 1955). pp.160-180.

Gallie, W. B. 'Essentially Contested Concepts,' Proceedings of the Aristotelian Society. New Series, Vol. 56 (1955-1956). pp.167-198.

Gallie, W. B. 'What Makes a Subject Scientific?,' The British Journal for the Philosophy of Science. Vol. 8, No. 30 (August 1957). pp.118-139.

Gallie, W. B. 'The Historical Understanding,' History and Theory. Vol. 3, No. 2 (1963). pp.149202.

Gallie, W. B. Philosophy and the Historical Understanding. $2^{\text {nd }}$ Edition. Schocken Books: New York, 1968.

Gardiner, Patrick. 'The "Objects" of Historical Knowledge,' Philosophy, Vol. 27, No. 102 (July 1952). pp.211-220.

Gardiner, Patrick. The Nature of Historical Explanation. Oxford University Press: London, 1952.

Gardiner, Patrick. 'Review of Laws and Explanation in History by William Dray,' The English Historical Review. Vol. 73, No. 289 (October 1958). pp.746-747.

Gardiner, Patrick. 'Review of Analytical Philosophy of History by Arthur C. Danto,' The British Journal for the Philosophy of Science. Vol. 17, No. 4. (February 1967). pp.328-331.

Garfield, E. 'The 250 most-cited authors in the Arts and Humanities Citation Index, 19761983,' Current Contents. Vol. 48 (December 1986). pp.3-10.

Goldstein, Doris S. 'J. B. Bury's Philosophy of History: A Reappraisal,' The American Historical Review. Vol. 82, No. 4 (October 1977). pp.896-919.

Goldstein, Leon J. Historical Knowing. University of Texas Press: Austin, 1976.

Goldstein, Leon J. The What and Why of History: Philosophical Essays. E. J. Brill: Leiden, The Netherlands, 1996. 
Goudge, T. A. 'Causal Explanations in Natural History.' The British Journal for the Philosophy of Science. Vol. 9, No. 35 (November 1958). pp.194-202.

Goudge, T. A. The Ascent of Life: A Philosophical Study of the Theory of Evolution. George Allen \& Unwin, Ltd.: London, 1961.

Gould, Stephen Jay. Wonderful Life: The Burgess Shale and the Nature of History. Hutchinson Radius: London, 1989.

Gould, Stephen Jay. 'Nonoverlapping Magisteria,' Natural History. 106 (March 1997). pp.1622.

Harrah, David. 'Gallie and the Scientific Tradition,' The British Journal for the Philosophy of Science. Vol. 10, No. 39 (November 1959). pp.234-239.

Hegel, G. W. F. The Philosophy of History. J. Sibree (trans.) Dover Publications: New York, 1956.

Hempel, Carl G. 'The Function of General Laws in History,' The Journal of Philosophy. Vol. 39, No. 2 (15 January 1942). pp.35-48.

Hempel, Carl G. and Oppenheim, Paul. 'Studies in the Logic of Explanation,' Philosophy of Science. Vol. 15, No. 2 (April 1948). pp.135-175.

Hempel, Carl G. 'Deductive-Nomological vs. Statistical Explanation,' in H. Feigl \& G. Maxwell (eds). Scientific Explanation, Space, and Time. Minnesota Studies in the Philosophy of Science Vol. 3. University of Minnesota Press: Minneapolis, 1962. pp.98-169.

Hempel, Carl G. 'Explanation and Prediction by Covering Laws,' in Bernard Baumrin (ed.) Philosophy of Science: The Delaware Seminar - Volume 1. (1961-62). Interscience: New York, 1963. pp.107-133.

Hempel, Carl G. 'Explanation in Science and in History,' in Ronald H. Nash (ed). Ideas in History, Volume II: The Critical Philosophy of History. E. P. Dutton \& Co.: New York, 1969. pp.79-106.

Hodge, M. J. S. 'England,' in Thomas F. Glick (ed). The Comparative Reception of Darwinism. University of Chicago Press: Chicago \& London, 1988. pp.3-31.

Hollinger, David A. 'T. S. Kuhn's Theory of Science and its Implications for History,' The American Historical Review. Vol. 78, No. 2 (April 1973). pp.370-393.

Holmes, Bob. 'Meet Your Ancestor,' New Scientist. 9 September 2006. pp.35-39.

Hull, David L. 'What Philosophy of Biology is Not,' Synthese. Vol. 20, No. 2, Methodological Problems in Biology (August 1969). pp.157-184.

Hull, David L. 'Essay Review: What the Philosophy of Biology is Not,' The Journal of the History of Biology. Vol. 2, No. 1, Explanation in Biology (Spring 1969). pp.241-268.

Hull, David L. 'Charles Darwin and Nineteenth Century Philosophies of Science,' in Ronald N. Giere \& Richard S. Westfall (eds). Foundations of Scientific Method: The Nineteenth Century. Indiana University Press: Bloomington \& London, 1973. pp.115-132.

Hull, David L. The Philosophy of Biological Science. Prentice-Hall: Englewood Cliffs, New Jersey, 1974. 
Hull, David L. 'Central Subjects and Historical Narratives,' History and Theory. Vol. 14, No. 3 (October 1975). pp.253-274.

Hull, David L. 'The Particular-Circumstance Model of Scientific Explanation,' in Matthew H. Nitecki \& Doris V. Nitecki (eds). History and Evolution. State University of New York Press: Albany, 1992. pp.69-80.

Huxley, T. H. 'On The Educational Value of the Natural History Sciences, 1854' in T. H. Huxley. The Essence of T. H. Huxley: Selections from his Writings. Cyril Bibby (ed). St. Martin's Press: New York, 1967. pp.51-55.

Iggers, Georg G. 'Review of Analytical Philosophy of History by Arthur C. Danto,' The American Historical Review. Vol. 72, No. 2 (January 1967). pp.523-524.

Inkpen, Robert John. 'Explaining the Past in the Geosciences,' Philosophia. Vol. 36, No. 4 (2008). pp.495-507.

Inkpen, Rob. 'The Philosophy of Geology,' in Aviezer Tucker (ed). A Companion to the Philosophy of History and Historiography. Wiley-Blackwell: Chichester, 2011. pp.318-329.

Jardine, Nicholas. 'Philosophy of History of Science,' in Aviezer Tucker (ed). A Companion to the Philosophy of History and Historiography. Wiley-Blackwell: Chichester, 2011. pp.287-296.

Jarvik, E. 'On the Fish-Like Tail in the Ichthyostegid Stegocephalians,' Meddelelser Øm Grönland. Vol. 114, No. 2 (1952). pp.1-90.

Jarvik, E. 'The Oldest Tetrapods and Their Forerunners,' The Scientific Monthly. Vol. 80, No. 3 (March 1955). pp.141-154.

Jarvik, E. Basic Structure and Evolution of Vertebrates. Academic Press: London \& New York, 1980.

Jarvik, E. 'The Devonian Tetrapod Ichthyostega,' Fossils and Strata. Vol. 40 (1996). pp.1-206.

Jeffares, Benjamin. Testing Times: Confirmation in the Historical Sciences. PhD Thesis, Australian National University, 2008.

Jeffares, Ben. 'The Philosophy of Archaeology,' in Aviezer Tucker (ed). A Companion to the Philosophy of History and Historiography. Wiley-Blackwell: Chichester, 2011. pp.330-341.

Jenkins, Keith. Re-Thinking History. Routledge: London \& New York, 1991.

Jenkins, Keith. 'A Postmodern Reply to Perez Zagorin,' History and Theory. Vol. 39, No. 2 (May 2000). pp.181-200.

Joynt, Carey B. and Rescher, Nicholas. 'The Problem of Uniqueness in History,' History and Theory. Vol. 1, No. 2 (1961). pp.150-162.

Kincaid, Harold. 'Philosophies of Historiography and the Social Sciences,' in Aviezer Tucker (ed). A Companion to the Philosophy of History and Historiography. Wiley-Blackwell: Chichester, 2011. pp.297-306.

Kitts, David B. 'Grove Karl Gilbert and the Concept of "Hypothesis" in Late NineteenthCentury Geology,' in Ronald N. Giere \& Richard S. Westfall (eds). Foundations of Scientific Method: The Nineteenth Century. Indiana University Press: Bloomington \& London, 1973. pp.259-274. 
Kitts, David B. The Structure of Geology. Southern Methodist University Press: Dallas, 1977.

Kitts, David B. 'The Conditions for a Nomothetic Paleontology,' in Matthew H. Nitecki \& Doris V. Nitecki (eds). History and Evolution. State University of New York Press: Albany, 1992. pp.131-145.

Kleindienst, Maxine R. 'Review of Knowing the Past: Philosophical Issues of History and Archaeology by Peter Kosso,' American Antiquity. Vol. 69, No. 1 (January 2004). pp.189-190.

Kofahl, Robert E. and Zeisel, Hans. 'Popper on Darwinism,' Science. New Series, Vol. 212, No. 4497 (22 May 1981). p.873.

Kosso, Peter. 'Observation of the Past,' History and Theory. Vol. 31, No. 1 (February 1992). pp.21-36.

Kosso, Peter. Reading the Book of Nature: An Introduction to the Philosophy of Science. Cambridge University Press: Cambridge, 1992.

Kosso, Peter. 'Historical Evidence and Epistemic Justification: Thucydides as a Case Study,' History and Theory. Vol. 32, No. 1 (February 1993). pp.1-13.

Kosso, Peter. Knowing the Past: Philosophical Issues of History and Archaeology. Humanity Books: New York, 2001.

Kosso, Peter. 'Philosophy of Historiography,' in Aviezer Tucker (ed). A Companion to the Philosophy of History and Historiography. Wiley-Blackwell: Chichester, 2011. pp.9-25.

Kuhn, Thomas S. 'Historical Structure of Scientific Discovery,' Science. New Series, Vol. 136, No. 3518 (1 June 1962). pp.760-764.

Kuhn, Thomas S. The Structure of Scientific Revolutions. University of Chicago Press: Chicago, 1962.

Kuhn, Thomas S. 'The Relations Between History and History of Science,' Daedalus. Vol. 100, No. 2, The Historian and the World of the Twentieth Century (Spring 1971). pp.271-304.

Kupriyanova, N. S. 'Current View of the Origin and Diversification of Tetrapods,' Molecular Biology. Vol. 43, No. 5 (2009). pp.819-833.

Langlois, Charles-Victor and Seignobos, Charles. Introduction aux Etudes Historiques (Introduction to the Study of History). Duckworth \& Co.: London, 1898.

Laudan, Rachel. 'What's So Special About The Past?' in Matthew H. Nitecki \& Doris V. Nitecki (eds). History and Evolution. State University of New York Press: Albany, 1992. pp.55-67.

Levich, Marvin. 'Interpretation in History: Or What Historians Do and Philosophers Say,' History and Theory. Vol. 24, No. 1 (February 1985). pp.44-61.

Lewis, David. 'Counterfactual Dependence and Time's Arrow,' Nous. Vol. 13, No. 4 (November 1979). pp.455-476.

Lyell, Charles. Principles of Geology: Being an Attempt to Explain the Former Changes of the Earth's Surface, by Reference to Causes Now in Operation, Volume One. John Murray: London, 1830.

Lyell, Charles. Principles of Geology: Being an Attempt to Explain the Former Changes of the Earth's Surface, by Reference to Causes Now in Operation, Volume Two. John Murray: London, 
Lyell, Charles. Principles of Geology: Being an Attempt to Explain the Former Changes of the Earth's Surface, by Reference to Causes Now in Operation, Volume Three. John Murray: London, 1833.

Lyotard, Jean-Francois. The Postmodern Condition: A Report on Knowledge. Manchester University Press: Manchester, 1984.

McConnell, D. W., et. al. Economic Behaviour. Houghton Mifflin Company: New York, 1939.

McCullagh, C. Behan. 'Colligation and Classification in History,' History and Theory. Vol. 17, No. 3 (October 1978). pp.267-284.

McCullagh, C. Behan. Justifying Historical Descriptions. Cambridge University Press: Cambridge \& New York, 1984.

McCullagh, C. Behan. 'The Truth of Historical Narratives,' History and Theory. Vol. 26, No. 4, Beiheft 26: The Representation of Historical Events (December 1987). pp.30-46.

McCullagh, C. Behan. The Truth of History. Routledge: London \& New York, 1998.

McCullagh, C. Behan. 'Review of Our Knowledge of the Past: A Philosophy of Historiography by Aviezer Tucker,' Mind. Vol. 114, No. 455 (July 2005). pp.782-786.

McCullagh, C. Behan. 'Colligation,' in Aviezer Tucker (ed). A Companion to the Philosophy of History and Historiography. Wiley-Blackwell: Chichester, 2011. pp.152-161.

McMullin, Ernan. 'The Impact of Newton's Principia on the Philosophy of Science,' Philosophy of Science. Vol. 68, No. 3 (September 2001). pp.279-310.

McNeill, William H. 'The Changing Shape of World History.' Paper presented at the History and Theory World Conference, March 25-26, 1994. Available at: http://www.hartfordhwp.com/archives/10/041.html ; accessed 11 August 2011.

McNeill, William H. 'History and the Scientific Worldview,' History and Theory. Vol. 37, No. 1 (February 1998). pp.1-13.

McNeill, William H. 'Passing Strange: The Convergence of Evolutionary Science with Scientific History,' History and Theory. Vol. 40, No. 1 (February 2001). pp.1-15.

Macdonald, Graham and Macdonald, Cynthia. 'Reductionism: Historiography and Psychology,' in Aviezer Tucker (ed). A Companion to the Philosophy of History and Historiography. Wiley-Blackwell: Chichester, 2011. pp.342-352.

Macdonald, Graham and Macdonald, Cynthia. 'Explanation in Historiography,' in Aviezer Tucker (ed). A Companion to the Philosophy of History and Historiography. Wiley-Blackwell: Chichester, 2011. pp.131-141.

Mandelbaum, Maurice. 'Historical Explanation: The Problem of "Covering Laws",' History and Theory. Vol. 1, No. 3 (1961). p.229-242.

Mandelbaum, Maurice. 'Review of Philosophy and the Historical Understanding by W. B. Gallie,' The American Historical Review. Vol. 70, No. 1 (October 1964). pp.95-96.

Mandelbaum, Maurice. 'A Note on History as Narrative,' History and Theory. Vol. 6, No. 3 (1967). pp.413-419. 
Mandelbaum, Maurice. 'Objectivism in History,' in Sidney Hook (ed). Philosophy and History: A Symposium. New York University Press: New York, 1963. pp.43-56.

Martin, Raymond. 'The Essential Difference Between History and Science,' History and Theory. Vol. 36, No. 1 (February 1997). pp.1-14.

Marwick, Arthur. The New Nature of History: Knowledge, Evidence, Language. Palgrave: Hampshire, 2001.

Meyerhoff, Hans (ed). The Philosophy of History in Our Time: An Anthology. Doubleday / Anchor: New York, 1957.

Mink, Louis O. 'The Autonomy of Historical Understanding,' History and Theory. Vol. 5, No. 1 (1966). pp.24-47.

Mink, Louis O. 'History and Fiction as Modes of Comprehension,' New Literary History. Vol. 1, No. 3 (Spring 1970). pp.541-558.

Mink, Louis O. 'Review of Our Knowledge of the Historical Past by Murray G. Murphey,' The American Historical Review. Vol. 79, No. 2 (April 1974). pp.482-483.

Mitchell, Sandra D. 'Dimensions of Scientific Law,' Philosophy of Science. Vol. 67, No. 2 (June 2000). pp.242-265.

Murphey, Murray G. Our Knowledge of the Historical Past. Bobbs-Merrill: Indianapolis, 1973.

Murphey, Murray G. 'Review of The Logic of Historical Explanation by Clayton Roberts,' American Historical Review. Vol. 102, No. 4 (October 1997). pp.1117-1118.

Naccache, Albert F. H. 'A Brief History of Evolution,' History and Theory. Vol. 38, No. 4, Theme Issue 38: The Return of Science: Evolutionary Ideas and History (December 1999). pp.1032.

Nagel, Ernest. 'The Logic of Historical Analysis,' in Herbert Feigl \& May Brodbeck (eds). Readings in the Philosophy of Science. Appelton, Century, Crofts: New York, 1953. pp.688700 .

Nickles, Thomas. 'Philosophy of Science and History of Science,' Osiris. $2^{\text {nd }}$ Series, Vol. 10, Constructing Knowledge in the History of Science (1995). pp.138-163.

Niedzwiedzki, G., Szrek, P., Narkiewicz, K., Narkiewicz, M., Ahlberg, P. E. 'Tetrapod trackways from the early Middle Devonian period of Poland.' Nature. Vol. 463, No. 7277 (January 2010). pp.43-48.

Nitecki, Matthew H. 'History: La Grande Illusion,' in Matthew H. Nitecki \& Doris V. Nitecki (eds). History and Evolution. State University of New York Press: Albany, 1992. pp.3-15.

Nore, Ellen. 'Charles A. Beard's Act of Faith: Context and Content,' The Journal of American History. Vol. 66, No. 4 (March 1980). pp.850-866.

Novick, Peter. That Noble Dream: The "Objectivity Question" and the American Historical Profession. Cambridge University Press: Cambridge, 1988.

O'Sullivan, Luke. 'Leon Goldstein and the Epistemology of Historical Knowing,' History and Theory. Vol. 45, No. 2 (May 2006). pp.204-228.

Parker, Christopher. 'English Historians and the Opposition to Positivism,' History and Theory. Vol. 22, No. 2 (May 1983). pp.120-145. 
Passmore, J. A. 'The Objectivity of History,' in Patrick Gardiner (ed). The Philosophy of History. Oxford University Press: Oxford, 1974. pp.145-160.

Peña, Alonso. 'On the Role of Mathematical Biology in Contemporary Historiography,' History and Theory. Vol. 38, No. 4, Theme Issue 38: The Return of Science: Evolutionary Ideas and History (December 1999). pp.101-120.

Popper, Karl. The Open Society and Its Enemies, Volume II: The High Tide of Prophecy - Hegel, Marx and the Aftermath. Revised $3^{\text {rd }}$ Edition. Routledge \& Kegan Paul: London, 1952.

Popper, Karl. The Poverty of Historicism. ${ }^{\text {nd }}$ Edition. Routledge \& Kegan Paul: London, 1960.

Popper, Karl R. The Logic of Scientific Discovery. Hutchinson \& Co.: London, 1959.

Popper, Karl. 'Darwinism as a Metaphysical Research Programme,' in P. A. Schilpp (ed). The Philosophy of Karl Popper: Volume One. Open Court: LaSalle, Illinois, 1974. pp.133-143.

Popper, Karl R. 'Models, Instruments, and Truth,' in Karl R. Popper. The Myth of the Framework. Routledge: London \& New York, 1994. pp.154-184.

Ranke, Leopold von. The Theory and Practice of History. Georg G. Iggers \& Konrad von Moltke (ed and trans). Bobs-Merrill Company: Indianapolis \& New York, 1973.

Reid, James, 'Dilthey's Epistemology of the Geisteswissenschaften: Between Lebensphilosophie and Wissenschaftstheorie,' in Journal of the History of Philosophy. Vol. 39, No. 3 (2001). pp.407436.

Reisch, George A. 'Chaos, History, and Narrative,' History and Theory. Vol. 30, No. 1 (February 1991). pp.1-20.

Richards, Robert J. 'The Structure of Narrative Explanation in History and Biology,' in Matthew H. Nitecki \& Doris V. Nitecki (eds). History and Evolution. State University of New York Press: Albany, 1992. pp.19-53.

Ritter, Gerhard. 'Scientific History, Contemporary History, and Political Science,' History and Theory. Vol. 1, No. 3 (1961). pp.261-279.

Roberts, Clayton. The Logic of Historical Explanation. Pennsylvania State University Press: University Park, Pennsylvania, 1996.

Romer, A. S. Man and the Vertebrates. $3^{\text {rd }}$ Edition. University of Chicago Press: Chicago, 1941.

Romer, A. S. 'Major Steps in Vertebrate Evolution,' Science, New Series, Vol. 158, No. 3809 (29 December 1967). pp.1629-1637.

Ruby, Jane E. 'The Origins of Scientific "Law",' Journal of the History of Ideas. Vol. 47, No. 3 (July-September 1986). pp.341-359.

Rudwick, Martin J. S. 'The Strategy of Lyell's Principles of Geology,' Isis. Vol. 61, No. 1 (Spring 1970). pp.3-43.

Rudwick, Martin J. S. Bursting the Limits of Time: The Reconstruction of Geohistory in the Age of Revolution. University of Chicago Press: Chicago \& London, 2005.

Rudwick, Martin J. S. Worlds Before Adam: The Reconstruction of Geohistory in the Age of Reform. University of Chicago Press: Chicago \& London, 2008. 
Ruse, Michael. The Philosophy of Biology. Hutchinson \& Co.: London, 1973.

Ruse, Michael. 'Charles Lyell and the Philosophers of Science,' The British Journal for the History of Science. Vol. 9, No. 2 (July 1976). pp.121-131.

Ruse, Michael. 'Karl Popper's Philosophy of Biology,' Philosophy of Science. Vol. 44, No. 4 (December 1977). pp.638-661.

Ruse, Michael. 'The Philosophy of Evolutionary Theory,' in Aviezer Tucker (ed). A Companion to the Philosophy of History and Historiography. Wiley-Blackwell: Chichester, 2011. pp.307317.

Salmon, Merrilee H. and Salmon, Wesley C. 'Alternative Models of Scientific Explanation,' American Anthropologist. New Series, Vol. 81, No. 1 (March 1979). pp.61-74.

Salmon, Wesley C. 'The Spirit of Logical Empiricism: Carl G. Hempel's Role in TwentiethCentury Philosophy of Science,' Philosophy of Science. Vol. 66, No. 3 (September 1999). pp.333-350.

Schuyler, Robert Livingston. 'Law and Accident in History,' Political Science Quarterly. Vol. 45, No. 2 (June 1930). pp.273-278.

Shaw, David Gary. 'The Return of Science,' History and Theory. Vol. 38, No. 4, Theme Issue 38: The Return of Science: Evolutionary Ideas and History (December 1999). pp.1-9.

Shubin, Neil H. 'Giving Fish a Hand,' Science. New Series, Vol. 301, No. 5634 (8 August 2003). pp.766-767.

Shubin, Neil H. 'The "Great" Transition,' in John Brockman (ed). Intelligent Thought: Science Versus The Intelligent Design Movement. Vintage: New York, 2006. pp.82-91.

Skinner, Quentin. 'The Limits of Historical Explanations,' Philosophy. Vol. 41, No. 157 (July 1966). pp.199-215.

Skinner, Quentin. 'Meaning and Understanding in the History of Ideas,' History and Theory. Vol. 8, No. 1 (1969). pp.3-53.

Sorenson, Lloyd R. 'Charles A. Beard and German Historiographical Thought,' The Mississippi Valley Historical Review. Vol. 42, No. 2 (September 1955). pp.274-287.

Spengler, Oswald. The Decline of the West. 2 volumes. A. A. Knopf: New York, 1926 \& 1928.

Steinle, Friedrich. 'The Amalgamation of a Concept - Laws of Nature in the New Sciences,' in Friedel Weinert (ed). Laws of Nature: Essays on the Philosophical, Scientific and Historical Dimensions. De Gruyter: Berlin \& New York, 1995. pp.316-368.

Stover, Robert C. 'Dray on Historical Explanation,' Mind. New Series, Vol. 70, No. 280 (October 1961). pp.540-543.

Stuart-Fox, Martin. 'Evolutionary Theory of History,' History and Theory. Vol. 38, No. 4, Theme Issue 38: The Return of Science: Evolutionary Ideas and History (December 1999). pp.3351.

Thomson, Keith Stewart. 'Ecology of Devonian Lobe-finned Fishes,' in A. L. Panchen (ed). The Terrestrial Environment and the Origin of Land Vertebrates: The Systematics Association Special Volume No. 15. Academic Press: London \& New York, 1980. pp.187-222. 
Tosh, John. The Pursuit of History: Aims, Methods and New Directions in the Study of History. $3^{\text {rd }}$ Edition. Longman: Harlow, 2002.

Toynbee, Arnold J. A Study of History. 12 Volumes. Oxford University Press: London \& New York, 1948-1961.

Trevelyan, G. M. 'Clio, A Muse,' in G. M. Trevelyan. Clio, A Muse and Other Essays. Longman's Green \& Co.: London, 1968. pp.140-176.

Tucker, Aviezer. 'The Future of the Philosophy of Historiography,' History and Theory. Vol. 40, No. 1 (February 2001). pp.37-56.

Tucker, Aviezer. Our Knowledge of the Past: A Philosophy of Historiography. Cambridge University Press: Cambridge, 2004.

Tucker, Aviezer. 'Back From The Drift: Philosophy of History,' Philosophia. Vol. 36, No. 4 (2008). pp.399-401.

Tucker, Aviezer. 'Causation in Historiography,' in Aviezer Tucker (ed). A Companion to the Philosophy of History and Historiography. Wiley-Blackwell: Chichester, 2011. pp.98-108.

Tucker, Aviezer. 'Origins: Common Causes in Historiographic Reasoning,' in Aviezer Tucker (ed). A Companion to the Philosophy of History and Historiography. Wiley-Blackwell: Chichester, 2011. pp.220-230.

Turchin, Peter. 'Does Population Ecology Have General Laws?,' Oikos. Vol. 94, No. 1 (July 2001). pp.17-26.

Turchin, Peter. 'Arise “Cliodynamics",' Nature. Vol. 454 (3 July 2008). pp.34-35.

Udehn, Lars. 'The Ontology of the Objects of Historiography,' in Aviezer Tucker (ed). A Companion to the Philosophy of History and Historiography. Wiley-Blackwell: Chichester, 2011. pp.209-219.

Vann, Richard T. 'Louis Mink's Linguistic Turn,' in History and Theory. Vol. 2, No. 1 (February 1987). pp.1-14.

Vann, Richard T. 'The Reception of Hayden White,' History and Theory. Vol. 37, No. 2 (May 1998). pp.143-161.

Vico, Giambattista. New Science: Principles of the New Science Concerning the Common Nature of Nations. David Marsh (trans.) Penguin Classics: London, 2001.

Walsh, W. H. 'Intelligibility in History,' Philosophy. Vol. 17, No. 66 (April 1942). pp.128-143.

Walsh, W. H. "Plain' and 'Significant' Narrative in History,' The Journal of Philosophy. Vol. 55, No. 11 (May 1958). pp.479-484.

Walsh, W. H. 'Review of Analytical Philosophy of History by Arthur C. Danto,' The English Historical Review. Vol. 82, No. 322 (January 1967). pp.220-221.

Walsh, W. H. An Introduction to the Philosophy of History. Revised $3^{\text {rd }}$ Edition. Hutchinson \& Co.: London, 1967.

Walsh, W. H. 'Colligatory Concepts in History,' in Patrick Gardiner (ed). The Philosophy of History. Oxford University Press: Oxford, 1974. pp.127-144. 
Weingartner, Rudolph H. 'Danto on History,' Philosophy and Phenomenological Research. Vol. 28, No. 1 (September 1967). pp.100-113.

Whewell, William. Philosophy of the Inductive Sciences, Founded Upon Their History - Volume Two. $2^{\text {nd }}$ Edition. John W. Parker: London, 1847.

White, Hayden. Metahistory: The Historical Imagination in Nineteenth-Century Europe. Johns Hopkins University Press: Baltimore, 1973.

White, Hayden. 'Interpretation in History,' New Literary History. Vol. 4, No. 2, On Interpretation: II (Winter 1973). pp.281-314.

White, Hayden. 'The Value of Narrativity in the Representation of Reality,' Critical Inquiry. Vol. 7, No. 1, On Narrative (Autumn 1980). pp.5-27.

White, Hayden. 'The Question of Narrative in Contemporary Historical Theory,' History and Theory. Vol. 23, No. 1 (February 1984). pp.1-33.

White, Hayden. The Content of the Form: Narrative Discourse and Historical Representation. Johns Hopkins University Press: London and Baltimore, 1990.

White, Morton. 'The Logic of Historical Narration,' in Sidney Hook (ed). Philosophy and History: A Symposium. New York University Press: New York, 1963. pp.3-31.

Windelband, Wilhelm. 'Rectorial Address, Strasbourg 1894,' History and Theory. Vol. 19, No. 2 (February 1980). pp.169-185.

Windschuttle, Keith. The Killing of History: How a Discipline is Being Murdered by Literary Critics and Social Theorists. Revised and Expanded International Edition. Macleay Press: Paddington, 1996.

Zagorin, Perez. 'History, the Referent, and Narrative: Reflections on Postmodernism Now,' History and Theory. Vol. 38, No. 1 (February 1999). pp.1-24.

Zagorin, Perez. 'Rejoinder to a Postmodernist,' History and Theory. Vol. 39, No. 2 (May 2000). pp.201-209.

Zilsel, Edgar. 'The Genesis of the Concept of Physical Law,' The Philosophical Review. Vol. 51, No. 3 (May 1942). pp.245-279.

Zimmer, Carl. 'Coming Onto The Land,' Discover Magazine. June 1995. Available at: http://discovermagazine.com/1995/jun/comingontothelan523/; accessed 11 August 2011. 